

\title{
ANALYSIS OF HOURLY DEMAND, COST, AND EMISSION FACTOR FROM THE ELECTRICITY SECTOR - A TOOL FOR RENEWABLE ENERGY ASSESSMENT
}

by

Christian Gordon

Bachelor of Engineering, Mechanical Engineering,

Ryerson University, 2003

\author{
A thesis \\ presented to Ryerson University \\ in partial fulfillment of the \\ requirements for the degree of \\ Master of Applied Science \\ in the Program of \\ Mechanical Engineering
}

Toronto, Ontario, Canada, 2008

(C) Christian Gordon 2008 
I hereby declare that I am the sole author of this thesis or dissertation. I authorize Ryerson University to lend this thesis or dissertation to other institutions or individuals for the purpose of scholarly reséarch,

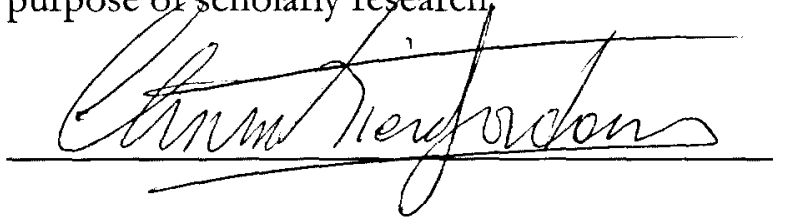

I further authorize Ryerson University to reproduce this thesis or dissertation by photocopying or by other means, in total or in part, at the request of other institutions or individuals för the purpose of scholarly research.

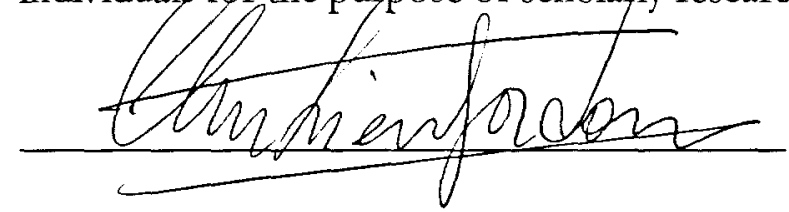




\begin{abstract}
ANALYSIS OF HOURLY DEMAND, COST, AND EMISSION FACTOR FROM THE ELECTRICITY SECTOR - A TOOL FOR RENEWABLE ENERGY ASSESSMENT
\end{abstract}

\author{
Christian Gordon
}

MASc, Mechanical Engineering, Ryerson University, 2008

In this study, seasonal greenhouse gas (GHG) emission factors were developed to realize the true $\mathrm{CO}_{2}$ reduction potential of a small scale renewable energy technology. The new hourly greenhouse gas emission factors based on hour-by-hour demand of electricity in Ontario, and the average Greenhouse Gas Intensity Factor $\left(\right.$ GHGIF $\left._{A}\right)$ were estimated by creating a series of emission factors and their corresponding profiles that could be easily incorporated into simulation software. The use of regionally specific climate-modeled factors, such as those identified, allowed for a more accurate representation of the benefits associated with GHG reducing technologies, such as photovoltaic, wind, etc. It was determined that using Time Dependent Valuation (TDV) emission factors provided an upper limit while using hourly emission factors provided a lower limit. In addition, since there is a correlation between the electricity generated and emissions from utilities, several neural network (NN) models were developed in order to predict the hourly emission factor for the province of Ontario. Two methodologies were explored and resulted in good predictions. However, methodology 2 proved to be more accurate in predicting the hourly emission factor for the Province of Ontario. 


\section{Acknowledgement}

I would like to gratefully acknowledge the enthusiastic supervision of Dr. Alan Fung during this work, and for the technical discussions and encouragement on the importance of this study. I would like to mention that I have also enjoyed having our afternoon discussions about the world and its problems.

As well, I am thankful to the Independent Electricity System Operator (IESO), particularly Robert Doyle, for answering all my questions regarding the electricity demand in Ontario, as well as providing me with the data to complete this report.

Finally, I am forever indebted to my parents and my wife Rosa for their understanding, endless patience, encouragement and love when it was most required. 


\section{Table of Contents}

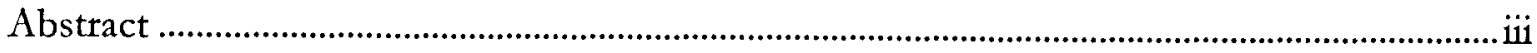

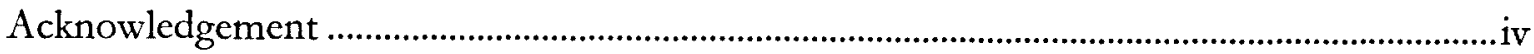

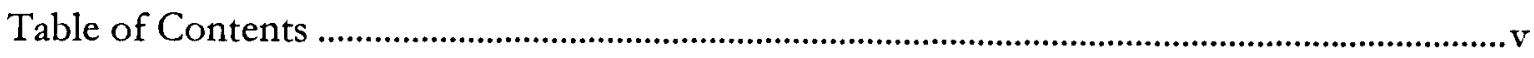

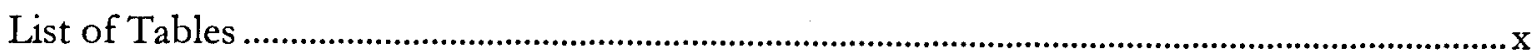

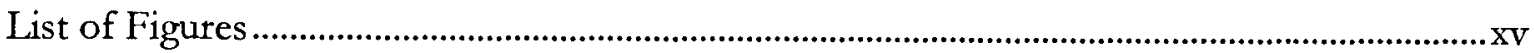

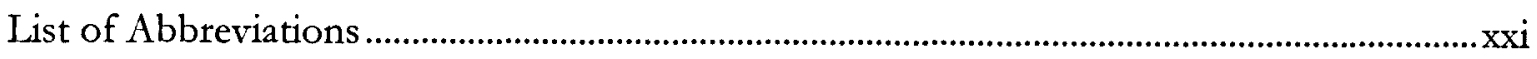

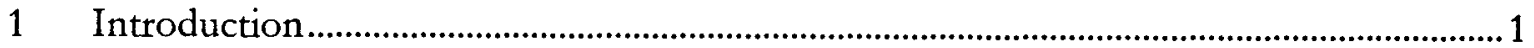

$1.1 \quad$ Historical Energy Supply and Demand ......................................................................

1.2 Environmental Concerns of Pollution and GHG .......................................................2

$1.3 \quad$ Kyoto Protocol..................................................................................................................

1.3.1 Protocol Requirements ................................................................................

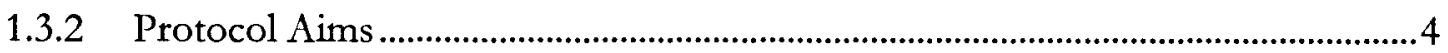

1.3.3 Current International Response ..............................................................................

$1.4 \quad$ Canadian Proposal .............................................................................................

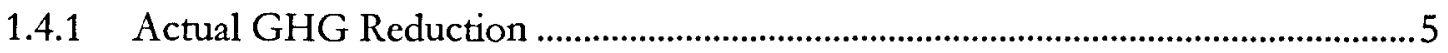

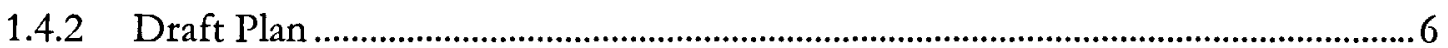

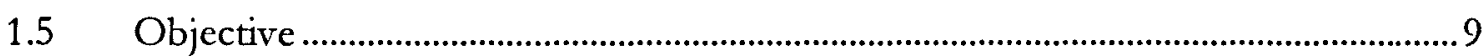

1.5.1 Emission Factors ..................................................................................................

1.5.2 Neural Networks ...........................................................................................

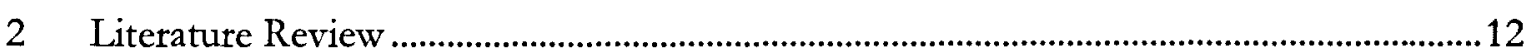

2.1 Electricity Sector in Ontario......................................................................................12

2.1.1 Electricity Market ...................................................................................................12

2.1.2 Dispatching Mechanisms ………………………............................................12

2.2 Emissions in Canada ...............................................................................................14

2.3 Traditional Ways to Estimate Pollutant and GHG Emissions from the Building and Electricity Generation Sectors ...................................................................................15

2.4 Identification of Potential Problems in Estimating Pollutant and GHG Emissions from the Building and Electricity Generation Sectors .............................................................15 2.5 Potential Ways of Better Estimating the True GHG Emission Reduction Potentials with Sustainable Integtated Building Energy Systems............................................16 
2.6 Forecasting Methods

$2.7 \quad$ Review of Neural Network Modeling........................................................................18

2.7.1 Background ..................................................................................................18

2.7.2 Neural Networks in Energy Modeling...................................................................19

2.7.3 Overview of the NN Model ..................................................................................20

3 Electricity Demand and GHG Emission Factors ................................................................23

3.1 Hourly Electricity Demand and Percentage Share of Supply from Different Generation Mix.

3.2 Electricity Generation Technologies and their Fuel and Emission Characteristics 23

3.3 Data Classification for Estimating Hourly Pollutant and GHG Emissions from Power Generation .24

3.4 Estimation of Hourly Pollutants and GHG Emission Factor per kWh of Electricity Supplied. .24

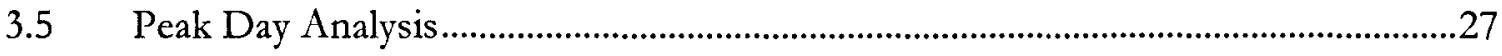

3.6 Time Dependent Valuation Analysis (TDVA) for Greenhouse Gases ....................27

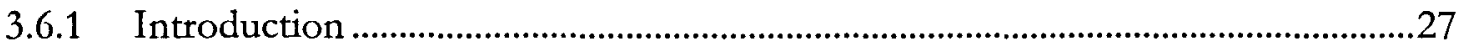

3.6.2 TDV GHGIF Profile Methodology …………….................................................27

3.7 Time Dependent Valuation Economic Analysis (TDVEA) for Greenhouse Gases 28

3.7.1 Introduction .28

3.7.2 Greenhouse Gas Cost Factor (GHGCF) Methodology ………...............................28

$3.8 \quad$ ESP-r Simulations .................................................................................................

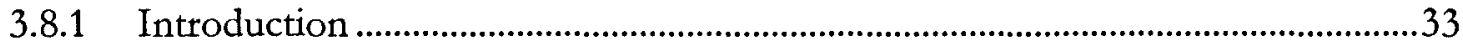

3.8.2 Test Case House and Year of Assessment ..............................................................33

3.8.3 Economic Analysis of Building Integrated Renewable Technologies ...................34

$4 \quad$ Neural Network Modeling......................................................................................................36

4.1 Predictive Models using Neural Network Modeling ……………………………….....36

4.2 Development of Artificial Neural Network Architecture and Training...................36

4.2.1 Overview of Neural Network Modeling ………………………..............................36

4.3 Selection of Input Parameters........................................................................................37

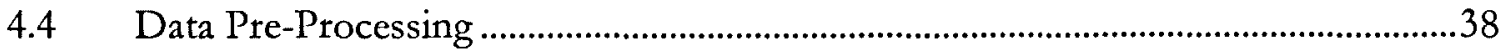


4.5 Development of the Artificial Neural Network Architecture .....................................38

4.6 NN Model Testing and Training...............................................................................38

4.6.1 Development of the Neural Network Input Parameters .......................................39

4.6.2 Development of the NN Architecture.......................................................................41

$5 \quad$ Hourly Supply and Demand of Electricity for Ontario ........................................................49

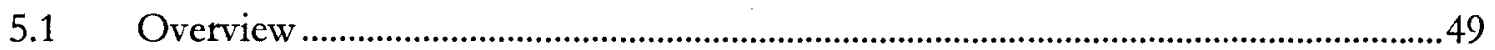

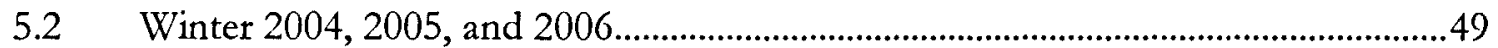

5.2.1 Peak Day Electricity Analysis for Winter 2004, 2005, and 2006 ..........................52

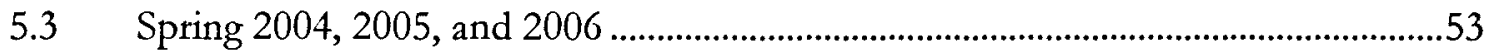

5.3.1 Peak Day Electricity Analysis for Spring 2004, 2005, and 2006 ...........................56

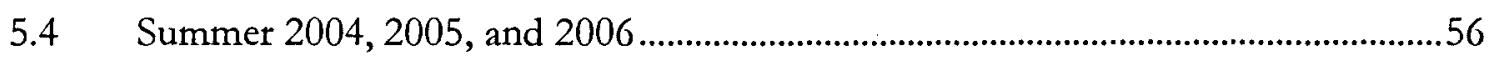

5.4.1 Peak Day Electricity Analysis for Summer 2004, 2005, and 2006 .......................59

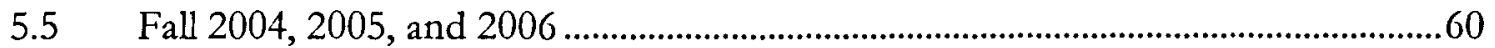

5.5.1 Peak Day Electricity Analysis for Fall 2004, 2005, and 2006...............................63

$5.6 \quad$ Years 2004, 2005, and 2006 .....................................................................................63

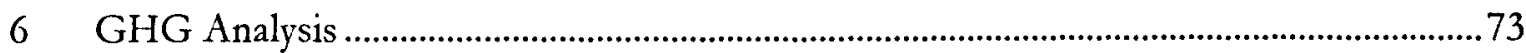

6.1 Winter 2004, 2005, and 2006 Emissions ..................................................................73

6.1.1 Winter Emission Factors....................................................................................

6.1.2 Peak Day GHG Analysis for Winter 2004, 2005, and 2006 .................................78

6.2 Spring 2004, 2005, and 2006 Emissions ......................................................................

6.2.1 Spring Emission Factors .......................................................................................... 82

6.2.2 Peak Day GHG Analysis for Spring 2004, 2005, and 2006 …..............................85

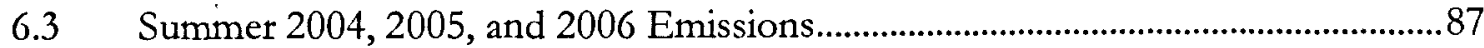

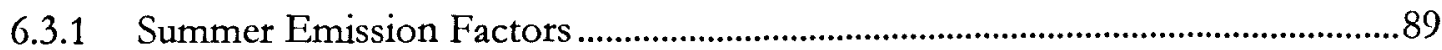

6.3.2 Peak Day GHG Analysis for Summer 2004, 2005, and 2006 .............................. 92

6.4 Fall 2004, 2005, and 2006 Emissions.........................................................................94

6.4.1 Fall Emission Factors ............................................................................................

6.4.2 Peak Day GHG Analysis for Fall 2004, 2005, and 2006 ……..............................99

6.5 Annual Emissions .........................................................................................................101

6.5.1 Annual Emission Factors ................................................................................104

6.5.2 Annual Peak Day GHG Analysis for 2004, 2005, and 2006...............................111

$7 \quad$ Test-Case Scenatios ...............................................................................................................115 
7.1 Introduction

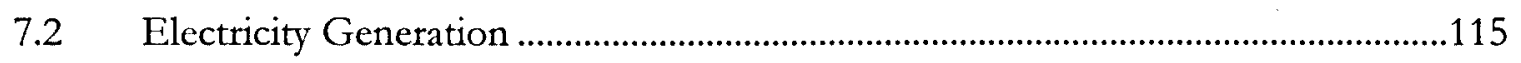

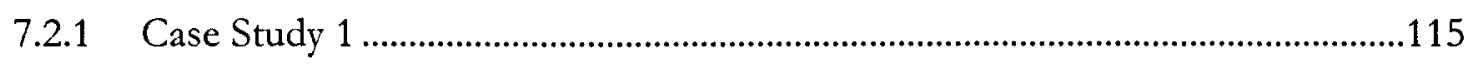

7.2.2 Case Study 2 …............................................................................................118

7.2.3 Case Study 3 ………………….................................................................119

7.3 GHG Analysis ................................................................................................121

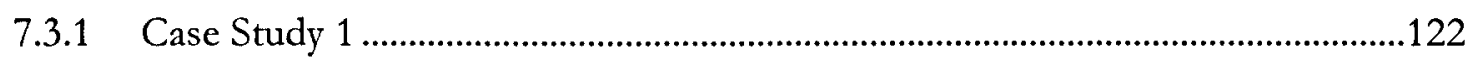

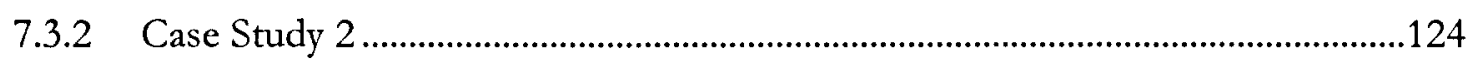

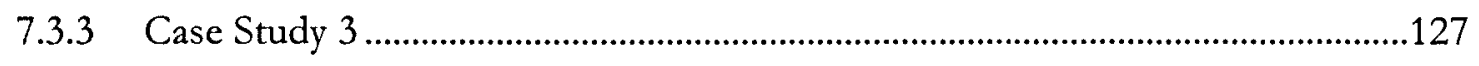

7.4 Revenue Generated by Test-Cases ..........................................................................129

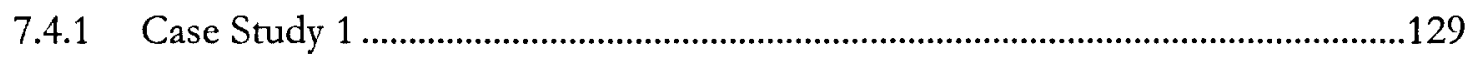

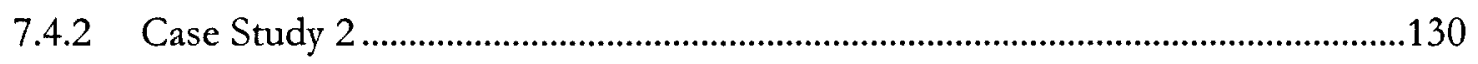

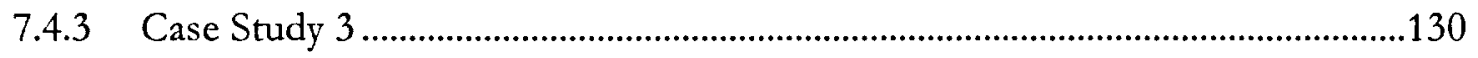

7.5 Greenhouse Gas Cost Factor Analysis ………………............................................130

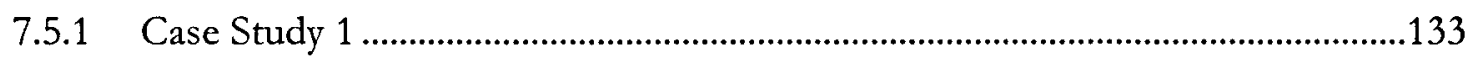

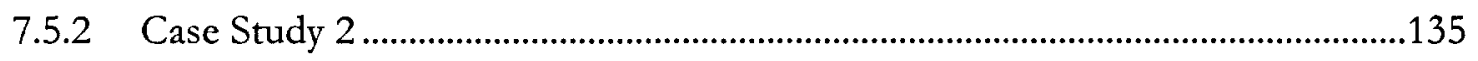

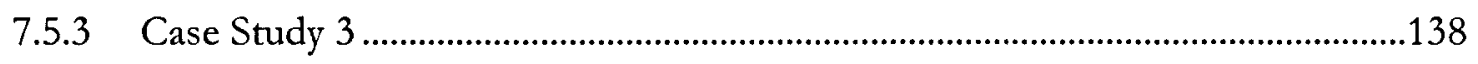

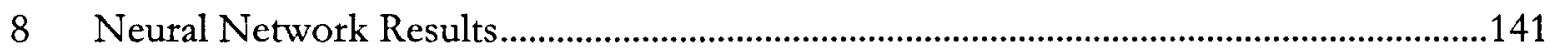

8.1 Overview .............................................................................................................141

$8.2 \quad$ Hourly Electricity Demand Forecasting..................................................................141

8.2.1 Test Case Using Load Forecasting NN Model.......................................................143

8.3 Hourly Percentage Mix from Generation Sources NN Model.................................144

8.3.1 Percentage Nuclear NN ...................................................................................... 144

8.3.2 Percentage Hydro NN ........................................................................................147

8.3.3 Percentage Coal NN ......................................................................................150

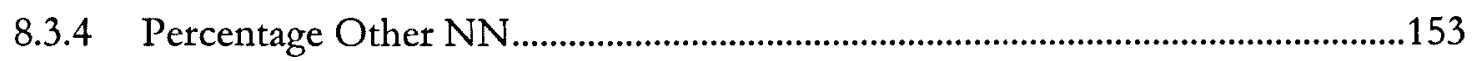

8.4 Emission Factor Forecasting using Neural Networks ..............................................157

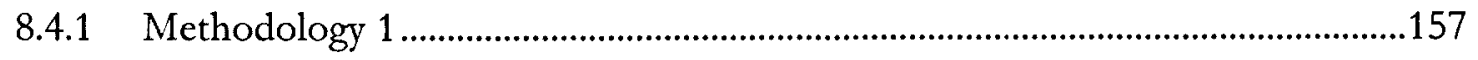

8.4.2 Methodology 2................................................................................................160

8.4.3 Comparison of Emission Factor Methodologies .................................................162

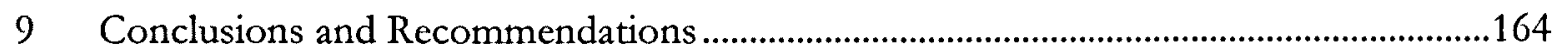

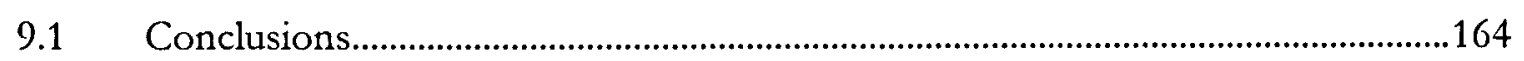


9.2 Recommendations

References

Appendix A: Neural Network Algorithms and Performance 174

Appendix B: Neural Network Model Development

Appendix C: Neural Network Model Results 


\section{List of Tables}

Table 1-1: Three Steps Draft Plan (GOC, 2002)..........................................................................

Table 2-1: GHG Trends in the Electricity Generation Sector, $1990-2004, \mathrm{Mt} \mathrm{CO}_{2}$ eq.......14

Table 3-1: Time-of-Use Pricing for Winter Months (OEB, 2006) ..............................................30

Table 3-2: Time-of-Use Pricing for Summer Months (OEB, 2006) ............................................30

Table 3-3: Time-of-Use Pricing for Weekends (OEB, 2006) ......................................................30

Table 4-1: Input parameters for the hourly percentage mix NN models...................................40

Table 4-2: Performance of the elec. demand network trained using five different learning algorithms

Table 4-3: Performance of the nuclear network trained using five different learning algorithms

Table 4-4: Performance of emission factor network trained using five different learning algorithms.

Table 4-5: Performance of selected $\mathrm{NN}$ architectures

Table 5-1: Season definition

Table 5-2: Output and capability generation comparison for winter 2004-2006. 51

Table 5-3: Electricity demand by generation type comparison for winter 2004-2006 .52

Table 5-4: Electricity demand comparison for winter peak days 2004-2006 .52

Table 5-5: Output and capability generation comparison for spring 2004-2006 55

Table 5-6: Electricity demand by generation type comparison for spring 2004-2006 .55

Table 5-7: Electricity demand comparison for spring peak days 2004-2006 .56

Table 5-8: Output and capability generation comparison for summer 2004-2006 .58

Table 5-9: Electricity demand by generation type comparison for summer 2004-2006. .59

Table 5-10: Electricity demand comparison for summer peak days 2004-2006 59

Table 5-11: Output and capability generation comparison for fall 2004-2006 62

Table 5-12: Electricity demand by generation type comparison for fall 2004-2006 .62

Table 5-13: Electricity demand comparison for fall peak days 2004-2006 .63

Table 5-14: Electricity demand comparison for seasonal peak days for 2004 65

Table 5-15: Electricity demand comparison for seasonal peak days for 2005 ..........................67

Table 5-16: Electricity demand comparison for seasonal peak days for 2006 .69

Table 5-17: Output and capability generation comparison for 2004-2006 70 
Table 5-18: Electricity demand by generation type comparison for 2004-2006 .....................71

Table 6-1: GHG emissions from the power generation sector - winter 2004-2006 ...............75

Table 6-2: Average Emission factors for winter 2004-2006 ….................................................75

Table 6-3: TDV emission factor comparison for winter 2004-2006 .......................................76

Table 6-4: Average GHG cost factors using flat rate pricing scheme 2004-2006 ...................77

Table 6-5: Average GHG cost factors using TOU pricing scheme 2004-2006 .......................78

Table 6-6: Average GHG cost factors using wholesale pricing scheme 2004-2006 ...............78

Table 6-7: $\mathrm{CO}_{2}$ emissions during winter peak day for 2004, 2005, and 2006 ..........................79

Table 6-8: Average emission factors during peak winter day 2004-2006.................................80

Table 6-9: GHG emissions from the power generation sector - spring 2004-2006 ................82

Table 6-10: Average Emission factors for spring 2004-2006 ................................................82

Table 6-11: TDV emission factor comparison for spring 2004-2006 ...................................... 83

Table 6-12: Average GHG cost factors using flat rate pricing scheme 2004-2006.................84

Table 6-13: Average GHG cost factors using TOU pricing scheme 2004-2006....................85

Table 6-14: Average GHG cost factors using wholesale pricing scheme 2004-2006 ..............85

Table 6-15: $\mathrm{CO}_{2}$ emissions during spring peak day for 2004, 2005, and 2006 ........................86

Table 6-16: Average emission factors during peak spring day 2004-2006................................87

Table 6-17: GHG emissions from the power generation sector - summer 2004-2006 ...........89

Table 6-18: Average Emission factors for summer 2004-2006 ...............................................89

Table 6-19: TDV emission factor comparison for summer 2004-2006....................................90

Table 6-20: Average GHG cost factors using flat rate pricing scheme 2004-2006.................91

Table 6-21: Average GHG cost factors using TOU pricing scheme 2004-2006.....................92

Table 6-22: Average GHG cost factors using wholesale pricing scheme 2004-2006 ..............92

Table 6-23: $\mathrm{CO}_{2}$ emissions during summer peak day for 2004, 2005, and 2006.....................93

Table 6-24: Average emission factors during peak summer day 2004-2006 ............................94

Table 6-25: GHG emissions from the power generation sector - fall 2004-2006...................96

Table 6-26: Average Emission factors for fall 2004-2006........................................................96

Table 6-27: TDV emission factor comparison for fall 2004-2006...........................................97

Table 6-28 : Average GHG cost factors using flat rate pricing scheme 2004-2006................98

Table 6-29: Average GHG cost factors using TOU pricing scheme 2004-2006.....................99

Table 6-30: Average GHG cost factors using wholesale pricing scheme 2004-2006 ..............99

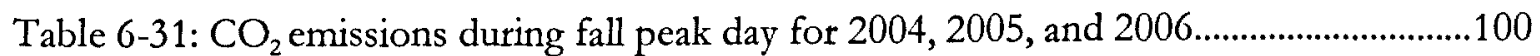


Table 6-32 : Average emission factors during peak fall day 2004-2006.

Table 6-33: GHG emissions from the power generation sector for 2004

Table 6-34: GHG emissions from the power generation sector for 2005

Table 6-35: GHG emissions from the power generation sector for 2006

Table 6-36: GHG emissions from the power generation sector comparing 2004-2006

Table 6-37: Average Emission factors for 2004

Table 6-38: Average Emission factors for 2005

Table 6-39: Average Emission factors for 2006

Table 6-40: Average Emission factors comparing 2004-2006.

Table 6-41: Annual TDV emission factor comparison for 2004-2006

Table 6-42: Average GHG cost factors using flat rate pricing scheme 2004-2006

Table 6-43: Average GHG cost factors using TOU pricing scheme 2004-2006

Table 6-44: Average GHG cost factors using wholesale pricing scheme 2004-2006

Table 6-45: $\mathrm{CO}_{2}$ Emissions during seasonal peak days for 2004

Table 6-46: $\mathrm{CO}_{2}$ emissions during seasonal peak days for 2005

Table 6-47: $\mathrm{CO}_{2}$ emissions during seasonal peak days for 2006

Table 7-1: Annual electricity generated by PV and micro-wind turbine for test-case study 1

Table 7-2: Annual electricity generated by PV for test-case study 2

Table 7-3: Total electricity generated by PV for test-case study 3 .

Table 7-4: Emission reduction comparison for test-case study 1

Table 7-5: Different emission factor types vs. hourly emission factor for test-case study 1124

Table 7-6: Emission reduction comparison for test-case study 2

Table 7-7: Different emission factor types vs. hourly emission factor for test-case study 2126

Table 7-8: Emission reduction comparison for test-case study 3

Table 7-9: Different emission factor types vs. hourly emission factor for test-case study 3128

Table 7-10: Revenue generated from PV and micro-wind turbine technologies for case-study 1

Table 7-11: Revenue generated from PV for case-study 2

Table 7-12: Revenue generated from PV for casc-study 3

Table 7-13: Hourly emissions cost comparison using the different pricing schemes test-case study 1 
Table 7-14: TDV emissions cost comparison using the different pricing schemes test-case study 1

Table 7-15: Hourly emissions cost comparison using the different pricing schemes test-case study 2

Table 7-16: TDV emissions cost comparison using the different pricing schemes test-case study 2

Table 7-17: Hourly emissions cost comparison using the different pricing schemes test-case study 3

Table 7-18: TDV emissions cost comparison using the different pricing schemes test-case study 3

Table 8-1: Prediction performance of NN model - load forecasting. 141

Table 8-2: NN load forecasting statistics 143

Table 8-3: Average MAPE values for test case - 2005 144

Table 8-4: Prediction performance of NN model - \% nuclear. 145

Table 8-5: NN \% nuclear training statistics 146

Table 8-6: Average MAPE values for test case - 2006 147

Table 8-7: Prediction performance of NN model - \% hydro 148

Table 8-8: NN \% hydro training statistics 149

Table 8-9: Average MAPE values for \% hydro test case - 2006 150

Table 8-10: Prediction performance of NN model - \% coal. .151

Table 8-11: NN \% coal training statistics. 152

Table 8-12: Average MAPE values for \% coal test case - 2006 .153

Table 8-13: Prediction performance of NN model - \% other .154

Table 8-14: NN \% other training statistics. .155

Table 8-15: Average MAPE values for \% other test case - 2006. .156

Table 8-16: Average seasonal MAPE values comparing actual and predicted NGHGIF $_{\mathrm{A}}$ 2005

Table 8-17: Average seasonal MAPE values comparing actual and predicted NGHGIF $_{\mathrm{A}}$ using alternate methodology - 2005 160

Table 8-18: Prediction performance of NN model - emission factor. 161

Table 8-19: NN EF training statistics 162 
Table B-1: Performance of the hourly electricity demand network with different architectures

Table B-2: Performance of the percentage from nuclear network with different architectures

Table B-3: Performance of the percentage from hydro network with different architectures

Table B-4: Performance of the percentage from coal network with different architectures 184 Table B-5: Performance of the percentage from other network with different architectures

Table B-6: Performance of the hourly emission factor network with different architectures 186

Table B-7: Performance of hydro network trained using five different learning algorithms 187 Table B-8: Performance of the coal network trained using five different learning algorithms

Table B-9: Performance of other network trained using five different learning algorithms 187 


\section{List of Figures}

Figure 1-1: Ontario supply and demand projections (IESO, 2006) …………………..............

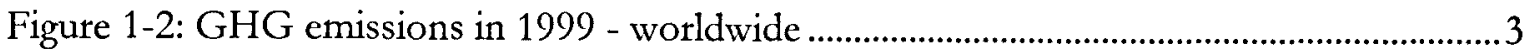

Figure 1-3: Actual GHG Reduction (Wojczynsk, 2002) .............................................................6

Figure 1-4: Photovoltaic system house installation (Sunpowered, 2007) .................................... 8

Figure 2-1: Electricity price for a typical summer day (IESO, 2007) ……………………….......13

Figure 2-2: Architectural graph of a MLP with one hidden layer.............................................21

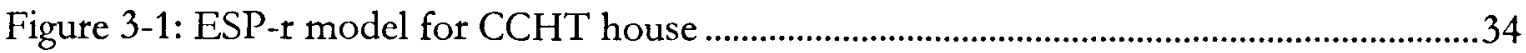

Figure 4-1: Flowchart diagram depicting the methodology used for the development of the

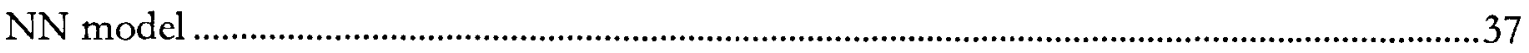

Figure 4-2: Minimum error values for the hourly electricity demand NN ................................42

Figure 4-3: Akaike's Information Criterion for the hourly electricity demand NN ..................43

Figure 4-4: Minimum error values for the percentage from nuclear NN ...................................4

Figure 4-5: Akaike's Information Criterion for the percentage from nuclear NN...................45

Figure 4-6: Minimum error values for the hourly emission factor NN .....................................46

Figure 4-7: Akaike's Information Criterion for the hourly emission factor NN ......................4 47

Figure 5-1: Hourly electricity supply and demand for Ontario winter 2004 .............................50

Figure 5-2: Hourly electricity supply and demand for Ontario winter 2005 .............................50

Figure 5-3: Hourly electricity supply and demand for Ontario winter 2006 ..............................51

Figure 5-4: Electricity demand during peak winter weekday 2004-2006 ...................................53

Figure 5-5: Hourly electricity supply and demand for Ontario Spring 2004..............................53

Figure 5-6: Hourly electricity supply and demand for Ontario Spring 2005 ...............................54

Figure 5-7: Hourly electricity supply and demand for Ontario spring 2006 ..............................54

Figure 5-8: Electricity demand during peak spring weekday 2004-2006.....................................56

Figure 5-9: Hourly electricity supply and demand for Ontario summer 2004 ............................57

Figure 5-10 Hourly electricity supply and demand for Ontario summer 2005 .........................57

Figure 5-11: Hourly electricity supply and demand for Ontario summer 2006 ……..................58

Figure 5-12: Electricity demand during peak summer weekday 2004-2006 ………………........60

Figure 5-13: Hourly electricity supply and demand for Ontario fall 2004................................60

Figure 5-14: Hourly electricity supply and demand for Ontario fall 2005 .................................61

Figure 5-15: Hourly electricity supply and demand for Ontario fall 2006.................................61 
Figure 5-16: Electricity demand during peak fall weekday 2004-2006...

Figure 5-17: Hourly electricity supply and demand for Ontario 2004 ..................................64

Figure 5-18: Hourly electricity Capability and Output - 2004 .................................................65

Figure 5-19: Electricity demand during seasonal peak days for 2004 ....................................66

Figure 5-20: Hourly electricity supply and demand for Ontario 2005 ......................................66

Figure 5-21: Hourly electricity Capability and Output -2005 .................................................67

Figure 5-22: Electricity demand during seasonal peak days for 2005 .....................................68

Figure 5-23: Hourly electricity supply and demand for Ontario 2006 .....................................68

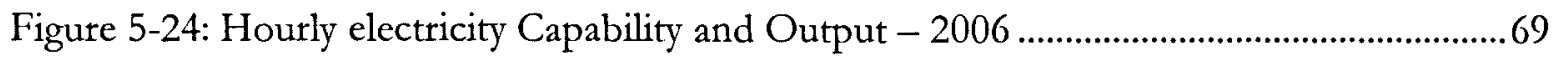

Figure 5-25: Electricity demand during seasonal peak days for 2006.....................................70

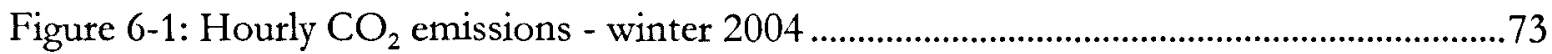

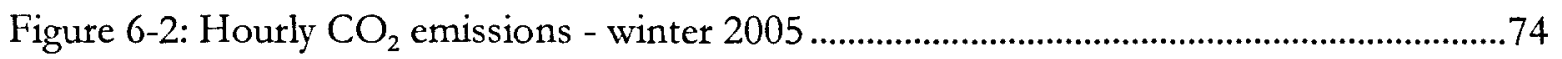

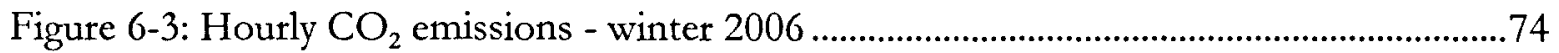

Figure 6-4: TDV emission factor profile comparison for winter 2004-2006 ….......................77

Figure 6-5: Hourly emissions during winter peak days for 2004, 2005, and 2006..................78

Figure 6-6: Hourly $\mathrm{CO}_{2}$ emission factors during peak winter day 2004-2006...........................79

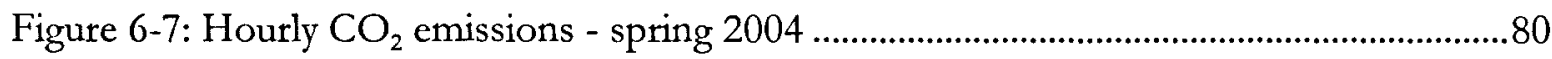

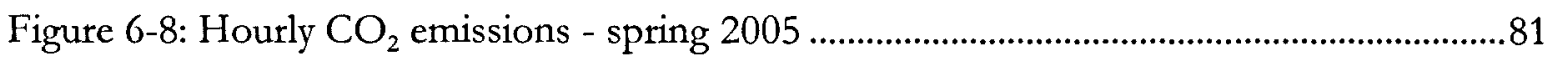

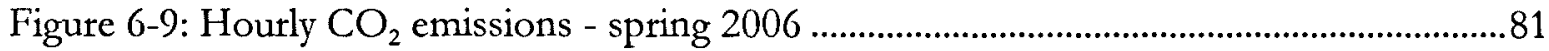

Figure 6-10: TDV emission factor profile comparison for spring 2004-2006.........................84

Figure 6-11: Hourly emissions during spring peak days for 2004, 2005, and 2006.................85

Figure 6-12: Hourly $\mathrm{CO}_{2}$ emission factors during peak spring day 2004-2006.......................86

Figure 6-13: Hourly $\mathrm{CO}_{2}$ emissions - summer 2004 ..........................................................87

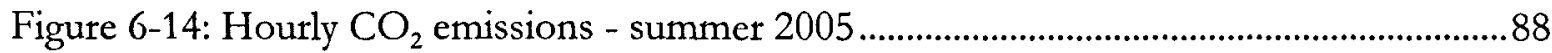

Figure 6-15: Hourly $\mathrm{CO}_{2}$ emissions - summer 2006 .............................................................8

Figure 6-16: TDV emission factor profile comparison for summer 2004-2006.....................91

Figure 6-17: Hourly emissions during summer peak days for 2004, 2005, and 2006 .............92

Figure 6-18: Hourly $\mathrm{CO}_{2}$ emission factors during peak summer day 2004-2006 .................... 93

Figure 6-19: Hourly $\mathrm{CO}_{2}$ emissions - fall 2004 ................................................................94

Figure 6-20: Hourly $\mathrm{CO}_{2}$ emissions - fall 2005 .........................................................................95

Figure 6-21: Hourly $\mathrm{CO}_{2}$ emissions - fall 2006 ...............................................................95

Figure 6-22: TDV emission factor profile comparison for fall 2004-2006 ..............................98 
Figure 6-23: Hourly emissions during fall peak days for 2004, 2005, and 2006

Figure 6-24: Hourly $\mathrm{CO}_{2}$ emission factors during peak fall day 2004-2006 ...........................100

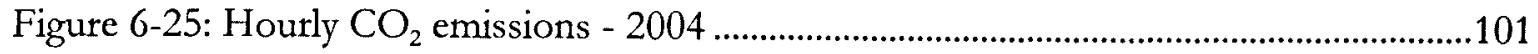

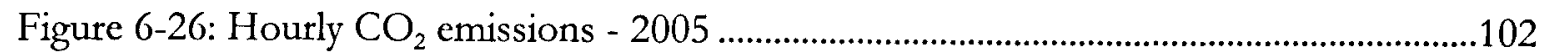

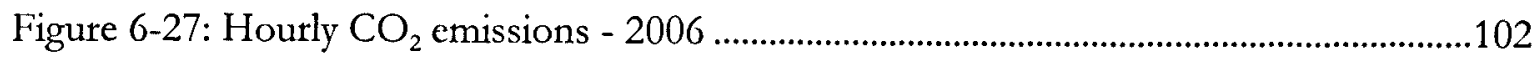

Figure 6-28: Seasonal TDV emission factor profile for 2004.................................................106

Figure 6-29: Seasonal TDV emission factor profile for 2005 .............................................107

Figure 6-30: Seasonal TDV emission factor profile for 2006...............................................107

Figure 6-31: TDV emission factor profile comparison 2004-2006 .....................................109

Figure 6-32: Hourly seasonal emission factors during peak days for 2004 ..........................112

Figure 6-33: Hourly seasonal emission factors during peak days for 2005 ...........................113

Figure 6-34: Hourly seasonal emission factors during peak days for 2006 ...........................114

Figure 7-1: PV output profile for test-case study 1 in Toronto ............................................116

Figure 7-2: Micro-wind turbine output profile for test-case study 1 in Toronto ..................116

Figure 7-3: Monthly electricity generated by PV and micro-wind turbine for test-case study 1

Figure 7-4: PV output profile for test-case study 2 in Ottawa ...............................................118

Figure 7-5: Daily electricity generated by PV for test-case study 2 .........................................119

Figure 7-6: PV output profile for test-case study 3 in Toronto ..............................................119

Figure 7-7: Monthly electricity generated by PV for test-case study 3 ....................................120

Figure 7-8: Monthly emission reductions for PV and micro-wind turbine test-case study 1

Figure 7-9: Daily emission reductions for PV test-case study 2 ..............................................127

Figure 7-10: Monthly emission reductions for PV test-case study 3 .......................................129

Figure 7-11: Monthly emission cost for PV and micro-wind turbine test-case study 1 ........135

Figure 7-12: Daily emission cost for PV test-case study 2 2.................................................138

Figure 7-13: Monthly emission cost for PV and micro-wind turbine test-case study 3 ........140

Figure 8-1: Error distribution for the load forecasting NN ..................................................142

Figure 8-2: Input importance percentage for the load forecasting NN .................................143

Figure 8-3: Error distribution for the \% nuclear NN .................................................................145

Figure 8-4: Input importance percentage for the \% nuclear NN ............................................146

Figure 8-5: Error distribution for the \% hydro NN ....................................................................148 
Figure 8-6: Input importance percentage for the \% hydro NN

Figure 8-7: Error distribution for the $\% \operatorname{coal} N N$

Figure 8-8: Input importance percentage for the \% coal NN.

Figure 8-9: Error distribution for the \% other NN.

Figure 8-10: Input importance percentage for the $\%$ other NN

Figure 8-11: Error distribution for the EF NN.

Figure 8-12: Input importance percentage for the EF NN

Figure B-1: Minimum error values for the percentage from hydro NN

Figure B-2: Minimum error values for the percentage from coal NN.

Figure B-3: Minimum error values for the percentage from other NN.

Figure B-4: Akaike's Information Criterion for the percentage from hydro NN.

Figure B-5: Akaike's Information Criterion for the percentage from coal NN..

Figure B-6: Akaike's Information Criterion for the percentage from other NN

Figure C-1: Scatter plot comparing actual vs. predicted values for the training of the network

Figure C-2: Scatter plot comparing actual vs. predicted values for the validation of the network.

Figure C-3: Scatter plot comparing actual vs. predicted values for the testing of the network

Figure C-4: MAPE profile for winter test case - load forecasting network.

Figure C-5: MAPE profile for spring test case - load forecasting network.

Figure C-6: MAPE profile for summer test case - load forecasting network.

Figure C-7: MAPE profile for fall test case - load forecasting network

Figure C-8: Scatter plot comparing actual vs. predicted values for the training of the \% nuclear NN

Figure C-9: Scatter plot comparing actual vs. predicted values for the validation of the \% nuclear NN

Figure C-10: Scatter plot comparing actual vs. predicted values for the testing of the \% nuclear NN

Figure C-11: MAPE profile for winter \% nuclear test case

Figure C-12: MAPE profile for spring \% nuclear test case 
Figure C-15: Scatter plot comparing actual vs. predicted values for the training of the \% hydro NN....

Figure C-16: Scatter plot comparing actual vs. predicted values for the validation of the \% hydro NN.

Figure C-17: Scatter plot comparing actual vs. predicted values for the testing of the \% hydro NN.

Figure C-18: MAPE profile for winter \% hydro test case 196

Figure C-19: MAPE profile for spring \% hydro test case. 197

Figure C-20: MAPE profile for summer \% hydro test case 197

Figure C-21: MAPE profile for fall \% hydro test case 198

Figure C-22: Scatter plot comparing actual vs. predicted values for the training of the $\%$ coal NN 198

Figure C-23: Scatter plot comparing actual vs. predicted values for the validation of the \% coal NN

Figure C-24: Scatter plot comparing actual vs. predicted values for the testing of the $\%$ coal NN

Figure C-25: MAPE profile for winter \% coal test case. 200

Figure C-26: MAPE profile for spring \% coal test case 200

Figure C-27: MAPE profile for summer \% coal test case 201

Figure C-28: MAPE profile for fall \% coal test case .201

Figure C-29: Scatter plot comparing actual vs. predicted values for the training of the \% other NN

Figure C-30: Scatter plot comparing actual vs. predicted values for the validation of the \% other NN

Figure C-31: Scatter plot comparing actual vs. predicted values for the testing of the \% other NN

Figure C-32: MAPE profile for winter \% other test case .203

Figure C-33: MAPE profile for spring \% other test case... .204

Figure C-34: MAPE profile for summer $\%$ other test case .204

Figure C-35: MAPE profile for fall \% other test case 205

Figure C-36: MAPE profile for $\mathrm{NGHGIF}_{\mathrm{A}}$ - winter test case. .206 
Figure C-37: MAPE profile for NGHGIF $_{\mathrm{A}}$ - spring test case ................................................206

Figure C-38: MAPE profile for $\mathrm{NGHGIF}_{\mathrm{A}}$ - summer test case …...........................................207

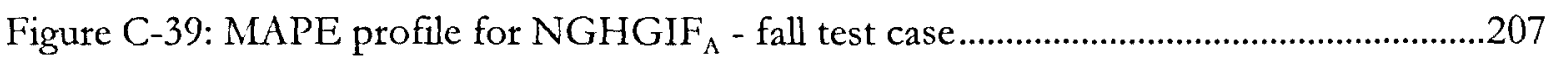

Figure C-40: Scatter plot comparing actual vs. predicted values for the training of the EF

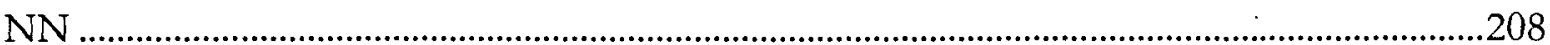

Figure C-41: Scatter plot comparing actual vs. predicted values for the validation of the EF $\mathrm{NN}$ .208

Figure C-42: Scatter plot comparing actual vs. predicted values for the testing of the EF NN 


\section{List of Abbreviations}

CGHGI - Canadian Greenhouse Gas Inventory

$\operatorname{Cost}_{\text {el.flat }} \quad$ Cost of electricity using a flat rate electricity price (\$)

D Distribution charge

Demand $_{e l} \quad$ Electricity demand $(\mathrm{kWh})$

DRC Debt Retirement Charge

GHGIF $_{\text {A }} \quad$ Average GHG Intensity Factor

FFF Fossil fuel fired

GHGIF $_{\mathrm{M}} \quad$ GHG intensity factor calculated for only FFF electricity generation

GWP Global Warming Potential multiplier

GHG Greenhouse Gas

GHGCF $F_{\text {el, flat }}$ Greenhouse Gas Cost Factor for electricity using flat rate pricing scheme

$G H G C F_{\text {el,Tou }}$ Greenhouse Gas Cost Factor using TOU pricing scheme

$G H G C F_{e l, W h o l}$ Greenhouse Gas Cost Factor using wholesale electricity pricing scheme

$\mathrm{HCO} 2 \quad \mathrm{Hourly} \mathrm{CO}_{2}$ production (tonnes)

HDDV Heavy-Duty Diesel Vehicles

HECOAL Hourly Electricity generated by Coal fired plants

HEOTHER Hourly Electricity generated by Other

HEP Hourly Electricity Price paid to generators

HETOTAL Hourly total electricity demand

HNO Hourly NO production (tonnes)

$\mathrm{HSO} 2 \quad$ Hourly $\mathrm{SO}_{2}$ production (tonnes)

IESO Independent Electricity System Operator

IMO Independent Market Operators

IPCC Intergovernmental Panel on Climate Change

LUCF Land-use Change and Forestry

LDGT Light-Duty Gasoline Trucks

MAPE Mean Average Percentage Error

Mt Megatonnes 
MLP Multi-layer perceptron

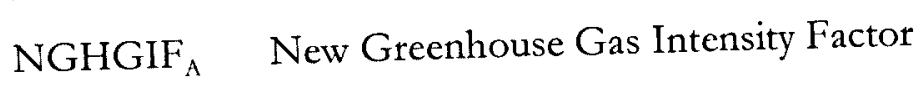

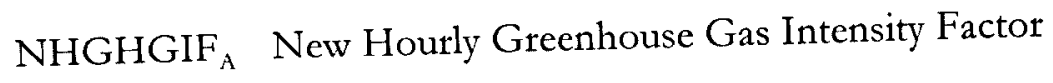

NN Neural Networks

NGHGIF $_{\text {A }} \quad$ New Greenhouse Gas Intensity Factor

NHGHGIF $_{A}$ Hourly New Greenhouse Gas Intensity Factor

$O_{\text {TOU }}$

Ontario time-of-use electricity price $(\$ / \mathrm{kWh})$

OPG

Ontario Power Generation

$P_{e l, \text { flat }}$

Flat rate price of electricity $(\$ / \mathrm{kWh})$

$P_{\text {el.TOU }}$

Price of electricity using TOU pricing scheme $(\$ / \mathrm{kWh})$

PV

Photovoltaic

$\mathrm{RCI}$

Residential, Commercial, and Institutional

RPPAC Regulated Price Plan Administration Charge

SGHGIF Summer greenhouse gas intensity factor

$T \quad$ Transmission charge

TDV

Time Dependent Valuation

TOU Time of Use

UNFCCC United Nations Framework Convention on Climate Change

WGHGIF Winter greenhouse gas intensity factor

WMOC Wholesale Market Operation Charge 


\section{Introduction}

\subsection{Historical Energy Supply and Demand}

The increase in electricity demand in the Province of Ontario in recent years has caused some concerns about the potential of an electricity supply shortage in the near future. The dilemma regarding the supply and demand of electricity in Ontario is of major concern not only to the province, but also to the country. Ontario's economy as a whole will not be sustainable without a secure and affordable source of energy (RWE, 2006). Currently, Ontario is able to meet their domestic electricity demand on their own; however, it has been projected that Ontario faces a looming electricity supply shortfall in the years ahead as coalfired plants are taken out of service and existing nuclear plants approach the end of their planned operating lives. Current projections suggest that, without new supply and substantial conservation efforts, Ontario could have insufficient power to meet its peak requirements by 2006. By 2014, the province would have only half the generation capacity it needs to ensure adequate and reliable electricity service (IESO, 2006).

The Independent Electricity System Operators (IESO) medium growth projection shows that annual peak demand will rise to almost $27,000 \mathrm{MW}$ in 2013. Including reserve requirements for the same time span, the figures rise from $28,000 \mathrm{MW}$ to over $30,000 \mathrm{MW}$ (IESO, 2006a). At the same pace of growth, peak demand would reach 32,000 MW in 2020 and, with required reserves; Ontario would require nearly 37,000 MW of capacity as shown in Figure 1-1. The IMO is responsible for the administration of the market rules ${ }^{1}$ and procedures and for the development of amendments and replacements to each.

In recent years, energy consumption and the associated Greenhouse Gas (GHG) emissions and their potential effects on the global climate change have been of worldwide concern. Climate change and global warming has been the subject of intensive investigation

\footnotetext{
${ }^{1}$ The IESO uses a consultative process to develop amendments to the Market Rules. Any individual with an interest in the operation of the electricity market can request an amendment to the Market Rules or comment on a rule amendment under consideration.
} 
provincially, nationally, and internationally for a number of years. While the complexity o the global climate change remains difficult to predict, one must attempt to develop a systen to measure the amount of GHG released into the environment. Thus, for this reason it $\mathrm{i}$ important to have an accurate method to look at the true impact of GHG on the earth.

\section{Existing Generation vs. Peak Demand}

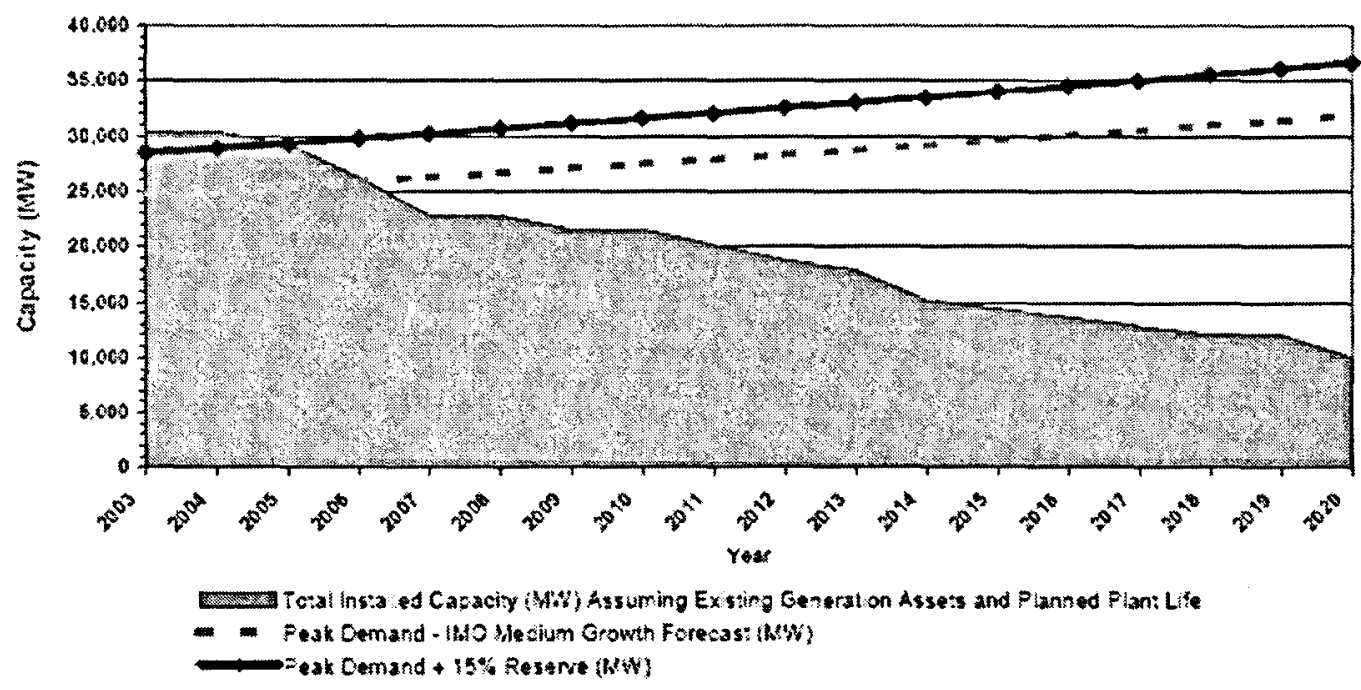

Figure 1-1: Ontario supply and demand projections (IESO, 2006)

\subsection{Environmental Concerns of Pollution and GHG}

Throughout history, our civilization has been using energy from its earliest, most basic form to its technologically advanced state. Prior to the industrial revolution, the sun was the mair source for heat. However, solar energy could not always be used for the production of hea due to its restriction of use during the day, therefore, organic matter available on a renewabl basis was used (agricultural crops, and wastes, animal wastes, etc.) in order to generate heal Animal and wind power were also used as means to produce energy for transportatior. where water was used to operate simple machines. However, after the industrial revolutior the release of massive clouds of smoke and soot from factories burning coal as a means $t$ generate power created the beginning era of GHG emissions. As the pollution continuec mankind did not realize the seriousness of the matter in hand until 1911, when 1,15 Londoners died from respiratory problems due to the smog in the air. It was not until th early 80 's that scientists started to notice that both the air and the ozone layer were changing This change was the result of the use of chemicals and other pollutants such a 
chlorofluorocarbons (CFC's) throughout the years. Consequently, these pollutants were destroying the ozone layer and contaminating the air. Figure 1-2 shows the global greenhouse gas emissions distribution for 1999 (UNFCCC, 1999).

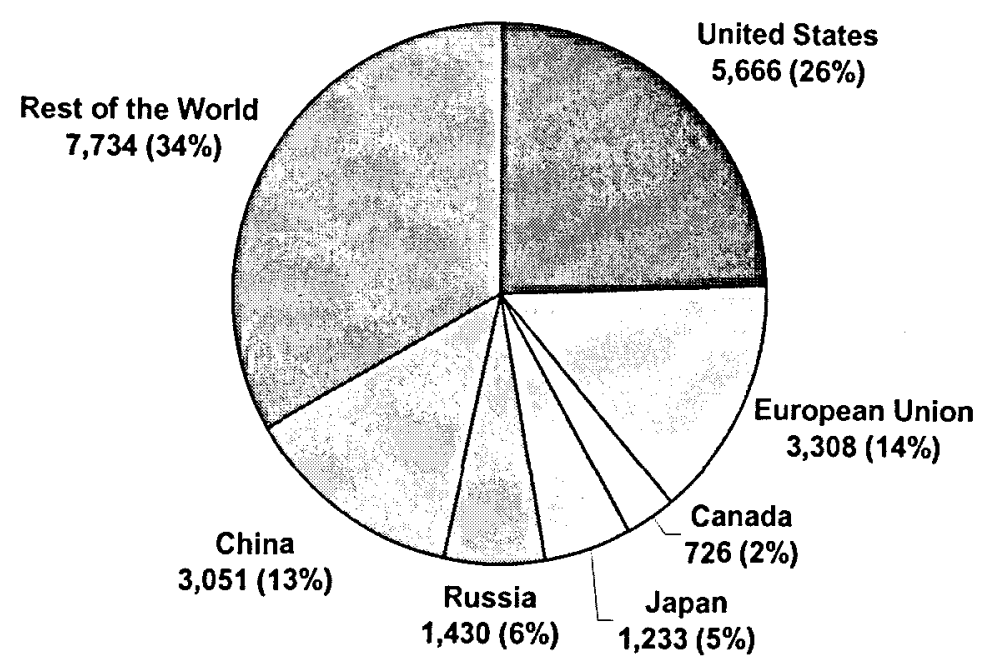

Figure 1-2: GHG emissions in 1999 - worldwide

\subsection{Kyoto Protocol}

The recent climate changes and future damage predictions, as well as the constant increase of demand of electricity in Ontario, whether they are conservative or extreme, have served to capture the awareness of the seriousness of our current lifestyle. Climate change is a global concern and it requires a global response. Global warming is arguably the single greatest environmental challenge facing the world today. Due to the scope of the concern, the response must be shared between the federal, provincial, and municipal levels of government - creating an even economic commitment to environmental technologies. This is the initiative behind the Kyoto Protocol - an agreement that does not sacrifice the competitiveness of any particular country. Negotiated in 1997 and signed by 180 countries, the Kyoto Protocol is an international agreement addressing climate change produced by the 
rising concentration of atmospheric greenhouse gases (GHG). Much of the world population live and work in cities that are built on an economic and social network which depend on day-to-day energy production and consumption. It would be unrealistic to propose a response that stopped our consumption, so the reaction must be technical in nature and aimed at reducing consumption or increasing efficiency.

\subsubsection{Protocol Requirements}

The Kyoto Protocol is an international agreement negotiated in Kyoto, Japan during the 1997 environmental summit. It is a product of a decade of international negotiations starting with the United Nations Framework Convention on Climate Change (UNFCCC) negotiated during the earth summit in Rio de Janeiro in 1992 (UNFCCC, 1999). The Kyoto protocol is a subset to the UNFCCC that seeks to apply a binding international agreement for GHG reduction. Under the Kyoto Protocol, developed countries are committed to collectively reduce greenhouse gas emissions by $5.2 \%$ below 1990 levels by the period 2008-2012. The federal government decided to ratify the accord in 2003, and as a result, Canada's share of this burden will be by $6 \%$ (CME, 2003).

\subsubsection{Protocol Aims}

Although the protocol deals with environmental issues, it is not directly concerned with air or water quality. Instead, its main target is to reduce six specific greenhouse gases to curb the global warming trend. The six gases are carbon dioxide $\left(\mathrm{CO}_{2}\right)$, nitrous oxide $\left(\mathrm{N}_{2} \mathrm{O}\right)$, methane $\left(\mathrm{CH}_{4}\right)$, sulfur hexafluoride $\left(\mathrm{SF}_{6}\right)$, hydrofluorocarbons (HFCs), and perfluorocarbons (PFCs). Although there is some uncertainty among scientists as to the extent of the human contribution to global warming, it is clear that the greenhouse gas concentrations have risen sharply since the industrial revolution. Ice core samples indicate that the level of atmospheric $\mathrm{CO}_{2}$ has risen by $30 \%$ since the start of the $19^{\text {th }}$ century. Unless there is a reduction in our dependence on fossil fuel as the prime source of energy production, the small changes in overall climate temperatures could dramatically influence global weather patterns.

\subsubsection{Current International Response}

Currently 97 countries have ratified the Kyoto accord. However, the participating parties only account for $37.4 \%$ of the global greenhouse gas emissions (KPT, 2003). Canada represents $2 \%$ of the global greenhouse gases produced. This may not seem like a large 
contribution, but when we consider our relatively small population, $2 \%$ is substantial. In fact, Canadians are the 3 rd largest producers of greenhouse gases per capita. One of the most influential parties currently onboard the Kyoto movement is the European Union. In some ways, Europe is the ideal test case because it involves a number of countries all committing to the same goal, creating an even playing field for economic stability. Canada's ratification did further increase the credibility of the accord, however, it failed to put political pressure to our closest trading partner, the United States. The US accounts for $26 \%$ of the global greenhouse gas production that is by far the largest globally (UNFCCC, 1999). In 2003, the US government decided to pull out of the agreement over fears of severe economic repercussions. Many worried that because Canada has close economic ties to our southerly neighbours, ratifying the accord will push industry south to escape the stricter environmental regulations. However, this does not account for the fact that many states already have GHG emission regulations in place. However, the current government has decided that it will not be able to meet the terms of the Kyoto protocol in the near future.

\subsection{Canadian Proposal}

\subsubsection{Actual GHG Reduction}

Although the requirement of a $6 \%$ reduction of greenhouse gas emissions may seem small, recall that the baseline year is 1990 . Estimates by the government indicate that the emission levels were $13.5 \%$ higher in 2000 than in 1990 . Given current trends, the actual reduction necessary will be 33\% above 1990 levels by 2010 as shown in Figure 1-3 (Wojczynsk, 2002). 


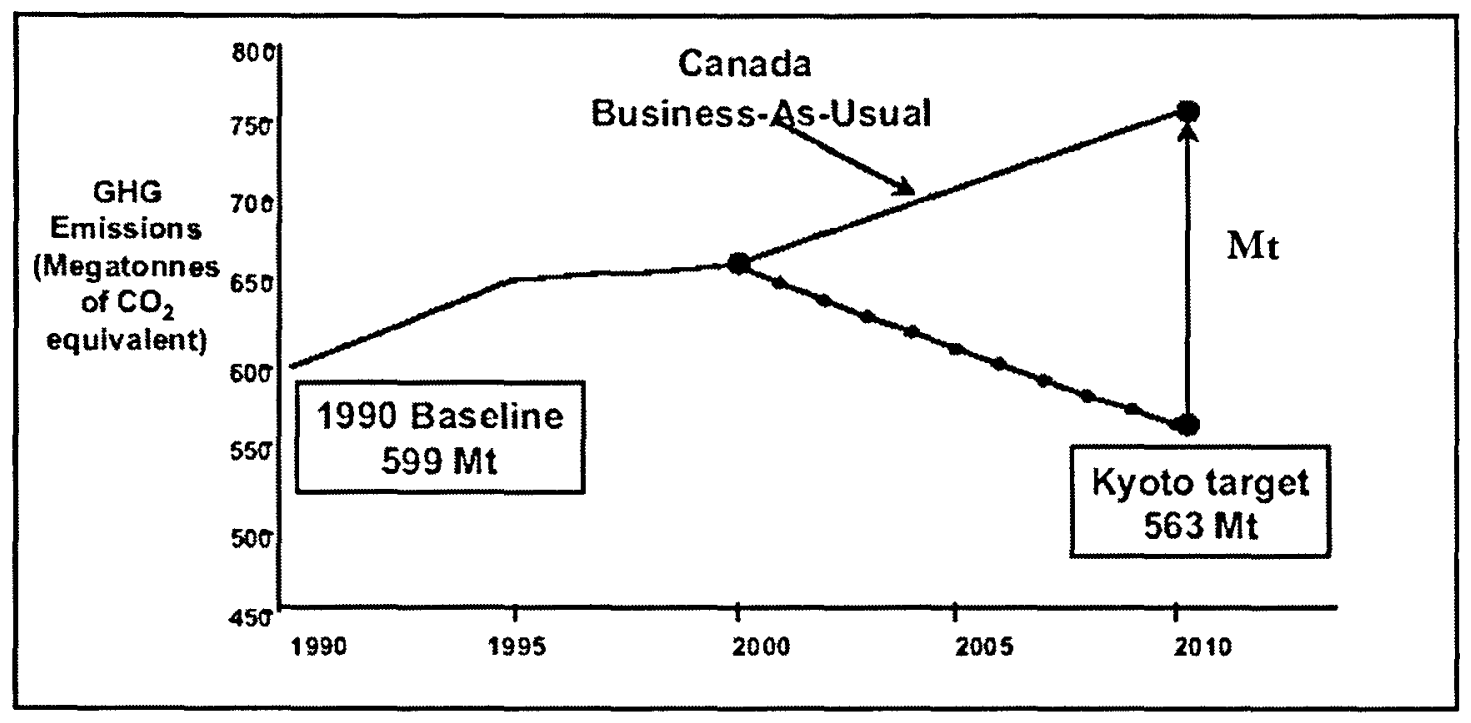

Figure 1-3: Actual GHG Reduction (Wojczynsk, 2002)

Canada is a sprawling country with a low population density, making the average commuter highly vehicle dependent. In addition, our cold climate forces us to consume a lot of energy in heating alone. These two facts, along with the required Kyoto reductions, make meeting the requirements a significant national challenge.

\subsubsection{Draft Plan}

In 2003 the Canadian government released a climate change draft plan addressing the necessary reduction in the form of a three-step process. Referring to Table 1-1 (GOC, 2002), the breakdown of each step proposed provides a GHG reduction goal in mega tonnes (MT) for a total reduction of 240 MT by 2010 . 
Table 1-1: Three Steps Draft Plan (GOC, 2002)

Overview of the Three Steps

\begin{tabular}{|c|c|c|c|}
\hline & $\begin{array}{l}\text { Step l: } \\
\text { Actions to date }\end{array}$ & $\begin{array}{l}\text { Srep 1: Action: } \\
\text { in this Step }\end{array}$ & $\begin{array}{l}\text { Step liv: Option: } \\
\text { for the Remaincer }\end{array}$ \\
\hline $\begin{array}{l}\text { Canadians and Government Actior } \\
\text { Transportation and buidding. }\end{array}$ & $15 \mathrm{MT}$ & $15-20 \mathrm{MT}$ & \multirow{6}{*}{$\begin{array}{l}\text { About } 60 \text { \&T } \\
\text { (See page 19) }\end{array}$} \\
\hline Industrial Emitters & $25 \mathrm{MT}$ & $55 \mathrm{MT}$ & \\
\hline $\begin{array}{l}\text { Other Industrial Emissions: } \\
\text { Technotogy, infrututucture and } \\
\text { efficiency gains }\end{array}$ & & $15 \mathrm{MT}$ & \\
\hline $\begin{array}{l}\text { Agriculture, Forestry and } \\
\text { Municipalities }\end{array}$ & $10 \mathrm{MT}$ & Offsets' & \\
\hline International Market & & $\min 10 \mathrm{MT}$ & \\
\hline TOTAL. & About $80 \mathrm{MT}$ & About $100 \mathrm{MT}$ & \\
\hline
\end{tabular}

* Estimated at 20 to $28 \mathrm{MT}$

Since 1998, the federal government has allocated $\$ 1.6$ billion for climate change programs. These initiatives are considered to be the first step and are expected to account for a $50 \mathrm{MT}$ GHG reduction. An additional $30 \mathrm{MT}$ will be credited to carbon sinks such as forestry and agriculture locations. Step two involves a $100 \mathrm{MT}$ reduction of greenhouse gases through a number of areas of action. A large portion of these reductions is expected to come from large industrial emitters. The draft plan does not give many specifics concerning the final 60 MT allocated to the third step. This final reduction will be a result of decisions and policies made in the future and will likely be left open until new technologies become available (GOC, 2002).

Between 1990 and 2002 secondary energy use in Canada increased 18 percent, resulting in an 18 percent increase in greenhouse gas (GHG) emissions (NRCan, 2004). In addition, energy use in the building sector rose by 30 percent, resulting in a 35 percent increase in GHG emissions (NRCan, 2004). The current trends will only make it harder for Canada to reach its goal to reduce emissions unless conservation strategies and implementation of renewable energy technologies are employed. In recent years, energy consumption and the associated GHG emissions and their potential effects on the global climate change have been of worldwide concern. While the complexity of the global climate change remains difficult to predict, it has been observed that there is a relationship between time of use of electricity and GHG emissions (MacCracken, 2006). Thus, it is necessary to develop an accurate method to predict the amount of GHGs released into the environment. 
Solar energy is a renewable resource that is environmentally friendly. Unlike fossil fuels, solar energy is available just about everywhere on earth. Solar energy is also free, immune to rising energy prices and can be used in many ways such as: providing heat, lighting, mechanical power and electricity.

Photovoltaic technology has experienced a phenomenal $20 \%$ annual growth rate during the past decade. In a photovoltaic system, sunlight is converted to electricity using photovoltaic or solar cells. Photovoltaic (PV) cells are semiconductor devices, usually made of silicon, which contain no liquids, corrosive chemicals or moving parts. Sun waves are absorbed by a PV cell and as a result excitation of the electrons within the material begins. Figure 1-4 shows a PV system installation on a house.

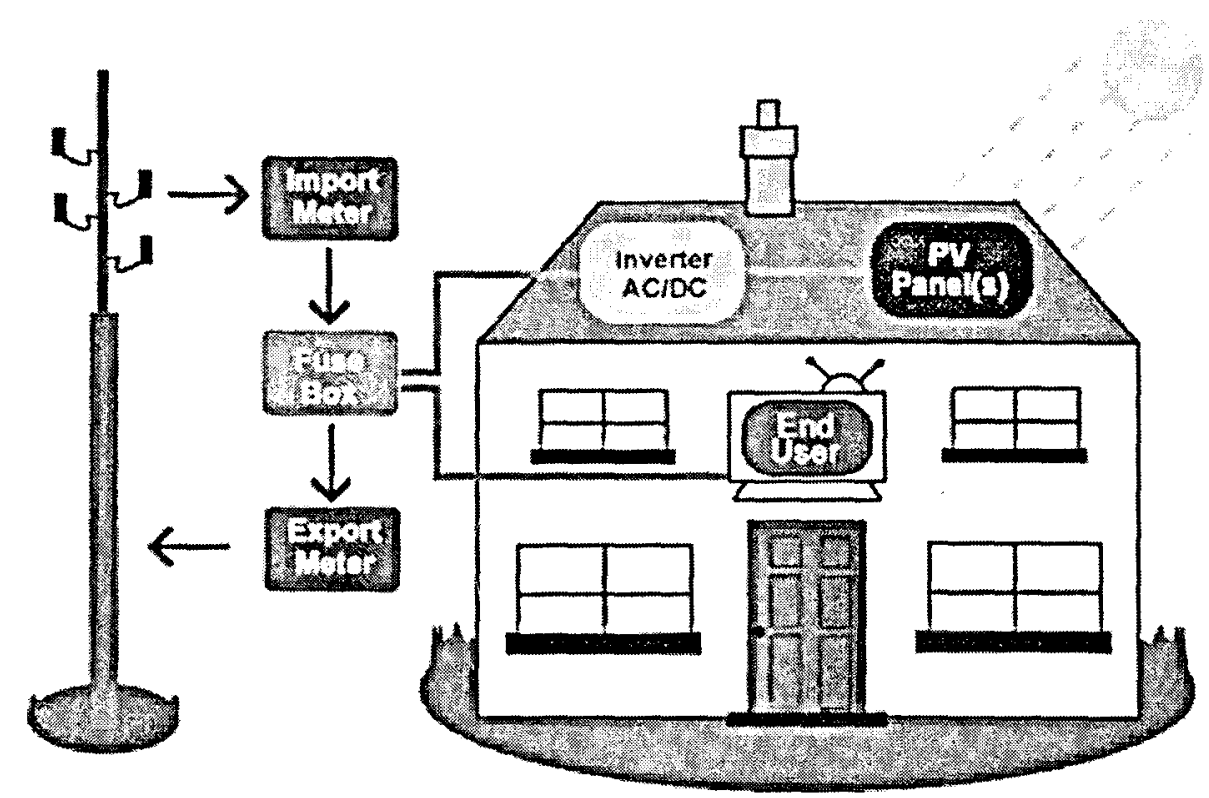

Figure 1-4: Photovoltaic system house installation (Sunpowered, 2007)

The excited electrons create a potential, in the form of electricity which is captured by wires connected to the PV cells. The wires transmit the electricity to the load of a home through an inverter. The inverter converts direct current (DC) from the PV cells to alternating current (AC) for the purpose of supplying electricity to appliances in a house. Solar cells require little maintenance, they do not pollute and operate silently, making PV energy the cleanest and safest method of power generation. 


\subsection{Objective}

\subsubsection{Emission Factors}

In recent years, energy consumption and associated Greenhouse Gas (GHG) emissions and their potential effects on the global climate change have been increasing steadily. Climate change and global warming has been the subject of intensive investigation provincially, nationally, and internationally for a number of years. While the complexity of the global climate change remains difficult to predict, one must attempt to develop a system to measure the amount of GHG released into the environment. Thus, the purpose of this thesis is to develop a better method to estimate the true GHG emission reduction potential from renewable technologies. The research proposed in this thesis will help to achieve the goals set out by the Kyoto Protocol - reducing fuel consumption and related GHG emissions, promoting decentralization of electricity supply, and encouraging the use of renewable energy technologies.

There are several methods in estimating emission factors from facilities: direct measurement, mass balance, and engineering estimates. Direct measurement involves continuous emission monitoring throughout a given period. Mass balance methods involve the application of conservation equations to a facility, process, or piece of equipment. Emissions are determined from input/output differences as well as from the accumulation and depletion of substances. The engineering method involves the use of engineering principles and knowledge of chemical and physical processes (EnvCan, 2007). In Guler (2000) the method used to estimate emission factors considers only the total amount of fuel and electricity produced from power plants. This method does not take into consideration the offset cyclical relationship, daily and yearly, between electricity generated by renewable technologies. It should be noted that none of the methods mentioned above include seasonal/daily adjustments to annual emission factors.

Specifically, the proposed research would include analyzing existing methods in calculating emission factors and attempt to estimate new emission factors based on the hourly electricity demand for the Province of Ontario. The hourly data would be divided into six categories technologies: nuclear, coal, hydro, imported, exported and other (includes natural gas, oil, 
and wood waste). In addition, in order to determine the emission factors for the years 2004, 2005, and 2006 an in-depth analysis of the electricity supply and demand for Ontario for those years would have to be conducted.

\subsubsection{Neural Networks}

Another aspect of this thesis would be to develop a Neural Network (NN) model using external variables that can estimate the electricity demand in Ontario using 2005 data. In addition, several NN models would be created in order to predict what percentage of Ontario's energy mix is produced by each source (nuclear, hydro, etc.) using hourly electricity demand values for 2005 .

There is a relationship between the electricity produced by a photovoltaic (PV) system and the availability of solar energy. These changes occur throughout the period of a day, and throughout the period of one year. Due to the divergence between when electricity can be generated via PV cells, and when it is required, there are several undetermined factors such as the economic savings attached to the use of a PV system. First, during times of low electricity demand and high solar availability, the excess electricity generated from the PV cell would be primarily used to generate income. The government of Ontario has offered to pay residents 42 cents/kWh for PV generated electricity, the excess electricity from PV would be used to help create incorne for the residents as well as reducing the load of electricity supplied by Ontario generators. Consequently, the purpose of this section would be to determine the economic potential for Ontario residents by selling electricity to the government via PV cells. Moreover, a NN model would be created in order to predict the hourly price for electricity that Ontario residents would pay based on environmental factors and time of use data.

Once the emission factor and economic analysis has been conducted several simulations would be run. Employing the model of the representative Canadian house from the Canadian Center for Housing Technology (CCHT) in conjunction with the PV model, $\mathrm{CO}_{2}$ reduction potential and economic analyses would be performed. Utilizing the CCHT model, a comprehensive residential model that details the energy consumption in an average newly 
constructed energy efficient (R-2000) Canadian house, would provide valuable data on the benefits and applicability of this system across Canada.

The purpose of this report will be to perform an hour-by-hour analysis of the electricity supply and demand and its associated emissions in Ontario for 2004, 2005 and 2006. In addition, several NN models will be developed in order to predict hourly information needed to demonstrate the true reduction potential of renewable and other new emerging technologies. The analysis performed in this thesis is based on hour-by-hour data acquired from the IESO, as well as simulation results from ESP-r for electricity produced by microwind and PV installed in the different house archetypes. The objectives of this study are as follows:

- To develop potential ways in better estimating the true GHG emission reduction potentials with sustainable integrated building energy systems.

- To evaluate hourly electricity supply and demand from Ontario for the years of 2004, 2005 , and 2006.

- To develop different GHG emission factors in order to represent the true potential for $\mathrm{CO}_{2}$ reduction using renewable energy technologies.

- To analyze the economic and GHG reduction potential from ESP-r simulations from photovoltaic and micro-wind turbine technologies using different house archetypes.

- To determine the environmental impact of PV and micro-wind by using the different GHG emission factors. Analyses on the GHG emissions will be conducted and conclusions drawn about the environmental impacts using different GHG emission factors.

- To determine the economic feasibility of PV and micro-wind in Ontario by using both wholesale price and government incentive of 42 cents/kWh for electricity. The GHG reduction potential from these technologies will be examined by employing a test-case model house for Toronto and Ottawa.

- To develop Neural Network models for the prediction of the hour-by-hour electricity demand, associated greenhouse gases, and percent mix from the different generating technologies for the Province of Ontario. 


\section{Literature Review}

\subsection{Electricity Sector in Ontario}

\subsubsection{Electricity Market}

Ontario's population has 12.5 million Canadians making it the country's most populous province and largest provincial economy (Statcan, 2006). The Ontario electricity system is one of the largest in North America accounting for $28 \%$ of the total electricity consumed in Canada, which is second only to Quebec's $35 \%$ share.

In Canada, most policy decisions in the electricity sector are under the jurisdiction of the provinces. The Ontario government's Ministry of Energy (MOE) oversees the electricity system in Ontario by employing institutional levers to carry out its objectives. Before 1998, the government owned and operated the utility, Ontario Hydro (OH). However, in 1998, the Ontario Electricity Act reorganized the electricity sector. Ontario Hydro was divided into three parts. Ontario Power Generation (OPG) became a crown corporation responsible for generating and operating plants. Hydro One became a commercial entity responsible for transmitting and distributing electricity, and the Independent Electricity System Operator (IESO), which became a non-profit organization responsible for controlling the electricity market, as well as producing electricity demand forecasts.

\subsubsection{Dispatching Mechanisms}

Before 1998, the electricity purchased by the end-user came from a distributor, such as Toronto Hydro, and generator, such as Ontario Hydro. Any additional electricity was purchased by $\mathrm{OH}$ from other utilities. After 1998, the electricity market has become a little bit more complicated. As a consumer, the electricity is distributed the same way as before; however, the generator might not be the same, and therefore, the IESO is responsible for operating the market and dealing with settlement issues.

In the new market, the IESO directs the physical flow of all electricity in the province by balancing demand with supply. This is accomplished by operating as a wholesale electricity 
"spot" market. In the spot market, the IESO collects offers from suppliers and bids from purchasers and through a coordinated auction, settlements based on market clearing prices are determined.

The wholesale price is determined by a bidding process that is driven by supply and demand. Offers from generators in Ontario and other jurisdictions that are connected to the Ontario grid are ranked for each hour of the day from the cheapest to the most expensive. A "market clearing price" is determined for each house which reflects the offer of the last generator accepted (i.e., the price of the highest offer that is accepted), regardless of their original bid. The market clearing price is used to determine the Hourly Ontario Energy Price (HOEP) (see Figure 2-1), which is the hourly price that is charged to local distributing companies and other non-dispatchable loads. The HOEP is calculated by averaging the price set every five minutes in a particular hour (IESO, 2006a)

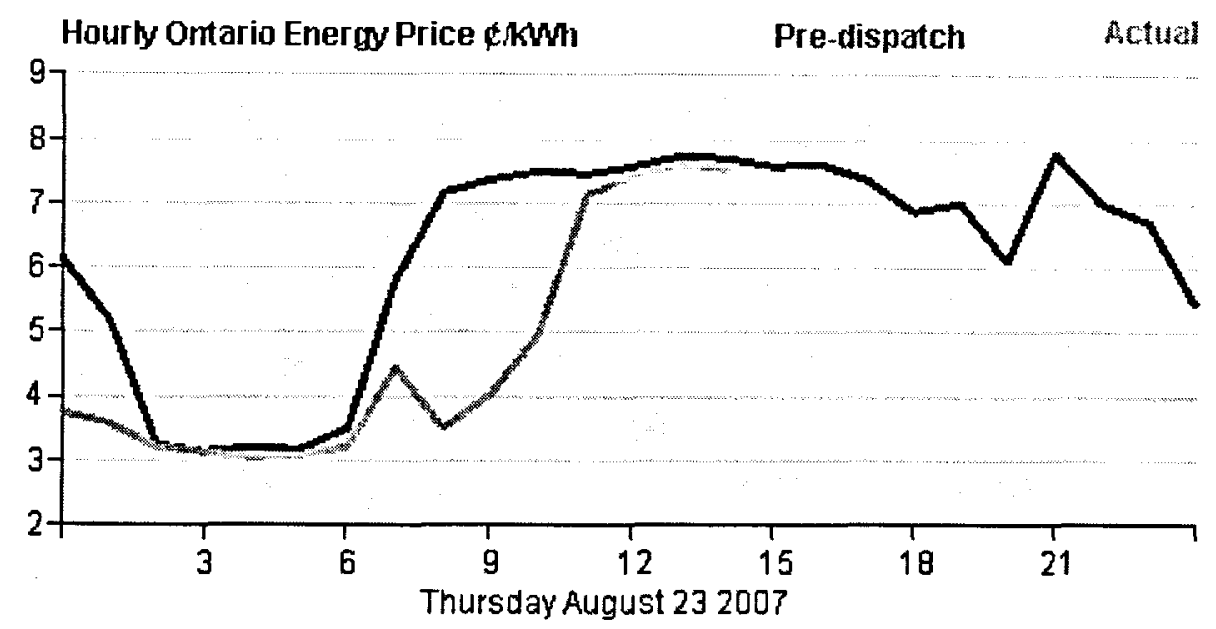

Figure 2-1: Electricity price for a typical summer day (IESO, 2007)

The wholesale price fluctuates throughout the day to reflect incremental changes in demand and supply. In periods of increased demand (on-peak), higher rates must be accepted from generators. Conversely, in periods of decreased demand, the price of electricity decreases, thus more expensive generators are not required. In the short term, demand is affected by several variables such as seasonal variations and time-of-day consumption patterns (IESO, 2006). The IESO must compensate for seasonal variations, and thus a reserve of electricity must be present at all times. The IESO must have sufficient 10 minute operating reserve to cover the largest single contingency. If the largest generator on the grid is $750 \mathrm{MW}$, there 
must be $750 \mathrm{MW}$ of operating reserve whose energy can be made available within 10 minutes of the loss of that unit to restore the supply/demand balance. Normally, 25\% of this ten-minute capacity must be spinning or synchronized. Spinning operating reserve is generation that is already synchronized to the grid. This spinning reserve helps reduce the impact of the contingency on system frequency before any of the energy associated with the operating reserve is activated. Only generators can provide ten-minute spinning reserve. The IESO must also maintain 30 minute operating reserve over and above the ten-minute requirement. There must be sufficient thirty-minute reserve to cover one-half of the second largest single contingency on the IESO-controlled grid. Dispatchable loads/generators, imports and exports can be used to satisfy 30 minute operating reserve requirements. Typically, this results in an operating reserve requirement of approximately 1,400 MW with the largest and second largest single contingency being a Darlington nuclear unit (which is approximately $\sim 900 \mathrm{MW}$ ).

\subsection{Emissions in Canada}

In 2004 , the electricity generation sector contributed $17 \%(130 \mathrm{Mt})$ of $\mathrm{CO}_{2}$ equivalent of Canada's total GHG emissions for 2004 as shown in Table 2-1. In addition, GHG reporting in Ontario is done mostly by Ontario Power Generation since it owns and operates most of the electricity generating facilities. Thus it should be noted that Ontario Power Generation's GHG emission factors only include $\mathrm{CO}_{2}, \mathrm{SO}_{2}$, and $\mathrm{NO}$ due to the negligible contribution from $\mathrm{CH}_{4}$ and $\mathrm{N}_{2} \mathrm{O}$ (OPG, 2004).

Table 2-1: GHG Trends in the Electricity Generation Sector, $1990-2004, \mathrm{Mt} \mathrm{CO}_{2} \mathrm{eq}$

\begin{tabular}{|l|c|c|c|c|c|c|c|c|c|c|c|c|c|c|c|}
\hline Sector & 1990 & 1991 & 1992 & 1993 & 1994 & 1995 & 1996 & 1997 & 1998 & 1999 & 2000 & 2001 & 2002 & 2003 & 2004 \\
\hline Electricity Gencration1 & 94.6 & 96 & 102 & 93.3 & 95.4 & 99.7 & 98.6 & 110 & 122 & 120 & 131 & 132 & 128 & 138 & 128 \\
\hline
\end{tabular}

Between 1990 and 2004, emissions from the electricity generation sector increased by almost $22 \%$ of the total emissions growth. The electricity generation sector has increased more than any other category in the national inventory. Overall, emissions increased $37 \%$ since 1990 (EnvCan, 2004). 


\subsection{Traditional Ways to Estimate Pollutant and GHG Emissions from the}

\section{Building and Electricity Generation Sectors}

One of the objectives of this thesis is to estimate GHG emission factors from the electricity generation sector. There are different methods to estimate GHG emissions. Direct measurement is typically the most accurate method that can be used. Normally, these data are not readily available and, historically, the majority of GHG emissions from fossil fuel and process-related activities have been estimated. Estimation is the method used by many countries when preparing their national GHG inventories (IPCC, 1997). Guler (2000) calculated the amount of GHG emissions from the electricity generation by using the Average GHG Intensity Factor $\left(\mathrm{GHGIF}_{\mathrm{A}}\right)$, which assumes that the reduction in electricity consumption is uniformly distributed amongst all types of electricity generation. GHGIF $_{\mathrm{A}}$ is the amount of GHG emissions produced as a result of generating one $\mathrm{kWh}$ of electricity. The GHGIF in 1993 for the Province of Ontario was estimated to be $136 \mathrm{~g} / \mathrm{kWh}$ using the methodology mentioned above.

In Canada, electricity is primarily produced from three sources: fossil, nuclear, and hydro. Recently, there has been a small addition to the mix from alternative power generation (wind).

The combustion of fossil fuels produces several major greenhouse gases: carbon dioxide $\left(\mathrm{CO}_{2}\right)$, methane $\left(\mathrm{CH}_{4}\right)$, sulphide dioxide $\left(\mathrm{SO}_{2}\right)$, nitrogen oxide $(\mathrm{NO})$, nitrous oxide $\left(\mathrm{N}_{2} \mathrm{O}\right)$, etc. The amount of emissions from $\mathrm{CO}_{2}, \mathrm{CH}_{4}, \mathrm{SO}_{2}, \mathrm{NO}$, and $\mathrm{N}_{2} \mathrm{O}$ varies from one fuel to another, and they are calculated using emission factors. Emission factors are commonly expressed in tons of $\mathrm{CO}_{2}$ per MWh or grams per $\mathrm{kWh}$ of electricity produced.

\subsection{Identification of Potential Problems in Estimating Pollutant and GHG Emissions from the Building and Electricity Generation Sectors}

Butt et al. (2006) stated that the simplest way to reduce emissions is through modifying behaviour. Awareness programmes, especially those supported with information on current energy usage, are very effective at reducing electricity demand which help reduce emissions. 
Time of use of electricity is strongly related to emissions since they both vary throughout the day (MacCracken, 2006). Therefore, before these programmes can be implemented, it is necessary to develop a better method to accurately estimate GHG emissions from fossil plants.

Ontario has a unique mix of electricity producing technologies. Generally, hydro and nuclear are considered to be base load power (IESO, 2006), because they are operated at constant load all the time. Fluctuations in electricity demand are generally handled by fossil fuel fired (FFF) plants. As a result, it can be argued that the GHGIF $_{\mathrm{A}}$ calculated using the methodology in the previous section would result in estimates of GHG emission reductions based on the generation mix for the Province of Ontario, which comes from different sources (nuclear, hydro, coal, and other). In order to replace fossil plants completely, a different emission factor has to be used instead of the $\mathrm{GHGIF}_{\mathrm{A}}$. In response to this, a second GHG intensity factor $\left(\mathrm{GHGIF}_{\mathrm{M}}\right)$ was developed by Guler (2000), in which the GHGIF $_{M}$ was calculated by dividing the net FFF plant electricity production, transmission and distribution losses by the total equivalent $\mathrm{CO}_{2}$ emissions. The $\mathrm{GHGIF}_{\mathrm{M}}$ calculated for the Province of Ontario was 903.7 t/GWh in 1993 (Guler, 2000). The latter emission factor assumes that all of the electricity consumed by a residence comes from fossil, which could be used if trying to replace fossil plants with renewable technologies. Both of these methods neglect to show changes in emission factors throughout the day. It should be noted that GHGIF $_{\mathrm{A}}$ estimates would reflect Ontario's electricity supply mix.

\subsection{Potential Ways of Better Estimating the True GHG Emission Reduction \\ Potentials with Sustainable Integrated Building Energy Systems}

Renewable technologies are used to generate electricity and heat from renewable energy sources such as the sun, rivers, wind, and the earth's core temperatures. When sunlight hits a photovoltaic cell, electricity is produced. Similarly, when wind flows through a turbine, it provides rotational energy which in turn produces electricity through a generator. There are many advantages in using solar and wind energy. Some of these are: a free energy source, an abundant amount of energy, and an effective method in reducing GHG emissions. However, the electricity produced by a renewable technology, such as a photovoltaic (PV), or micro- 
wind turbine and the availability of solar and wind energy, changes throughout the period of a day. Due to the divergence between when electricity can be generated and when it is required, an hourly GHG emission analysis is needed to truly understand the impact that renewable technologies have on emissions.

Technologies for incorporating renewable energy into the residential area include, photovoltaic, micro-wind turbines, ground source heat pumps, and advance solar thermal technologies. These technologies are continuously being improved and are responsible for the emergence of hybrid homes. By combining renewable energy sources with complementing residential technologies, further end-use energy savings and emission reductions can be obtained. However, before employing a renewable energy technology, a better estimation of the true GHG emission factors must be developed in order to get a clear picture of the saving potentials for the various renewable energy technologies.

Currently, the most common method used by Environment Canada to estimate emissions is based on fuel consumption calculations from the electricity sector. This method can be too simplistic, time-consuming and errors may occur because of the many unit conversions that are required, as well as the difficulty in obtaining certain types of data. Fuel based methods only estimate an annual average and do not reflect the cyclic behaviour of emission factors throughout the day. MacCracken (2006) introduced a time dependent valuation (IDV) model for electricity and, in October 2005, TDV was adopted by the California energy efficiency standards for residential and non-residential buildings. TDV views energy demand differently depending on the time of use (MacCracken, 2006). In MacCracken (2006), it is shown that California has devised a means to determine the societal impacts on when energy is consumed. As a result, this method of analysis would allow for a more accurate representation of the potential reduction of GHGs by using renewable technologies.

\subsection{Forecasting Methods}

There is an immediate demand for precision in load forecasting. Electricity-supply planning is a crucial component in energy management, where decisions concerning additional capacity must be precise. Demand prediction is an important aspect in the development of any model for electricity planning. Long-term forecasts address future capacity and short- 
term forecasts are required for the control and scheduling of electricity supply. Predictions are required as inputs to scheduling algorithms for the generation and transmission of electricity. Short-term forecasts, in particular, have become increasingly important since the rise of competitive energy markets. Many countries have recently privatised and deregulated their power systems, and electricity has been turned into a commodity. Forecasting can help determine which devices to operate in a given period, so as to minimize costs and secure demand. In short-term modeling, the load is mainly influenced by weather conditions, seasonal effects (daily and weekly cycles, holidays) and special events. Weather related variation is certainly critical in predicting the electricity demand for lead times beyond a dayahead (Chow and Leung, 1996; Taylor and Buizza, 2003). Many researchers have considered the forecasting of electricity demand using a variety of modeling techniques. Some of these methods range from manual methods which rely on operator experience (Lonergan and Ringwood, 1995) to mathematical approaches, such as structural techniques (Bruce et al., 1994), multiple regression (Perry, 1999), exponential smoothing (Christiaanse, 1971), time series (Arnjady, 2001), and intelligent methods, such as neural networks (Park et al., 1991). A review of these methods was conducted by Alfares and Nazeeruddin (1999) and it was concluded that new load forecasting methods based on neural networks have been the most active. Over the past few years, neural network modeling has been proposed as a substitute for statistical approaches for forecasting. The comparison of the results from NNs and statistical approaches indicates that neural networks offer an accurate alternative to classical methods (Feuston and Thurtell, 1994 and Alfuhaid et al., 1997).

\subsection{Review of Neural Network Modeling}

In this section, a brief background of neural network modeling is presented and followed by a literature review on the use of $\mathrm{NN}$ in load forecasting.

\subsubsection{Background}

A neural network (NN), also commonly referred to as an artificial neural network, is an information-processing model densely interconnected and with a parallel structure to that of the human brain. In other words, NNs are simplified mathematical models mimicking biological neural networks. A neural network is an information processing system composed of a large number of highly interconnected processing elements that are analogous to 
neurons, and tied together with weighted connections that are analogous to synapses. Neural networks are capable of finding internal representations of interrelations within raw data. The key element of NNs is that they learn by example and not by following programming rules. This typical characteristic, together with the simplicity of building and training NNs, has encouraged their application to the task of prediction. Because of their inherent nonlinearity, neural networks are able to identify complex interactions between independent variables without the need for complex functional models to describe the relationships between dependent and independent variables as stated in Alfuhaid et al. (1997).

\subsubsection{Neural Networks in Energy Modeling}

Neural networks have been widely used in electricity load forecasting. There are many papers in the literature on the application of NN for utility forecasting. It is clear that NN modeling has a superior capability over conventional methods (such as regression analysis). One of the first team of researchers to use NN for load forecasting was Park et al. (1991). The authors used a multi-layer NN model to forecast the electrical load in the Seattle area. The NN model could predict 1 -hour and 24 hours ahead of time with $2 \%$ and $4 \%$ absolute error respectively. Using electricity load and environmental factors, their NN model could predict the future load with an absolute error of approximately $2 \%$ for 1 hour intervals. Lee and Park (1992) proposed a non-linear model and several NN structures which included past load data. Lee and Park demonstrated that the NN model could forecast loads for a given day with accepted accuracy. Kiartzis et al. (1995) also used a multi-layer NN model that could forecast the next 24 -hour load profile on an hourly basis with an average absolute error of $2.66 \%$. The authors concluded that incorporation of additional weather information such as humidity, rainfall, etc., would improve predicting performance.

Ho et al. (1992) also used a multilayer NN model to predict electricity demand with a new adaptive learning algorithm. The momentum ${ }^{2}$ in this learning algorithm automatically adapted in the training process. Srinivasan et al. (1991) used an NN model based on back propagation for load forecasting and showed superiority to traditional methods. Asar and Mcdonald (1994) trained a variety of $\mathrm{NNs}$ and demonstrated via examples the learning

\footnotetext{
2 the momentum amplifies the learning rate causing a faster convergence
} 
ability of a neural net to predict half-hourly and daily peak loads in England and Wales. The authors used actual load data from a power utility and trained the NN using a back propagation algorithm and obtained an average absolute error of $1.96 \%$.

As this literature review indicates, neural network modeling has been widely used for load forecasting. Different NN models and architectures have been studied. However, NNs have not yet been used to model Ontario's hourly electricity demand and percent output by source.

\subsubsection{Overview of the NN Model}

Neural networks use simple processing units, called neurons, to combine data, and store relationships between dependent and independent variables. The NN model consists of several layers of neurons that are connected to each other. This connection is referred to the information transport link from one sending to one receiving neuron.

A widely used NN model called the multi-layer perceptron (MLP) NN is shown in Figure 2-2. This type of NN consists of one input layer, one or more hidden layers, and one output layer. Each layer has several neurons, and each neuron in a layer is interconnected to the neurons in the adjacent layer with different weights.

Signals enter the input layer, which can have several inputs (independent variables), pass through the hidden layer(s), and arrive at the output layer (dependent variable) as shown in Figure 2-2. It should be noted that with the exception of the input layer, each neuron receives signals from the neurons of the previous layer. The incoming signals $\left(x_{i j}\right)$ are multiplied by the weights $\left(v_{i j}\right)$ and summed up with the bias $\left(b_{j}\right)$ contribution (Anstett and Kreider, 1993).

The output of a neuron is evaluated by applying an activation function to the total input (netj) calculated using Equation 2.1. The output of a neuron is determined by applying an activation function to the total input $\left(n e t_{j}\right)$. The bias $\left(b_{j}\right)$ has the effect of increasing or decreasing the total input to the activation function, depending on whether it has a positive 
or negative value, respectively, and can be evaluated similar to the intercept term in a linear regression model.

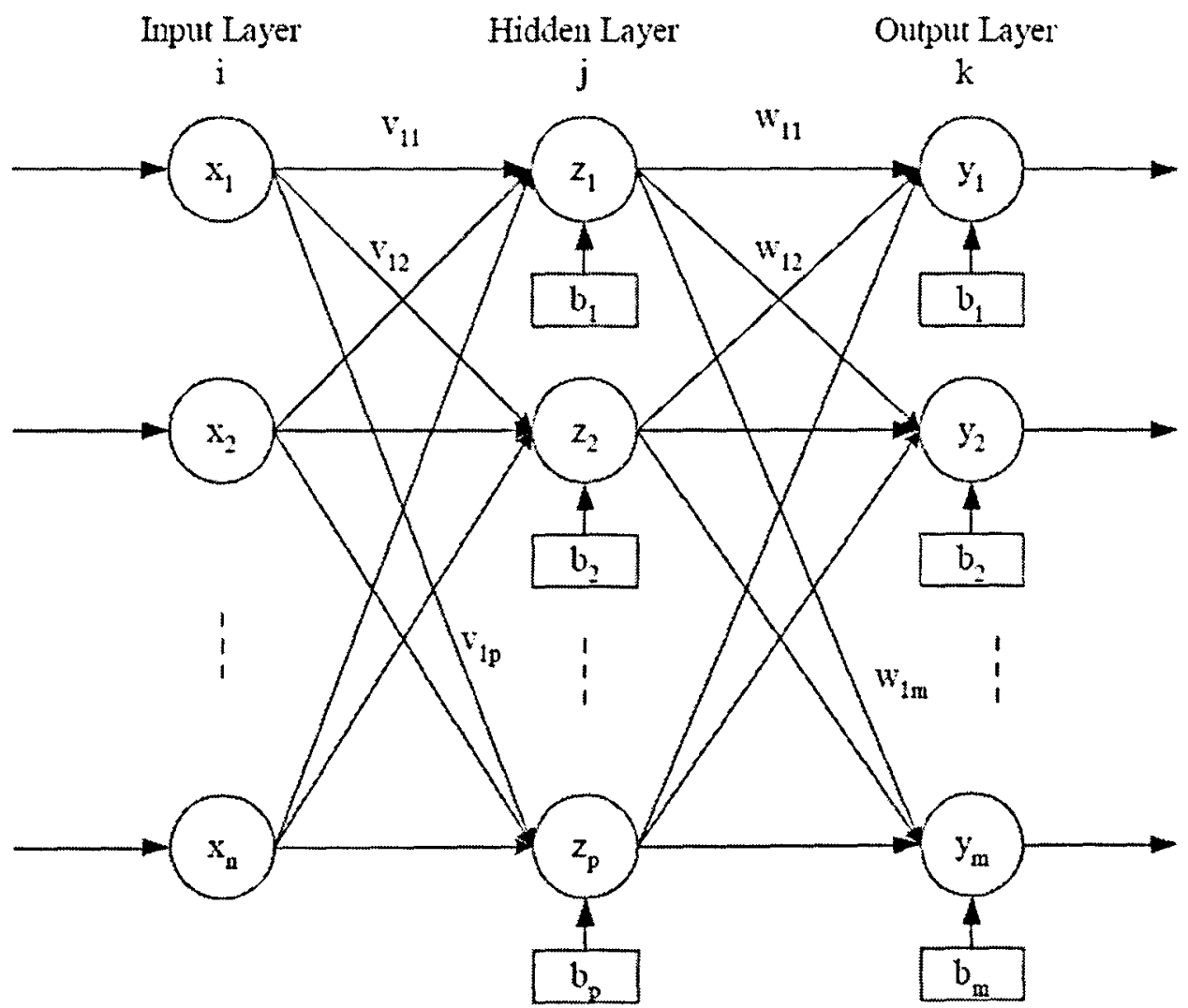

Figure 2-2: Architectural graph of a MLP with one hidden layer

$$
n e t_{j}=\sum_{i=1}^{n} x_{i} v_{i j}+b_{j}
$$

Where,

net $_{j}=$ total input of the hidden layer neuron $j$

$x_{i}=$ input to the hidden layer neuron $\mathrm{j}$ from input layer neuron $\mathrm{i}$

$v_{i j}=$ weight between the input layer neuron $\mathrm{i}$ and hidden layer neuron $\mathrm{j}$

$b_{j}=$ bias of the hidden layer neuron $\mathfrak{j}$

$n=$ number of neurons in the input layer 
In order to develop a NN two things are needed: input data and output data. The input data consists of independent variables and the output data consists of dependent variables Equation 2.2 shows the relationship between dependent and independent variables:

$$
y_{i}=c 1\left(x_{1}\right)+c 2\left(x_{2}\right)+c 3\left(x_{3}\right)+c 4\left(x_{4}\right)+\ldots
$$

Where,

$$
\begin{aligned}
& \mathrm{y}_{\mathrm{i}}=\text { dependent variable } \\
& x_{1}, x_{2}, x_{3}, x_{4}=\text { independent variables } \\
& \mathrm{c} 1, \mathrm{c} 2, \mathrm{c} 3, \mathrm{c} 4=\text { coefficients }
\end{aligned}
$$

Since the number of input and output units are decided based on the available data and the desired output, respectively, only the number of units in the hidden layer(s) is left to be determined. However, there are no rules to establish the number of hidden layers and the number of neurons for each hidden layer for a particular application as stated in Anslett and Kreider (1993).

Once the architecture type has been determined the training of the Neural Network can begin by selecting the appropriate activation function. There are several training functions each with its own mathematical characteristic such as quick propagation, quasi-Newton, back propagation, etc., these, as well as assessing the prediction performance of neural networks are presented in Appendix A 


\section{Electricity Demand and GHG Emission Factors}

\subsection{Hourly Electricity Demand and Percentage Share of Supply from Different Generation Mix}

The total supply and demand of electricity in Ontario was estimated for the years 2004, 2005 and 2006 by dividing the hour-by-hour data obtained from the IESO into the categories mentioned in section 3.2. These data were compared to published values by the following companies:

- Ontario Power Generation (nuclear, coal, hydro, gas and oil)

- Bruce Power (nuclear)

- Other Power Companies (TransCanada Energy Limited, Great Lakes Power Limited, etc.)

The total electricity demand, as well as the percentage share of supply from the different generating technologies was calculated and tabulated in graphs.

The hourly data from the IESO for 2004, 2005, and 2006 were analyzed and divided into seasonal periods (winter, spring, summer, and fall) in order to determine their inherent characteristics, thus focusing on hourly trends of the supply and demand of electricity for Ontario.

\subsection{Electricity Generation Technologies and their Fuel and Emission Characteristics}

Electricity generation in Ontario comes from three major sources: nuclear, coal, and hydro. Nuclear and hydro are generally considered to be base load power, because they are operated at constant power. However, coal plants are generally used when there are fluctuations in electricity demand. Nuclear plants produce very little $\mathrm{CO}_{2}$ from non-reactor processes and from the transportation of materials within the plant. On the other hand, fossil fuels fired (FFF) plants produce large amounts of pollutants and are the major contributors of $\mathrm{CO}_{2}$ in the electricity generation sector. Conversely, hydro produces zero air pollutants. 
The data obtained from the IESO was divided into the following categories:

- Nuclear

- Coal

- Hydro

- Other (natural gas, oil, and wood waste)

- Wind (only for 2006)

- Imported and exported

\subsection{Data Classification for Estimating Hourly Pollutant and GHG Emissions from Power Generation}

The hour-by-hour supply and demand of electricity data for Ontario used in this thesis was obtained from the Independent Electricity System Operators (IESO). The IESO is responsible for operating the wholesale electricity market and forecasting the demand as well as ensuring that the supply of electricity is available to meet that demand. In other words, all electricity producing companies in Ontario must report to the IESO.

The use of hour-by-hour data helps to provide a more accurate picture of the true potential of $\mathrm{CO}_{2}$ reductions using renewable energy technologies such as photovoltaic, wind, geothermal, etc. The scope of this thesis will be to look at the true estimate of $\mathrm{CO}_{2}$ emissions, as well as the electricity supply and demand markets for the years 2004, 2005 and 2006 for the Province of Ontario by using hour-by-hour data ${ }^{3}$.

\subsection{Estimation of Hourly Pollutants and GHG Emission Factor per kWh of Electricity Supplied}

The amount of GHG emissions from the electricity generation sector was calculated using the "Average GHG Intensity Factor" $\left(\mathrm{GHGIF}_{\mathrm{A}}\right)(\mathrm{Guler}, 2000)$. The GHGIF $\mathrm{A}_{\mathrm{A}}$ represents the

\footnotetext{
${ }^{3}$ Note: The IESO has not included the Lennox plant under the coal section. As a result, the Lennox plant was removed from the OPG Sustainable report (OPG, 2006a) for the purpose of comparative analysis of greenhouse gas intensity factors. Also, hourly data for natural gas and oil plants is classified as "other" by the IESO
} 
amount of GHG emissions produced as a result of generating one $\mathrm{kWh}$ of electricity. The GHGIF $_{\mathrm{A}}$ in 1993 for the Province of Ontario was estimated to be $136 \mathrm{~g} \mathrm{CO}_{2} / \mathrm{kWh}_{\text {(Guler, }}$ 2000). The $\mathrm{GHGIF}_{\mathrm{A}}$ for 2004, 2005, and 2006 was estimated using the methodology mentioned above in conjunction with the electricity output information (IESO, 2006a). It should be noted that the emission factor for $\mathrm{CO}_{2}$ does not take into consideration $\mathrm{CH}_{4}$ and $\mathrm{N}_{2} \mathrm{O}$ because Ontario Power Generation and Bruce Power do not show this data in their sustainable reports mainly due to their negligible effect in comparison to $\mathrm{CO}_{2}, \mathrm{SO}_{2}$, and $\mathrm{NO}$ (OPG, 2006).

The GHG emissions due to coal fired and natural gas plants were determined using Equations 3.1, 3.2 and 3.3.

$$
\begin{aligned}
& \mathrm{HCO}_{2}=(\text { HECOAL })(i)+(\text { HEOTHER })(j) \\
& \mathrm{HSO}_{2}=(H E C O A L)(k) \\
& H N O=(H E C O A L)(l)
\end{aligned}
$$

Where,

$\mathrm{HCO}_{2}=$ Hourly $\mathrm{CO}_{2}$ production $(\mathrm{kg})$

$\mathrm{HSO}_{2}=$ Hourly $\mathrm{SO}_{2}$ production $(\mathrm{kg})$

$H N O=$ Hourly $\mathrm{NO}$ production $(\mathrm{kg})$

$H E C O A L=$ Hourly Electricity generated by Coal plants

HEOTHER = Hourly Electricity generated by Other (natural gas, etc.)

$i=\mathrm{OPG} \mathrm{CO} 2$ emission factor $\left(1.001745 \mathrm{~kg} \mathrm{CO}_{2} / \mathrm{kWh}\right.$ for the year 2004) (OPG, 2004)

$j=$ Environment Canada natural gas emission factor $(0.447 \mathrm{~kg} \mathrm{CO} / \mathrm{kWh}$ for the year 2004) (Environment Canada (2005))

$k=\mathrm{OPG} \mathrm{SO} \mathrm{SO}_{2}$ emission factor $(0.00433 \mathrm{~kg} \mathrm{SO} / \mathrm{kWh}$ for the year 2004) (OPG, 2004) 
$l=$ OPG NO cmission factor $(0.00096 \mathrm{~kg} \mathrm{NO} / \mathrm{kWh}$ for the year 2004) (OPG, 2004)

The new hourly greenhouse gas emission factors $\left(\mathrm{NHGHGIF}_{\hat{N}}\right)$ model was based on the hour-by-hour demand of electricity in Ontario from the following sources: nuclear, fossil, hydro, other (natural gas, etc) (IESO, 2006a). The estimation of the new hourly greenhouse gas intensity factors $\mathrm{NHGHGIF}_{\mathrm{A}}$ was accomplished by dividing the hour-by-hour emissions from $\mathrm{CO}_{2} \mathrm{SO}_{2}$, and $\mathrm{NO}$ by the hour-by-hour total electricity generated from the sources mentioned abore. Consequently the new greenhouse gas intensity factor (NGHGIF $)_{A}$ was estimated by taking the arerage of the hourly emission factors for each season. The values obtained for the $\mathrm{NGHGIF}_{\mathrm{A}}$ were compared to the $\mathrm{GHGIF}_{\mathrm{A}}$ ralues using the methodology outlined in the literature.

The NGHGIF ${ }_{\mathrm{A}}$ was determined using Equations 3.4 and 3.5.

$$
\begin{aligned}
& \operatorname{NHGHGIF}_{A}=\frac{\mathrm{HCO}_{2}}{H E G T O T A L} \\
& \operatorname{NGHGIF}_{A}=\sum_{i=1}^{8760} \frac{N H G H G I F_{A i}}{8760}
\end{aligned}
$$

Where,

$$
\begin{aligned}
& N H G H G I F_{A}=\text { New Houtly Greenhouse Gas Intensity Factor }(\mathrm{g} \mathrm{CO} / \mathrm{kWh}) \\
& N G H G I F_{1}=\text { New Greenhouse Gas Intensity Factor }(\mathrm{g} \mathrm{CO} / \mathrm{kWh}) \\
& \mathrm{HCO}_{2}=\text { Hourly } \mathrm{CO}_{2} \text { production }(\mathrm{g}) \\
& \text { HEGTOTAL = Hourly Electricity Gencrated Total }(\mathrm{kWh}) \\
& i=\text { hour }
\end{aligned}
$$

The value obtaincd for the NGHGIF, was compared to the GHGIF from Enritonment Canada (2006) for the years 2004, 2005, and 2006. 


\subsection{Peak Day Analysis}

A seasonal peak day analysis was performed for the years 2004, 2005, and 2006 in order to demonstrate the variability of the emission factor and electricity demand in a 24 hour period. In addition, a comparison of the peak days for the time period indicated above will help to determine a trend for the shifting of electricity demand in Ontario which in turn is associated with GHG emission factors. This will show a clear representation of the benefits associated with the use of hourly data during peak hours in order to reflect the true potential of GHG reduction by using renewable technologies.

\subsection{Time Dependent Valuation Analysis (TDVA) for Greenhouse Gases}

\subsubsection{Introduction}

Currently, there is no TDV profile for greenhouse gases for the Province of Ontario in the public domain. Hourly GHG emissions data based on provincial location are not readily available, and it has been shown that emission factors vary with electricity demand (MacCracken, 2006). In addition, the shape and magnitude of GHGIF profiles also vary with factors such as time of day, time of year, geographical location, and climate. Due to the inaccessibility to emission data from the power generating sector, rather than using one GHGIF value for the entire year, seasonal GHGIF profiles based on the electricity demand for the Province of Ontario were developed. The approach detailed below was used in order to provide a better method to properly estimate greenhouse gases within the Province of Ontario.

\subsubsection{TDV GHGIF Profile Methodology}

Hourly electricity consumption data from the IESO and hourly GHG emission factors estimated in section 3.4 were used to determine Hourly Average NGHGIF profiles for the years 2004, 2005, and 2006. These profiles were calculated using Equation 3.6 for each hour in a day.

$$
T D V N G H G I F_{A}=\frac{\sum_{i=1}^{N} N G H G I F_{A}\left(h_{j}\right)}{N}
$$


Where,

$T D V N G H G F_{A}=$ Time Dependent Valuation New Greenhouse Gas Intensity Factor $(\mathrm{g} \mathrm{CO} / \mathrm{kWh})$

$N=$ number of days in the season

$i=$ day number

$j=$ hour number

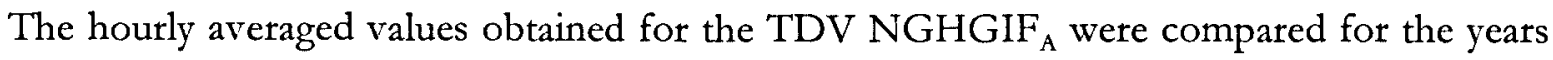
2004,2005 , and 2006.

\subsection{Time Dependent Valuation Economic Analysis (TDVEA) for Greenhouse Gases}

\subsubsection{Introduction}

Currently in the Province of Ontario there is no economic profile placing a value on emissions in the power generation sector. Electricity costs do not account for seasonal or time-of-use (TOU) patterns for emissions. Thus, it is necessary to develop a profile in order to place a monetary value and quantify the effects of greenhouse gases for Ontario. The price Ontarians pay for energy and the cost of delivering energy is dependant on the time-ofuse and location. This section will attempt to develop a more accurate energy costing analysis for time dependent valuation, which accounts for variations related to time of day, season, and geography.

The use of TDV criteria would place a higher value on energy savings during peak cost times and encourage more energy and cost efficient design and construction of buildings which as a result would reduce peak demands on the energy system in Ontario. Over time, this would lead to significant cost savings for both building owners and for the electricity supply and demand system, along with improved reliability for utilities, customers and society.

\subsubsection{Greenhouse Gas Cost Factor (GHGCF) Methodology}

The development of hourly TDV factors for the cost of electricity includes several components. The estimation included the generating price for electricity obtained from the 
IESO, which varies by time-of-use. Then the transmission and distribution costs (T\&D) were added and finally, an environmental component was applied, which reflected the cost of emissions from fossil plants in Ontario.

Using the electricity cost data and emission factors from the previous section the GHGCF was calculated shown in the following sections.

\subsubsection{Electricity Cost}

The cost of electricity generation represents the minimum amount that society is willing to pay. However, this cost does not include external costs associated with health and environmental damages. The total costs of generation are sensitive to the methodology used to estimate these additional costs. When these costs are included into the equation, the total cost of fossil-fired generation rises dramatically. This additional cost will be shown in the following sections. In the past the total cost of electricity was estimated by using a flat rate pricing structure for Ontario, however, recently Ontario has adopted a time-of-use (TOU) pricing scenario, assigning different prices depending on the time of day the electricity is used (OEB, 2006) where the final price is paid by the customer including delivery charges, etc.. However, most provinces in Canada still use the flat rate pricing scheme with the exception of Ontario and Nova Scotia. In this thesis understanding how the pricing scheme affects the emission cost is explored.

\subsubsection{Flat Rate Electricity Cost Analysis}

The flat rate electricity price for Ontario is $\$ 0.10 / \mathrm{kWh}$ (Toronto Hydro, 2006). To determine the cost of electricity using the flat rate price, the number of kilowatt-hours $(\mathrm{kWh})$ is multiplied by the flat rate price of electricity according to Equation 3.7.

$$
\operatorname{Cost}_{e l, f l a t}=P_{e l, f a t}\left(\text { Demand }_{e l}\right)
$$

Where,

$$
\begin{aligned}
& \operatorname{Cost}_{\text {el,fat }}=\text { cost of electricity using a flat rate electricity price }(\$) \\
& P_{e l, f a t}=\text { flat rate price of electricity }(\$ / \mathrm{kWh})
\end{aligned}
$$


Demand $_{e l}=$ electricity demand $(\mathrm{kWh})$

\subsubsection{Time-of-Use Electricity Cost Analysis}

The TOU scenario implemented in Ontario on May 1, 2006 is detailed in Table 3-1, Table 3-2, and Table 3-3 showing the retail electricity prices for the winter, summer, and weekends. It should be noted this is how much consumers pay for electricity and are different from what the government pays generators for their electricity produced. This distinction will help demonstrate that by having an emission cost factor added to the price of electricity for consumers and generators will have different effects.

Table 3-1: Time-of-Use Pricing for Winter Months (OEB, 2006)

\begin{tabular}{|c|c|c|}
\hline Hours & Time Period & $\begin{array}{c}\text { Final } \\
\text { Price } \\
(\$ / \mathbf{k W h})\end{array}$ \\
\hline $1-6$ & Off-Peak & 0.077 \\
\hline $7-10$ & On-Peak & 0.147 \\
\hline $11-16$ & Mid-Peak & 0.117 \\
\hline $17-19$ & On-Peak & 0.147 \\
\hline $20-21$ & Mid-Peak & 0.117 \\
\hline $22-24$ & Off-Peak & 0.077 \\
\hline
\end{tabular}

Table 3-2: Time-of-Use Pricing for Summer Months (OEB, 2006)

\begin{tabular}{|c|c|c|}
\hline Hours & Time Period & $\begin{array}{c}\text { Final } \\
\text { Price } \\
(\$ / \mathbf{k W h})\end{array}$ \\
\hline $1-6$ & Off-Peak & 0.077 \\
\hline $7-10$ & Mid-Peak & 0.117 \\
\hline $11-16$ & On-Peak & 0.147 \\
\hline $17-21$ & Mid-Peak & 0.117 \\
\hline $22-24$ & Off-Peak & 0.077 \\
\hline
\end{tabular}

Table 3-3: Time-of-Use Pricing for Weekends (OEB, 2006)

\begin{tabular}{|c|c|c|}
\hline Hours & Time Period & $\begin{array}{c}\text { Final } \\
\text { Price } \\
(\$ / \mathbf{k W h})\end{array}$ \\
\hline $1-24$ & Off-Peak & 0.077 \\
\hline
\end{tabular}

The hourly price paid by the customers for electricity at each hour for the entire year is defined in Equation 3.8. 


$$
P_{\text {el. } . T O U}=O_{\text {TOU }}+T+D+D R C+R P P A C+W M O C
$$

Where,

$$
\begin{aligned}
& P_{\text {el.TOU }}=\text { Price of electricity using TOU pricing scheme }(\$ / \mathrm{kWh}) \\
& O_{\text {TOU }}=\text { Ontario time-of-use electricity price }(\$ / \mathrm{kWh}) \\
& T=\text { Transmission charge }(0.0102 \$ / \mathrm{kWh}) \\
& D=\text { Distribution charge }(0.0186 \$ / \mathrm{kWh}) \\
& D R C=\text { Debt Retirement Charge }(0.007 \$ / \mathrm{kWh}) \\
& R P P A C=\text { Regulated Price Plan Administration Charge }(0.00000347 \$ / \mathrm{kWh}) \\
& W M O C=\text { Wholesale Market Operation Charge }(0.0062 \$ / \mathrm{kWh})
\end{aligned}
$$

The price of electricity for customers and generators for the Province of Ontario will be used in order to estimate a monetary value for emissions.

\subsubsection{Wholesale Electricity Price for Generators}

The wholesale electricity price that the government pays for electricity to generators varies every hour throughout the day. For example, an electricity generator might received anywhere between $\$ 0.04 / \mathrm{kWh}$ up to $\$ 1.6 / \mathrm{kWh}$ depending on when they are providing the electricity (i.e. during peak times). Usually fossil plants receive a higher rate than nuclear due to capacity limitations and fluctuations.

\subsubsection{Emission Cost}

The hourly emission cost was estimated using both the hourly retail price for electricity estimated in section 3.7.2 and the hourly emission factors developed in section 3.4. There were three emission cost factors determined in order to show the different impact on customers and generators. The hourly emission costs for the different electricity pricing schemes were estimated using Equations 3.9, 3.10, and 3.11. 


\subsection{TDV GHGCF using flat rate pricing scheme}

$$
G H G C F_{\text {el.flat }}\left[\frac{\$}{g o f C \mathrm{O}_{2}}\right]=\frac{P_{\text {el.flat }}}{N H G H G I F_{A}}
$$

Where,

$G H G C F_{e l, f l a t}=$ Greenhouse Gas Cost Factor for electricity using flat rate pricing scheme

$P_{e l, f a t}=$ Price of electricity using flat rate pricing scheme $(\$ / \mathrm{kWh})$

$\mathrm{NHGHGIF}_{\mathrm{A}}=$ New Hourly Greenhouse Gas Intensity Factor ( $\mathrm{g}$ of CO $\mathrm{CO}_{2} / \mathrm{kWh}$ )

\subsection{TDV GHGCF using TOU pricing scheme}

$$
G H G C F_{e l, T O U}\left[\frac{\$}{g o f C \mathrm{O}_{2}}\right]=\frac{P_{e l, T O U}}{N H G H G I F_{A}}
$$

Where,

$G H G C F_{e l, T O U}=$ Greenhouse Gas Cost Factor using TOU pricing scheme ( $\mathrm{g}$ of $\left.\mathrm{CO}_{2} / \mathrm{kWh}\right)$

$P_{e l, T O U}=$ Price of electricity using TOU pricing scheme $(\$ / \mathrm{kWh})$

$N H G H G I F_{A}=$ New Hourly Greenhouse Gas Intensity Factor (g of $\mathrm{CO}_{2} / \mathrm{kWh}$ )

\subsection{TDV GHGCF using wholesale pricing scheme}

$$
G H G C F_{\text {el, wholesale }}\left[\frac{\$}{g \circ f \mathrm{CO}_{2}}\right]=\frac{H E P}{N H G H G I F_{A}}
$$

Where,

$G H G C F_{\text {el,Wholesale }}=$ Greenhouse Gas Cost Factor using wholesale electricity pricing scheme

$H E P=$ Hourly Electricity Price paid to generators $(\$ / \mathrm{kWh})$

$N H G H G I F_{A}=$ New Hourly Greenhouse Gas Intensity Factor (g of $\mathrm{CO}_{2} / \mathrm{kWh}$ ) 
Similarly to section 3.6 the Hourly Average GHGCF profiles were determined for the years 2004, 2005, and 2006. The GHGCF for either consumers or generators should be included in the electricity cost value in order to have a true representation of the impact of greenhouse gases from the power generation sector in Ontario.

\subsection{ESP-r Simulations}

\subsubsection{Introduction}

ESP- $\mathrm{r}$ is a building energy simulation software that can be used to perform highly complex thermal analysis, HVAC analysis and electrical power flow simulations. In simple terms, ESP-r attempts to simulate real world scenarios to a level that is consistent with current best practices in the international building simulation community. The use of calculation methods like ray tracing and computational fluid dynamics (CFD) make ESP-r useful for a wide range of projects.

Simulations in ESP-r were run for the city of Toronto by Syed et al. (2007). This location is the largest city for which weather files were available in ESP-r for the Province of Ontario. It should be noted that there are several smaller cities for which weather files are not available. The simulation cities were chosen mainly due to hourly electricity data only available for the Province of Ontario. The year of assessment for these cities was done for 2005.

\subsubsection{Test Case House and Year of Assessment}

Syed et al. (2007) performed simulations, using ESP-r, which included the use Photovoltaic (PV) and micro-wind turbine energy systems on the computational model for the Canadian Centre for Housing Technology (CCHT) research house located in Ottawa. The CCHT research house was built in 1998 based on R-2000 building standards. Identical twin houses were built in order for one house to be used as a reference while the twin house is tested with advance technologies to assess the energy performance of novel energy systems and materials (NRCan 2007).

The ESP-r model for the CCHT house is shown in Figure 3.1 and is composed of two above-ground storeys and a fully conditioned basement. It has a conditioned floor area (excluding the basement) of $240 \mathrm{~m}^{2}$. 


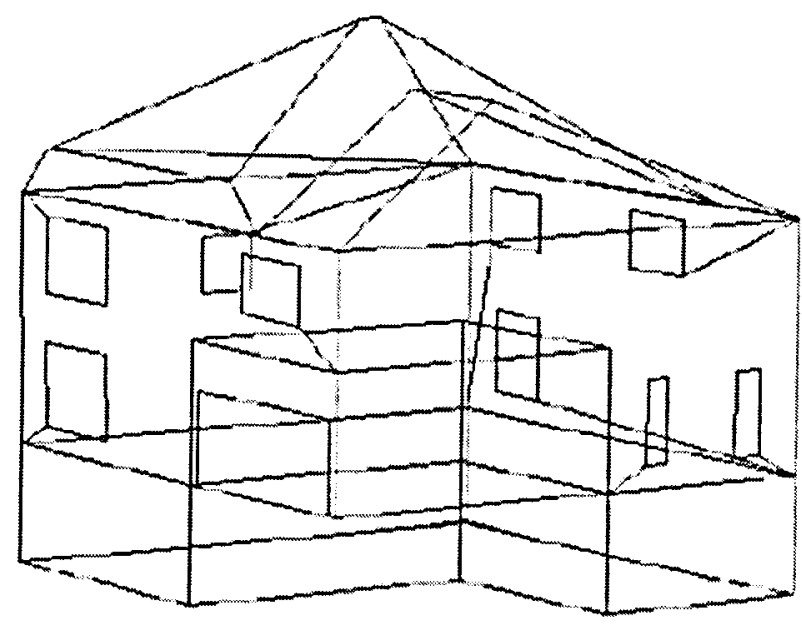

Figure 3-1: ESP-r model for CCHT house

Three sets of simulations were analysed in this thesis:

Case Study 1: CCHT research house with both a $5 \mathrm{~kW} \mathrm{PV}$ and a micto-wind turbine of $1 \mathrm{~kW}$ obtained from Syed et al. (2007) for Toronto.

Case Study 2: CCHT research house with a $5 \mathrm{~kW}$ PV system for Ottawa for only one week in the summer and one week in the winter for the year 2004 obtained from Good et al. (2006).

Case Study 3: The unit chosen was the end unit on the south east side of a townhouse complex in Toronto. Simulations were conducted by Tse et al. (2008) in TRNSYS in order to model the use of renewable technologies in a townhouse.

\subsubsection{Economic Analysis of Building Integrated Renewable Technologies}

\subsubsection{Introduction}

One of the objectives of this thesis was to estimate a New Greenhouse Gas Intensity Factor based on the hour-by-hour demand of electricity in Ontario. The hourly data allows for a better estimate of the true impact of the potential GHG reductions by using PV and microwind turbine technologies. In addition, an economic analysis was performed to estimate the 
income produced by PV and hypothetical micro-wind turbine system with the recent government initiative to pay 42 cents per $\mathrm{kWh}$ of electricity produced by PV systems.

\subsubsection{Case Study Simulations}

\subsection{Case Study 1}

A PV array of $5 \mathrm{~kW}$ and a micro-wind turbine of $1 \mathrm{~kW}$ capacities were installed in the house and hourly annual simulations were run to assess the potential electricity contribution, revenue generated, and GHG reduction due to these technologies. In addition, electricity generated from PV and micro-wind during peak days was analysed using greenhouse gas emission factors developed in the previous sections.

\subsection{Case Study 2}

The electricity produced by the PV system was obtained from Good et al. (2005). The capacity of the PV system selected was $5 \mathrm{~kW}$ and the location selected for the simulation was Ottawa. The simulation was performed during the weeks of January $9-15$ (winter) and July 11 - 17 (summer) for the year 2004. The hourly electricity production for both weeks was obtained from the IESO.

The estimation of the hourly $\mathrm{CO}_{2}$ emissions (grams) was calculated by multiplying hour-byhour emission factors from section 3.4 by the hour-by-hour electricity produced by the PV system for both the winter and summer weeks. The total $\mathrm{CO}_{2}$ emissions for each week were divided by the sum of their corresponding hourly electricity production. The different emission factors such as those described in the previous sections were applied to the data in order to demonstrate both the reduction potential and monetary value on emissions.

\subsection{Case Study 3}

Tse et al. (2008) used TRNSYS to simulate and help optimize the performance of the netzero energy townhouse, as well as the different systems that will be implemented in the home. The systems that were analyzed consist of a solar domestic hot water system, a photovoltaic system, and a ground source heat pump. Emissions were developed by using

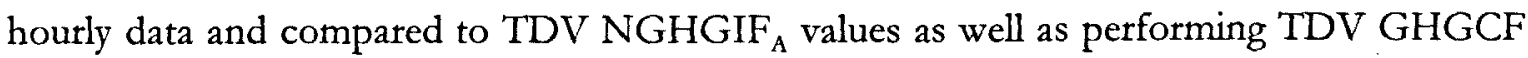
analysis of the townhouse. 


\section{$4 \quad$ Neural Network Modeling}

\subsection{Predictive Models using Neural Network Modeling}

This chapter presents the processes used in the development of the Neural Network (NN) models in order to develop several predictive models for the Province of Ontario. In this section the development of the NN models is presented, followed by detailed development of the input and output units, testing, and training parameters, and network architectures. This will entail a description of the methodology used, as well as a detailed overview of the model approach and information requirements of the models developed.

\subsection{Development of Artificial Neural Network Architecture and Training}

\subsubsection{Overview of Neural Network Modeling}

The second part of this thesis was to use Neural Network (NN) modeling using weather data for the city of Toronto obtained from Environment Canada (2006) due to its large population of 2.48 million people and 5 million in the Greater Toronto Area (GTA) according to the City of Toronto (2005). Some of these variables included windspeed, temperature, visibility, month, day, hour, relative humidity, dew point temperature, and weekend/weekday. This chapter contributes to a practical method for forecasting a wide range of outputs. These values were used to predict the hourly electricity demand, the percent of electricity produced from each source of the generation mix, and the price of wholesale electricity paid to generators for the Province of Ontario. The NN models were developed using the NeuroIntelligence modeling software (Alyuda, 2007). The models were refined based on a comparison with their initial target outputs. Figure 4-1 illustrates the relationship between input and output values. 


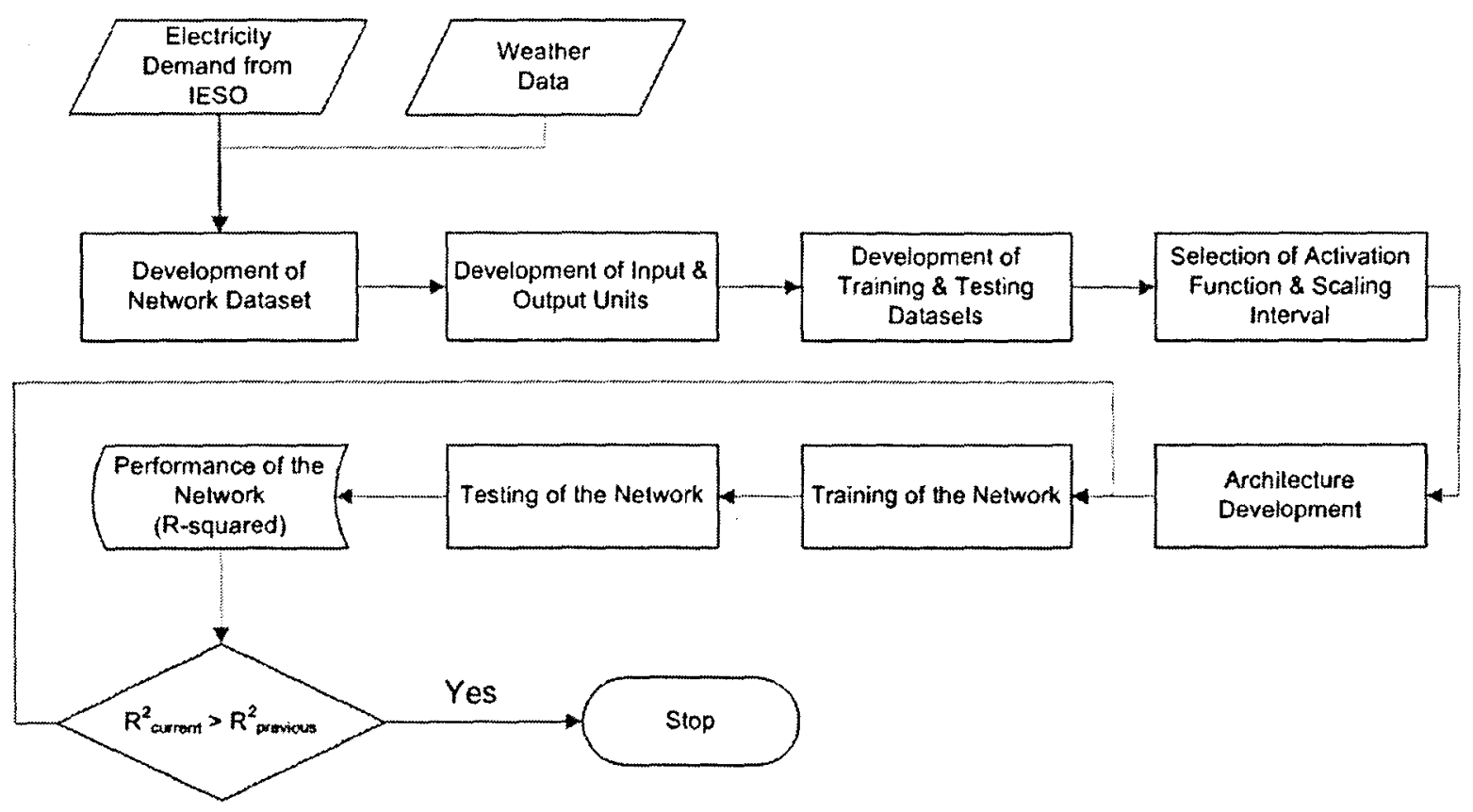

Figure 4-1: Flowchart diagram depicting the methodology used for the development of the NN model

\subsection{Selection of Input Parameters}

One of the key factors in the development of a successful predictive tool is the selection of appropriate input parameters (or independent variables), thus it is important to include only those parameters that have a significant influence on the value of the predicted result. To develop the NN model, the data was first obtained from Environment Canada. The data consisted of hourly weather conditions for the year 2004 and 2005. Ten sources were selected for the development of the input layer of the NN model. The output layer of the model was the actual hourly electricity demand for Ontario in 2004 obtained from the IESO (2004).

The selection process of the relevant variables for inputs was determined by conducting an exhaustive simulation on all the possible combinations of the variables. These simulations identified the relevant inputs and discarded irrelevant variables which did not significantly contribute to the performance of the NN model. It was determined that insignificant inputs were to be removed, thus improving the generalization performance of the model, in spite of loosing some input data. 


\subsection{Data Pre-Processing}

Before the data was ready to be used as input to a NN, it had to be subjected to some form of pre-processing, which was intended to make the forecasting more manageable. Preprocessing was needed to reduce the dimension of the input vector. This was required in order to avoid the exponential growth in the complexity of the problem that would result from an increase in the number of dimensions. Pre-processing was also needed to "clean" the data, by removing outliers, missing values or any irregularities, since NNs are sensitive to such defective data and the NeuroIntelligence software assisted with this task.

\subsection{Development of the Artificial Neural Network Architecture}

The data was divided into three sections: $68 \%$ of the data was for the training, $16 \%$ for the validation, and $16 \%$ for the test set, these were the default conditions selected by the software and were similar to the suggested data partition percentages by Anstett and Kreider (1993). Selection of suitable artificial neural network architectures is probably the hardest part of the problem, and critical to obtaining a useful artificial neural network. It is analogous to selecting the form and independent variables of a regression equation. The architecture of the model was determined by performing a heuristic search methodology for determining the number of hidden layers required for the NN. The number of units in the hidden layer of the network and the learning algorithm resulting in the highest prediction performance was chosen as the network architecture for the NN Model. After determining the number of neuron units and the learning algorithm resulting in the highest prediction performance, different networks were trained with the chosen learning algorithm to determine the best network architecture. In other words, thie number of hidden layers needed.

\subsection{NN Model Testing and Training}

The activation function or training algorithm used to train the NN was found to have quite an important influence on its accuracy and the speed with which the training converged (or whether it converged at all). In general, the NN starts with random weights and the training process adjusts these weights with the aim of producing an accurate prediction of the training data. Because this is a semi-random process, it is important to retrain the NN several times with different activation function. It is also important to allow sufficient iterations of the training regime to allow the NN to converge. Sufficient time and computational power 
was available to conduct an exhaustive search. In order to train the model an activation function had to be selected. As a result, all the activation functions included in the NN software package (Neurointelligence) where tested and it was determined that the online backward propagation function was the most suitable due to its high R-squared value, simplicity, and speed.

\subsubsection{Development of the Neural Network Input Parameters}

\subsubsection{Hourly Electricity Demand for Ontario}

In this section an hourly NN load forecasting model for Ontario was developed. First an exhaustive simulation was conducted in order to determine the relevant input variables. There were 510 simulations performed and it was determined that the best configuration of inputs with their ranges of value was the following:

- Month (1 - 12)

- $\operatorname{Day}(1-31)$

- Temperature $\left(-24.2-31.3 C^{\circ}\right)$

- Hour $(1-24)$

- Relative humidity (26-100\%)

- Dew point temperature $\left(-31.6-23.8 \mathrm{C}^{\circ}\right)$

- Windspeed $(0-50 \mathrm{~km} / \mathrm{h})$

- Visibility $(0-24.1 \mathrm{~km})$

- Weekend $=0 /$ Weekday $=1$

The electricity demand NN dataset was divided into subsets. The subsets were used for training, validation, and testing of the networks. The training set contained 5921 weather data points ( $68 \%$ of all data), the testing and validation sets each contained 1392 weather data points. The weather data in each subset was chosen randomly.

\subsubsection{Hourly Percentage Mix from Sources}

The input parameters for nuclear, hydro, coal, and other were determined by conducting input combination simulations as in Section 4.6.1.1. Table 4-1 shows simulation results in 
order to determine the relevant inputs for each of the generation sources. It should be noted that since the percent mix from nuclear is constant throughout the year and it is used for the determination of subsequent percentage mix from coal, hydro and other sources, it was decided to skip the input selection simulations for nuclear.

Table 4-1: Input parameters for the hourly percentage mix NN models

\begin{tabular}{|l|c|c|c|c|}
\hline \multicolumn{1}{|c|}{ Input Column Name } & Nuclear & Hydro & Coal & Other \\
\hline Month & $\mathrm{x}$ & $\mathrm{x}$ & $\mathrm{x}$ & $\mathrm{x}$ \\
\hline Hour & & $\mathrm{x}$ & $\mathrm{x}$ & $\mathrm{x}$ \\
\hline Day & $\mathrm{x}$ & $\mathrm{x}$ & $\mathrm{x}$ & $\mathrm{x}$ \\
\hline Temp & $\mathrm{x}$ & $\mathrm{x}$ & $\mathrm{x}$ & $\mathrm{x}$ \\
\hline Dew Point Temp & $\mathrm{x}$ & $\mathrm{x}$ & $\mathrm{x}$ & $\mathrm{x}$ \\
\hline Visibility (km) & & $\mathrm{x}$ & & \\
\hline Relative Humidity (\%) & $\mathrm{x}$ & $\mathrm{x}$ & & \\
\hline Windspeed (km/h) & & $\mathrm{x}$ & & \\
\hline Weekend=0/Weekday=1 & & $\mathrm{x}$ & $\mathrm{x}$ & $\mathrm{x}$ \\
\hline Elec. Gen. & $\mathrm{x}$ & $\mathrm{x}$ & & $\mathrm{x}$ \\
\hline$\%$ Nuclear & & & $\mathrm{x}$ & \\
\hline$\%$ Hydro & & & $\mathrm{x}$ & \\
\hline
\end{tabular}

The percentage mix NN dataset for all generation types was divided into subsets. The subsets were used for training, validation, and testing of the networks. The training set contained 5848 data points ( $68 \%$ of all data), the testing and validation sets each contained $1376(16 \% \mathrm{each})$ weather data points. The input data in each subset was chosen randomly. Noise in the dataset was automatically determined by the software. Furthermore, there should not be too much noise since the inputs are all true values obtained from Environment Canada and the IESO.

\subsubsection{Hourly Emission Factor}

The input parameters for the hourly emission factor network were determined by conducting an input combination simulation as in Section 4.6.1.1. There were 1023 simulations performed and it was determined that the best configuration of inputs was the following:

- Electricity Demand

- Month (1 - 12)

- Day (1 - 31) 
- Temperature $\left(-24-34.7 \mathrm{C}^{\circ}\right)$

- Hour $(1-24)$

- Dew point temperature $\left(-30.5-23.6 \mathrm{C}^{\circ}\right)$

The hourly emission factor NN dataset was divided into subsets. The subsets were used for training, validation, and testing of the networks. The training set contained 5848 data points ( $68 \%$ of all data), the testing and validation sets each contained 1376 data points. The electricity demand and weather data in each subset was chosen randomly.

\subsubsection{Development of the NN Architecture}

The initial test network architectures were constrained to three layers, one for input, hidden and output layers respectively. This architecture was chosen as previous research indicated that multiple hidden layers are rarely effective in terms of both accuracy and training speed, Neocleous and Schizas (1995).

A search was performed in order to determine the $\mathrm{NN}$ architecture for all the NN models developed. This was accomplished by conducting different architecture simulations. This allowed multiple networks to be trained with different numbers of hidden layer neurons and the results collated to display the optimum network.

Neural networks trained with large numbers of hidden layer neurons tend to suffer from overfitting. This overfitting cannot always be determined from the minimum validation set error if the dataset is small. In order to minimize the risk of overfitting the network architecture selection process was based on a criterion that balances minimum error again network complexity. One such measure is Akaike's Information Criterion (AIC), Akaike (1974), which has been widely used for model selection for both conventional statistical models and neural networks.

Of the measures available for comparing the accuracy of the neural networks, Akaike's criterion was found to be a useful quantity for comparing NN architectures with a single hidden layer and both R-squared and the correlation tended to be maximized for the neural networks with the highest fitness scores based on test error and Akaike's criterion. It should 
be noted that the accuracy of the predicted results from the NNs was also assessed in a qualitative manner by visual inspection of the performance of the $\mathrm{NN}$ architecture.

Once the network architecture was selected, different learning algorithms were applied to the networks in order to determine the best predicting algorithm.

\subsubsection{Hourly Electricity Demand Network}

It is important that both training and test set error be in broad agreement with the validation set error, and it can be seen from Figure 4-2 that the three sets of values correlate well as the number of hidden layer neurons increases.

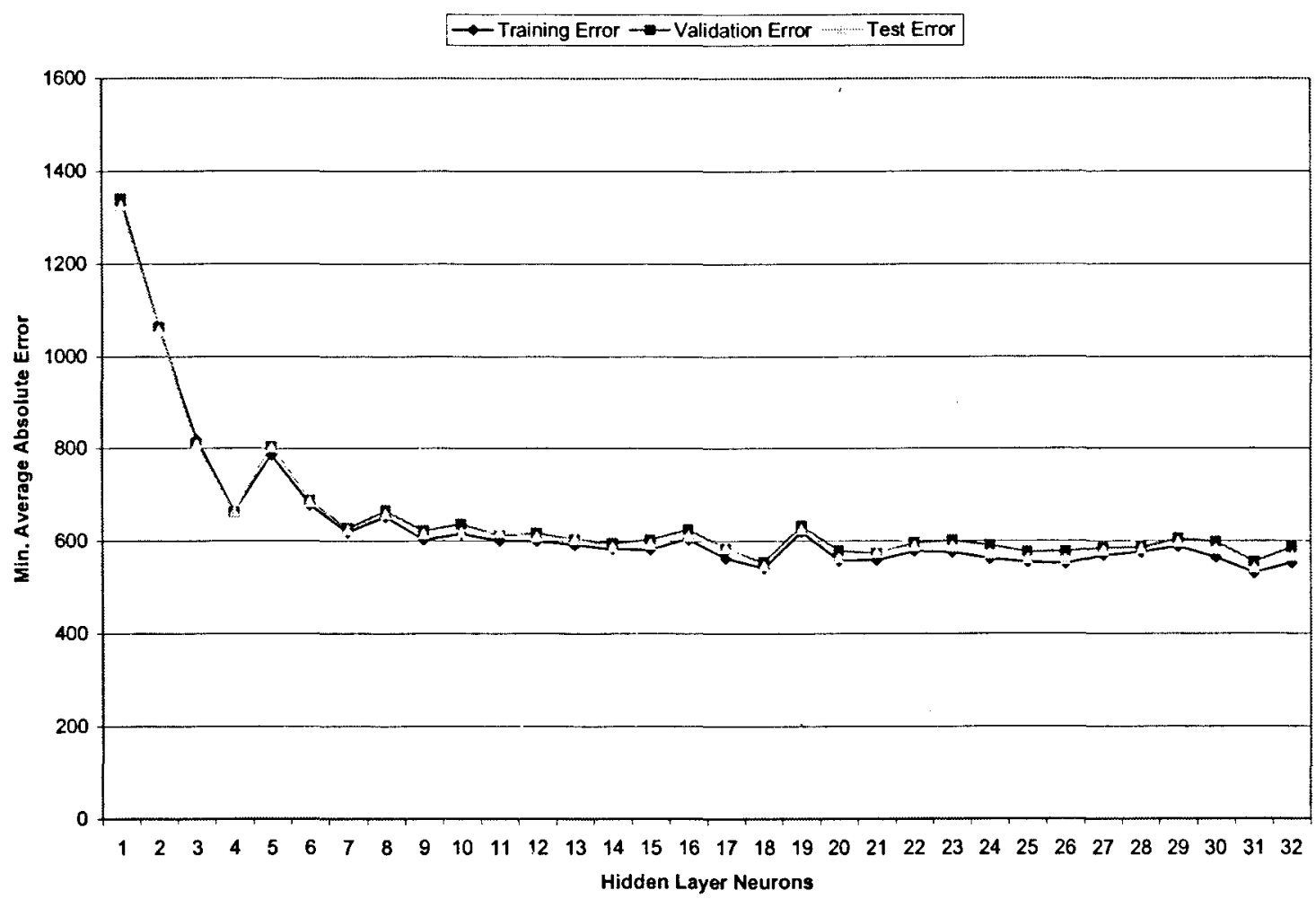

Figure 4-2: Minimum error values for the hourly electricity demand NN

To determine the network architecture that produces the best prediction performance, different network architectures with 1 to 32 hidden layers was analyzed for each NN model. The prediction performances and Akaike's criterion for the trained network are given in Figure 4-3. The R-squared and correlation data are presented in Table B-1 in Appendix B. It can be observed from Figure 4-3 that the minimum points at 18 and 31 neurons for the network architecture is a reasonable compromise between error values and network complexity. Thus, the configuration that consisted of 31 neurons in one hidden layer (9-31- 
1) was found to be the most suitable network architecture to predict the hourly electricity demand for the Province of Ontario due to its higher $R^{2}$ value.

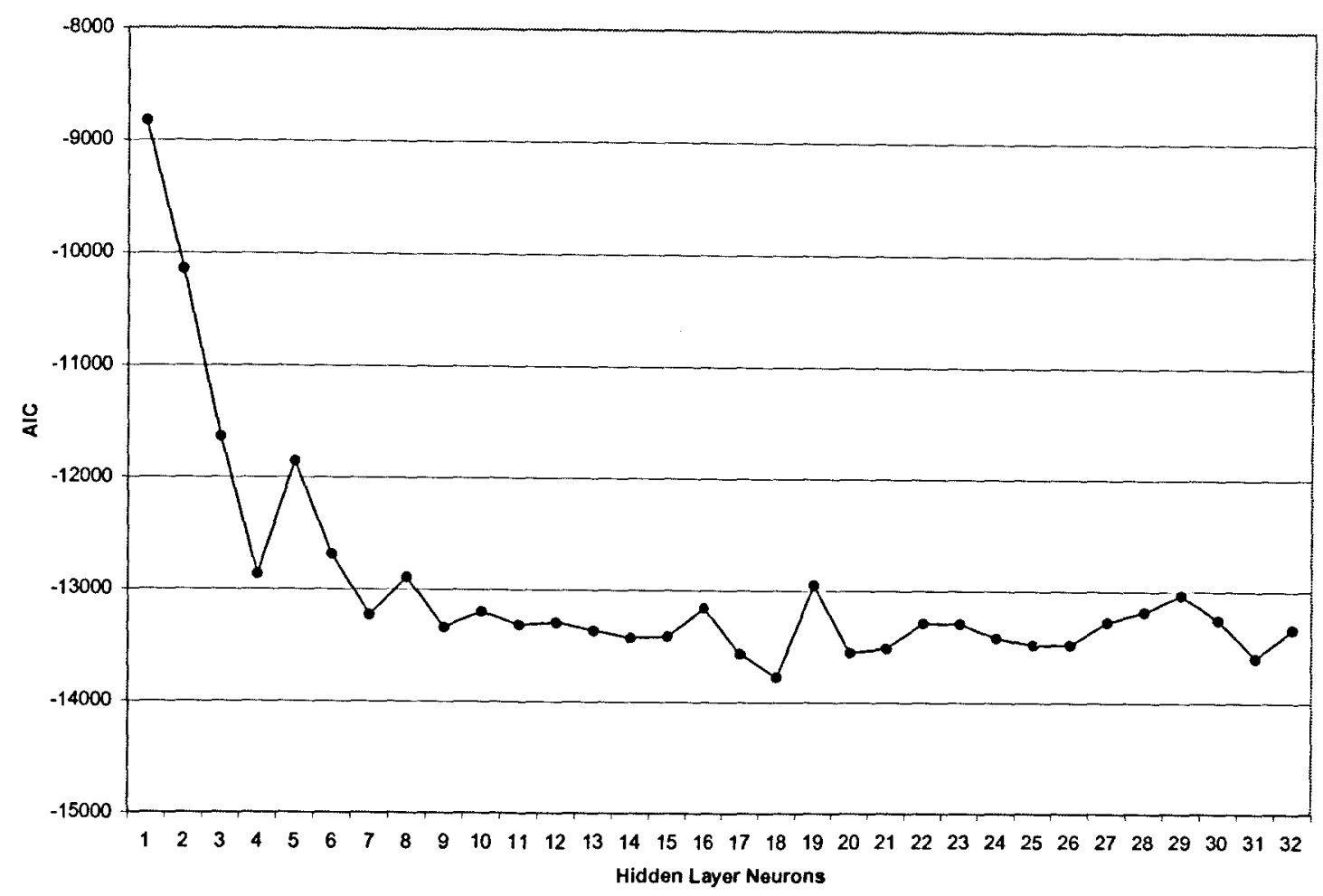

Figure 4-3: Akaike's Information Criterion for the hourly electricity demand NN

As seen from Table 4-2, the learning algorithms produced good predictions within the range of $R^{2}$ of 0.793 to 0.960 . The network trained with the Quick Propagation learning algorithm with 31 neurons resulted in the lowest Akaike value and highest $R^{2}$, indicating that this network has the highest prediction performance.

Table 4-2: Performance of the elec. demand network trained using five different learning algorithms

\begin{tabular}{|c|c|c|c|c|}
\hline Architecture & Training algorithm & AIC & Correlation & $\mathbf{R}^{2}$ \\
\hline$[9-31-1]$ & Quick Propagation & -15901 & 0.981 & 0.960 \\
\hline$[9-31-1]$ & Quasi-Newton & -13169 & 0.953 & 0.908 \\
\hline$[9-31-1]$ & Conjugate Gradient Descent & -11698 & 0.925 & 0.855 \\
\hline$[9-31-1]$ & Levenberg-Marquardt & -12924 & 0.954 & 0.908 \\
\hline$[9-31-1]$ & Online Back Propagation & -10534 & 0.891 & 0.793 \\
\hline
\end{tabular}




\subsubsection{Percentage Mix from Source NN}

\subsection{Percentage Mix from Nuclear}

For the percentage mix from nuclear network Figure 4-4 illustrates that the three sets of values correlate well as the number of hidden layer neurons increases.

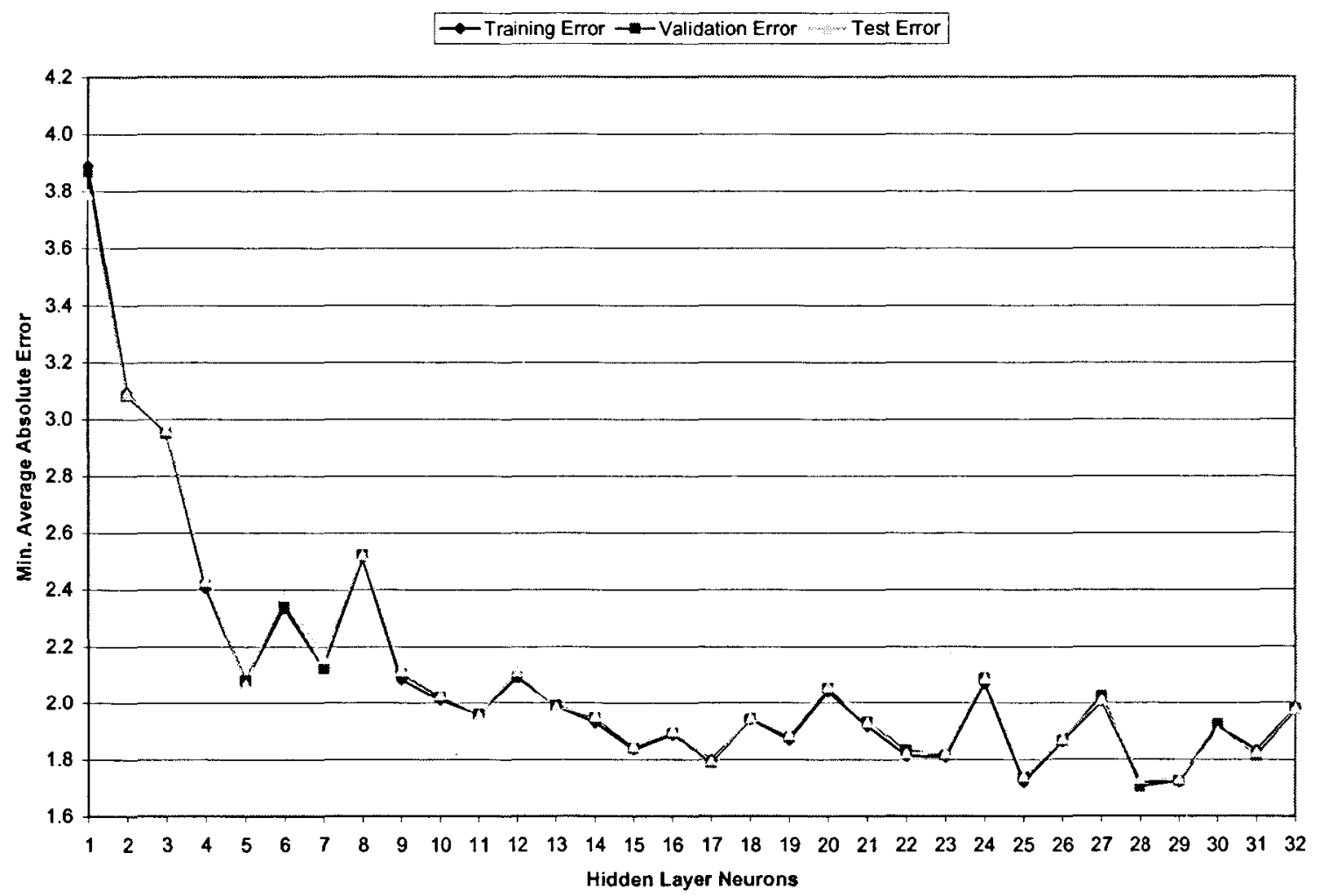

Figure 4-4: Minimum error values for the percentage from nuclear NN

Different network architectures with 1 to 32 hidden layers were analyzed for each NN model. The prediction performances and Akaike's criterion for the trained network are given in Figure 4-5. The R-squared and correlation data are presented in Table B-2 in Appendix B. It can be observed from Figure 4-5 that the minimum points at 25 and 29 neurons for the network architecture is a reasonable compromise between error values and network complexity. Thus, the configuration that consisted of 29 neurons in one hidden layer (6-291) was found to be the most suitable network architecture to predict the hourly electricity demand for the Province of Ontario. 


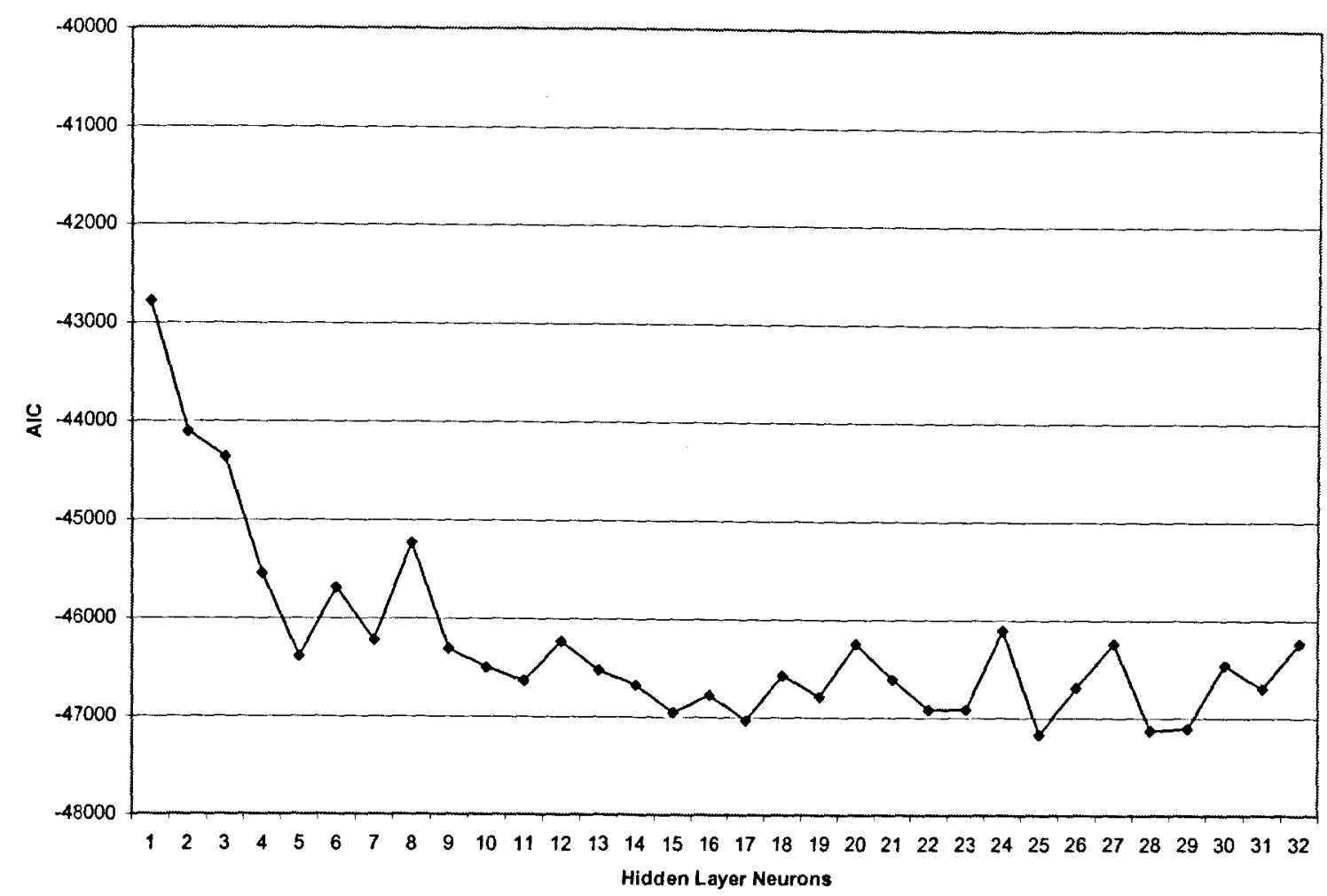

Figure 4-5: Akaike's Information Criterion for the percentage from nuclear NN

As seen from Table 4-3, the learning algorithms produced good predictions within the range of $R^{2}$ of 0.854 to 0.967 . The network trained with the Quick Propagation learning algorithm with 29 neurons resulted in the lowest Akaike value and highest $\mathrm{R}^{2}$, indicating that this network has the highest prediction performance.

Table 4-3: Performance of the nuclear network trained using five different learning algorithms

\begin{tabular}{|c|c|c|c|c|}
\hline Architecture & Training algorithm & AlC & Correlation & $\mathbf{R}^{2}$ \\
\hline$[6-29-1]$ & Quick Propagation & -50522 & 0.984 & 0.967 \\
\hline$[6-29-1]$ & Conjugate Gradient Descent & -45007 & 0.900 & 0.809 \\
\hline$[6-29-1]$ & Quasi-Newton & -48264 & 0.966 & 0.933 \\
\hline$[6-29-1]$ & Levenberg-Marquardt & -47187 & 0.959 & 0.920 \\
\hline$[6-29-1]$ & Online Back Propagation & -41518 & 0.898 & 0.854 \\
\hline
\end{tabular}

Similar to the nuclear network, the minimum error, AIC, and Performance results for the other percentage mix networks are presented in Figures B-1 to B-6, Tables B-3 to B-5, and B-7 to B-9 in Appendix B. 


\subsubsection{Hourly Emission Factor Network}

It is important that both training and test set error be in broad agreement with the validation set error, and it can be seen from Figure 4-6 that the three sets of values somewhat correlate well as the number of hidden layer neurons increases.

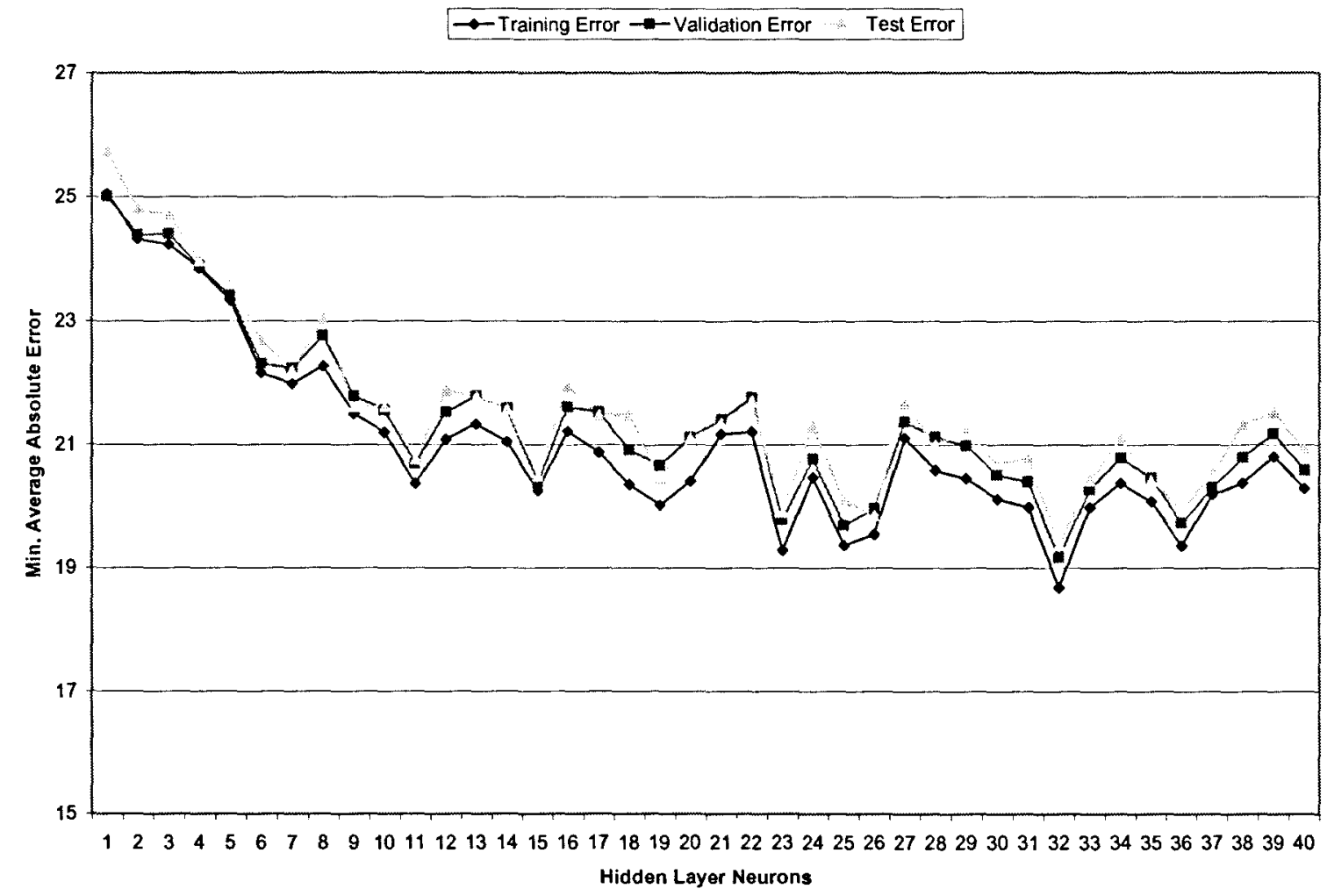

Figure 4-6: Minimum error values for the hourly emission factor NN

To determine the network architecture that produces the best prediction performance, different network architectures with 1 to 40 hidden layers was analyzed for each NN model. The prediction performances and Akaike's criterion for the trained network are given in Figure 4-7. The R-squared and correlation data The R-squared and correlation data are presented in Table B-6 in Appendix B. It can be observed from Figure 4-7 that the minimum points at 23 and 32 neurons for the network architecture is a reasonable compromise between error values and network complexity. Thus, the configuration that consisted of 32 neurons in one hidden layer (6-32-1) was found to be the most suitable network architecture to predict the hourly electricity demand for the Province of Ontario due to its higher $\mathrm{R}^{2}$ value. 


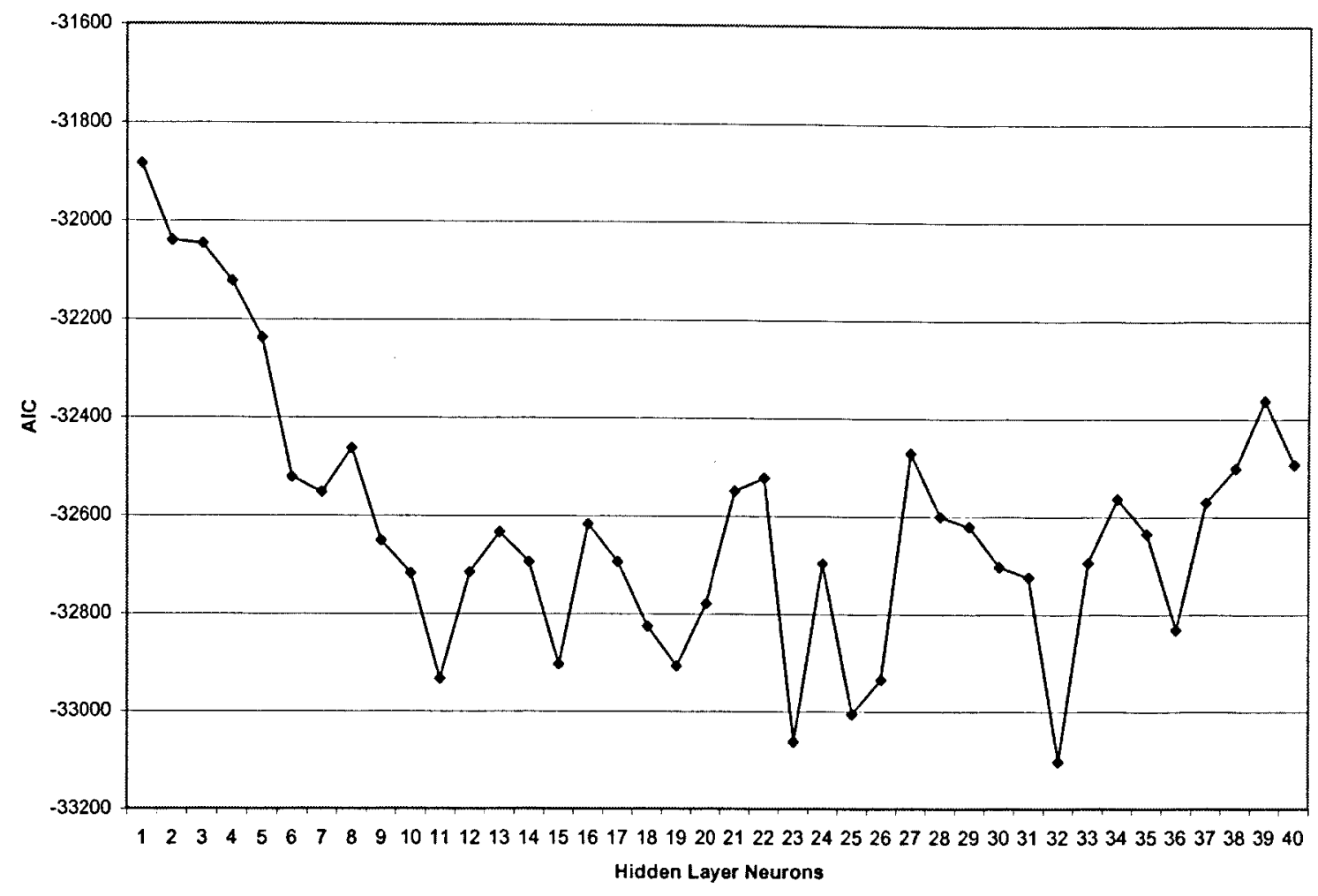

Figure 4-7: Akaike's Information Criterion for the hourly emission factor NN

As seen from Table 4-4, the learning algorithms produced good predictions within the range of $\mathrm{R}^{2}$ of 0.691 to 0.837 . The network trained with the Levenberg-Marquardt learning algorithm with 32 neurons resulted in the lowest Akaike value and highest $\mathrm{R}^{2}$, indicating that this network has the highest prediction performance.

Table 4-4: Performance of emission factor network trained using five different learning algorithms

\begin{tabular}{|c|c|c|c|c|}
\hline Architecture & Training algorithm & AIC & Correlation & $\mathbf{R}^{2}$ \\
\hline$[6-32-1]$ & Quick Propagation & -34267 & 0.912 & 0.832 \\
\hline$[6-32-1]$ & Conjugate Gradient Descent & -32450 & 0.831 & 0.691 \\
\hline$[6-32-1]$ & Quasi-Newton & -33144 & 0.864 & 0.747 \\
\hline$[6-32-1]$ & Levenberg-Marquardt & -34167 & 0.915 & 0.837 \\
\hline$[6-32-1]$ & Online Back Propagation & -33136 & 0.872 & 0.753 \\
\hline
\end{tabular}

Table 4-5 displays the results of the architecture search process with both the correlation and $\mathrm{R}$-squared values for each of the pre-training $\mathrm{NN}$ models in this thesis. The learning algorithms produced good predictions within a range of $\mathrm{R}^{2}$ of 0.837 to 0.967 . Most of the networks were trained using the Quick Propagation learning algorithm with the exception of 
the hourly emission factor network which performed better using the Levenberg-Marquardt algorithm.

Table 4-5: Performance of selected NN architectures

\begin{tabular}{|c|c|c|c|c|}
\hline NN Models & Architecture & AIC & Correlation & $\mathbf{R}^{\mathbf{2}}$ \\
\hline Hourly Electricity Demand & {$[9-31-1]$} & -15901 & 0.981 & 0.960 \\
\hline$\%$ Nuclear & {$[6-29-1]$} & -50522 & 0.984 & 0.967 \\
\hline$\%$ Hydro & {$[10-31-1]$} & -49748 & 0.968 & 0.933 \\
\hline$\%$ Coal & {$[8-21-1]$} & -51510 & 0.97 & 0.936 \\
\hline$\%$ Other & {$[7-36-1]$} & -51286 & 0.928 & 0.862 \\
\hline Hourly Emission Factor & {$[6-32-1]$} & -34167 & 0.915 & 0.837 \\
\hline
\end{tabular}

In this chapter, the network architectures were determined for the predictive models. In Chapter 8 , the training results of the neural network models are presented. 


\section{$5 \quad$ Hourly Supply and Demand of Electricity for Ontario}

\subsection{Overview}

One of the objectives of this study was to analyze the hourly supply and demand trends of electricity in the Province of Ontario. The hourly electricity demand was divided into seasons and different generation technologies. The limit for each season is shown in Table $5-1$.

Table 5-1: Season definition

\begin{tabular}{|c|c|}
\hline Season & Limit \\
\hline Winter & December 21 - March 20 \\
\hline Spring & March 21 - June 20 \\
\hline Summer & June 21 - September 20 \\
\hline Fall & September 21 - December 20 \\
\hline
\end{tabular}

In addition, in order to better understand the terminology used in figures and tables in this section the following terms should be defined:

Percentage Capability of a particular source is the amount of electricity that source is able to produce as a percentage of the total capability of all sources combined.

Percentage Output of a particular source is the amount of electricity consumed from a source as a percentage of the total amount of electricity consumed from all sources combined.

\subsection{Winter 2004, 2005, and 2006}

The hourly supply and demand of electricity illustrating the different generating technologies for Ontario is shown in Figure 5-1 for winter 2004. In general, there is a trend to use all the electricity produced by nuclear and coal sources rather than hydro or other sources. This may be due to the fact the processes that enable electricity production from nuclear cannot be easily paused or stopped. 


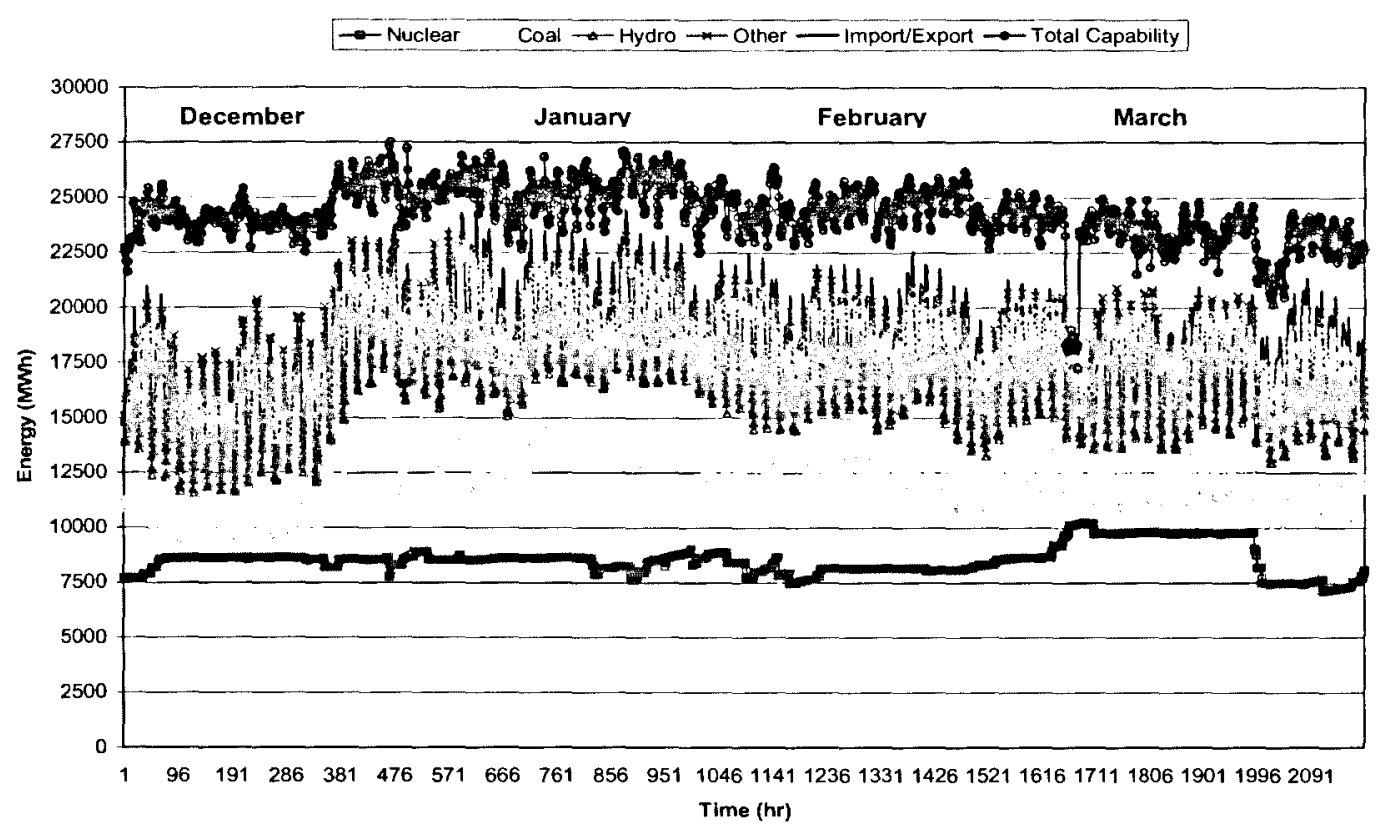

Figure 5-1: Hourly electricity supply and demand for Ontario winter 2004

The hourly supply and demand of electricity illustrating the different generating technologies for Ontario is shown in Figure 5-2 for winter 2005.

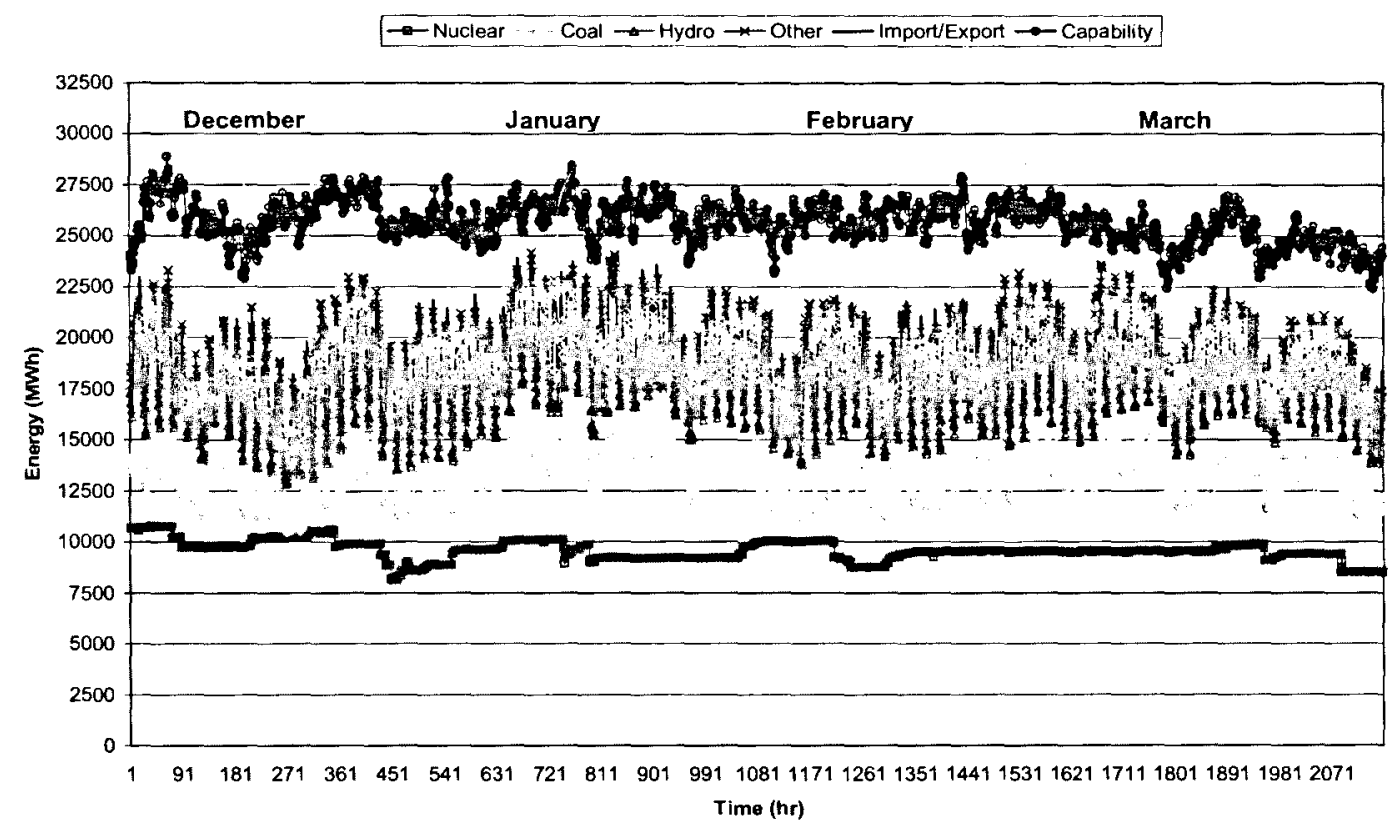

Figure 5-2: Hourly electricity supply and demand for Ontario winter 2005 
The hourly supply and demand of electricity illustrating the different generating technologies for Ontario is shown in Figure 5-3 for winter 2006.

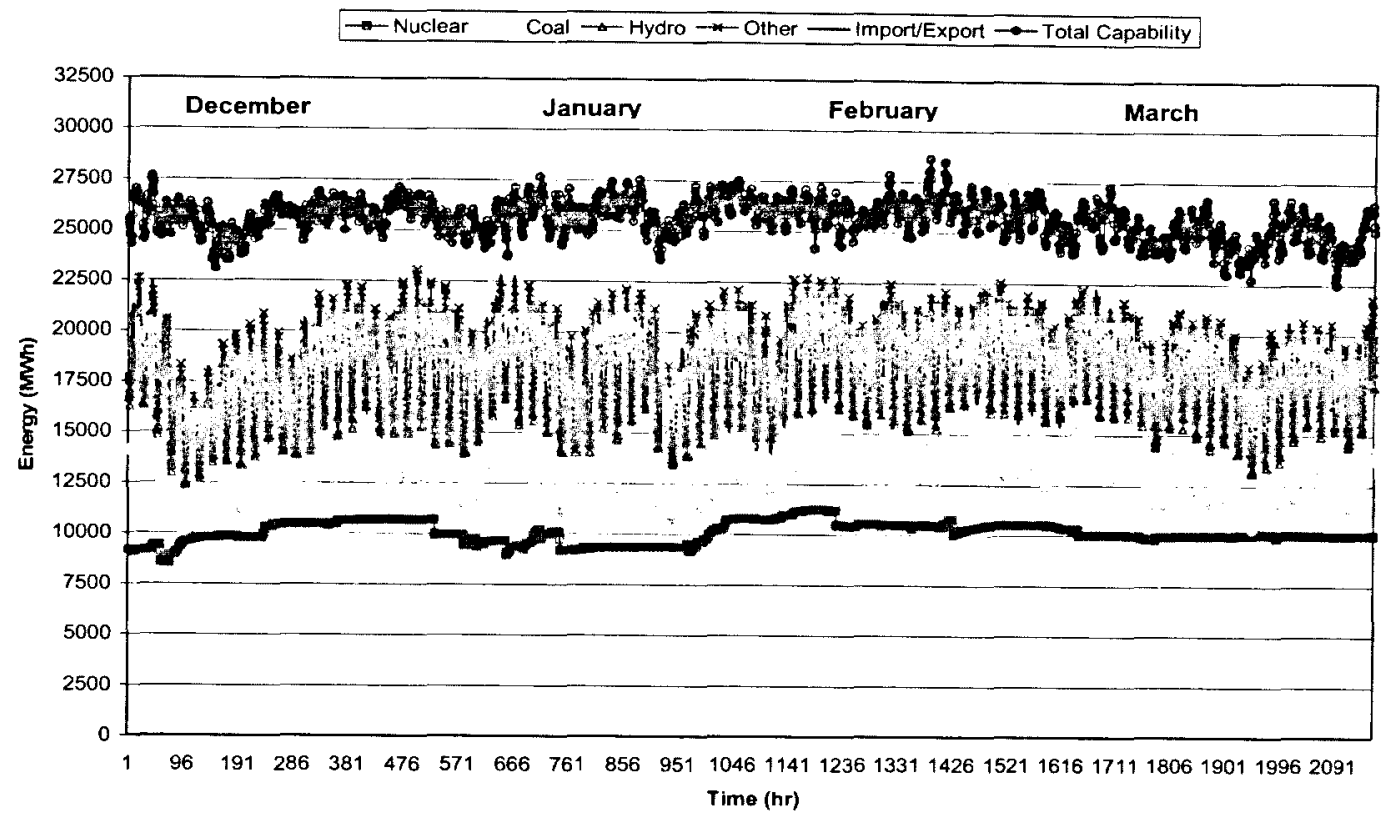

Figure 5-3: Hourly electricity supply and demand for Ontario winter 2006

Table 5-2 shows the capability and output of each generating source for the winters of 2004, 2005, and 2006. It can be observed that nuclear output and capability generation has been increasing for the last three years. In contrast, coal and hydro output and capability generation has been decreasing slowly by approximately 1\% between 2004 and 2006, and other output generation has decreased by $2 \%$.

Table 5-2: Output and capability generation comparison for winter 2004-2006

\begin{tabular}{|c|c|c|c|c|c|c|}
\hline \multicolumn{9}{|c|}{ Winter } \\
\hline \multirow{2}{*}{$\%$} & \multicolumn{2}{|c|}{2004} & \multicolumn{2}{c|}{ 2005 } & \multicolumn{2}{c|}{ 2006 } \\
\cline { 2 - 7 } & Capability & Output & Capability & Output & Capability & Output \\
\hline Nuclear & 36 & 48 & 38 & 51 & 39 & 55 \\
\hline Coal & 20 & 21 & 20 & 20 & 18 & 17 \\
\hline Hydro & 29 & 23 & 27 & 21 & 26 & 22 \\
\hline Other & 15 & 8 & 16 & 8 & 16 & 6 \\
\hline
\end{tabular}


Table 5-3 shows the electricity demand by generation type for the winters of 2004, 2005, and 2006. The total electricity demand for the Province of Ontario increased in 2005, but decreased in 2006 below 2004 levels. This might be as a result of weather fluctuations or unplanned outages throughout the year. Imported electricity has been decreasing while exported electricity numbers have been on the rise increasing by $37 \%$ between 2004 and 2005 and $9 \%$ between 2005 and 2006.

Table 5-3: Electricity demand by generation type comparison for winter 2004-2006

\begin{tabular}{|c|c|c|c|}
\hline \multicolumn{4}{|c|}{ Winter } \\
\hline \multirow{2}{*}{ Generation Type } & \multicolumn{3}{|c|}{ Electricity Demand (GWh) } \\
\cline { 2 - 4 } & $\mathbf{2 0 0 4}$ & $\mathbf{2 0 0 5}$ & $\mathbf{2 0 0 6}$ \\
\hline Nuclear & 18668 & 20686 & 21858 \\
\hline Coal & 8511 & 8401 & 7062 \\
\hline Hydro & 9262 & 8704 & 9016 \\
\hline Other & 3275 & 3318 & 2385 \\
\hline Imported & 2654 & 2534 & 2040 \\
\hline Exported & 1914 & 3026 & 3337 \\
\hline Total & $\mathbf{4 0 4 5 7}$ & $\mathbf{4 0 6 1 7}$ & $\mathbf{3 9 0 2 5}$ \\
\hline
\end{tabular}

5.2.1 Peak Day Electricity Analysis for Winter 2004, 2005, and 2006

Table 5-4 and Figure 5-4 show the electricity demand for winter peak days for 2004, 2005, and 2006. Electricity demand was the highest during the winter of 2004.

Table 5-4: Electricity demand comparison for winter peak days 2004-2006

\begin{tabular}{|c|c|c|}
\hline \multicolumn{3}{|c|}{ Winter } \\
\hline Year & Peak Day & Electricity Demand (GWh) \\
\hline 2004 & 26-Jan-04 & 518 \\
\hline 2005 & 18-Jan-05 & 515 \\
\hline 2006 & 21-Dec-05 & 482 \\
\hline
\end{tabular}




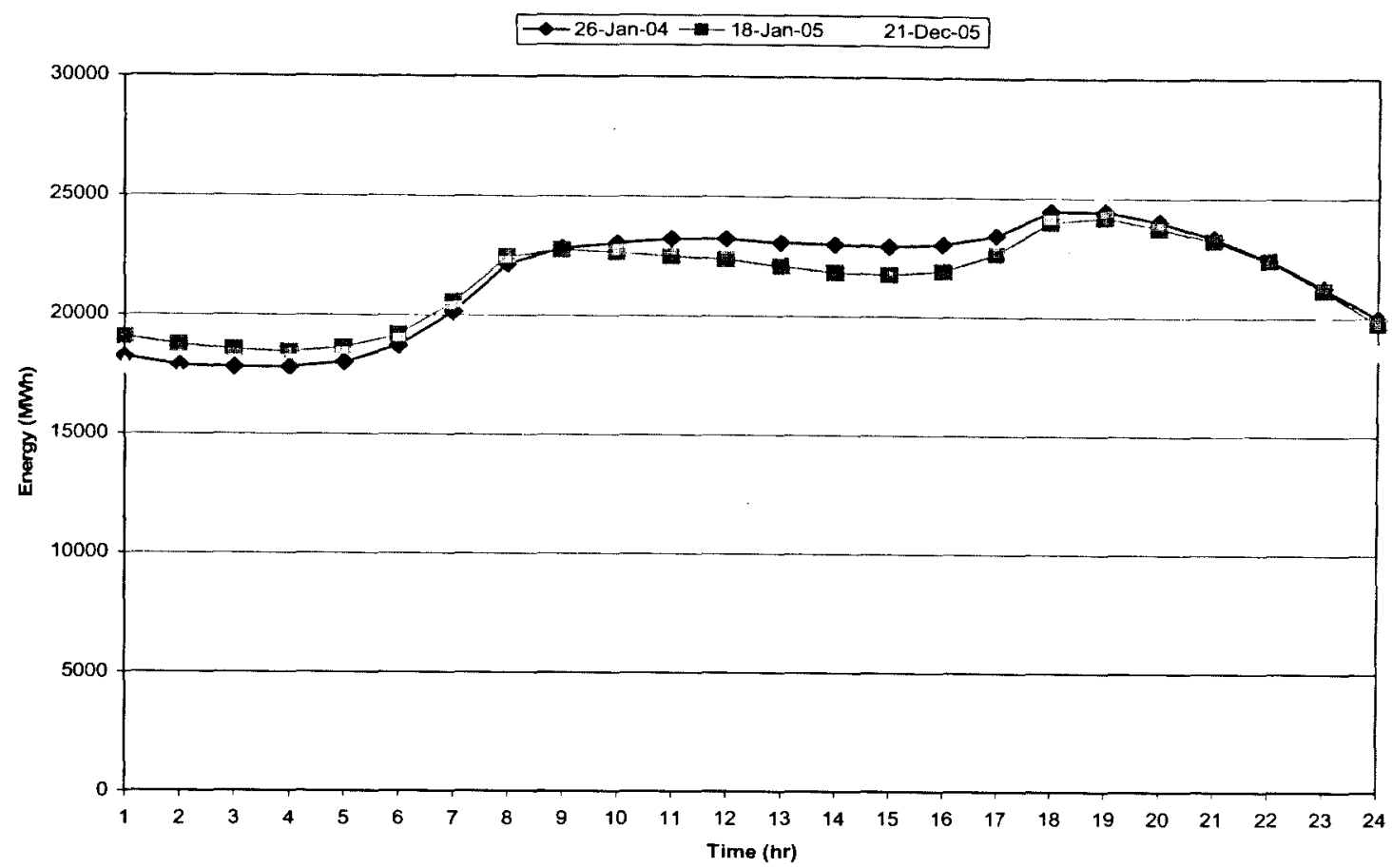

Figure 5-4: Electricity demand during peak winter weekday 2004-2006

\subsection{Spring 2004, 2005, and 2006}

The hourly supply and demand of electricity illustrating the different generating technologies for Ontario is shown in Figure 5-5 for spring 2004.

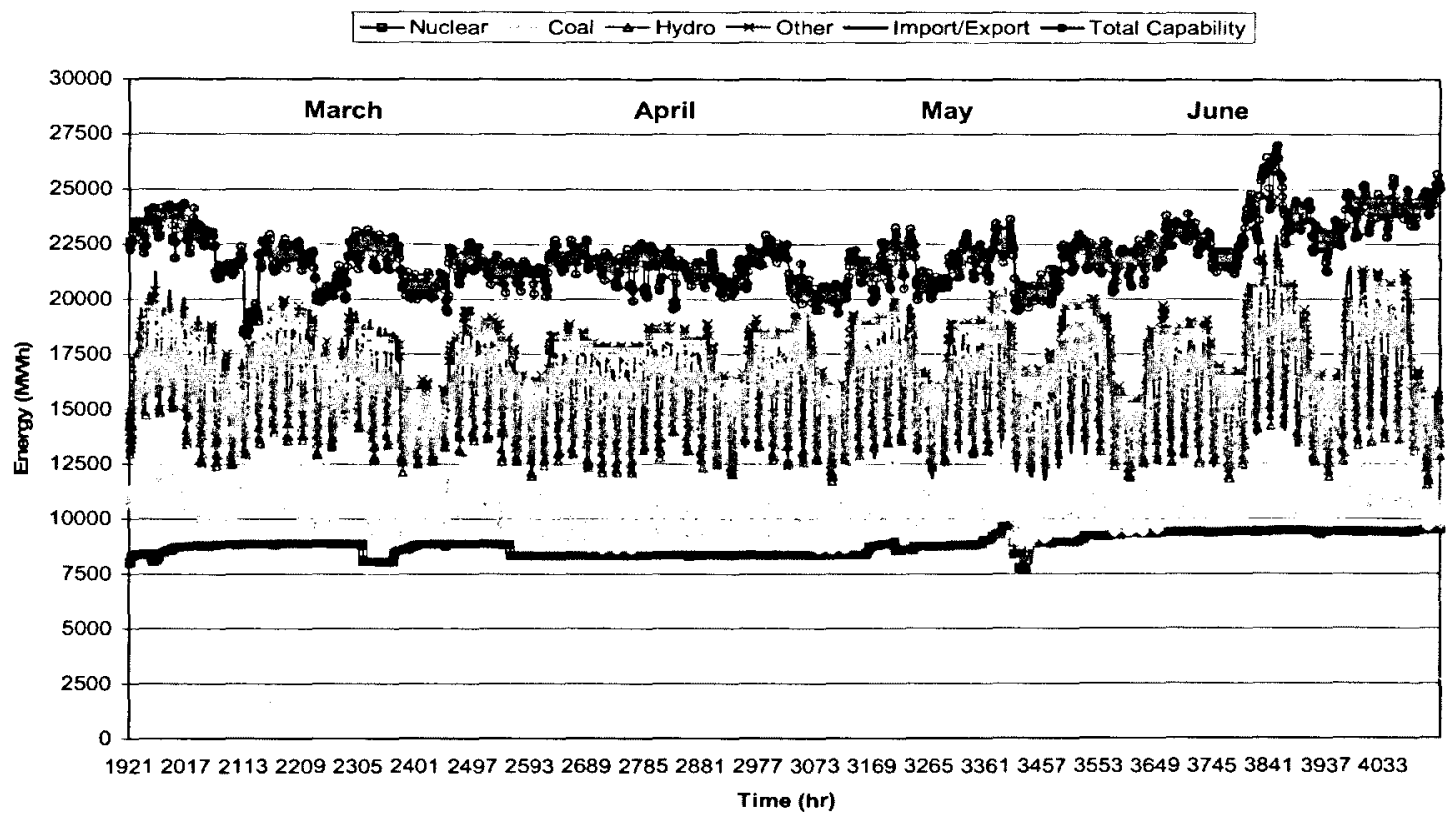

Figure 5-5: Hourly electricity supply and demand for Ontario Spring 2004 
The hourly supply and demand of electricity illustrating the different generating technologies for Ontario is shown in Figure 5-6 for spring 2005.

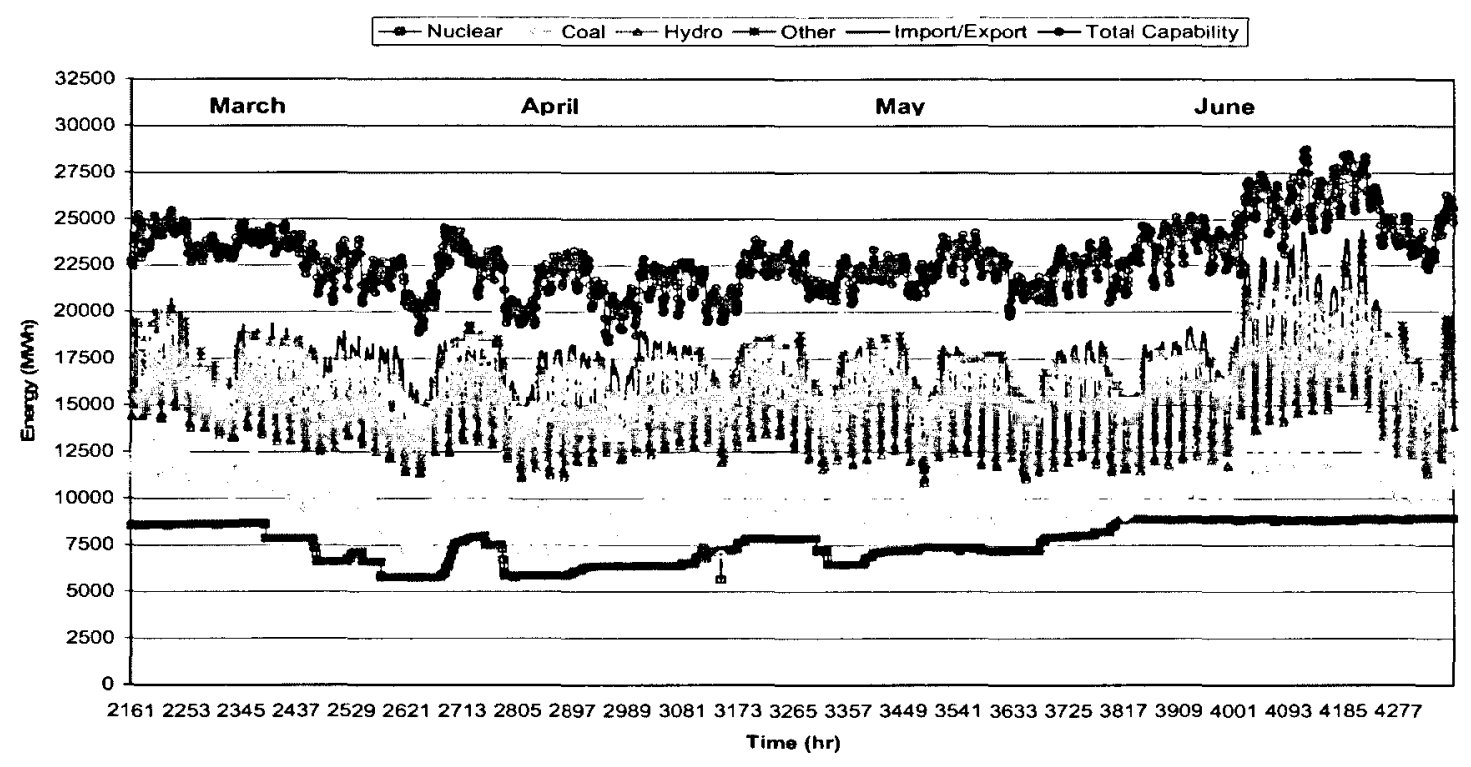

Figure 5-6: Ilourly electricity supply and demand for Ontario Spring 2005

The hourly supply and demand of electricity illustrating the different generating technologies for Ontario is shown in Figure 5-7 for spring 2006. It should be noted that wind generation was introduced in the spring of 2006.

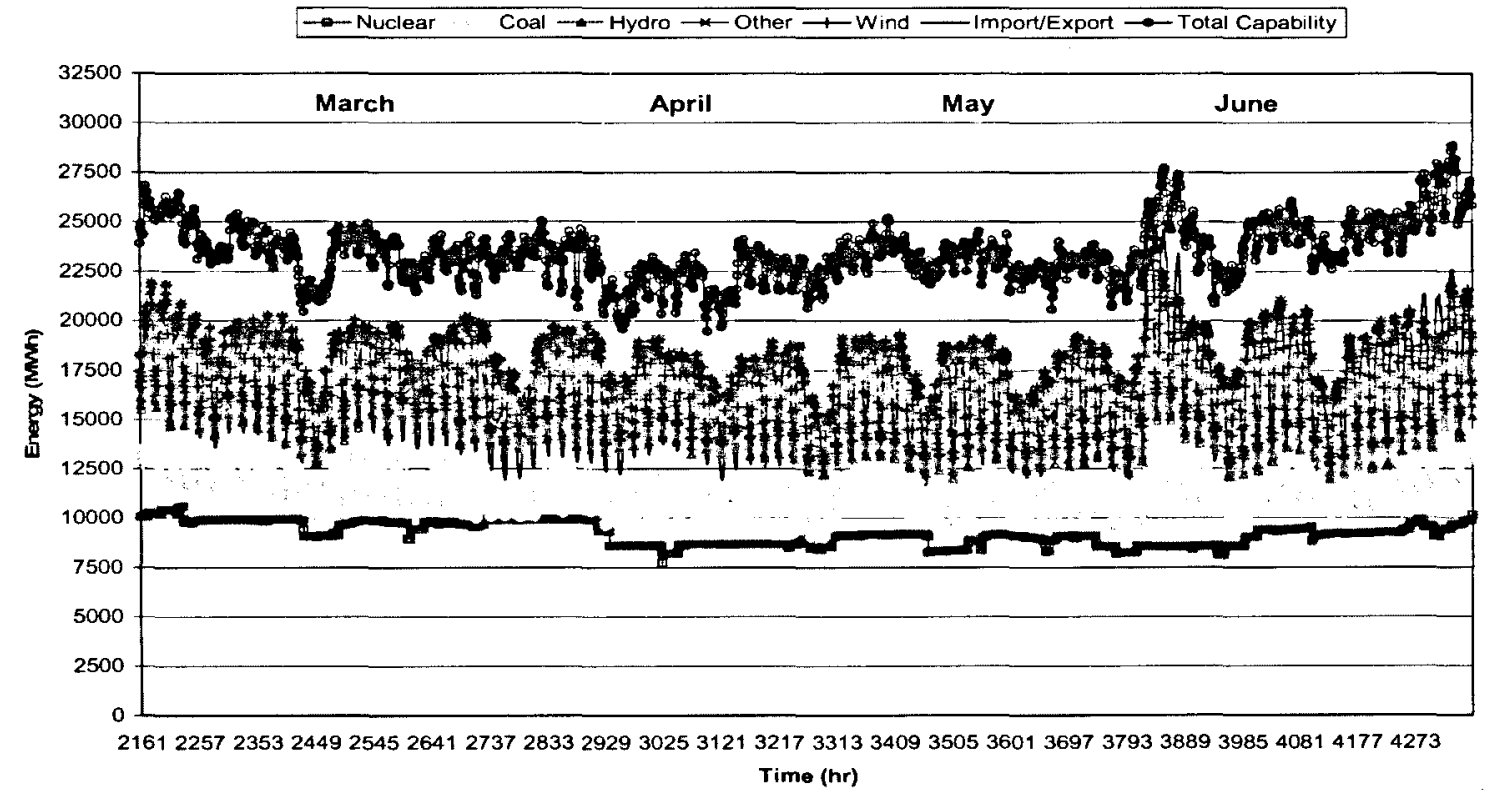

Figure 5-7: Hourly electricity supply and demand for Ontario spring 2006 
Table 5-5 shows the capability and output of each generating source for the springs of 2004, 2005 , and 2006. It can be observed that nuclear output and capability generation decreased in 2005 but increased in 2006 back to 2004 levels. Coal and hydro output and capability generation increased in 2005 but decreased in 2006. Other output generation has decreased by $1 \%$ and wind generated $0.26 \%$ while having a capability of $1 \%$.

Table 5-5: Output and capability generation comparison for spring 2004-2006

\begin{tabular}{|c|c|c|c|c|c|c|}
\hline \multicolumn{7}{|c|}{ Spring } \\
\hline$\%$ & \multicolumn{2}{|c|}{2004} & \multicolumn{2}{c|}{2005} & \multicolumn{2}{c|}{2006} \\
\cline { 2 - 7 } & Capability & Output & Capability & Output & Capability & Output \\
\hline Nuclear & 39 & 53 & 35 & 48 & 39 & 54 \\
\hline Coal & 17 & 13 & 18 & 17 & 15 & 13 \\
\hline Hydro & 29 & 26 & 31 & 27 & 28 & 25 \\
\hline Other & 15 & 7 & 17 & 8 & 17 & 7 \\
\hline Wind & N/A & N/A & N/A & N/A & 1 & 0.26 \\
\hline
\end{tabular}

Table 5-6 shows the electricity demand by generation type for the springs of 2004, 2005 and 2006. The total electricity demand for the Province of Ontario increased in 2005, but decreased in 2006 by $1.3 \%$. Imported electricity numbers increased in 2005 by $45 \%$ but decreased in 2006 back to 2004 levels while exported electricity numbers decreased by $26 \%$ between 2004 and 2005 but increased by 34\% between 2005 and 2006. It should be noted that nuclear generation dropped considerably during the spring of 2005. This might support the idea that there was an outage, thus increasing coal generation in order to compensate for the shortfall.

Table 5-6: Electricity demand by generation type comparison for spring 2004-2006

\begin{tabular}{|c|c|c|c|}
\hline \multicolumn{4}{|l|}{ Spring } \\
\hline \multirow{2}{*}{ Generation Type } & \multicolumn{3}{|c|}{ Electricity Demand (GWh) } \\
\cline { 2 - 4 } & $\mathbf{2 0 0 4}$ & $\mathbf{2 0 0 5}$ & $\mathbf{2 0 0 6}$ \\
\hline Nuclear & 19470 & 16910 & 20354 \\
\hline Coal & 5054 & 6374 & 5230 \\
\hline Hydro & 9763 & 9547 & 9621 \\
\hline Other & 2728 & 2993 & 2642 \\
\hline Wind & N/A & N/A & 103 \\
\hline Imported & 1519 & 2795 & 1308 \\
\hline Exported & 2889 & 2130 & 3242 \\
\hline Total & $\mathbf{3 5 6 4 5}$ & $\mathbf{3 6 4 8 9}$ & $\mathbf{3 6 0 1 7}$ \\
\hline
\end{tabular}


5.3.1 Peak Day Electricity Analysis for Spring 2004, 2005, and 2006

Table 5-7 and Figure 5-8 show the electricity demand for spring peak days for 2004, 2005, and 2006. Electricity demand was the highest during the spring of 2006.

Table 5-7: Electricity demand comparison for spring peak days 2004-2006

\begin{tabular}{|c|c|c|}
\hline \multicolumn{3}{|c|}{ Spring } \\
\hline Year & Peak Day & Electricity Demand (GWh) \\
\hline 2004 & 9-Jun-04 & 471 \\
\hline 2005 & 14-Jun-05 & 495 \\
\hline 2006 & 29-May-06 & 509 \\
\hline
\end{tabular}

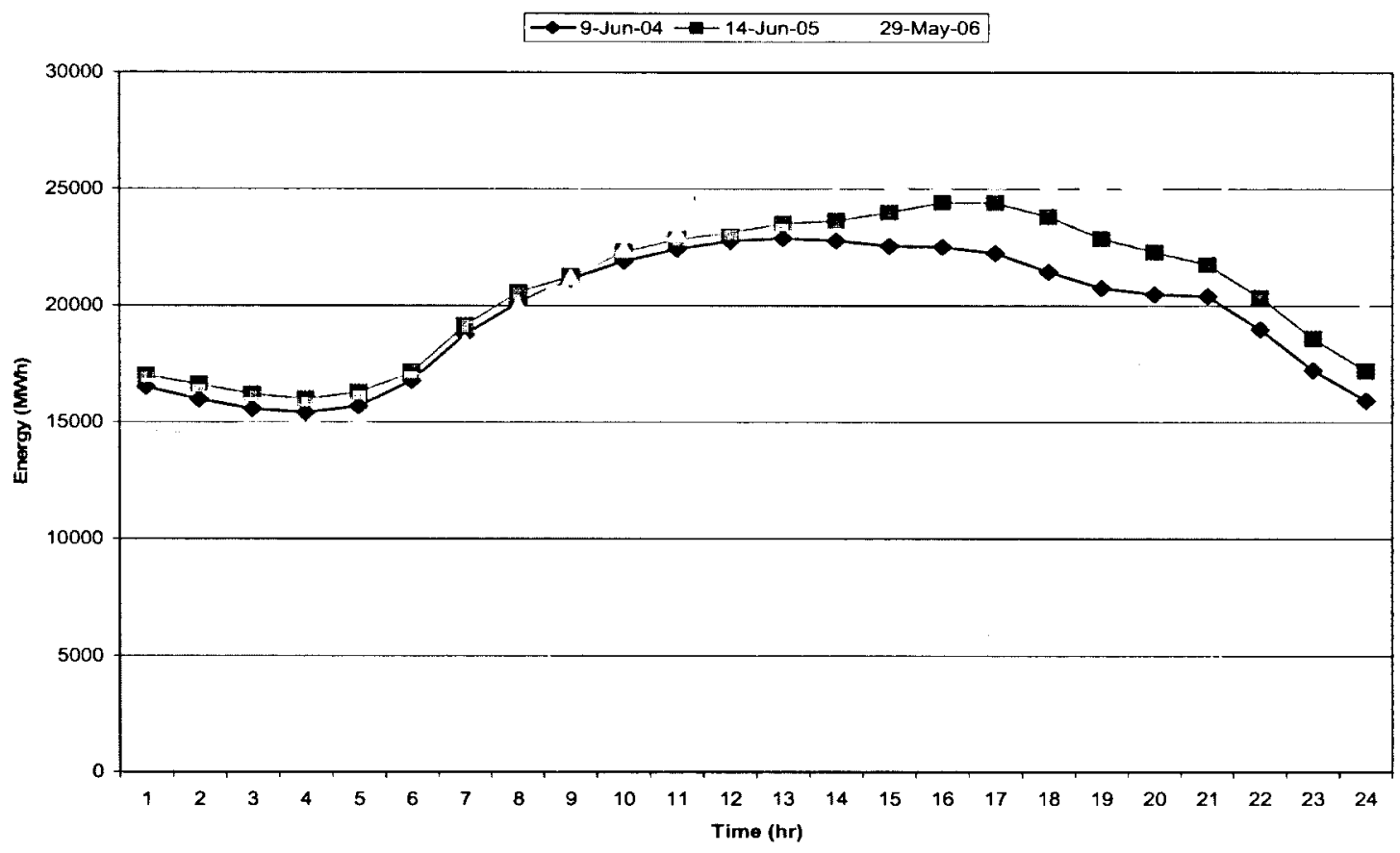

Figure 5-8: Electricity demand during peak spring weekday 2004-2006

\subsection{Summer 2004, 2005, and 2006}

The hourly supply and demand of electricity illustrating the different generating technologies for Ontario is shown in Figure 5-9 for summer 2004. 


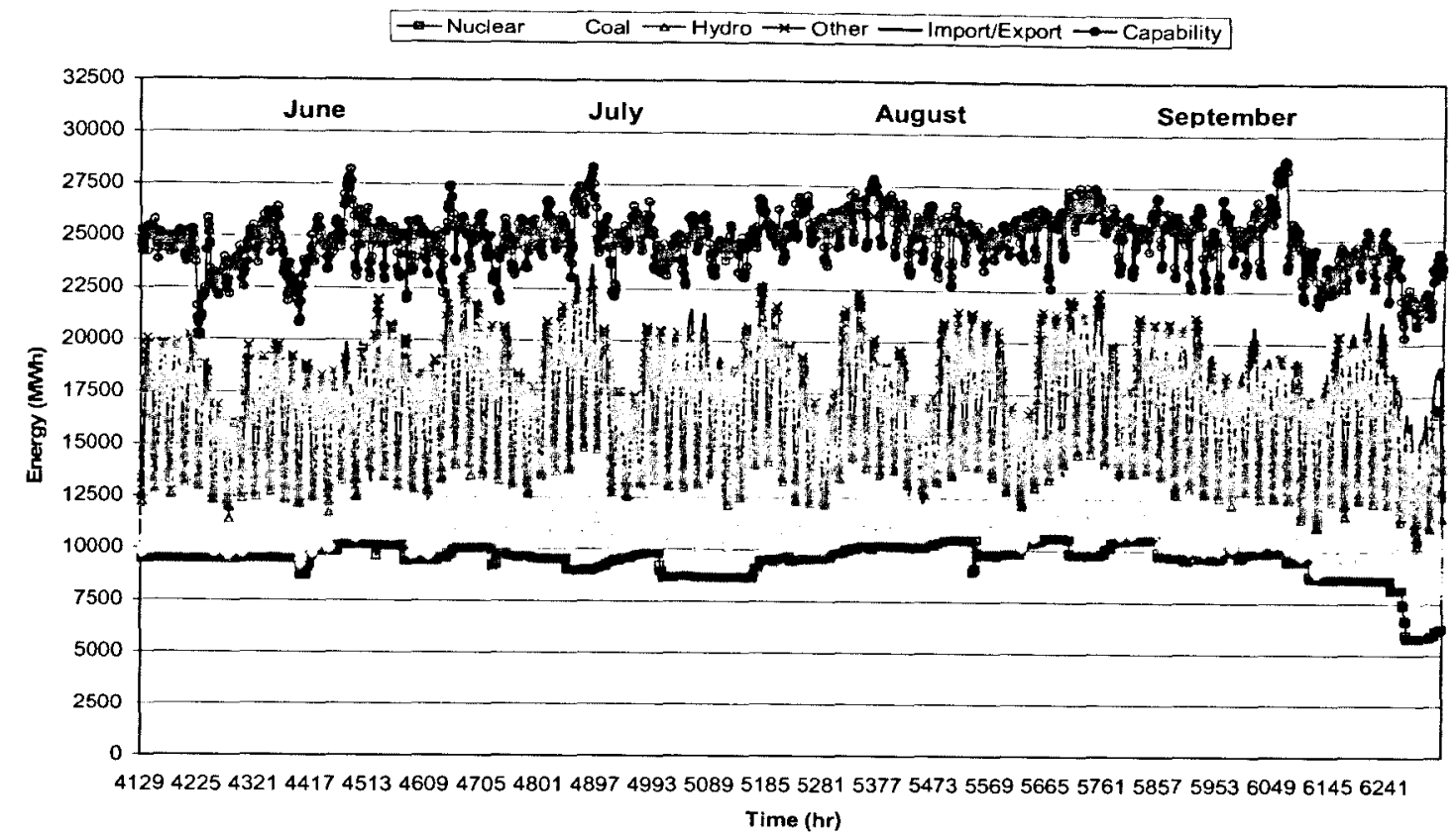

Figure 5-9: Hourly electricity supply and demand for Ontario summer 2004

The hourly supply and demand of electricity illustrating the different generating technologies for Ontario is shown in Figure 5-10 for summer 2005.

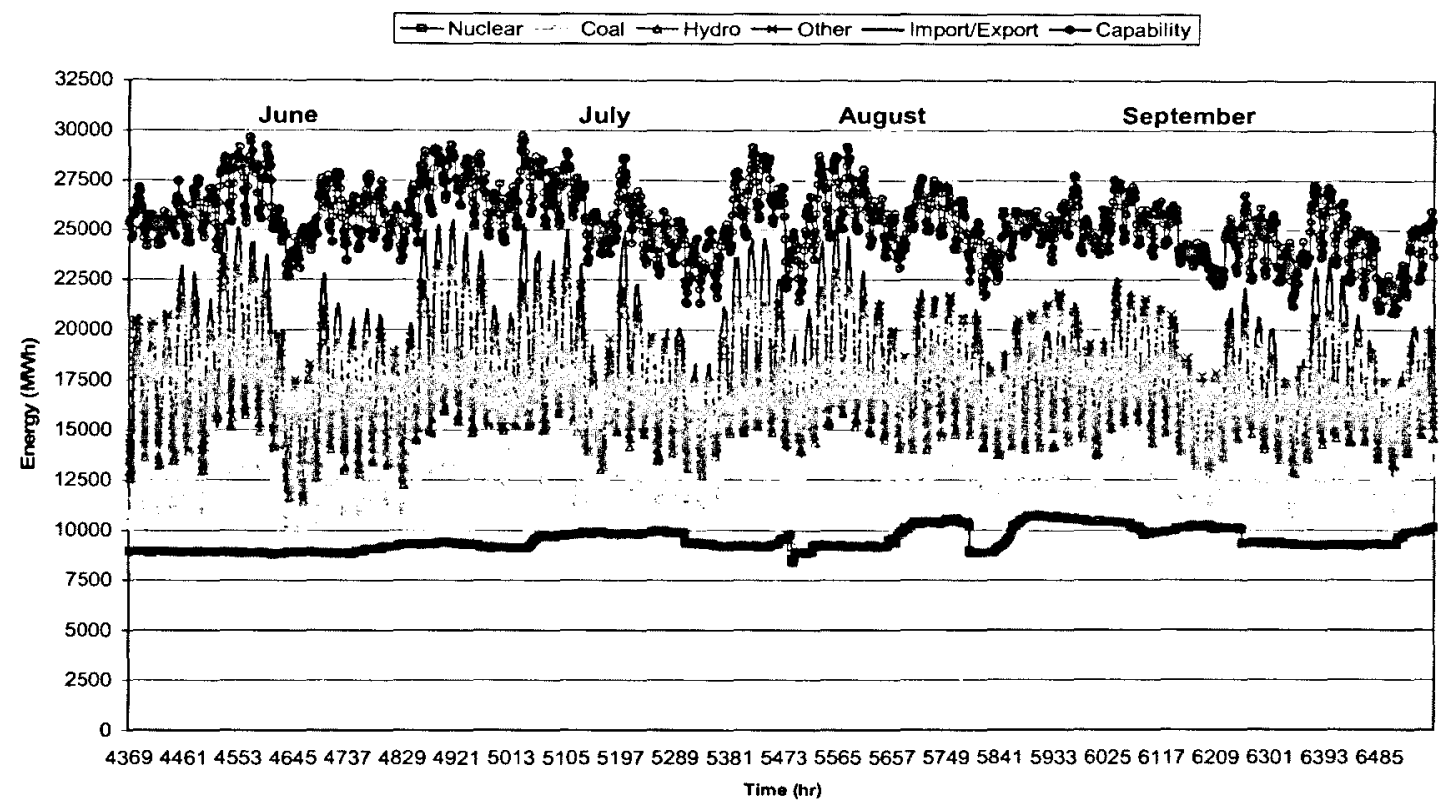

Figure 5-10 Hourly electricity supply and demand for Ontario summer 2005

The hourly supply and demand of electricity illustrating the different generating technologies for Ontario is shown in Figure 5-11 for summer 2006. 


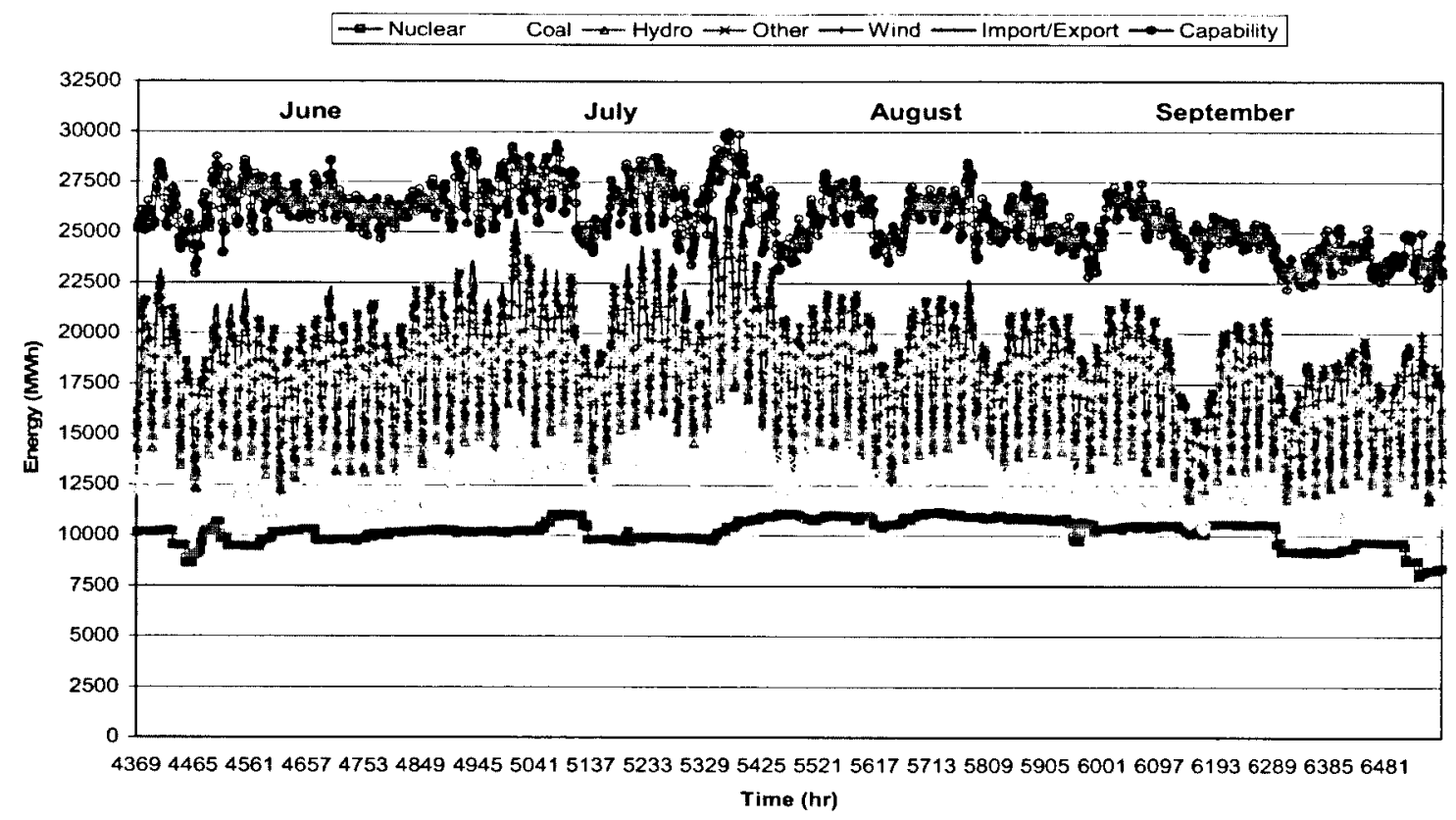

Figure 5-11: Hourly electricity supply and demand for Ontario summer 2006

Table 5-8 shows the capability and output of each generating source for the summers of 2004, 2005, and 2006. It can be observed that nuclear output and capability generation slightly decreased in 2005 but increased in 2006 back to 2004 levels. Coal output generation increased in 2005 but decreased in 2006 and hydro decreased in 2005 and remained the same for 2006. Other output generation increased by $2 \%$ in 2005 and wind generated $0.20 \%$ while having a capability of $0.89 \%$.

Table 5-8: Output and capability generation comparison for summer 2004-2006

\begin{tabular}{|c|c|c|c|c|c|c|}
\hline \multicolumn{7}{|c|}{ Summer } \\
\hline \multirow{2}{*}{$\%$} & \multicolumn{2}{|c|}{$\mathbf{2 0 0 4}$} & \multicolumn{2}{c|}{$\mathbf{2 0 0 5}$} & \multicolumn{2}{c|}{2006} \\
\cline { 2 - 7 } & Capability & Output & Capability & Output & Capability & Output \\
\hline Nuclear & 38 & 56 & 39 & 53 & 39 & 57 \\
\hline Coal & 20 & 14 & 19 & 21 & 17 & 18 \\
\hline Hydro & 27 & 23 & 26 & 17 & 25 & 17 \\
\hline Other & 16 & 7 & 17 & 9 & 17 & 8 \\
\hline Wind & N/A & N/A & N/A & N/A & 0.89 & 0.20 \\
\hline
\end{tabular}

Table 5-9 shows the electricity demand by generation type for the summers of 2004, 2005 and 2006. The total electricity demand for the Province of Ontario increased in 2005 by 
$8.5 \%$, but decreased in 2006 by $4.4 \%$. Imported electricity numbers increased in 2005 by $26 \%$ but decreased in 2006 by $50 \%$ while exported electricity numbers decreased by $27 \%$ between 2004 and 2005 but increased by $26 \%$ between 2005 and 2006 . Usually hydro is mostly used during the summer months. However, there was a substantial decrease in hydro generation during the summer of 2005 , probably due to an outage. This shortage in hydro generation had to be compensated by coal power plants.

Table 5-9: Electricity demand by generation type comparison for summer 2004-2006

\begin{tabular}{|c|c|c|c|}
\hline \multicolumn{4}{|c|}{ Summer } \\
\hline \multirow{2}{*}{ Generation Type } & \multicolumn{3}{|c|}{ Electricity Demand (GWh) } \\
\cline { 2 - 4 } & $\mathbf{2 0 0 4}$ & $\mathbf{2 0 0 5}$ & $\mathbf{2 0 0 6}$ \\
\hline Nuclear & 21017 & 21016 & 22573 \\
\hline Coal & 5736 & 8328 & 7452 \\
\hline Hydro & 8739 & 6766 & 7142 \\
\hline Other & 2597 & 3879 & 3193 \\
\hline Wind & N/A & N/A & 77 \\
\hline Imported & 2192 & 2978 & 1497 \\
\hline Exported & 3003 & 2204 & 2963 \\
\hline Total & 37277 & $\mathbf{4 0 7 6 2}$ & $\mathbf{3 8 9 7 1}$ \\
\hline
\end{tabular}

5.4.1 Peak Day Electricity Analysis for Summer 2004, 2005, and 2006

Table 5-10 and Figure 5-12 show the electricity demand for summer peak days for 2004, 2005, and 2006. Electricity demand was the highest during the summer of 2006.

Table 5-10: Electricity demand comparison for summer peak days 2004-2006

\begin{tabular}{|c|c|c|}
\hline \multicolumn{2}{|c|}{ Summer } \\
\hline Year & Peak Day & Electricity Demand (GWh) \\
\hline 2004 & 22-Jul-04 & 484 \\
\hline 2005 & 9 -Aug-05 & 517 \\
\hline 2006 & 1-Aug-06 & 561 \\
\hline
\end{tabular}




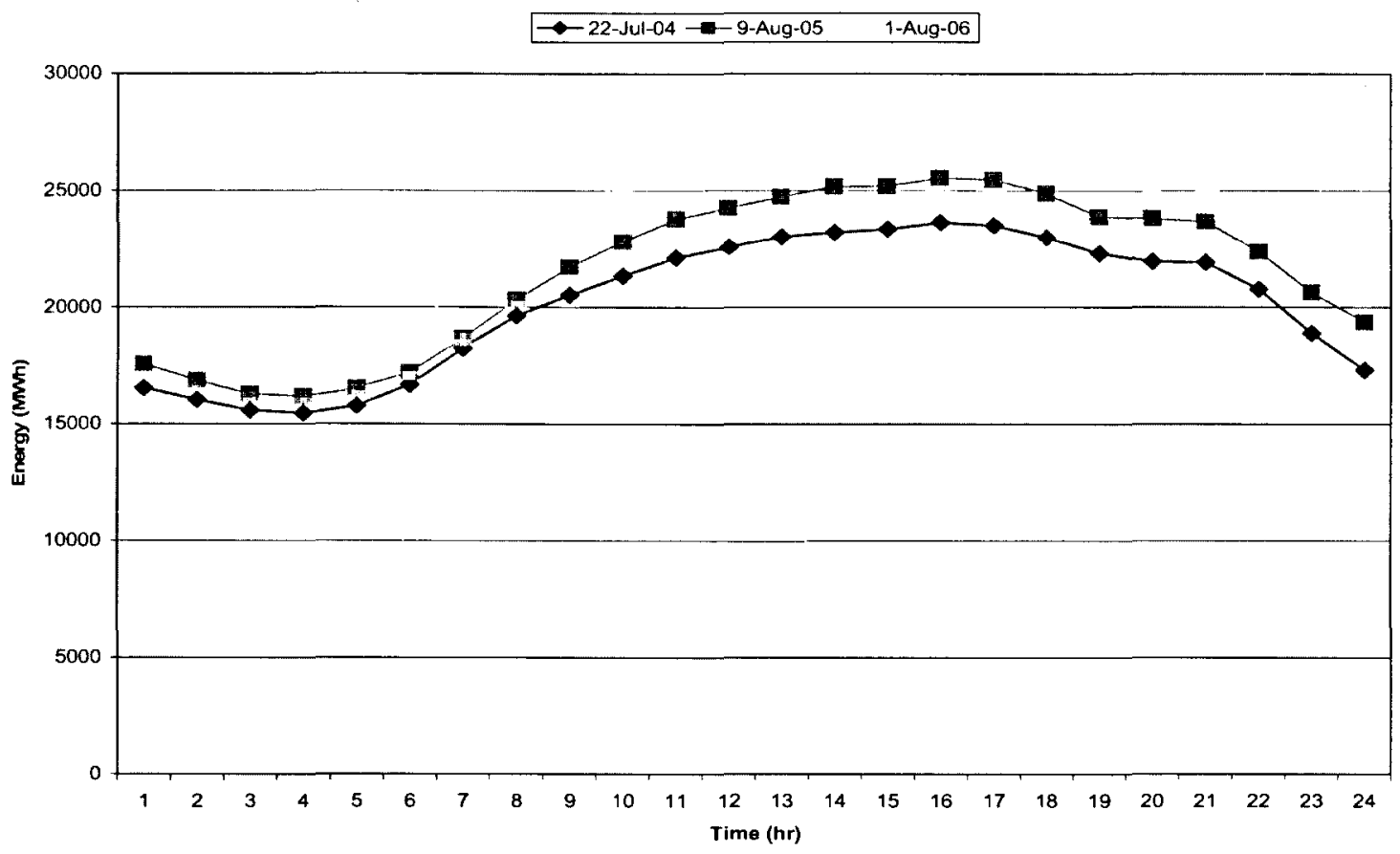

Figure 5-12: Electricity demand during peak summer weekday 2004-2006

\subsection{Fall 2004, 2005, and 2006}

The hourly supply and demand of electricity illustrating the different generating technologies for Ontario is shown in Figure 5-13 for fall 2004.

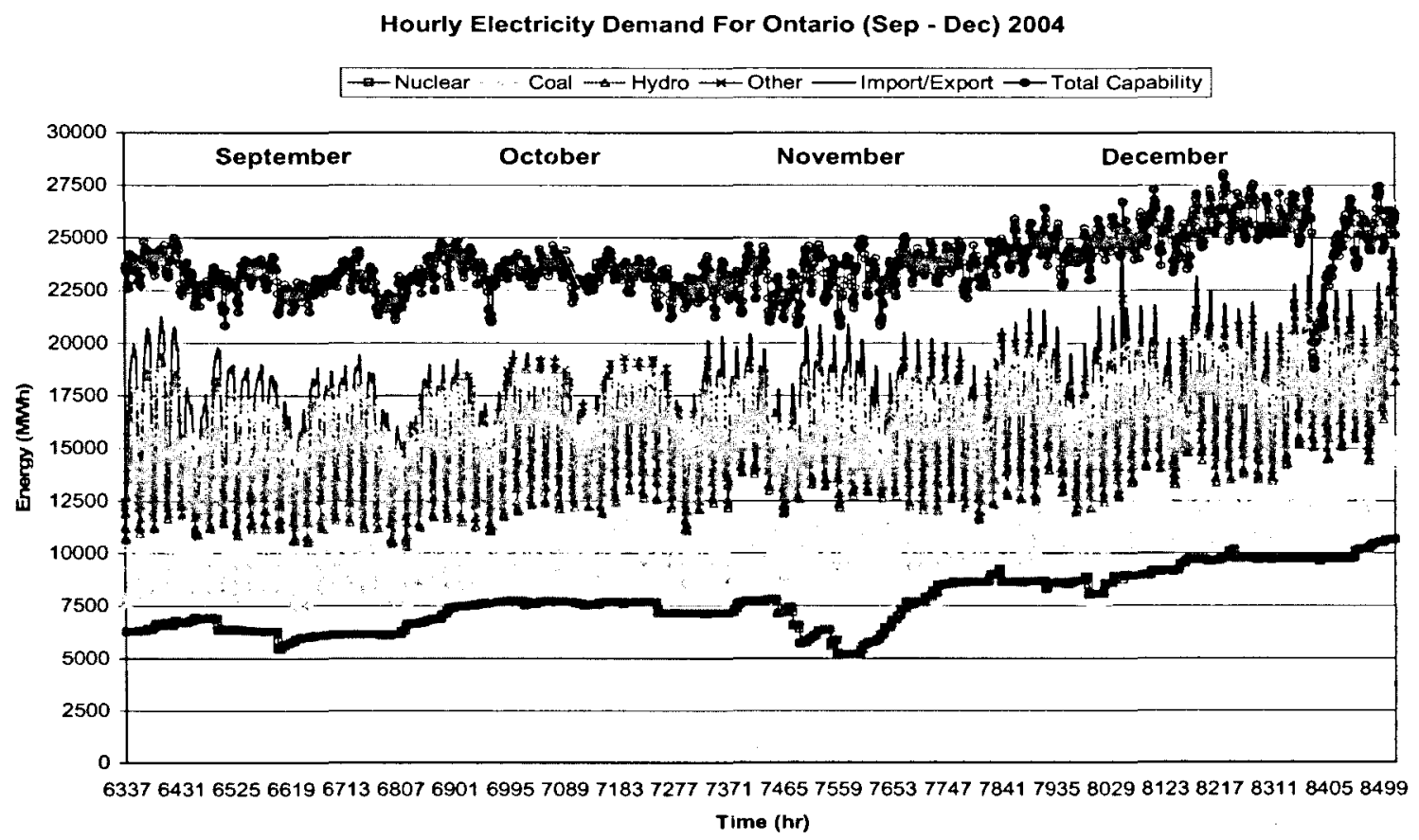

Figure 5-13: Hourly electricity supply and demand for Ontario fall 2004 
The hourly supply and demand of electricity illustrating the different generating technologies for Ontario is shown in Figure 5-14 for fall 2005.

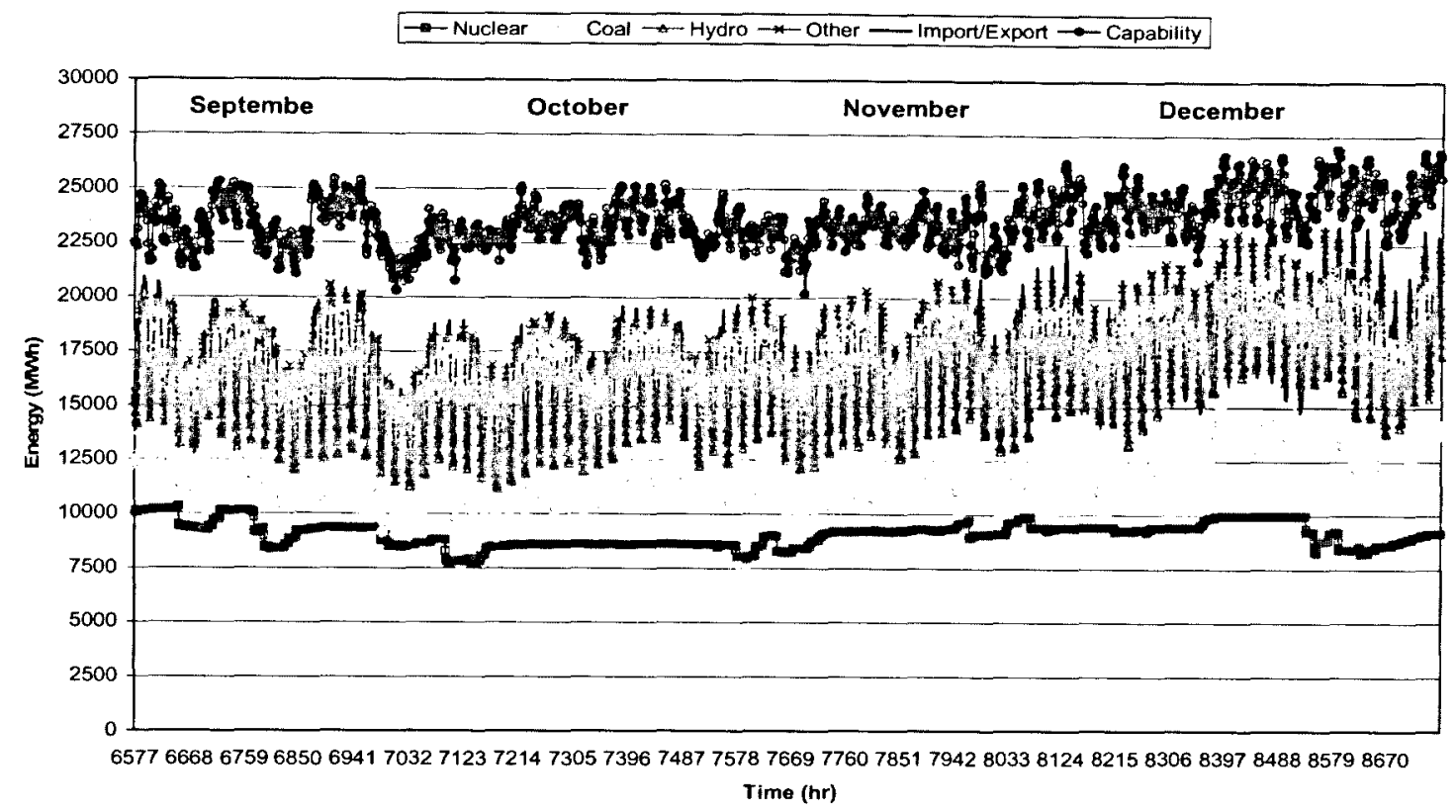

Figure 5-14: Hourly electricity supply and demand for Ontario fall 2005

The hourly supply and demand of electricity illustrating the different generating technologies for Ontario is shown in Figure 5-15 for fall 2006.

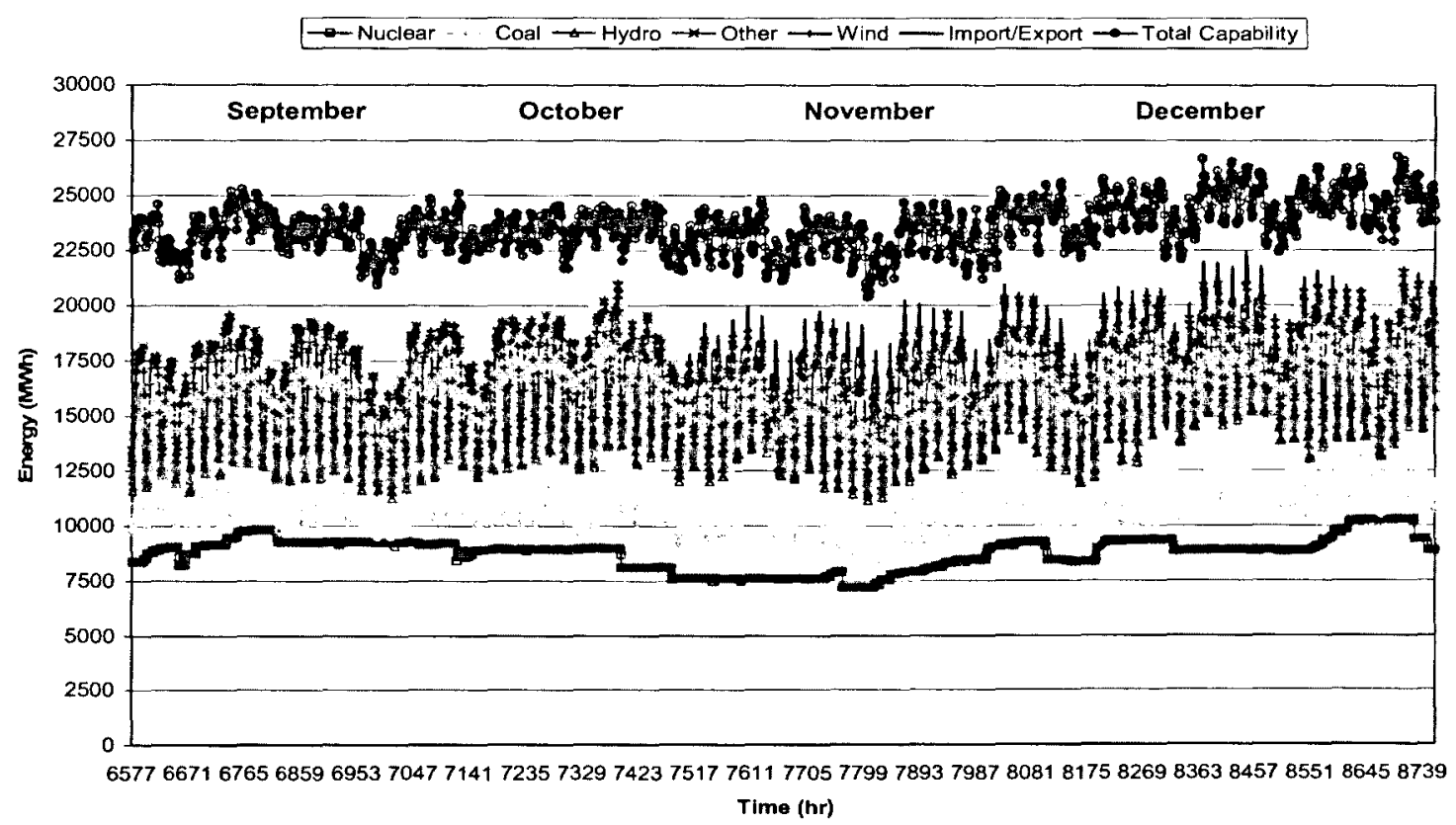

Figure 5-15: Hourly electricity supply and demand for Ontario fall 2006 
Table 5-11 shows the capability and output of each generating source for the falls of 2004, 2005, and 2006. It can be observed that nuclear output and capability generation increased in 2005 but slightly decreased in 2006. Coal and hydro output and capability generation decreased in 2005 and coal continued to decrease in 2006 while hydro increased back to 2004 levels. Other output generation decreased by $2 \%$ in 2005 and wind generated $0.66 \%$ while having a capability of $2.23 \%$.

Table 5-11: Output and capability generation comparison for fall 2004-2006

\begin{tabular}{|c|c|c|c|c|c|c|}
\hline \multicolumn{9}{|c|}{ Fall } \\
\hline \multirow{2}{*}{$\%$} & \multicolumn{2}{|c|}{2004} & \multicolumn{2}{c|}{ 2005 } & \multicolumn{2}{c|}{2006} \\
\cline { 2 - 7 } & Capability & Output & Capability & Output & Capability & Output \\
\hline Nuclear & 34 & 47 & 40 & 54 & 38 & 53 \\
\hline Coal & 20 & 20 & 17 & 18 & 15 & 15 \\
\hline Hydro & 29 & 24 & 27 & 21 & 28 & 23 \\
\hline Other & 17 & 9 & 16 & 7 & 18 & 8 \\
\hline Wind & N/A & N/A & N/A & N/A & 2.23 & 0.66 \\
\hline
\end{tabular}

Table 5-12 shows the electricity demand by generation type for the falls of 2004, 2005 and 2006. The total electricity demand for the Province of Ontario did not increase in 2005, but decreased in 2006 by $4 \%$. Imported electricity numbers decreased in 2005 by $23 \%$ and decreased in 2006 by another $40 \%$ while exported electricity numbers increased by $44 \%$ between 2004 and 2005 but decreased by $27 \%$ between 2005 and 2006 .

Table 5-12: Electricity demand by generation type comparison for fall 2004-2006

\begin{tabular}{|c|c|c|c|}
\hline \multicolumn{4}{|c|}{ Fall } \\
\hline \multirow{2}{*}{ Generation Type } & \multicolumn{3}{|c|}{ Electricity Demand (GWh) } \\
\cline { 2 - 4 } & $\mathbf{2 0 0 4}$ & $\mathbf{2 0 0 5}$ & $\mathbf{2 0 0 6}$ \\
\hline Nuclear & 16878 & 19872 & 19172 \\
\hline Coal & 7402 & 7038 & 5747 \\
\hline Hydro & 8511 & 8186 & 8511 \\
\hline Other & 3127 & 2729 & 2949 \\
\hline Wind & N/A & N/A & 241 \\
\hline Imported & 3379 & 2615 & 1564 \\
\hline Exported & 1572 & 2797 & 2040 \\
\hline Total & $\mathbf{3 7 7 2 6}$ & $\mathbf{3 7 6 4 4}$ & $\mathbf{3 6 1 4 4}$ \\
\hline
\end{tabular}


5.5.1 Peak Day Electricity Analysis for Fall 2004, 2005, and 2006

Table 5-13 and Figure 5-16 show the electricity demand for fall peak days for 2004, 2005, and 2006. Electricity demand was the highest during the fall of 2005.

Table 5-13: Electricity demand comparison for fall peak days 2004-2006

\begin{tabular}{|c|c|c|}
\hline \multicolumn{2}{|c|}{ Fall } \\
\hline Year & Peak Day & Electricity Demand (GWh) \\
\hline 2004 & 1-Dec-04 & 453 \\
\hline 2005 & 12-Dec-05 & 478 \\
\hline 2006 & 7-Dec-06 & 457 \\
\hline
\end{tabular}

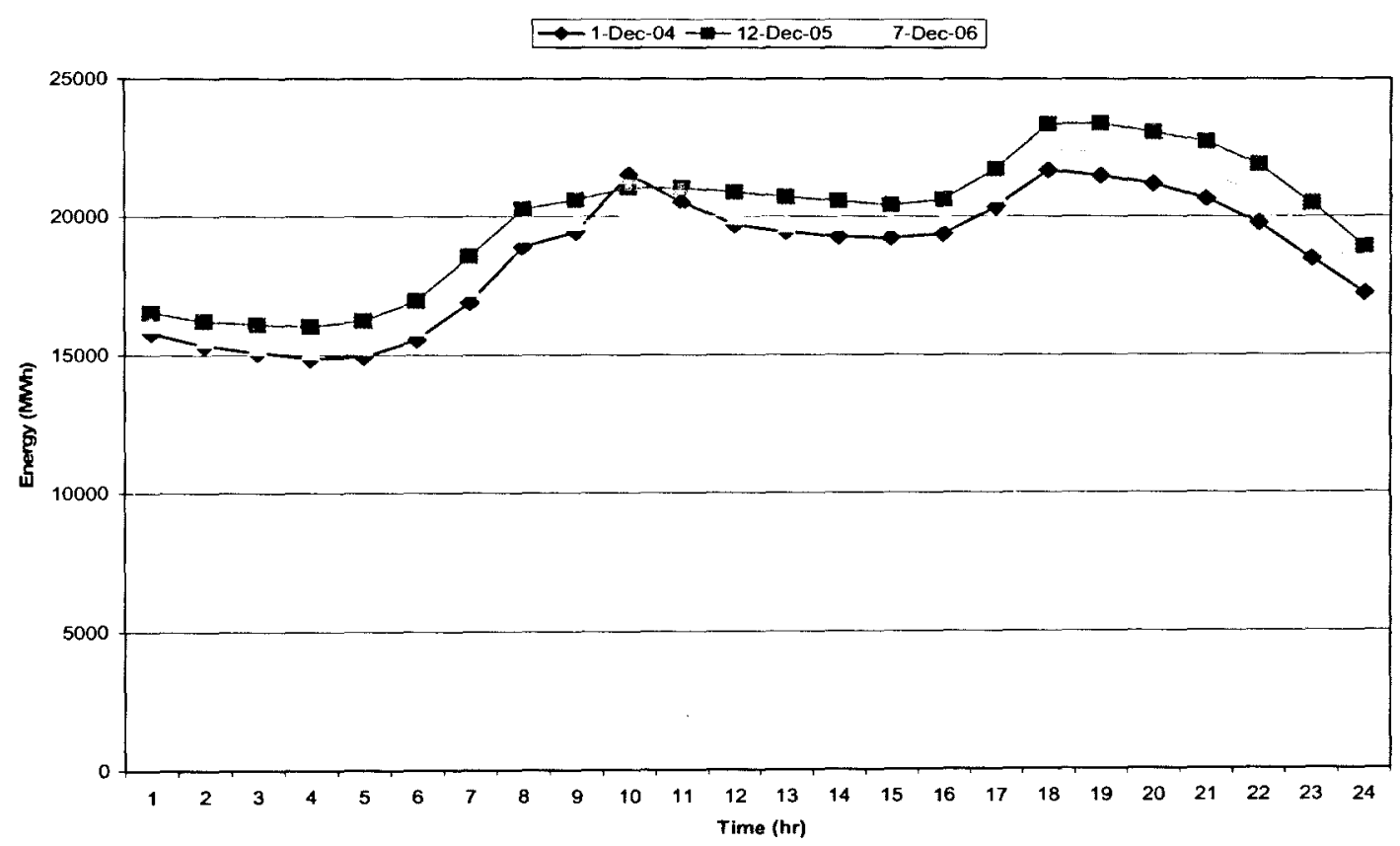

Figure 5-16: Electricity demand during peak fall weekday 2004-2006

\subsection{Years 2004, 2005, and 2006}

The hourly supply and demand of electricity illustrating the different generating technologies for Ontario is shown in Figure 5-17 for 2004. 


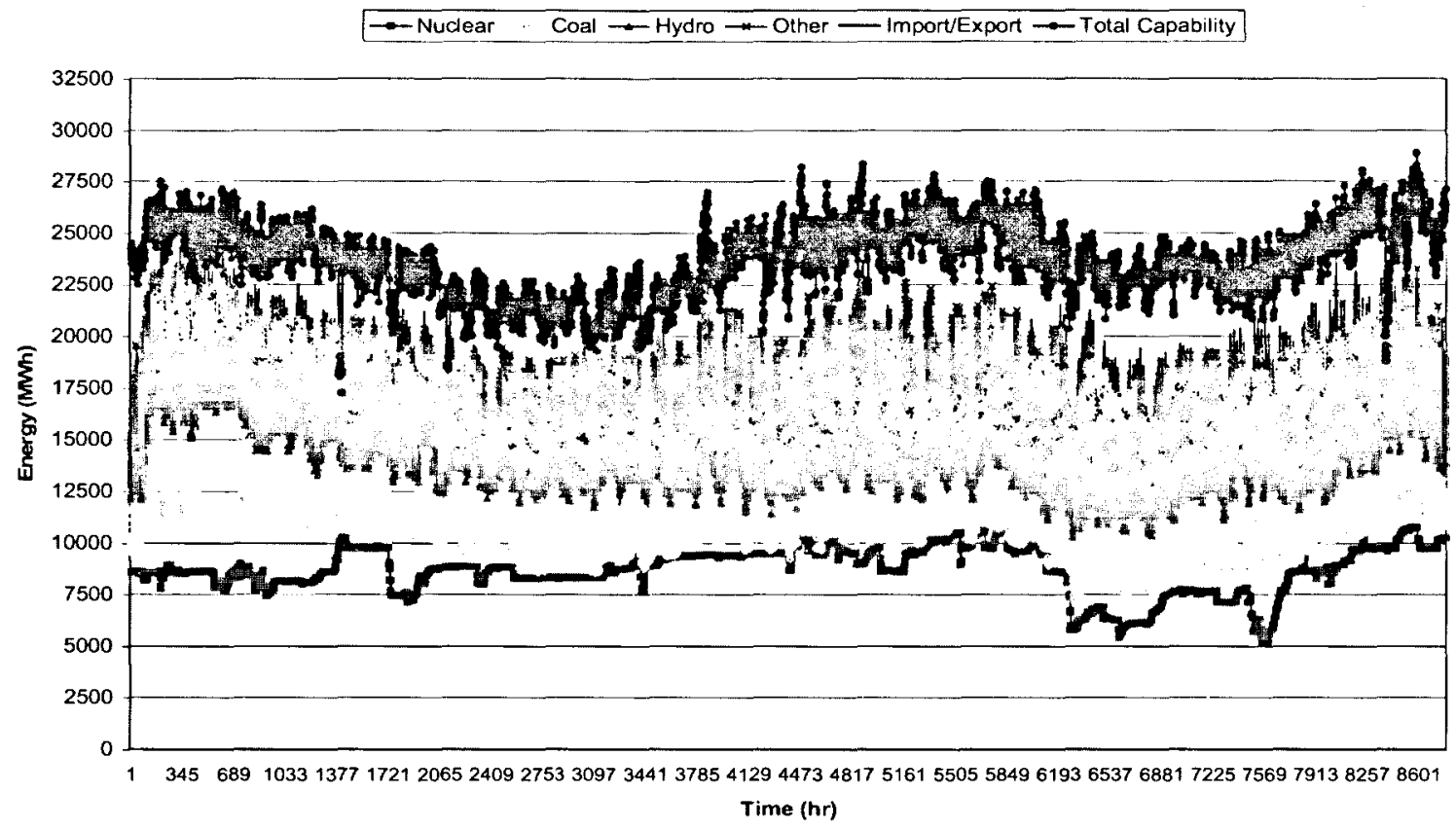

Figure 5-17: Hourly electricity supply and demand for Ontario 2004

As indicated in Figure 5-18, the difference between the capability and the output electricity for Ontario is approximately $15 \%$ in accordance with IESO regulations. In addition, a portion of the additional electricity generated in the Province is sold to the United States and/or to provinces bordering Ontario. 


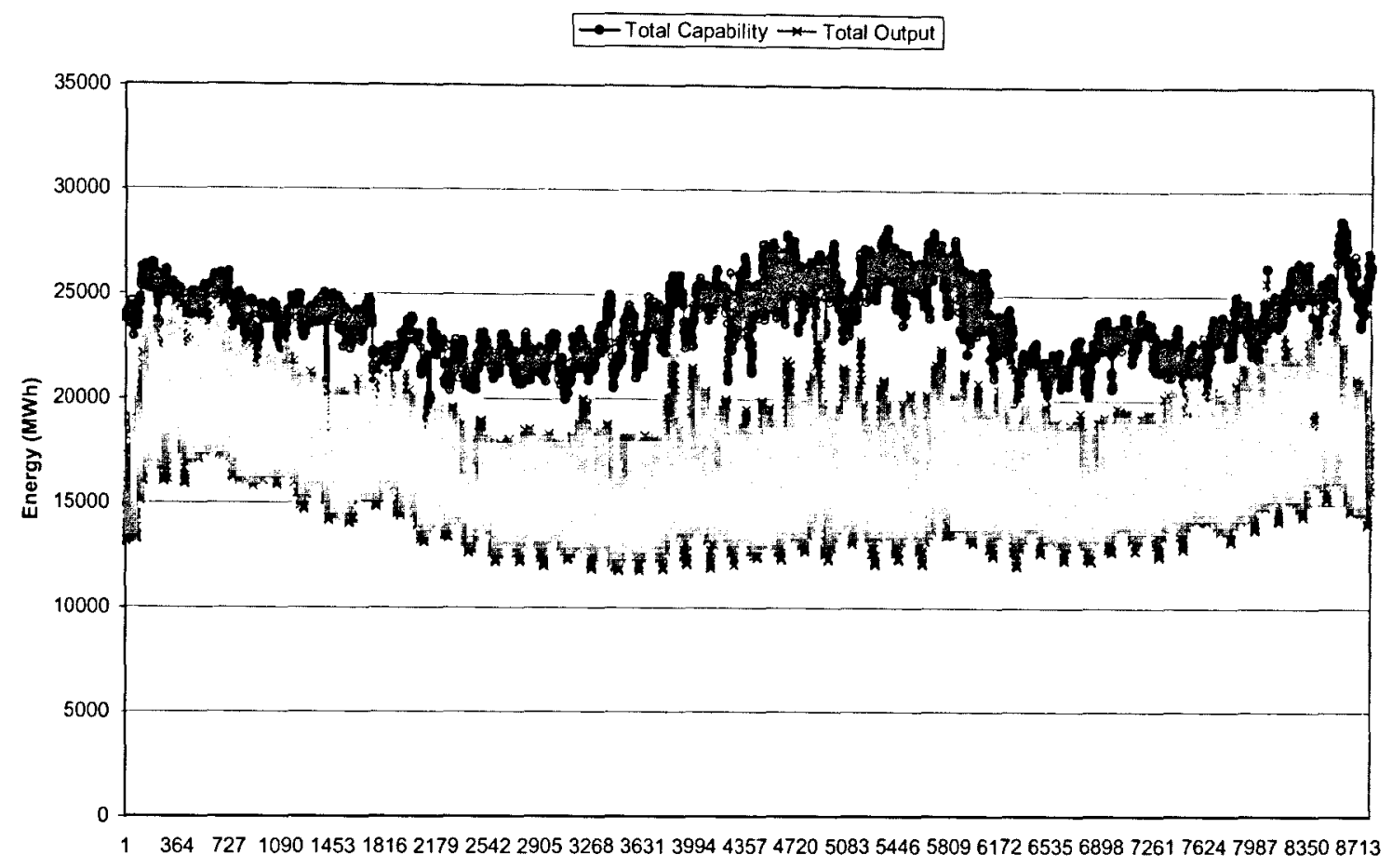

Figure 5-18: Hourly electricity Capability and Output - 2004

Table 5-14 and Figure 5-19 show the electricity demand for seasonal peak days for 2004 . Electricity demand was the highest during the winter.

Table 5-14: Electricity demand comparison for seasonal peak days for 2004

\begin{tabular}{|c|c|c|}
\hline \multicolumn{2}{|c|}{2004} \\
\hline Season & Peak Day & Electricity Demand (GWh) \\
\hline Winter & 26-Jan-04 & 518 \\
\hline Spring & 9-Jun-04 & 471 \\
\hline Summer & 22-Jul-04 & 484 \\
\hline Fall & 1-Dec-04 & 453 \\
\hline
\end{tabular}




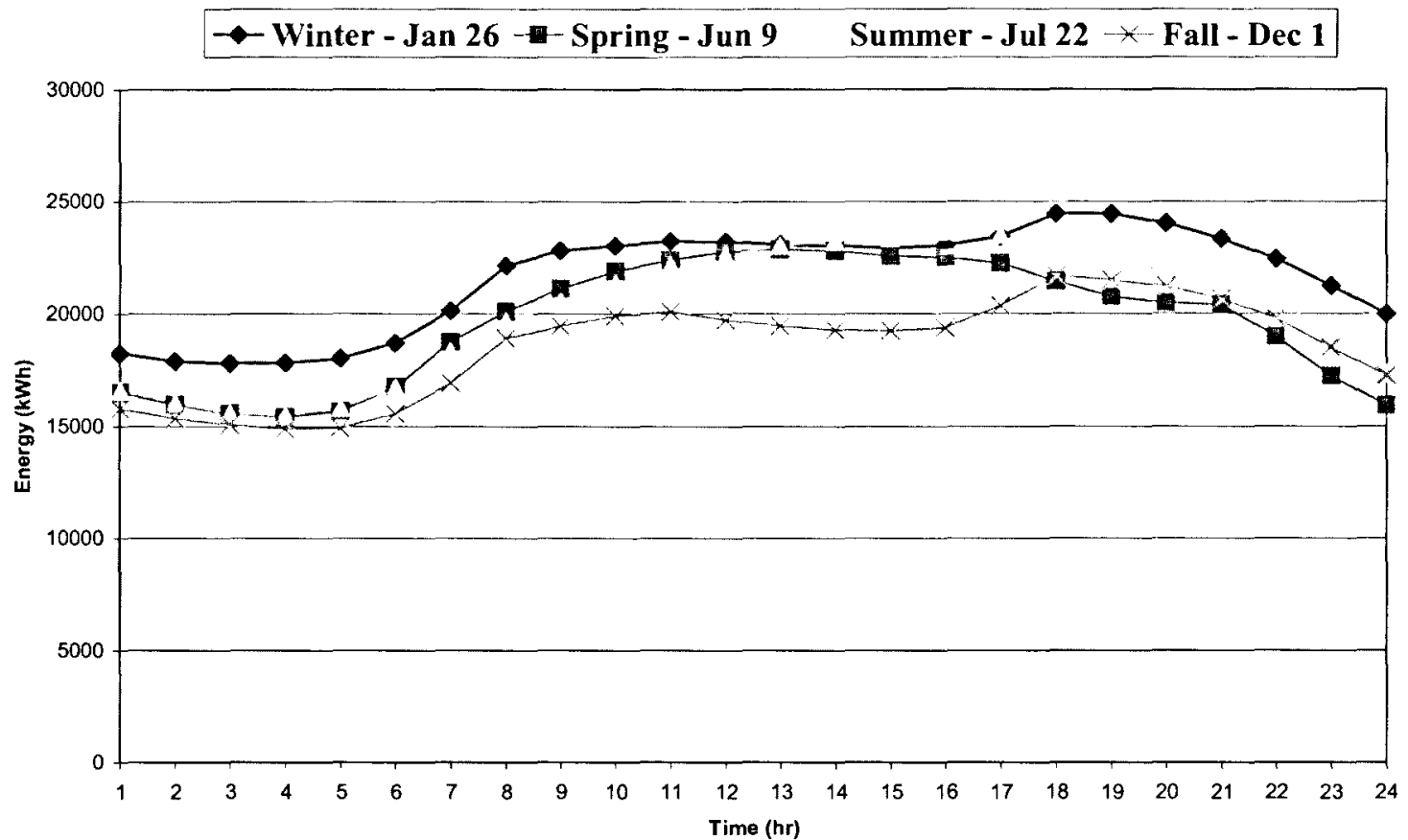

Figure 5-19: Electricity demand during seasonal peak days for 2004

The hourly supply and demand of electricity illustrating the different generating technologies for Ontario is shown in Figure 5-20 for 2005.

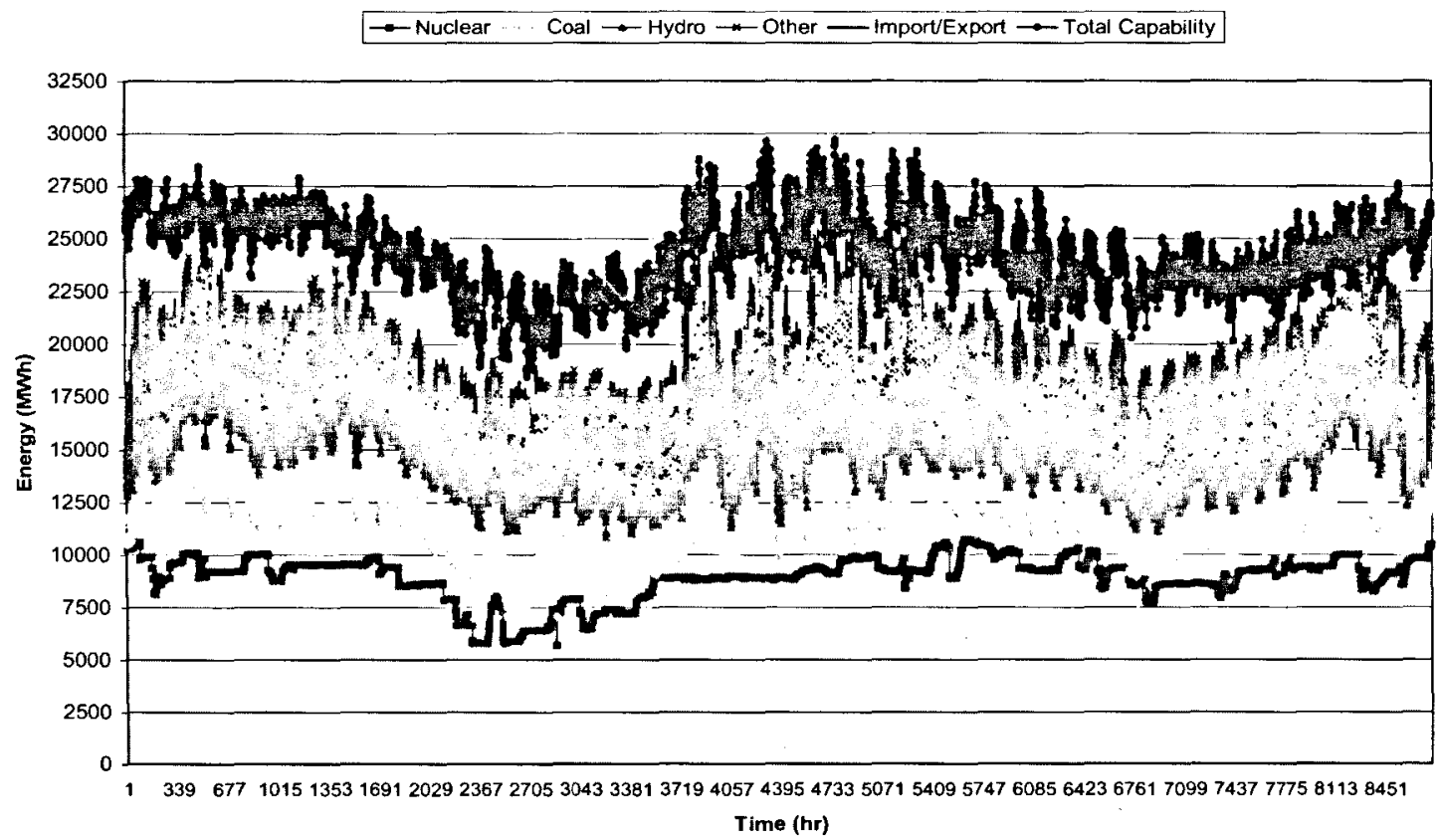

Figure 5-20: Hourly electricity supply and demand for Ontario 2005 
As indicated in Figure 5-21, the difference between the capability and the output electricity for Ontario is very small the during the summer months.

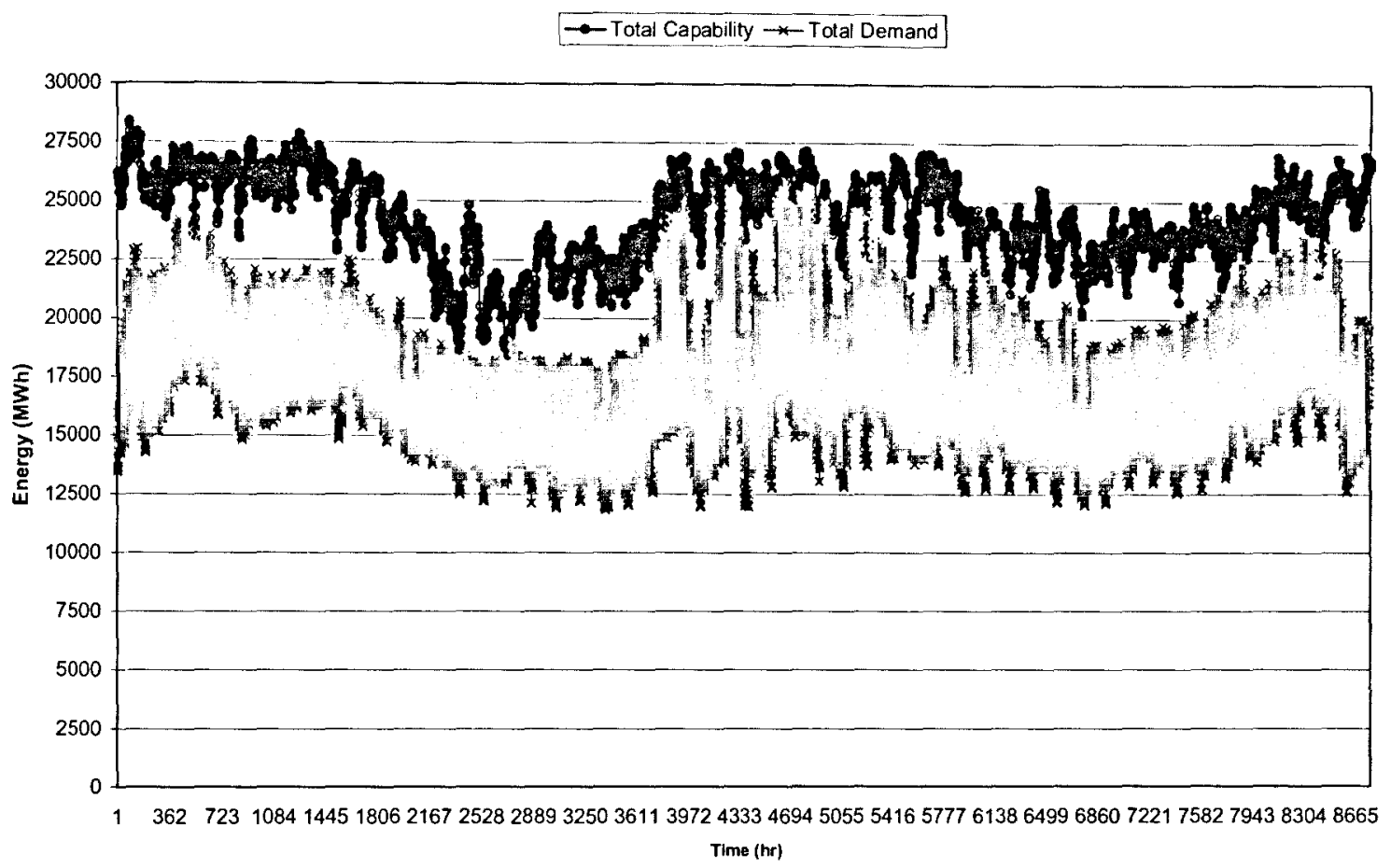

Figure 5-21: Hourly electricity Capability and Output -2005

Table 5-15 and Figure 5-22 show the electricity demand for seasonal peak days for 2005 .

Electricity demand was the highest during the summer.

Table 5-15: Electricity demand comparison for seasonal peak days for 2005

\begin{tabular}{|c|c|c|}
\hline \multicolumn{2}{|c|}{2005} \\
\hline Season & Peak Day & Electricity Demand (GWh) \\
\hline Winter & 18-Jan-05 & 515 \\
\hline Spring & 14-Jun-05 & 495 \\
\hline Summer & 9-Aug-05 & 517 \\
\hline Fall & 12-Dec-05 & 478 \\
\hline
\end{tabular}




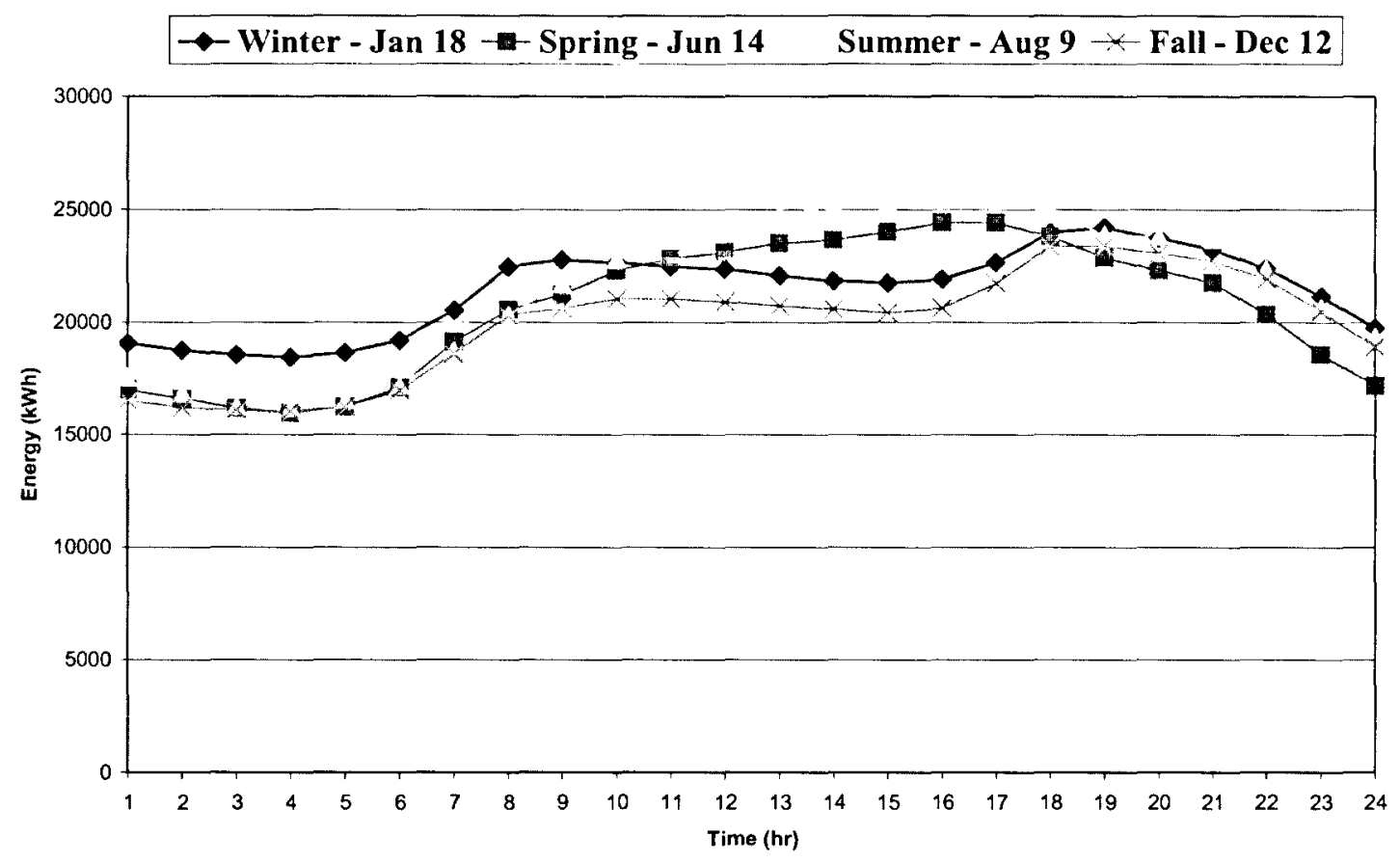

Figure 5-22: Electricity demand during seasonal peak days for 2005

The hourly supply and demand of electricity illustrating the different generating technologies for Ontario is shown in Figure 5-23 for 2006.

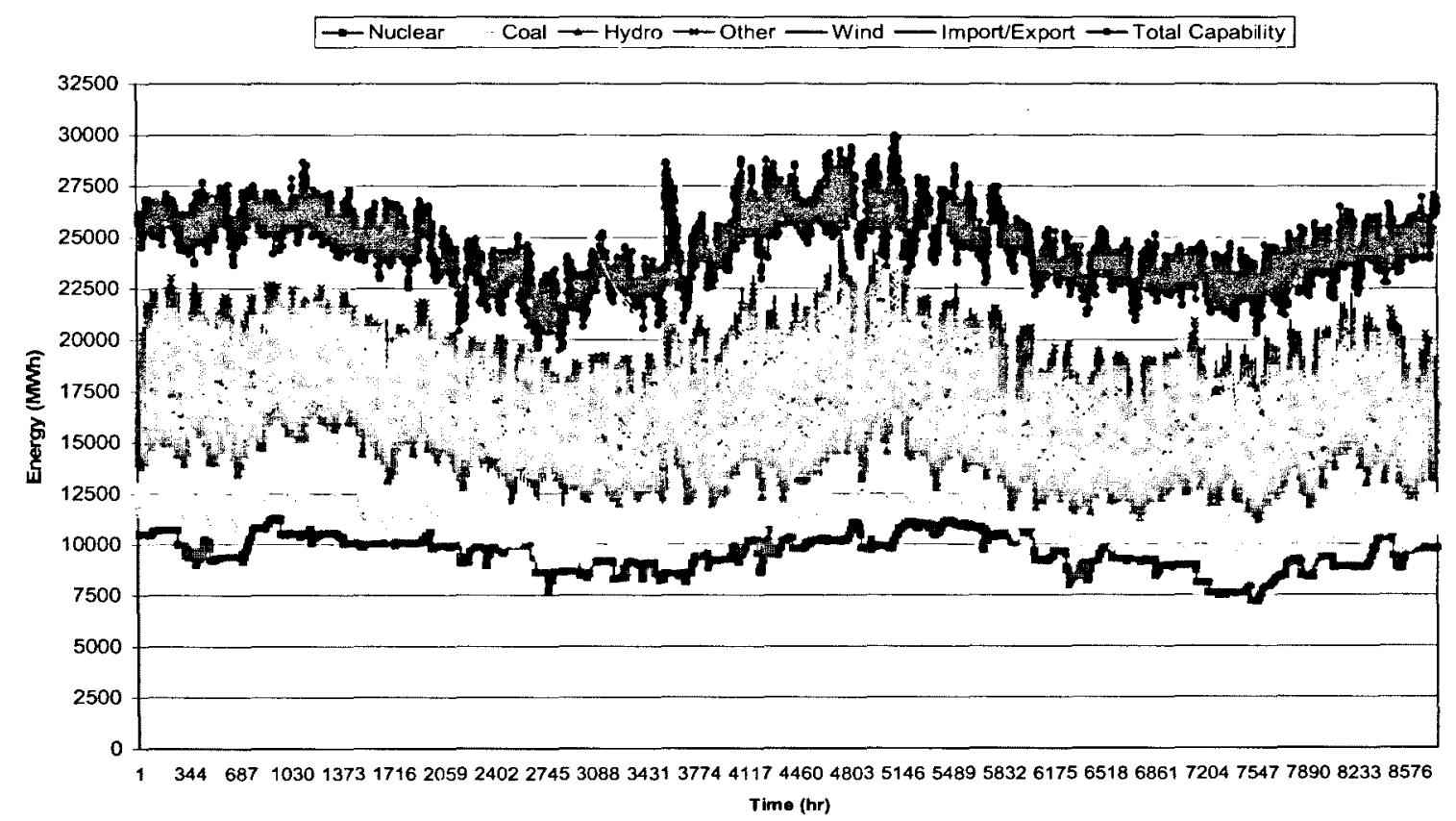

Figure 5-23: IIourly electricity supply and demand for Ontario 2006 
As indicated in Figure 5-24, the difference between the capability and the output electricity for Ontario is constant throughout the year.

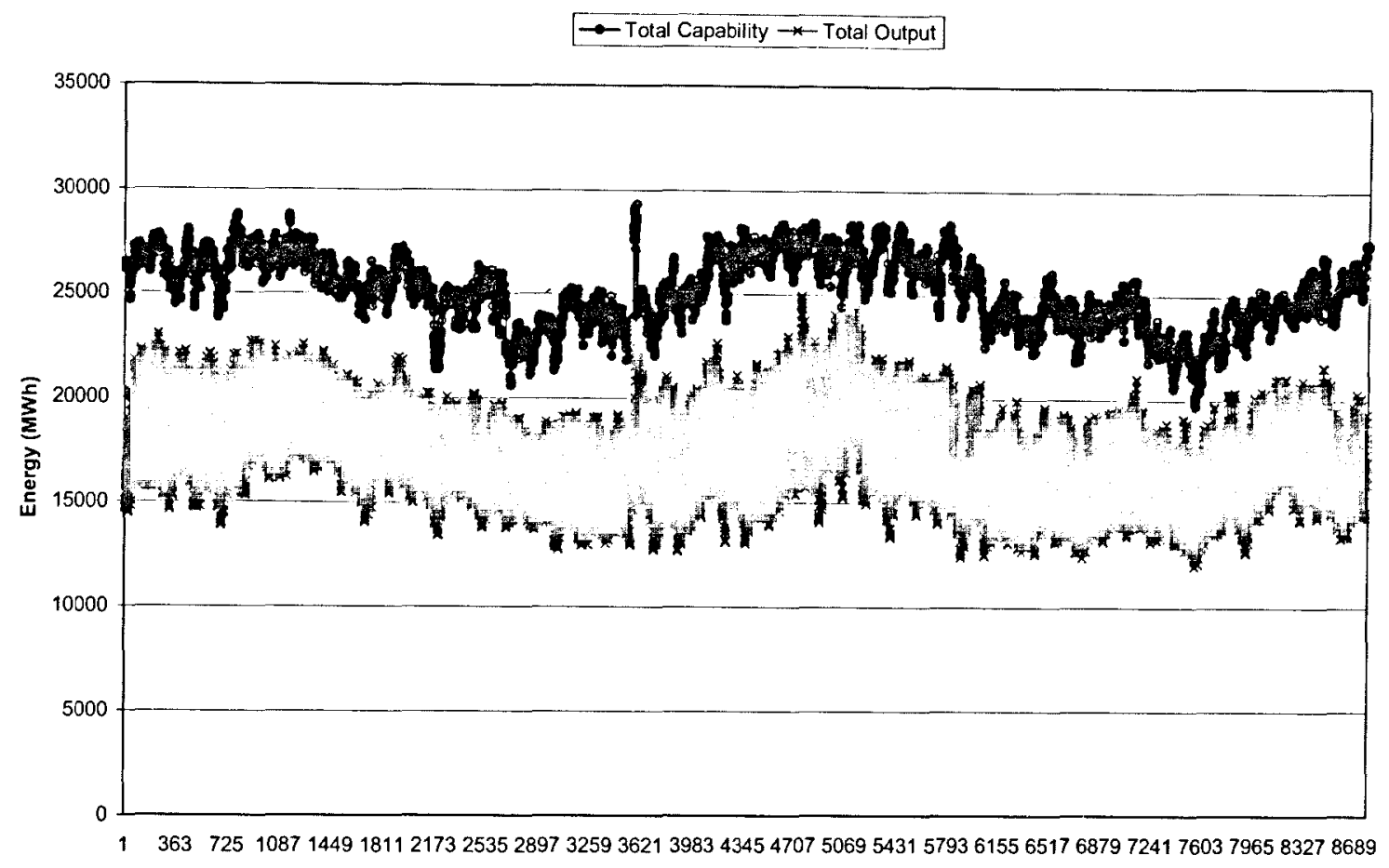

Figure 5-24: Hourly electricity Capability and Output - 2006

Table 5-16 and Figure 5-25 show the electricity demand for seasonal peak days for 2006 . Electricity demand was the highest during the summer.

Table 5-16: Electricity demand comparison for seasonal peak days for 2006

\begin{tabular}{|c|c|c|}
\hline \multicolumn{2}{|c|}{2006} \\
\hline Season & Peak Day & Electricity Demand (GWh) \\
\hline Winter & 21-Dec-05 & 482 \\
\hline Spring & 29-May-06 & 509 \\
\hline Summer & 1-Aug-06 & 561 \\
\hline Fall & 7-Dec-06 & 457 \\
\hline
\end{tabular}




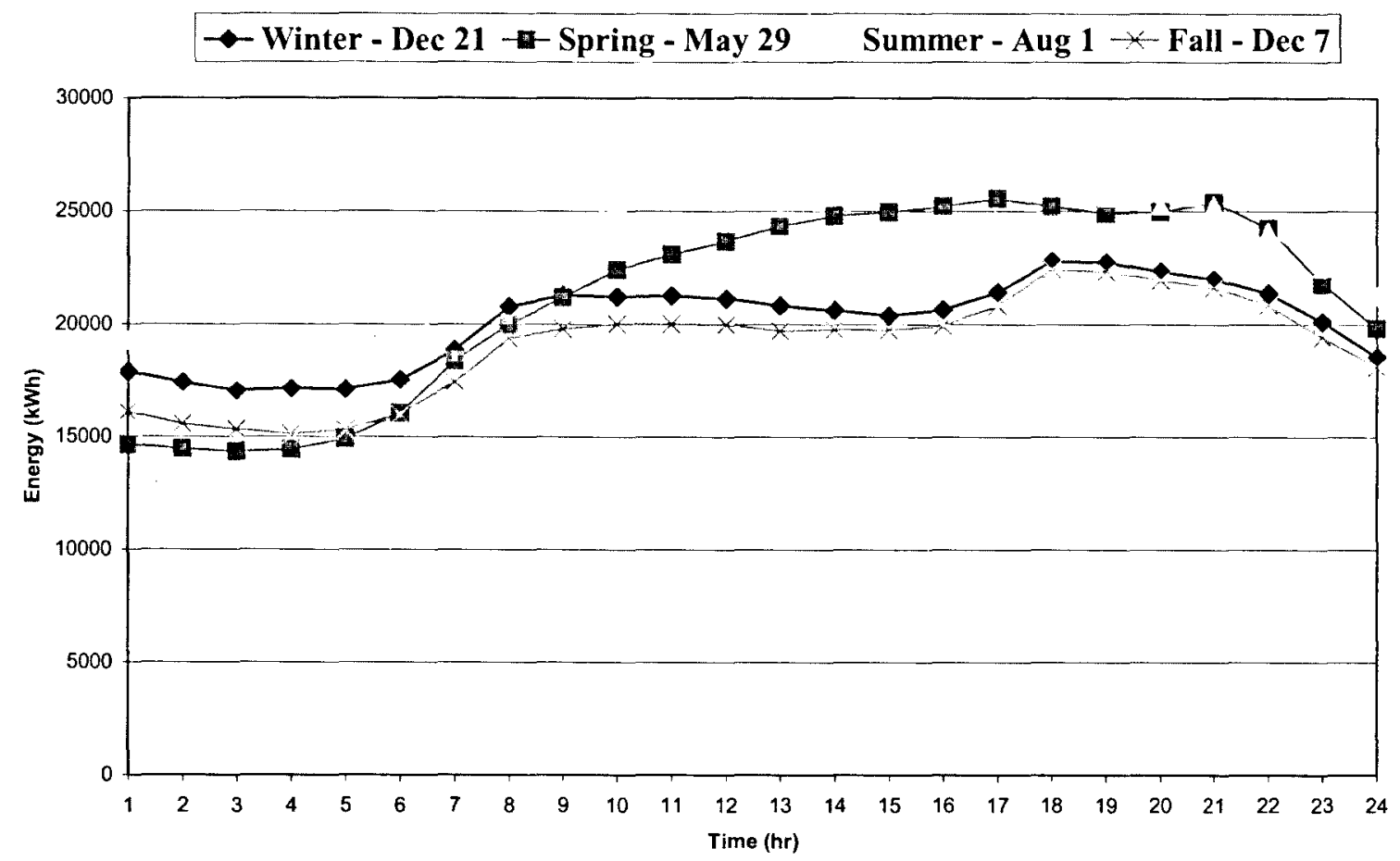

Figure 5-25: Electricity demand during seasonal peak days for 2006

Table 5-17 shows the capability and output of each generating source for 2004, 2005, and 2006. It can be observed that nuclear output and capability generation remained the same in 2005 but increased by $4 \%$ in 2006. Coal output generation increased in 2005 by $1 \%$ but decreased in 2006 by 3\%. Hydro output generation decreased in 2005 by $2 \%$ and remained the same in 2006. Other output generation remained unchanged while wind generated $0.30 \%$ while having a capability of $1.33 \%$.

Table 5-17: Output and capability generation comparison for 2004-2006

\begin{tabular}{|l|c|c|c|c|c|c|}
\hline \multicolumn{7}{|c|}{ Annual Total } \\
\hline \multirow{2}{*}{$\%$} & \multicolumn{2}{|c|}{$\mathbf{2 0 0 4}$} & \multicolumn{2}{c|}{$\mathbf{2 0 0 5}$} & \multicolumn{2}{c|}{2006} \\
\cline { 2 - 7 } & Capability & Output & Capability & Output & Capability & Output \\
\hline Nuclear & 37 & 51 & 38 & 51 & 39 & 55 \\
\hline Coal & 19 & 18 & 18 & 19 & 16 & 16 \\
\hline Hydro & 28 & 24 & 28 & 22 & 27 & 22 \\
\hline Other & 15 & 8 & 17 & 8 & 17 & 7 \\
\hline Wind & N/A & N/A & N/A & N/A & 1.33 & 0.30 \\
\hline
\end{tabular}


Table 5-18 shows the electricity demand by generation type for 2004, 2005 and 2006. The total electricity demand for the Province of Ontario increased in 2005 by $2.3 \%$, but decreased in 2006 by 3.5\%. Imported electricity numbers increased in 2005 by $11 \%$ but decreased in 2006 by $43 \%$ while exported electricity numbers increased by $7 \%$ and $11 \%$ in 2005 and 2006, respectively.

Table 5-18: Electricity demand by generation type comparison for 2004-2006

\begin{tabular}{|c|c|c|c|}
\hline \multicolumn{4}{|c|}{ Annual } \\
\hline \multirow{2}{*}{ Generation Type } & \multicolumn{3}{|c|}{ Electricity Demand (GWh) } \\
\cline { 2 - 4 } & $\mathbf{2 0 0 4}$ & $\mathbf{2 0 0 5}$ & $\mathbf{2 0 0 6}$ \\
\hline Nuclear & 76483 & 78343 & 83954 \\
\hline Coal & 26898 & 30084 & 25095 \\
\hline Hydro & 36199 & 33226 & 34354 \\
\hline Other & 11764 & 12835 & 11212 \\
\hline Wind & N/A & N/A & 456 \\
\hline Imported & 9774 & 10953 & 6189 \\
\hline Exported & 9490 & 10182 & 11388 \\
\hline Total & 151628 & 155259 & 149873 \\
\hline
\end{tabular}

It appears that the total electricity demand for the Province of Ontario increased in 2005, but decreased in 2006 which can be attributed to either unplanned outages of certain power plants or weather pattern changes. Nuclear generation continued to grow between 2004 and 2006, and coal increased in 2005, but returned back to 2004 levels in 2006. Nuclear generation was the highest during the summer months. In general, there is a norm to conduct planned outages during the spring and fall months in order to have all available nuclear generation for high peak demand during the summer. Clearly, without considering the year 2005 due to unforeseeable events, electricity generation from coal and other (natural gas, oil, etc) has been decreasing which could be explained as a result of the provincial government's initiative to shut down fossil plants by 2014. In general, electricity generation from coal was the highest during the winter months due to weather restrictions on hydro and other was the highest during the winter in 2004, and during the summer months in 2005 and 2006. In addition, it was observed that the exporting of electricity to other provinces has been increasing between 2004 and 2006. Conversely, there has been a reduction in consumption of imported electricity over the years due to lower electricity demand by the Province of Ontario. On the other hand, wind generation increased by almost $57 \%$ in 2006 and hydro has slightly decreased between 2004 and 2006. Hydro generation was the highest 
during the spring months due to warmer temperatures in the Province of Ontario. It was also observed that the highest consumption of electricity for the Province of Ontario occurred during the winters of 2004 and 2006. It should be noted that in 2005, the electricity demand during the summer surpassed the winter.

In the next chapter, the hourly electricity supply and demand data explored in this chapter will be utilized to develop GHG emission factors. 


\section{GHG Analysis}

\subsection{Winter 2004, 2005, and 2006 Emissions}

It has been shown that GHG emission factors are related to provincial electricity generation. These factors are at their highest during peak hours as utilities rely on fossil based generation plants due to their ability to be turned on rapidly in comparison to other generation types. In this study, hourly GHG emission factors were developed to realize the true GHG reduction potential for the Province of Ontario, as well as to help determine the shifting of energy demand from peak hours to off-peak hours, thus help lowering emissions. Figure 6-1, Figure 6-2, and Figure 6-3 show hourly GHG emissions for the winters of 2004, 2005, and 2006. The highest GHG emissions occurred during January, most likely due to weather conditions that limit the use of hydro generated electricity during the winter, thus relying on fossil plants to compensate for this shortfall. The following profiles use the data from Chapter 5.

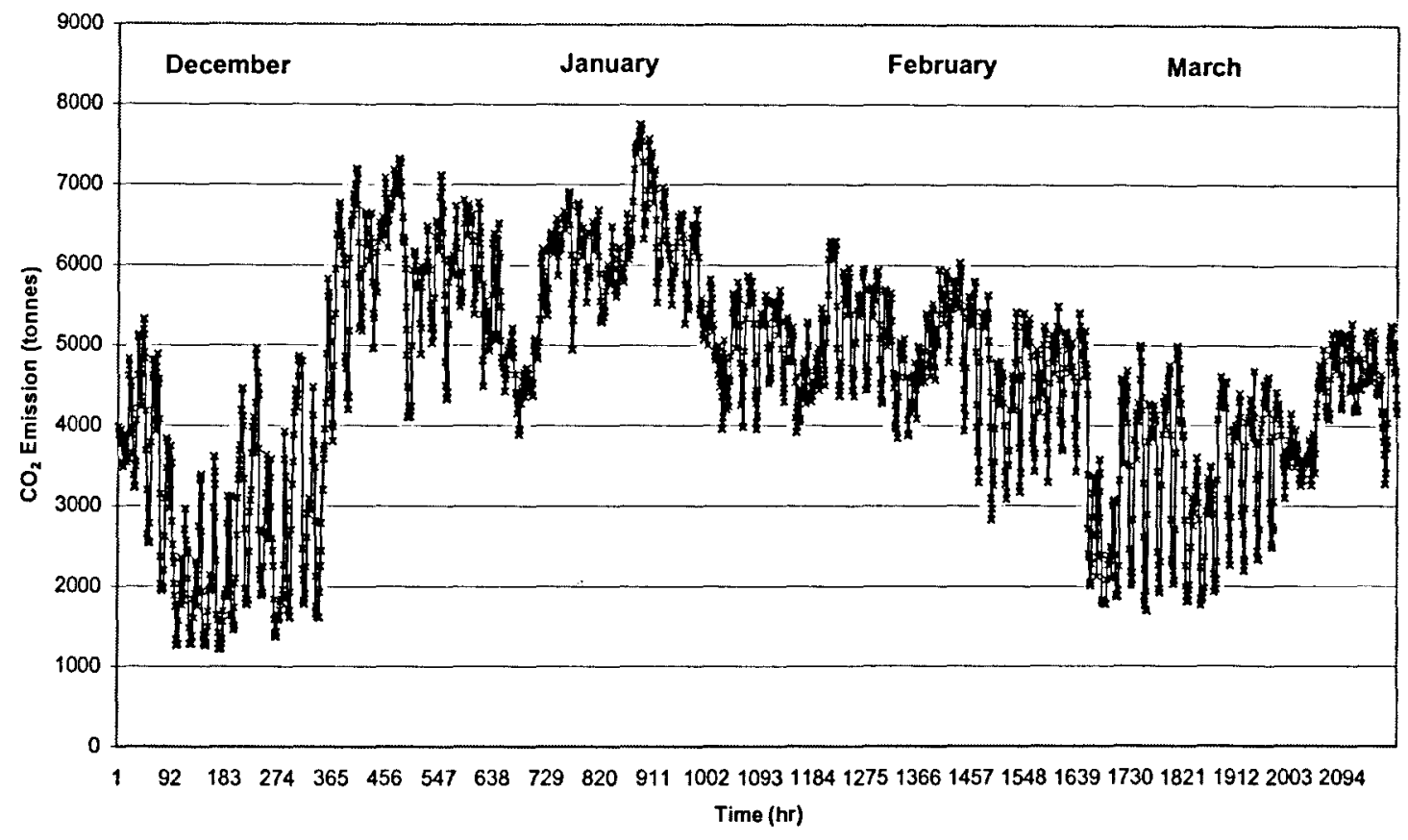

Figure 6-1: Hourly $\mathrm{CO}_{2}$ emissions - winter 2004 


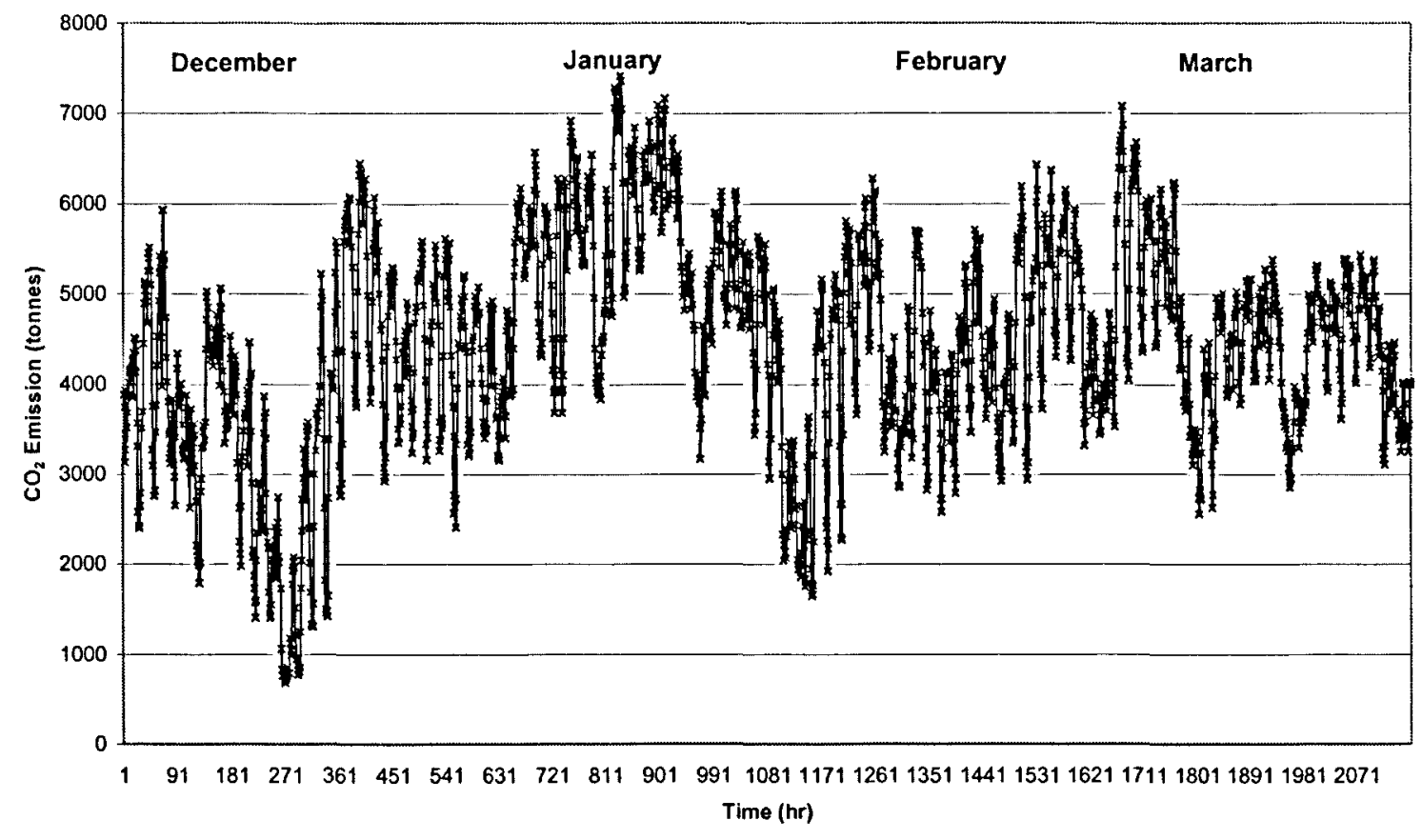

Figure 6-2: Hourly $\mathrm{CO}_{2}$ emissions - winter 2005

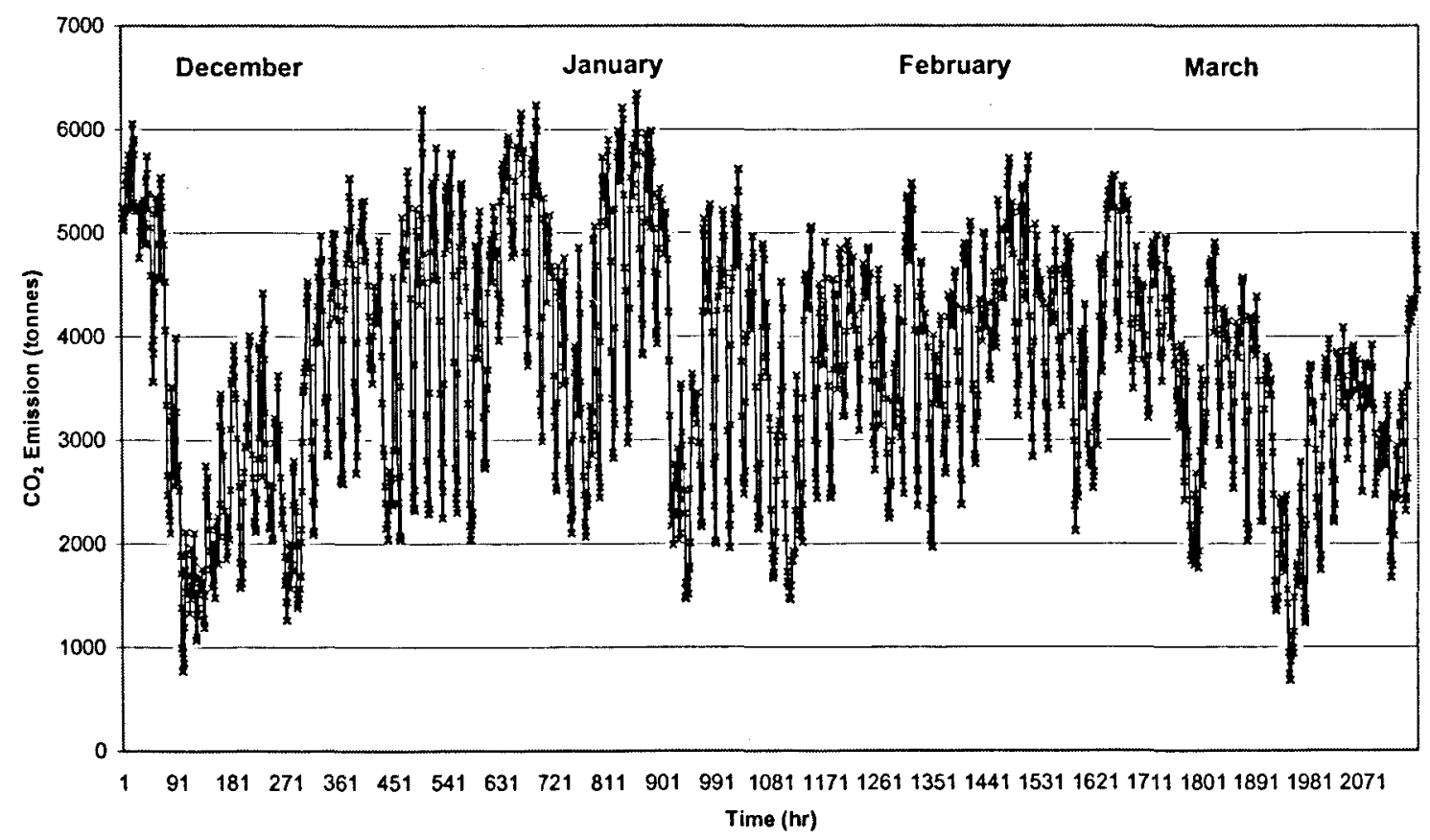

Figure 6-3: Hourly $\mathrm{CO}_{2}$ emissions - winter 2006 
Table 6-1 shows the total amount of GHG emissions for the winters of 2004, 2005, and 2006. It can be observed that $\mathrm{CO}_{2}$ emissions were the highest in 2004 , and have been decreasing in subsequent years, most likely due to the provincial government's initiative to phase out Coal plants by 2014. However, $\mathrm{SO}_{2}$ emissions increased by $10 \%$ in 2005 , but decreased by $37 \%$ in 2006 . NO emissions increased slightly in 2005 , and remained slightly the same in 2006 .

Table 6-1: GHG emissions from the power generation sector - winter 2004-2006

\begin{tabular}{|c|c|c|c|c|}
\hline \multicolumn{5}{|c|}{ Winter } \\
\hline \multirow{2}{*}{ Year } & \multicolumn{3}{|c|}{ Emissions (kt) } & Electricity Demand \\
\hline & $\mathrm{CO}_{2}$ & $\mathrm{SO}_{2}$ & No & (GWh) \\
\hline 2004 & 10023 & 36.99 & 9.11 & 40457 \\
\hline 2005 & 9616 & 41.16 & 9.49 & 40617 \\
\hline 2006 & 8049 & 25.79 & 9.39 & 39025 \\
\hline
\end{tabular}

\subsubsection{Winter Emission Factors}

The heart of the TDV proposal is a methodology for deriving hourly valuations for greenhouse gas emissions. The seasonal variability in emissions is due to different power generation mix and electricity demand throughout the year. The methodology for GHG emission valuation includes both seasonal averages and profile models. The resulting seasonal average and hourly valuations reward GHG emission reduction strategies and building energy efficiency dependent on time-of-use. In addition, TDV models for GHG costs will be developed in order to place a monetary value on emissions paid by either the customer or generator. Table 6-2 shows the average NGHGIF $_{\mathrm{A}}$ values for the winters of 2004, 2005, and 2006. The highest $\mathrm{CO}_{2}$ emission factor was in 2004 and has been slowly decreasing in subsequent years.

Table 6-2: Average Emission factors for winter 2004-2006

\begin{tabular}{|c|c|c|c|}
\hline \multicolumn{4}{|c|}{ Winter } \\
\hline \multirow{2}{*}{ Year } & \multicolumn{3}{|c|}{ NGHGIF $_{\mathbf{A}}(\mathrm{g} / \mathrm{kWh})$} \\
\cline { 2 - 4 } & $\mathrm{CO}_{2}$ & $\mathrm{SO}_{2}$ & $\mathrm{NO}$ \\
\hline 2004 & 248 & 0.91 & 0.23 \\
\hline 2005 & 231 & 0.99 & 0.23 \\
\hline 2006 & 196 & 0.63 & 0.23 \\
\hline
\end{tabular}


Table 6-3 and Figure 6-4 show TDV emission factors for the winters of 2004, 2005, and 2006. Emission factors are highest during the afternoon and evening hours.

Table 6-3: TDV emission factor comparison for winter 2004-2006

\begin{tabular}{|c|c|c|c|}
\hline \multicolumn{4}{|c|}{ Winter } \\
\hline \multicolumn{4}{|c|}{ TDV NGHGIF ${ }_{\mathrm{A}}(\mathrm{g}$ of $\mathrm{CO} 2 / \mathrm{kWh})$} \\
\hline Hour & 2004 & 2005 & 2006 \\
\hline 1 & 254.9 & 241.8 & 200.7 \\
\hline 2 & 254.8 & 234.8 & 191.4 \\
\hline 3 & 252.9 & 229.3 & 183.1 \\
\hline 4 & 250.9 & 226.8 & 179.8 \\
\hline 5 & 252.4 & 227.5 & 183.8 \\
\hline 6 & 255.3 & 231.9 & 186.5 \\
\hline 7 & 258.8 & 234.7 & 196.6 \\
\hline 8 & 262.5 & 240.9 & 208.5 \\
\hline 9 & 265.6 & 247.1 & 216.3 \\
\hline 10 & 266.8 & 250.5 & 219.7 \\
\hline 11 & 268.8 & 253.1 & 225.7 \\
\hline 12 & 270.9 & 254.8 & 228.5 \\
\hline 13 & 272.8 & 256.5 & 229.0 \\
\hline 14 & 272.8 & 256.5 & 227.8 \\
\hline 15 & 271.3 & 252.8 & 224.8 \\
\hline 16 & 268.8 & 246.5 & 219.2 \\
\hline 17 & 268.6 & 244.9 & 218.8 \\
\hline 18 & 270.9 & 250.3 & 224.4 \\
\hline 19 & 274.6 & 257.5 & 233.3 \\
\hline 20 & 273.4 & 258.5 & 235.3 \\
\hline 21 & 273.3 & 260.1 & 234.2 \\
\hline 22 & 271.4 & 259.2 & 229.1 \\
\hline 23 & 265.4 & 253.5 & 217.6 \\
\hline 24 & 255.3 & 243.3 & 207.8 \\
\hline
\end{tabular}

The TDV methodology assigns a value ( $\mathrm{g}$ of $\mathrm{CO}_{2} / \mathrm{kWh}$ ) to every hour of the year for a particular season. Table 6-3 shows that during the winter of 2006 at 4 p.m., for one $\mathrm{kWh}$ produced or reduced the emissions will be $219.2 \mathrm{~g}$ of $\mathrm{CO}_{2}$, while at 4 a.m. it would be 179.8 $\mathrm{g}$ of $\mathrm{CO}_{2}$, which shows a difference of $18 \%$ in just 12 hours. In addition, the maximum TDV values for the years 2004, 2005, and 2006 occurred at 7 p.m., 9 p.m., and 8 p.m., respectively. The corresponding $95 \%$ confidence interval was determined to be for each TDV hour $\pm 3.14, \pm 4.19$, and \pm 7.01 for the years 2004,2005 , and 2006 , respectively. 


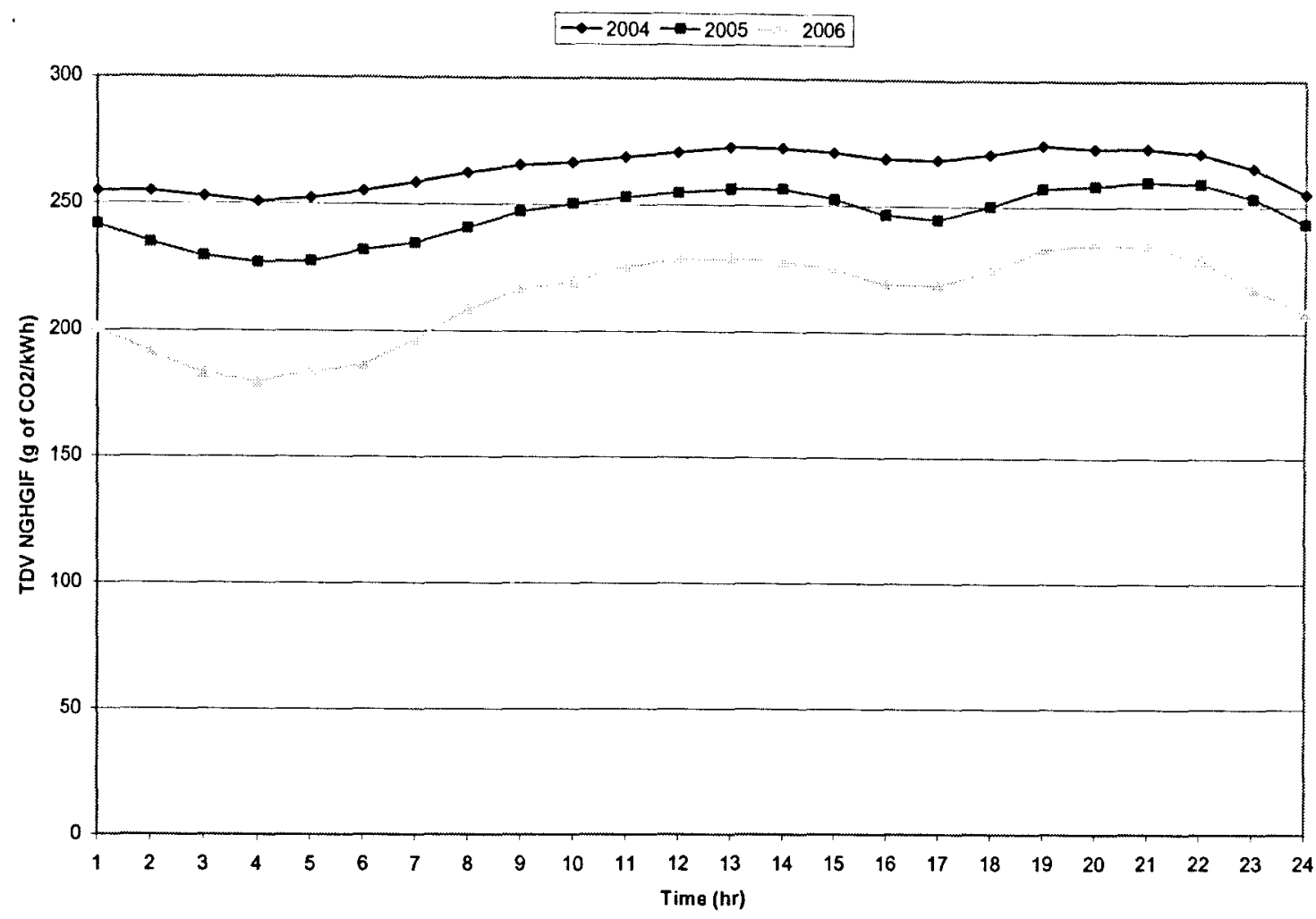

Figure 6-4: TDV emission factor profile comparison for winter 2004-2006

Monthly average GHG cost factors were developed for 2004, 2005, and 2006 based on flat rate, TOU, and wholesale pricing schemes as illustrated in Table 6-4, Table 6-5, and Table 6-6. These factors place a monetary value on GHG emissions. Cost factors have been increasing over the last three years and usually March has the highest value.

Table 6-4: Average GHG cost factors using flat rate pricing scheme 2004-2006

\begin{tabular}{|c|c|c|c|}
\hline \multicolumn{4}{|c|}{ NGHGCF $_{\text {Aelec, flat }}$ (\$/kg of CO $_{2}$ ) } \\
\hline Month & 2004 & 2005 & 2006 \\
\hline Jan & 0.372 & 0.467 & 0.494 \\
\hline Feb & 0.397 & 0.452 & 0.523 \\
\hline Mar & 0.495 & 0.443 & 0.587 \\
\hline
\end{tabular}


Table 6-5: Average GHG cost factors using TOU pricing scheme 2004-2006

\begin{tabular}{|c|c|c|c|}
\hline \multicolumn{4}{|c|}{ NGHGCF $_{\text {A elec, TOU }}$ (\$/kg of CO2) } \\
\hline Month & 2004 & 2005 & 2006 \\
\hline Jan & 0.363 & 0.448 & 0.481 \\
\hline Feb & 0.391 & 0.446 & 0.522 \\
\hline Mar & 0.490 & 0.439 & 0.579 \\
\hline
\end{tabular}

Table 6-6: Average GHG cost factors using wholesale pricing scheme 2004-2006

\begin{tabular}{|c|c|c|c|}
\hline \multicolumn{4}{|c|}{ NGHGCF $_{\text {A elec, }}$ wholesale (\$/kg of CO2) } \\
\hline Month & 2004 & 2005 & 2006 \\
\hline Jan & 0.233 & 0.245 & 0.259 \\
\hline Feb & 0.203 & 0.219 & 0.242 \\
\hline Mar & 0.228 & 0.262 & 0.274 \\
\hline
\end{tabular}

\subsubsection{Peak Day GHG Analysis for Winter 2004, 2005, and 2006}

GHG emissions were analyzed for all seasons and years. Figure 6-5 shows the $\mathrm{CO}_{2}$ emissions for the winter peak days for 2004, 2005, and 2006. $\mathrm{CO}_{2}$ emissions were highest during the afternoon hours.

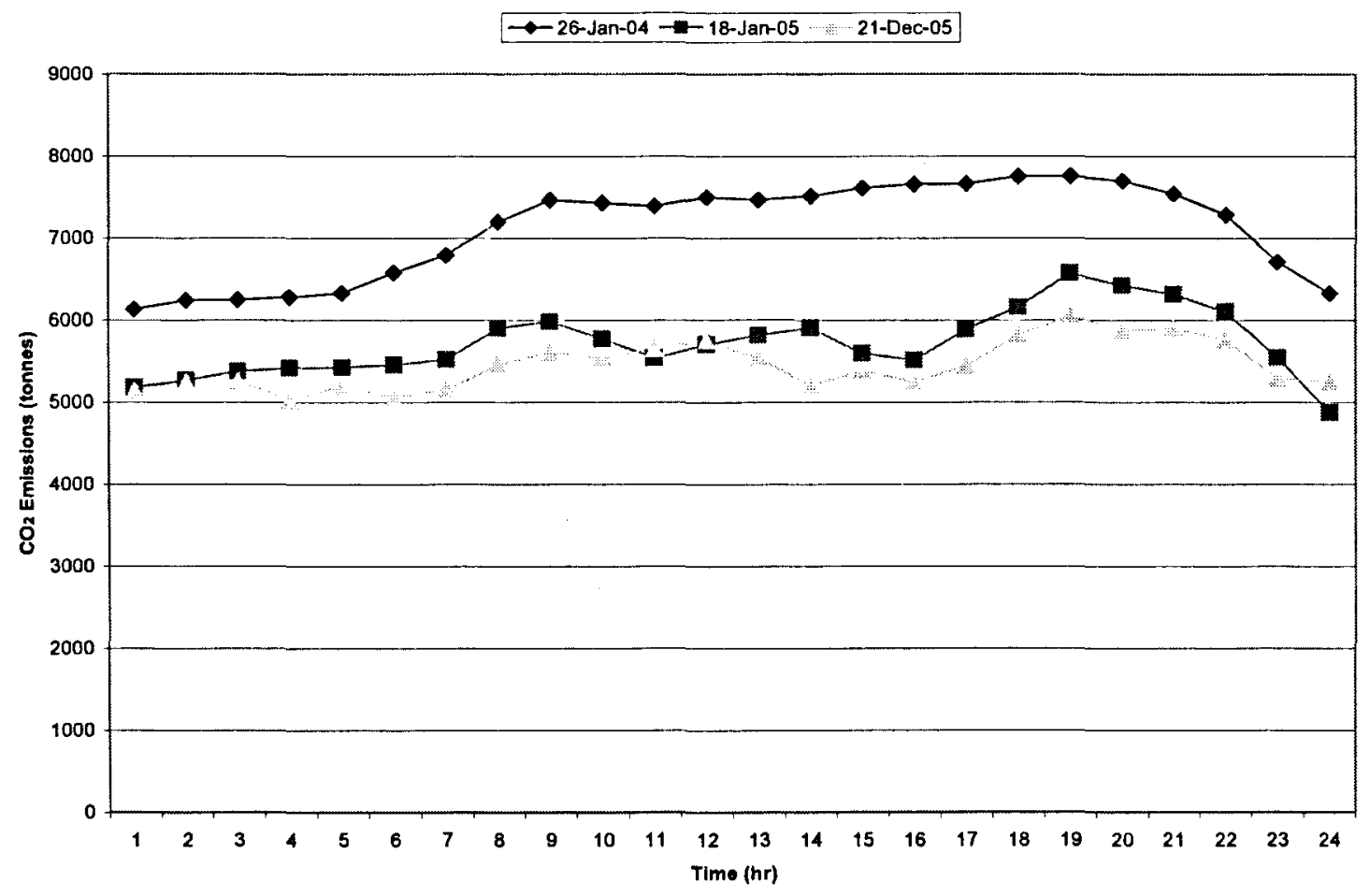

Figure 6-5: Hourly emissions during winter peak days for 2004, 2005, and 2006 
As illustrated in Table 6-7 $\mathrm{CO}_{2}$ emissions were the highest in 2004, and have decreased by $20 \%$ in 2005 , and $4.3 \%$ in 2006 . The decrease in emissions is most likely due to higher than normal temperatures for the Province of Ontario. As a result, the electricity demand for the province would decrease because less peak generated electricity would be required, which is usually provided by fossil plants.

Table 6-7: $\mathrm{CO}_{2}$ emissions during winter peak day for 2004, 2005, and 2006

\begin{tabular}{|c|c|c|}
\hline \multicolumn{3}{|c|}{ Winter } \\
\hline Year & Peak Day & Emissions (kt) \\
\hline 2004 & 26-Jan-04 & 171 \\
\hline 2005 & 18-Jan-05 & 137 \\
\hline 2006 & $21-$ Dec-05 & 131 \\
\hline
\end{tabular}

Figure 6-6 shows the $\mathrm{CO}_{2}$ emission factor profile for the winter peak days for 2004, 2005, and 2006. $\mathrm{CO}_{2}$ emission factors did not very much throughout the day.

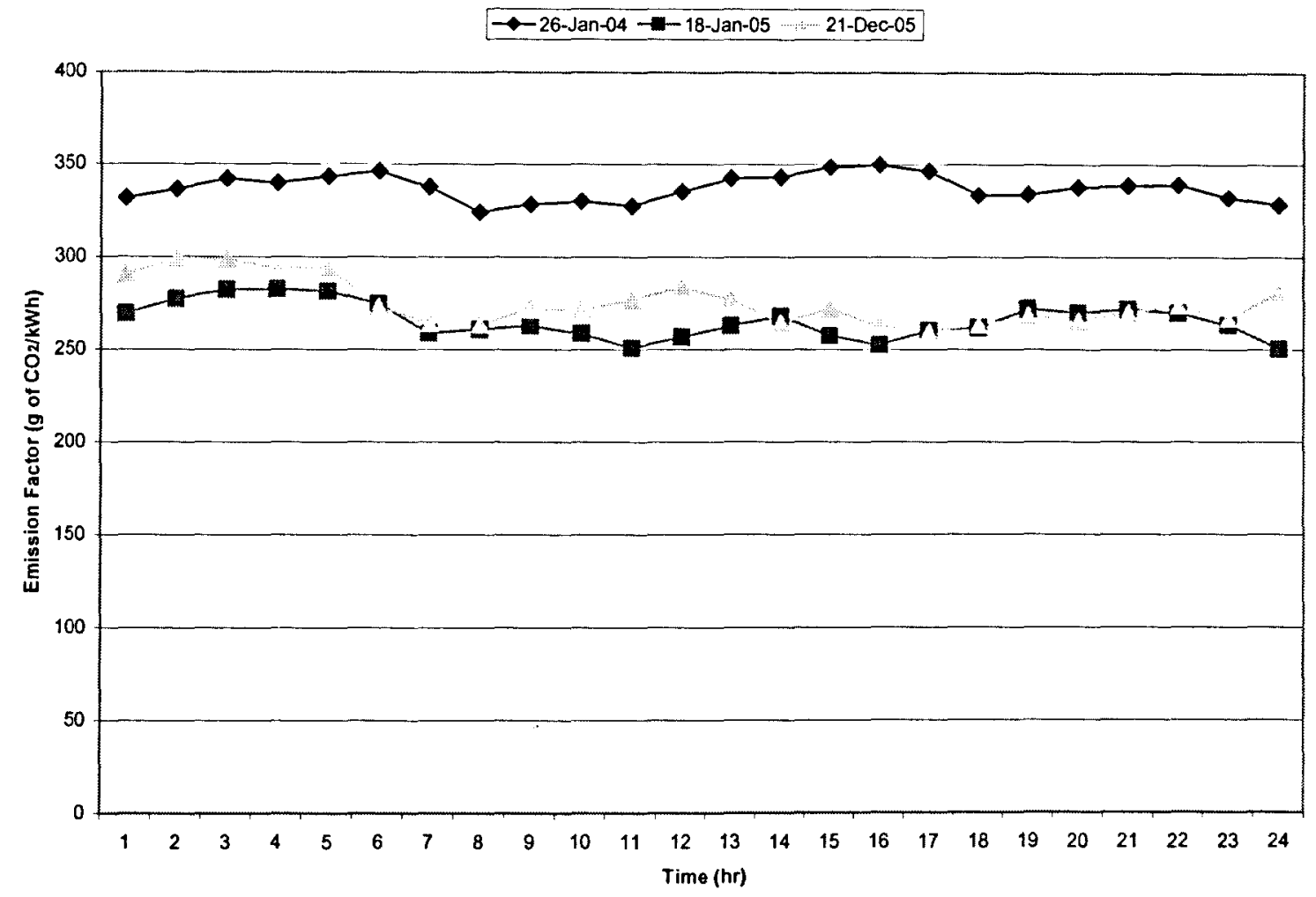

Figure 6-6: Hourly $\mathrm{CO}_{2}$ emission factors during peak winter day 2004-2006 
As illustrated in Table 6-8 average emission factors for the peak winter day were the highest in 2004 , and decreased by $21 \%$ in 2005 , but increased by $3.2 \%$ in 2006 .

Table 6-8: Average emission factors during peak winter day 2004-2006

\begin{tabular}{|c|c|c|}
\hline \multicolumn{3}{|c|}{ Winter } \\
\hline Year & Peak Day & NGHGIF $_{\text {A }}$ g of CO2/kWh) \\
\hline 2004 & 26-Jan-04 & 337 \\
\hline 2005 & 18-Jan-05 & 266 \\
\hline 2006 & 21-Dec-05 & 275 \\
\hline
\end{tabular}

\subsection{Spring 2004, 2005, and 2006 Emissions}

Figure 6-7, Figure 6-8, and Figure 6-9 show hourly GHG emissions for the springs of 2004, 2005, and 2006. The highest GHG emissions occurred during June.

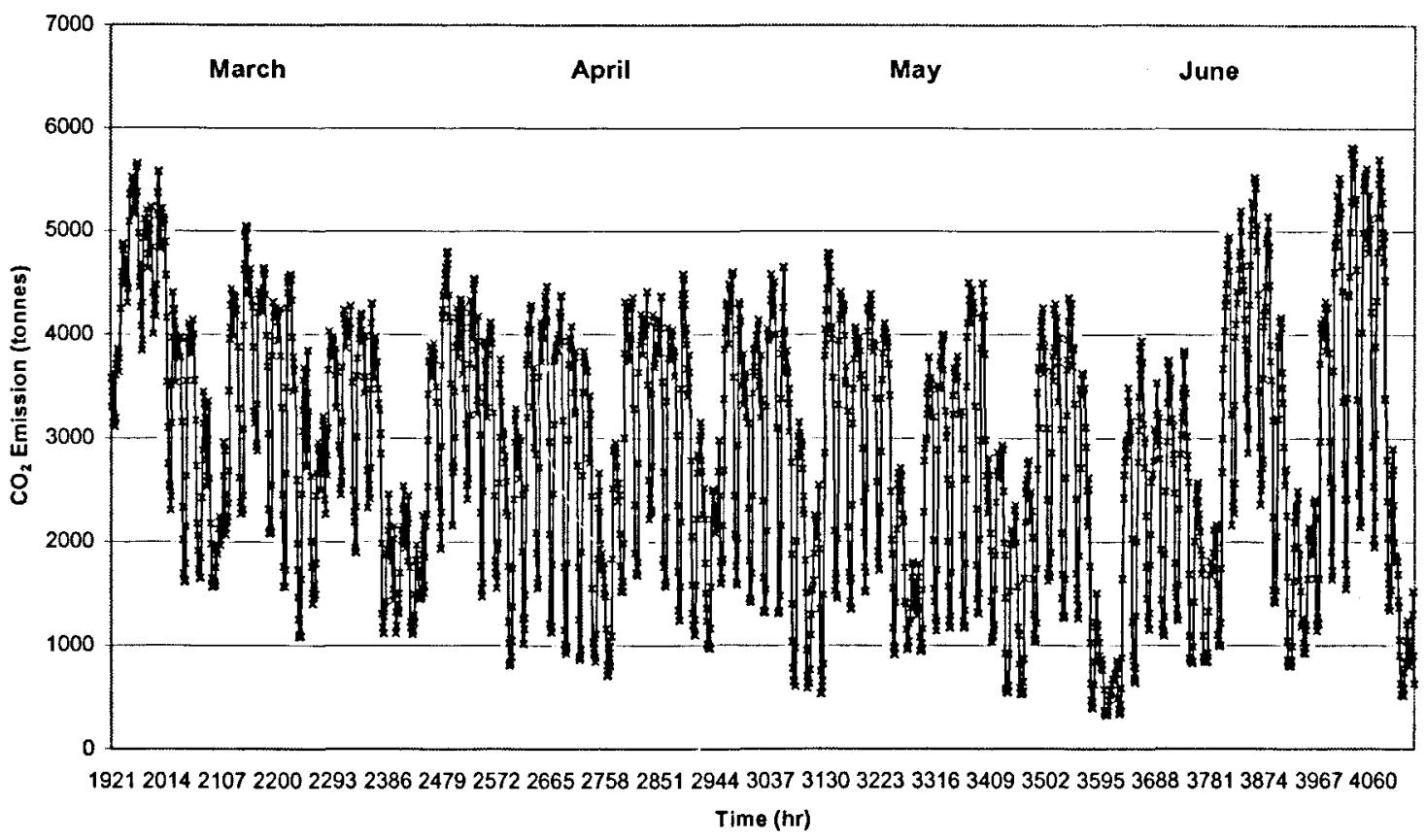

Figure 6-7: Hourly $\mathrm{CO}_{2}$ emissions - spring 2004 


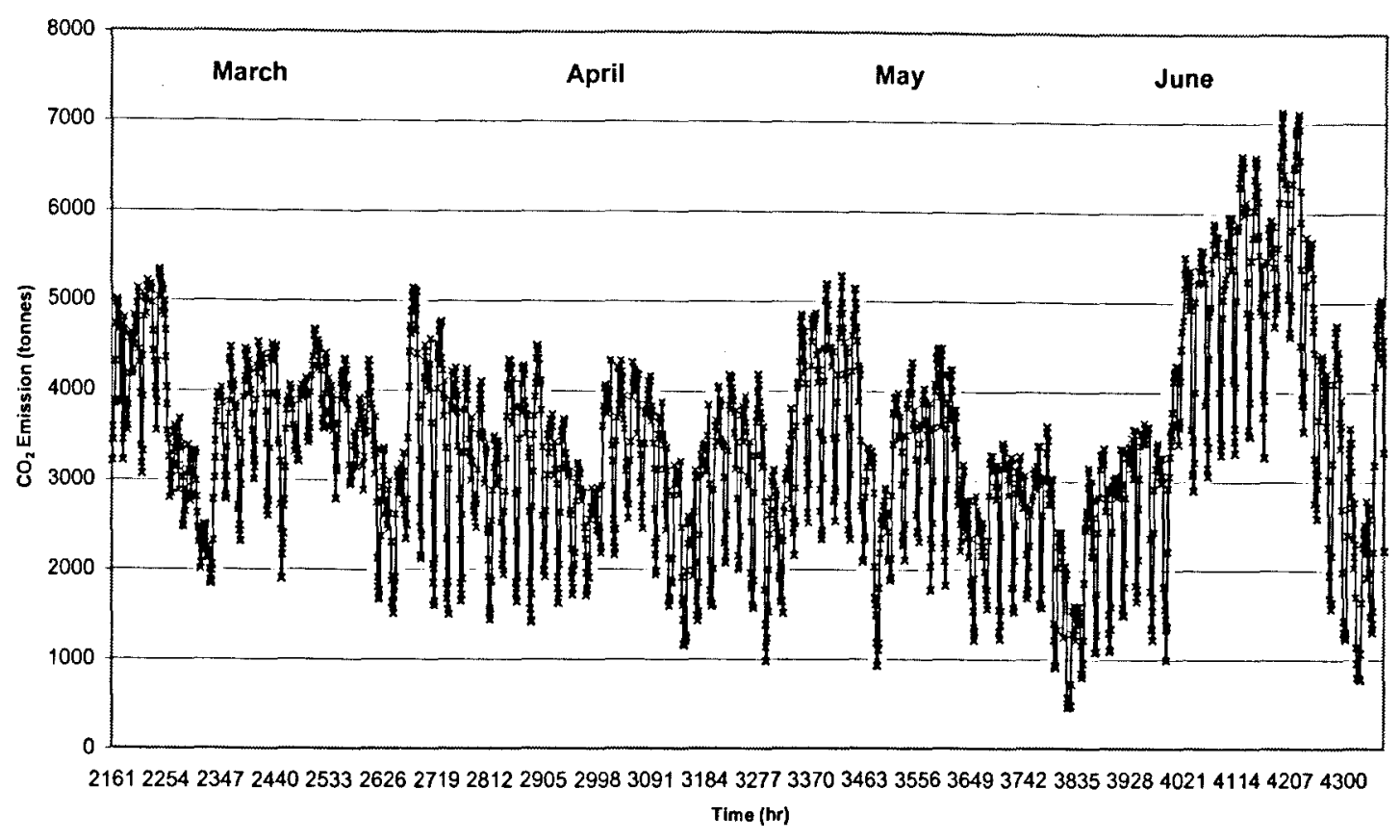

Figure 6-8: Hourly $\mathrm{CO}_{2}$ emissions - spring 2005

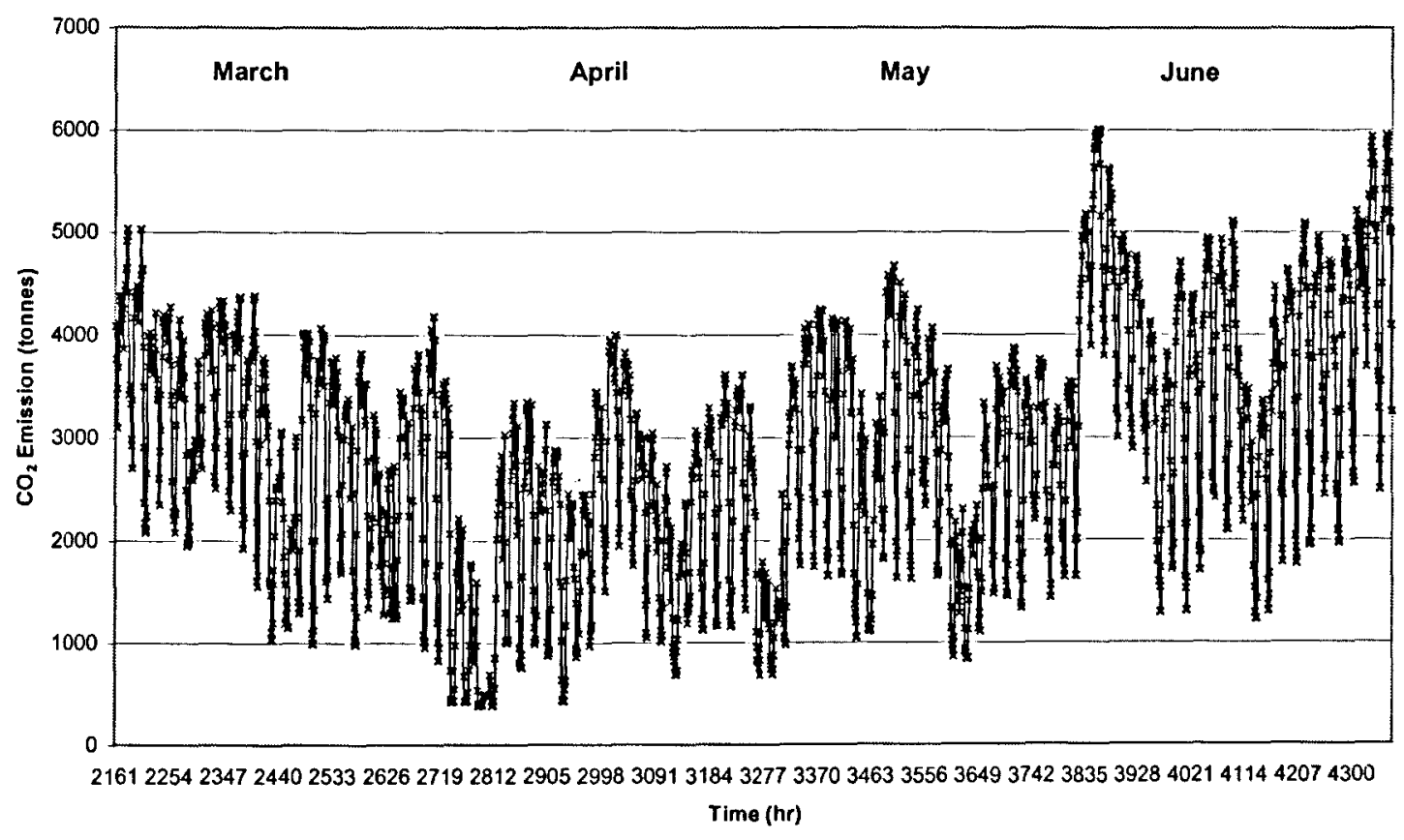

Figure 6-9: $\mathrm{Hourly} \mathrm{CO}_{2}$ emissions - spring 2006 
Table 6-9 shows the total amount of GHG emissions for the springs of 2004, 2005, and 2006. It can be observed that $\mathrm{CO}_{2}$ emissions increased by $16 \%$ in 2005 , but decreased in 2006 back to approximately 2004 levels. $\mathrm{SO}_{2}$ emissions increased by $34 \%$ in 2005 , but decreased in 2006 below 2004 levels. NO emissions increased by $25 \%$ in 2005 , and remained unchanged for 2006. It appears that an abnormal event during 2005 such as a change in weather patterns, or unplanned power generation outage could have caused this increase in 2005.

Table 6-9: GIIG emissions from the power generation sector - spring 2004-2006

\begin{tabular}{|c|c|c|c|c|}
\hline \multicolumn{5}{|c|}{ Spring } \\
\hline \multirow{2}{*}{ Year } & \multicolumn{3}{|c|}{ Emissions (kt) } & Electricity Demand \\
\cline { 2 - 5 } & $\mathrm{CO}_{2}$ & $\mathrm{SO}_{2}$ & NO & (GWh) \\
\hline 2004 & 6309 & 22 & 5.64 & 35645 \\
\hline 2005 & 7501 & 33.15 & 7.59 & 36489 \\
\hline 2006 & 6416 & 18.34 & 7.41 & 36017 \\
\hline
\end{tabular}

\subsubsection{Spring Emission Factors}

Table 6-10 shows the average NGHGIF Aalues for the springs of 2004, 2005, and 2006. The highest $\mathrm{CO}_{2}$ emission factor was in 2005, but decreased back to 2004 levels in 2006 .

Table 6-10: Average Emission factors for spring 2004-2006

\begin{tabular}{|c|c|c|c|}
\hline \multicolumn{4}{|c|}{ Spring } \\
\hline \multirow{2}{*}{ Year } & \multicolumn{3}{|c|}{ NGHGIF $_{\mathrm{A}}(\mathrm{g} / \mathbf{k W h})$} \\
\cline { 2 - 4 } & $\mathrm{CO}_{2}$ & $\mathrm{SO}_{2}$ & NO \\
\hline 2004 & 164 & 0.57 & 0.15 \\
\hline 2005 & 205 & 0.90 & 0.21 \\
\hline 2006 & 164 & 0.47 & 0.19 \\
\hline
\end{tabular}

Table 6-11 and Figure 6-10 show TDV emission factors for the winters of 2004, 2005, and 2006. Emission factors are highest during the afternoon hours. 
Table 6-11: TDV emission factor comparison for spring 2004-2006

\begin{tabular}{|c|c|c|c|}
\hline \multicolumn{4}{|c|}{ Spring } \\
\hline \multicolumn{4}{|c|}{ TDV NGHGIF $\left(\mathrm{g}\right.$ of $\left.\mathrm{CO}_{2} / \mathrm{kWh}\right)$} \\
\hline Hour & 2004 & 2005 & 2006 \\
\hline 1 & 133.3 & 192.3 & 147.0 \\
\hline 2 & 129.1 & 188.5 & 138.9 \\
\hline 3 & 126.6 & 180.0 & 132.9 \\
\hline 4 & 125.6 & 179.0 & 130.8 \\
\hline 5 & 130.7 & 186.8 & 140.2 \\
\hline 6 & 148.2 & 201.2 & 153.0 \\
\hline 7 & 171.0 & 213.2 & 171.3 \\
\hline 8 & 192.4 & 228.5 & 189.7 \\
\hline 9 & 203.0 & 234.2 & 194.5 \\
\hline 10 & 208.7 & 237.0 & 198.7 \\
\hline 11 & 213.2 & 239.8 & 202.8 \\
\hline 12 & 214.8 & 241.8 & 204.5 \\
\hline 13 & 215.5 & 244.3 & 204.4 \\
\hline 14 & 215.2 & 244.1 & 203.4 \\
\hline 15 & 212.3 & 242.0 & 201.3 \\
\hline 16 & 212.4 & 240.8 & 200.7 \\
\hline 17 & 212.4 & 240.5 & 201.1 \\
\hline 18 & 205.0 & 234.4 & 195.9 \\
\hline 19 & 198.5 & 224.8 & 190.5 \\
\hline 20 & 204.2 & 228.6 & 198.7 \\
\hline 21 & 206.5 & 238.3 & 203.1 \\
\hline 22 & 190.3 & 231.9 & 187.3 \\
\hline 23 & 161.5 & 218.2 & 170.4 \\
\hline 24 & 138.8 & 206.0 & 155.6 \\
\hline
\end{tabular}

The TDV methodology assigns a value ( $\mathrm{g}$ of $\mathrm{CO}_{2} / \mathrm{kWh}$ ) to every hour of the year for a particular season. Table 6-11 shows that during the spring of 2006 at 4 p.m., for one kWh produced or reduced the emissions will be $200.7 \mathrm{~g}$ of $\mathrm{CO}_{2}$, while at $4 \mathrm{a} . \mathrm{m}$. it would be 130.8 $\mathrm{g}$ of $\mathrm{CO}_{2}$, which shows a difference of $35 \%$ in just 12 hours. In addition, the maximum TDV values for both years 2004, and 2005, occurred at 1 p.m., and at 12 p.m., for the year 2006 . The corresponding $95 \%$ confidence interval was determined to be for each TDV hour \pm 13.63 , \pm 8.72 , and \pm 10.33 for the years 2004,2005 , and 2006 , respectively. 


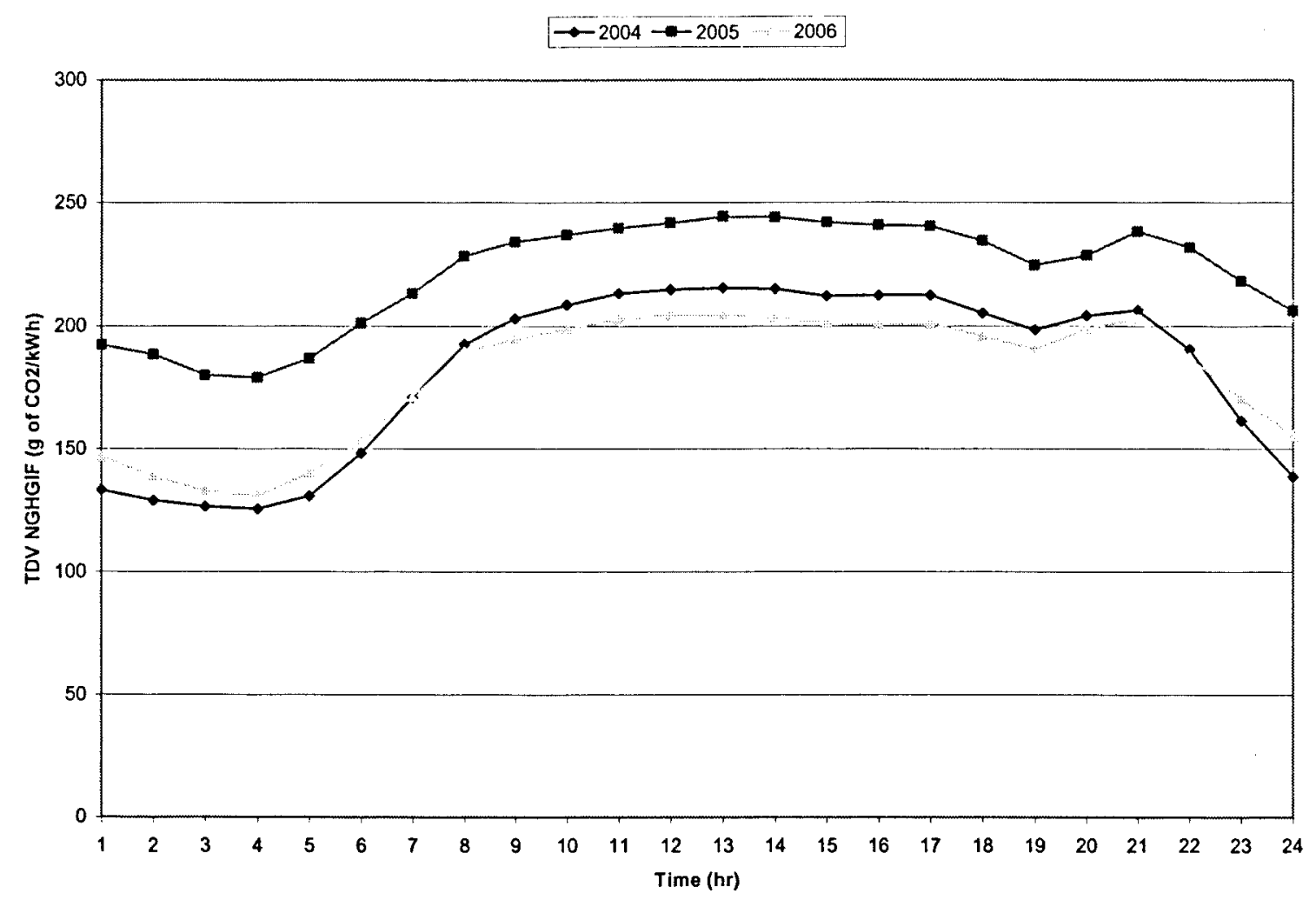

Figure 6-10: TDV emission factor profile comparison for spring 2004-2006

Monthly average GHG cost factors were developed for 2004, 2005, and 2006 based on flat rate, TOU, and wholesale pricing schemes as illustrated in Table 6-12, Table 6-13, and Table 6-14. These factors place a monetary value on GHG emissions. Cost factors increased in May, but decreased in June.

Table 6-12: Average GHG cost factors using flat rate pricing scheme 2004-2006

\begin{tabular}{|c|c|c|c|}
\hline \multicolumn{4}{|c|}{ NGHGCF } \\
Aelec, flat $\left(\$ / k g\right.$ of CO$_{2}$ ) \\
\hline Month & 2004 & 2005 & $\mathbf{2 0 0 6}$ \\
\hline Apr & 0.660 & 0.497 & 1.037 \\
\hline May & 0.916 & 0.606 & 0.686 \\
\hline Jun & 0.811 & 0.464 & 0.482 \\
\hline
\end{tabular}


Table 6-13: Average GHG cost factors using TOU pricing scheme 2004-2006

\begin{tabular}{|c|c|c|c|}
\hline \multicolumn{4}{|c|}{ NGHGCF $_{\text {Aelec, TOu }}(\$ / \mathrm{kg}$ of CO2) } \\
\hline Month & $\mathbf{2 0 0 4}$ & $\mathbf{2 0 0 5}$ & $\mathbf{2 0 0 6}$ \\
\hline Apr & 0.613 & 0.492 & 0.974 \\
\hline May & 0.818 & 0.571 & 0.646 \\
\hline Jun & 0.748 & 0.451 & 0.453 \\
\hline
\end{tabular}

Table 6-14: Average GHG cost factors using wholesale pricing scheme 2004-2006

\begin{tabular}{|c|c|c|c|}
\hline \multicolumn{4}{|c|}{ NGHGCF $_{\text {A elec, }}$ wholesale $\left(\$ / \mathrm{kg}\right.$ of $\mathrm{CO}_{2}$ ) } \\
\hline Month & $\mathbf{2 0 0 4}$ & $\mathbf{2 0 0 5}$ & $\mathbf{2 0 0 6}$ \\
\hline Apr & 0.274 & 0.294 & 0.353 \\
\hline May & 0.349 & 0.296 & 0.286 \\
\hline Jun & 0.312 & 0.272 & 0.210 \\
\hline
\end{tabular}

\subsubsection{Peak Day GHG Analysis for Spring 2004, 2005, and 2006}

Figure 6-11 shows the $\mathrm{CO}_{2}$ emissions for the spring peak days for 2004, 2005, and 2006 . $\mathrm{CO}_{2}$ emissions were highest during the afternoon and beginning evening hours.

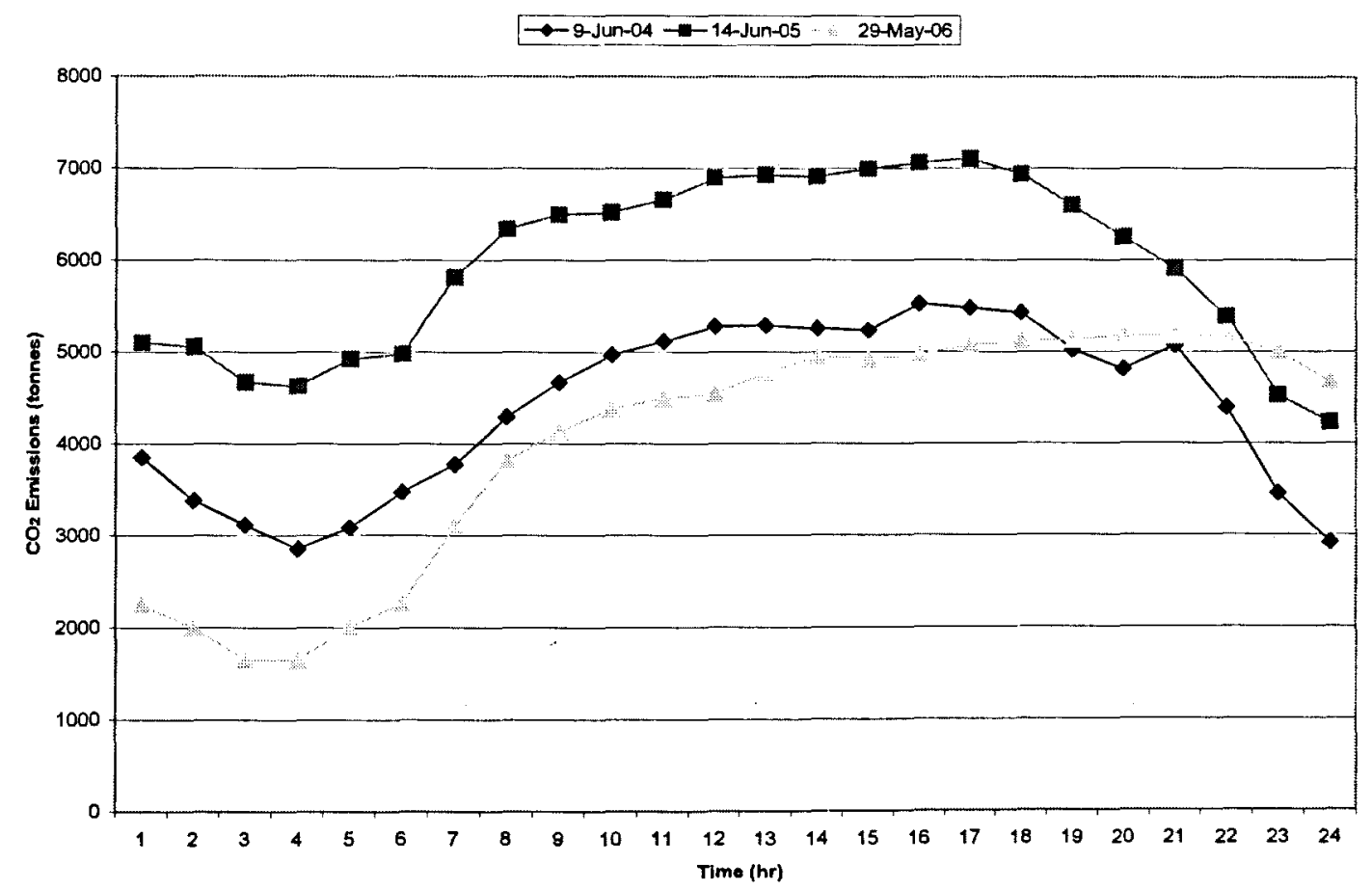

Figure 6-11: Hourly emissions during spring peak days for 2004, 2005, and 2006 
As illustrated in Table 6-15 $\mathrm{CO}_{2}$ emissions were the highest in $2005 . \mathrm{CO}_{2}$ emissions increased by $26 \%$ in 2005 , but decreased by $33 \%$ in 2006 .

Table 6-15: $\mathrm{CO}_{2}$ emissions during spring peak day for 2004, 2005, and 2006

\begin{tabular}{|c|c|c|}
\hline \multicolumn{2}{|c|}{ Spring } \\
\hline Year & Peak Day & Emissions (kt) \\
\hline 2004 & 9 -Jun-04 & 106 \\
\hline 2005 & 14-Jun-05 & 143 \\
\hline 2006 & 29 -May-06 & 96 \\
\hline
\end{tabular}

Figure 6-12 shows the $\mathrm{CO}_{2}$ emission factor profile for the spring peak days for 2004,2005 , and 2006. $\mathrm{CO}_{2}$ emission factors were highest during the afternoon hours.

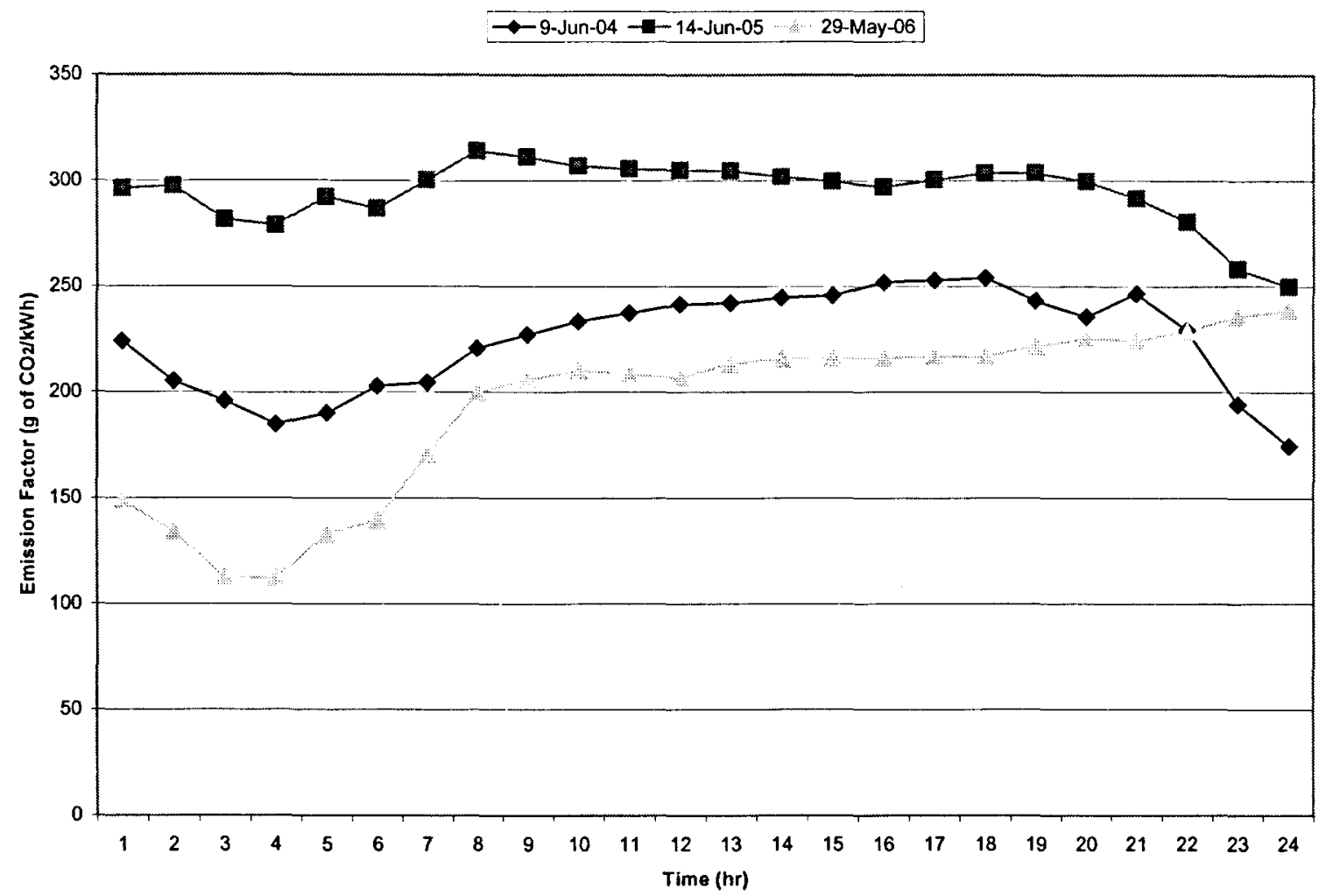

Figure 6-12: Hourly $\mathrm{CO}_{2}$ emission factors during peak spring day 2004-2006

As illustrated in Table 6-16 average emission factors for the peak spring day were the highest in 2005 , and decreased by $34 \%$ in 2006 . 
Table 6-16: Average emission factors during peak spring day 2004-2006

\begin{tabular}{|c|c|c|}
\hline \multicolumn{2}{|c|}{ Spring } \\
\hline Year & Peak Day & NGHGIF $_{\text {A }}$ g of CO2/kWh) \\
\hline 2004 & 9 -Jun-04 & 224 \\
\hline 2005 & $14-J u n-05$ & 295 \\
\hline 2006 & 29-May-06 & 194 \\
\hline
\end{tabular}

\subsection{Summer 2004, 2005, and 2006 Emissions}

Figure 6-13, Figure 6-14, and Figure 6-15 show hourly GHG emissions for the summers of 2004, 2005, and 2006. The highest GHG emissions occurred during July and beginning of August.

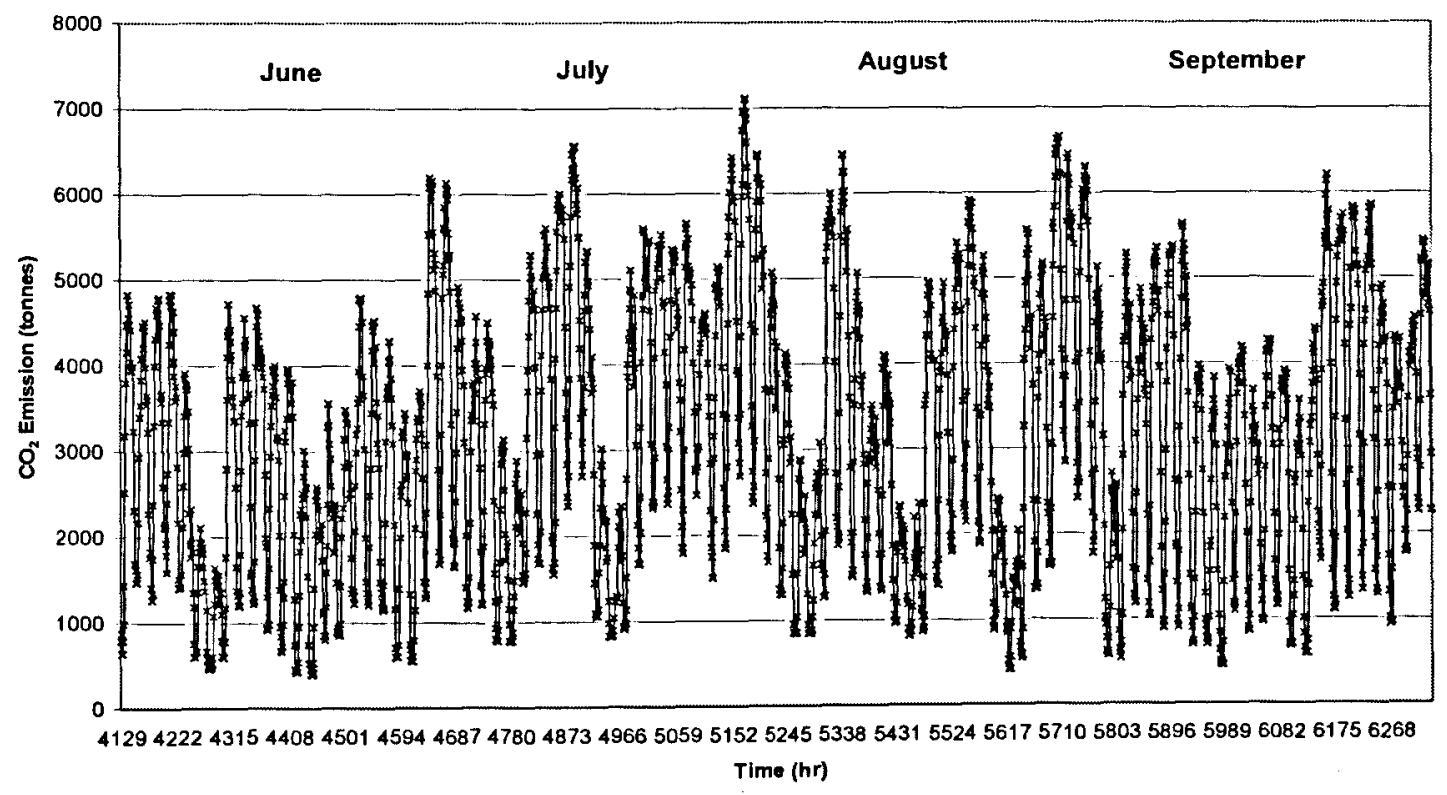

Figure 6-13: Hourly $\mathrm{CO}_{2}$ emissions - summer 2004 


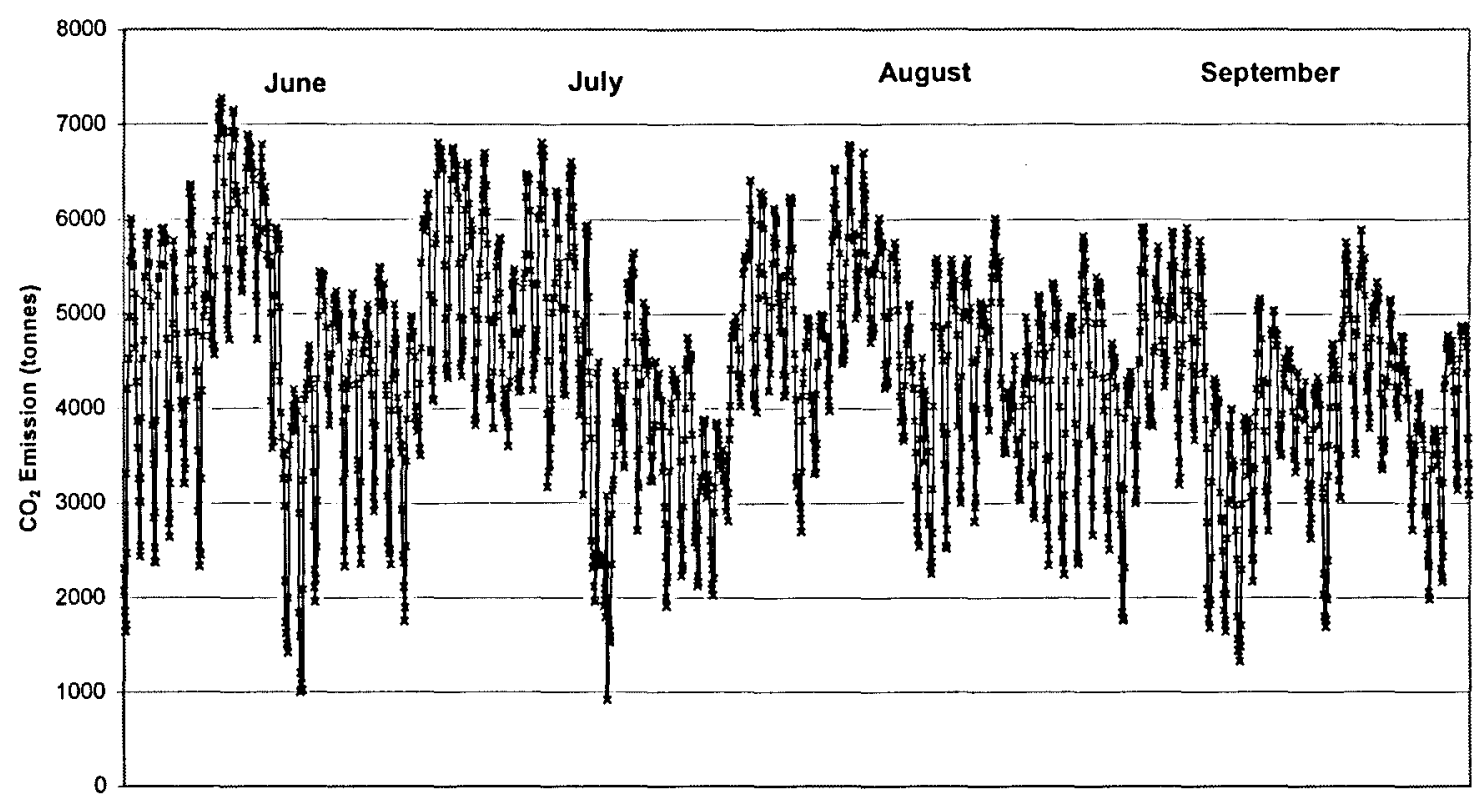

436944624555464847414834492750205113520652995392548555785671576458575950604361366229632264156508 Time (hr)

Figure 6-14: Hourly $\mathrm{CO}_{2}$ emissions - summer 2005

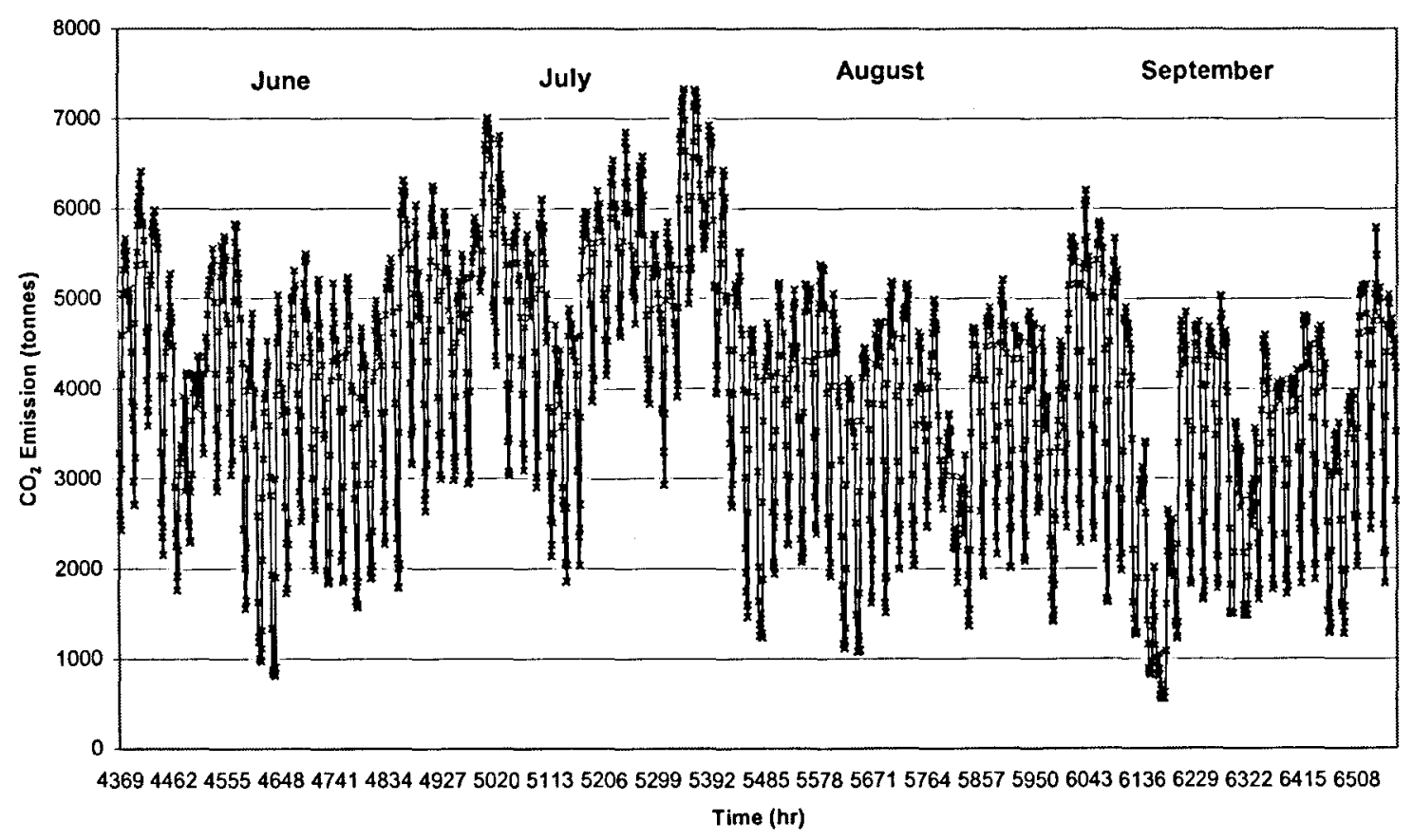

Figure 6-15: Hourly $\mathrm{CO}_{2}$ emissions - summer 2006 
Table 6-17 shows the total amount of GHG emissions for the summers of 2004, 2005, and 2006. It can be observed that $\mathrm{CO}_{2}$ emissions increased by $29 \%$ in 2005 , but decteased by $9 \%$ in 2006. $\mathrm{SO}_{2}$ emissions increased by $43 \%$ in 2005, but decreased in 2006 back to 2004 levels. NO emissions increased by $38 \%$ in 2005 , and remained unchanged for 2006 . It appears that during 2005 more coal plants were utilized due to weather changes or unplanned outages.

Table 6-17: GHG emissions from the power generation sector - summer 2004-2006

\begin{tabular}{|c|c|c|c|c|}
\hline \multicolumn{5}{|c|}{ Summer } \\
\hline \multirow{2}{*}{ Year } & \multicolumn{3}{|c|}{ Emissions (kt) } & Electricity Demand \\
\cline { 2 - 5 } & $\mathrm{CO}_{2}$ & $\mathrm{SO}_{2}$ & NO & (GWh) \\
\hline 2004 & 6933 & 24.95 & 6.25 & 37277 \\
\hline 2005 & 9787 & 44 & 10.07 & 40762 \\
\hline 2006 & 8881 & 26.12 & 10.34 & 38971 \\
\hline
\end{tabular}

\subsubsection{Summer Emission Factors}

Table 6-18 shows the average NGHGIF Aalues for the summers of 2004, 2005, and 2006. The highest $\mathrm{CO}_{2}$ emission factor was in 2005 , but decreased by $11.2 \%$ in 2006 .

Table 6-18: Average Emission factors for summer 2004-2006

\begin{tabular}{|c|c|c|c|}
\hline \multicolumn{4}{|c|}{ Summer } \\
\hline \multirow{2}{*}{ Year } & \multicolumn{3}{|c|}{ NGHGIF $_{\mathbf{A}}(\mathrm{g} / \mathrm{kWh})$} \\
\cline { 2 - 4 } & $\mathrm{CO}_{2}$ & $\mathrm{SO}_{2}$ & $\mathrm{NO}$ \\
\hline 2004 & 174 & 0.62 & 0.16 \\
\hline 2005 & 241 & 1.08 & 0.25 \\
\hline 2006 & 214 & 0.63 & 0.25 \\
\hline
\end{tabular}

Table 6-19 and Figure 6-16 show TDV emission factors for the summers of 2004, 2005, and 2006. Emission factors are highest during the afternoon hours. 
Table 6-19: TDV emission factor comparison for summer 2004-2006

\begin{tabular}{|c|c|c|c|}
\hline \multicolumn{4}{|c|}{ Summer } \\
\hline \multicolumn{4}{|c|}{ TDV NGHGIF $_{\mathrm{A}}(\mathrm{g}$ of $\mathrm{CO} 2 / \mathrm{kWh})$} \\
\hline Hour & 2004 & 2005 & 2006 \\
\hline 1 & 129.4 & 244.9 & 199.8 \\
\hline 2 & 119.8 & 236.6 & 186.5 \\
\hline 3 & 112.5 & 227.6 & 175.2 \\
\hline 4 & 109.9 & 224.1 & 173.2 \\
\hline 5 & 114.3 & 225.6 & 181.9 \\
\hline 6 & 134.7 & 229.1 & 189.5 \\
\hline 7 & 159.5 & 232.4 & 202.1 \\
\hline 8 & 187.5 & 251.1 & 227.3 \\
\hline 9 & 205.0 & 262.4 & 243.1 \\
\hline 10 & 220.1 & 268.1 & 250.7 \\
\hline 11 & 228.3 & 270.4 & 254.0 \\
\hline 12 & 234.5 & 273.4 & 256.3 \\
\hline 13 & 237.8 & 276.7 & 256.3 \\
\hline 14 & 236.6 & 276.4 & 254.6 \\
\hline 15 & 234.1 & 275.3 & 251.0 \\
\hline 16 & 234.7 & 273.5 & 251.3 \\
\hline 17 & 234.4 & 272.4 & 252.9 \\
\hline 18 & 228.5 & 272.1 & 252.0 \\
\hline 19 & 218.7 & 267.5 & 248.3 \\
\hline 20 & 223.3 & 267.3 & 251.3 \\
\hline 21 & 226.3 & 269.8 & 252.6 \\
\hline 22 & 209.7 & 264.3 & 245.7 \\
\hline 23 & 176.2 & 249.8 & 236.9 \\
\hline 24 & 146.7 & 248.7 & 214.9 \\
\hline
\end{tabular}

The TDV methodology assigns a value ( $\mathrm{g}$ of $\mathrm{CO}_{2} / \mathrm{kWh}$ ) to every hour of the year for a particular season. Table 6-19 shows that during the summer of 2006 at 4 p.m., for one kWh produced or reduced the emissions will be $251.3 \mathrm{~g}$ of $\mathrm{CO}_{2}$, while at $4 \mathrm{a}$.m. it would be 173.2 $\mathrm{g}$ of $\mathrm{CO}_{2}$, which shows a difference of $31 \%$ in just 12 hours. In addition, the maximum TDV values for years 2004, 2005, and 2006 occurred at 1 p.m. The corresponding $95 \%$ confidence interval was determined to be for each TDV hour $\pm 18.78, \pm 7.26$, and \pm 11.73 for the years 2004,2005 , and 2006, respectively. 


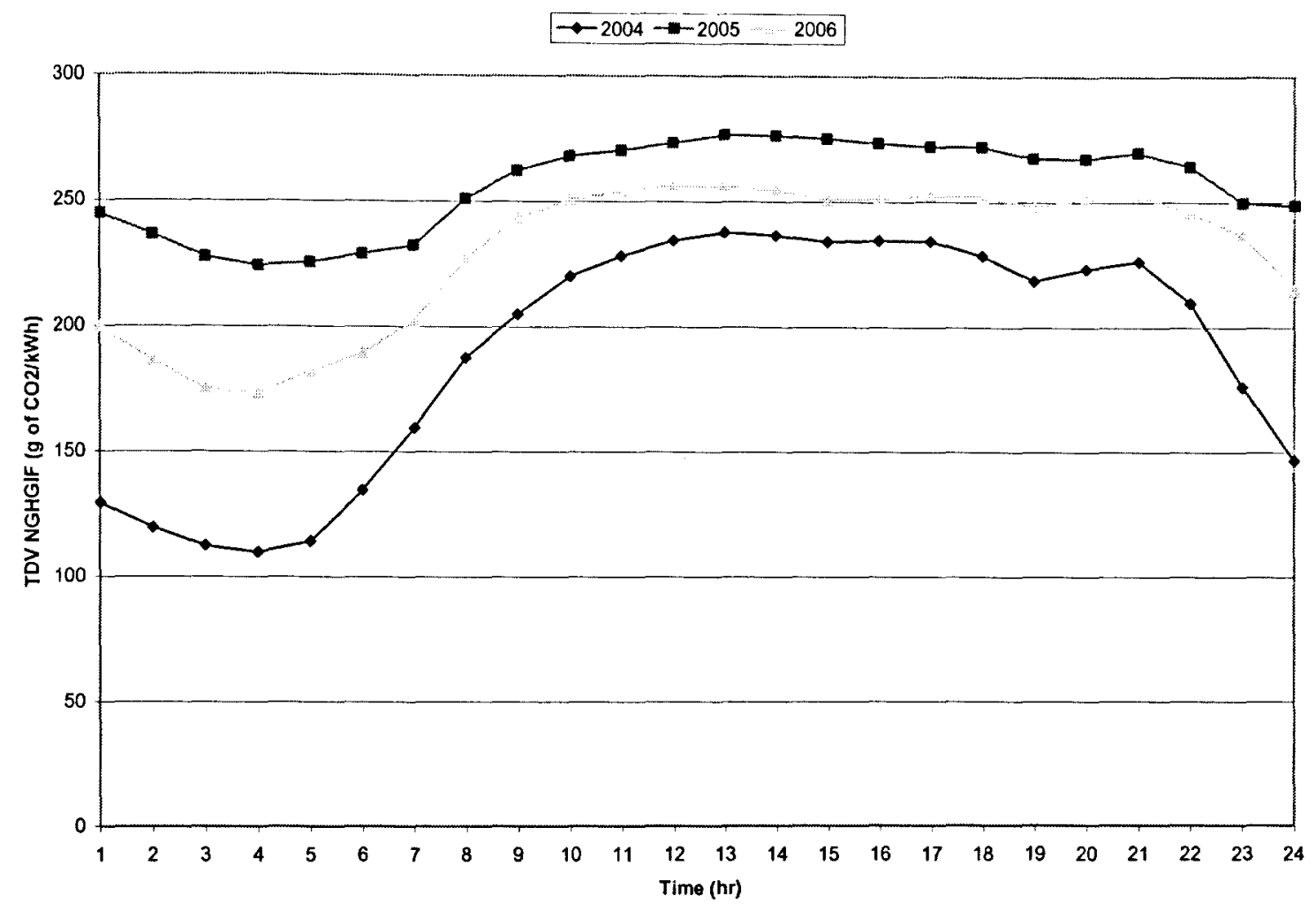

Figure 6-16: TDV emission factor profile comparison for summer 2004-2006

Monthly average GHG cost factors were developed for 2004, 2005, and 2006 based on flat rate, TOU, and wholesale pricing schemes as illustrated in Table 6-20, Table 6-21, and Table 6-22. Cost factors were the highest during July and August of 2004 for the flat rate electricity pricing scheme, TOU pricing scheme, and August and September of 2005 for the wholesale pricing scheme.

Table 6-20: Average GHG cost factors using flat rate pricing scheme 2004-2006

\begin{tabular}{|c|c|c|c|}
\hline \multicolumn{4}{|c|}{ NGHGCF $_{\text {Aelec, flat }}$ (\$/kg of CO2) } \\
\hline Month & 2004 & 2005 & 2006 \\
\hline Jul & 0.777 & 0.444 & 0.459 \\
\hline Aug & 0.709 & 0.417 & 0.524 \\
\hline Sep & 0.599 & 0.468 & 0.614 \\
\hline
\end{tabular}


Table 6-21: Average GHG cost factors using TOU pricing scheme 2004-2006

\begin{tabular}{|c|c|c|c|}
\hline \multicolumn{4}{|c|}{ NGHGCF } \\
A elec, Tou (\$/kg of CO2) \\
\hline Month & 2004 & 2005 & 2006 \\
\hline Jul & 0.712 & 0.423 & 0.440 \\
\hline Aug & 0.649 & 0.409 & 0.503 \\
\hline Sep & 0.555 & 0.453 & 0.566 \\
\hline
\end{tabular}

Table 6-22: Average GHG cost factors using wholesale pricing scheme 2004-2006

\begin{tabular}{|c|c|c|c|}
\hline \multicolumn{4}{|c|}{ NGHGCF $_{\text {A elec, wholesale }}\left(\$ / \mathrm{kg}\right.$ of CO $\left._{2}\right)$} \\
\hline Month & 2004 & 2005 & 2006 \\
\hline Jul & 0.294 & 0.315 & 0.210 \\
\hline Aug & 0.260 & 0.347 & 0.251 \\
\hline Sep & 0.256 & 0.408 & 0.191 \\
\hline
\end{tabular}

\subsubsection{Peak Day GHG Analysis for Summer 2004, 2005, and 2006}

Figure 6-17 shows the $\mathrm{CO}_{2}$ emissions for the summer peak days for 2004, 2005, and 2006 . $\mathrm{CO}_{2}$ emissions were highest during the afternoon and early evening hours.

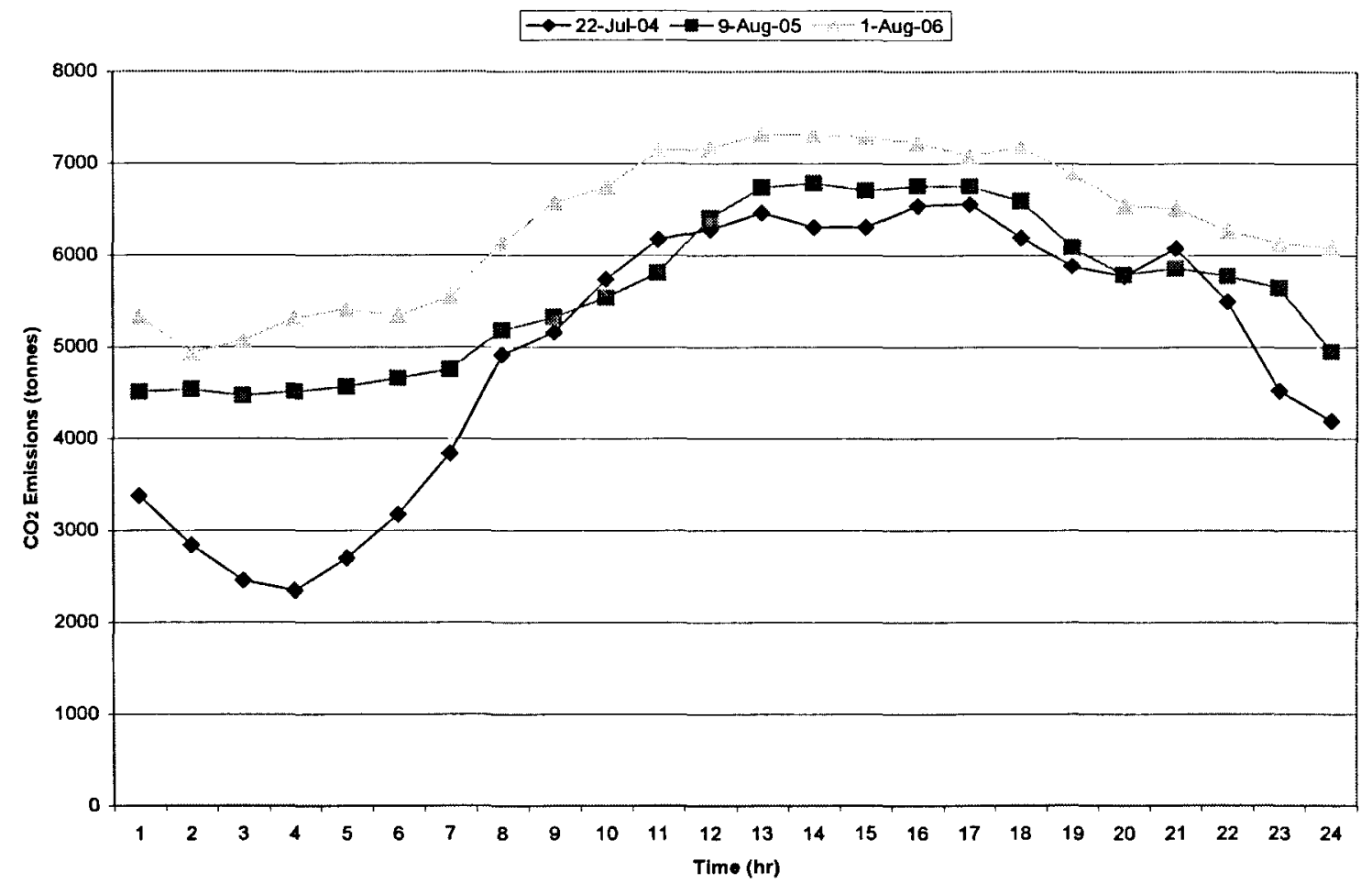

Figure 6-17: Hourly emissions during summer peak days for 2004, 2005, and 2006 
As illustrated in Table 6-23 $\mathrm{CO}_{2}$ emissions were the highest in 2006. $\mathrm{CO}_{2}$ emissions increased by $12 \%$ in 2005 , and again by $12 \%$ in 2006 .

Table 6-23: $\mathrm{CO}_{2}$ emissions during summer peak day for 2004, 2005, and 2006

\begin{tabular}{|c|c|c|}
\hline \multicolumn{3}{|c|}{ Summer } \\
\hline Year & Peak Day & Emissions (kt) \\
\hline 2004 & $22-J u l-04$ & 119 \\
\hline 2005 & 9 -Aug-05 & 135 \\
\hline 2006 & 1-Aug-06 & 153 \\
\hline
\end{tabular}

Figure 6-18 shows the $\mathrm{CO}_{2}$ emission factor profile for the summer peak days for 2004, 2005, and 2006. $\mathrm{CO}_{2}$ emission factors were highest during the afternoon hours, and remained constant throughout the day with the exception of 2004 where the emission factor varied considerably.

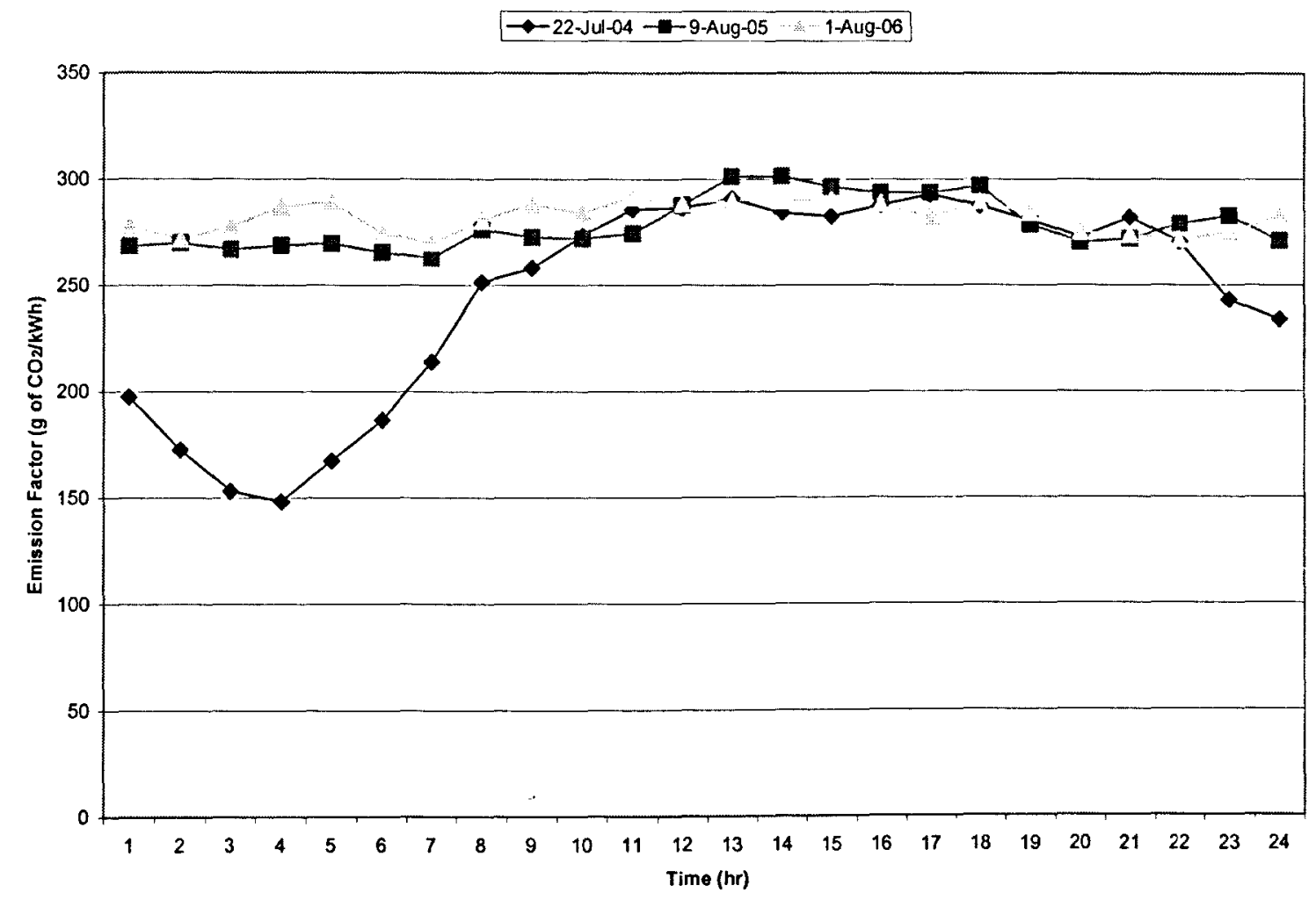

Figure 6-18: Hourly $\mathrm{CO}_{2}$ emission factors during peak summer day 2004-2006

As illustrated in Table 6-24 average emission factors for the peak summer day were the highest in 2006. 
Table 6-24: Average emission factors during peak summer day 2004-2006

\begin{tabular}{|c|c|c|}
\hline \multicolumn{3}{|c|}{ Summer } \\
\hline Year & Peak Day & NGHGIF $_{\mathbf{A}}$ (g of CO2/kWh) \\
\hline 2004 & 22 -Jul-04 & 246 \\
\hline 2005 & 9-Aug-05 & 279 \\
\hline 2006 & 1-Aug-06 & 282 \\
\hline
\end{tabular}

\subsection{Fall 2004, 2005, and 2006 Emissions}

Figure 6-19, Figure 6-20, and Figure 6-21 show hourly GHG emissions for the falls of 2004, 2005, and 2006. The highest GHG emissions occurred during December for 2005, and October for 2004 and 2006.

है

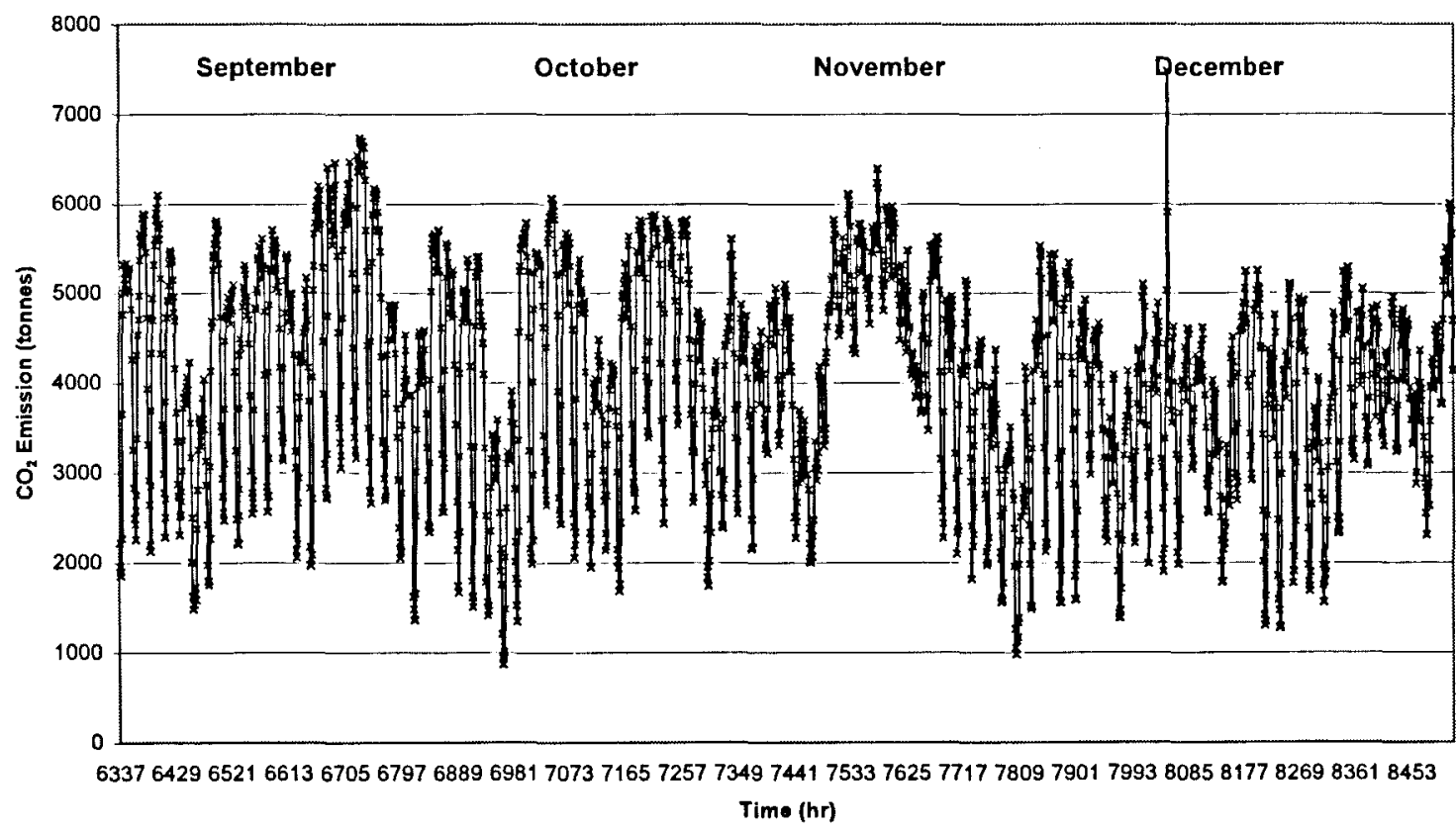

Figure 6-19: Hourly $\mathrm{CO}_{2}$ emissions - fall 2004 


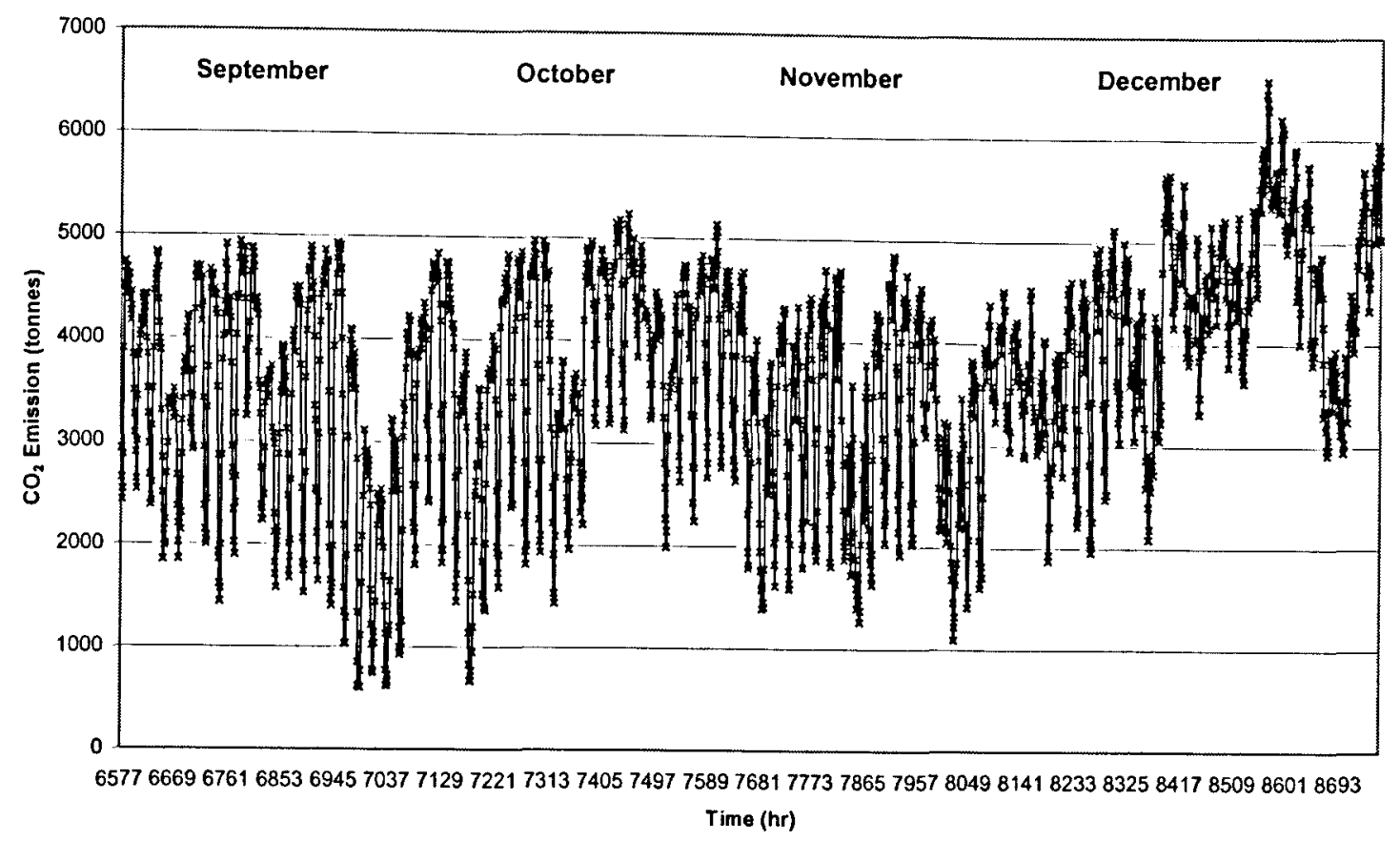

Figure 6-20: Hourly $\mathrm{CO}_{2}$ emissions - fall 2005

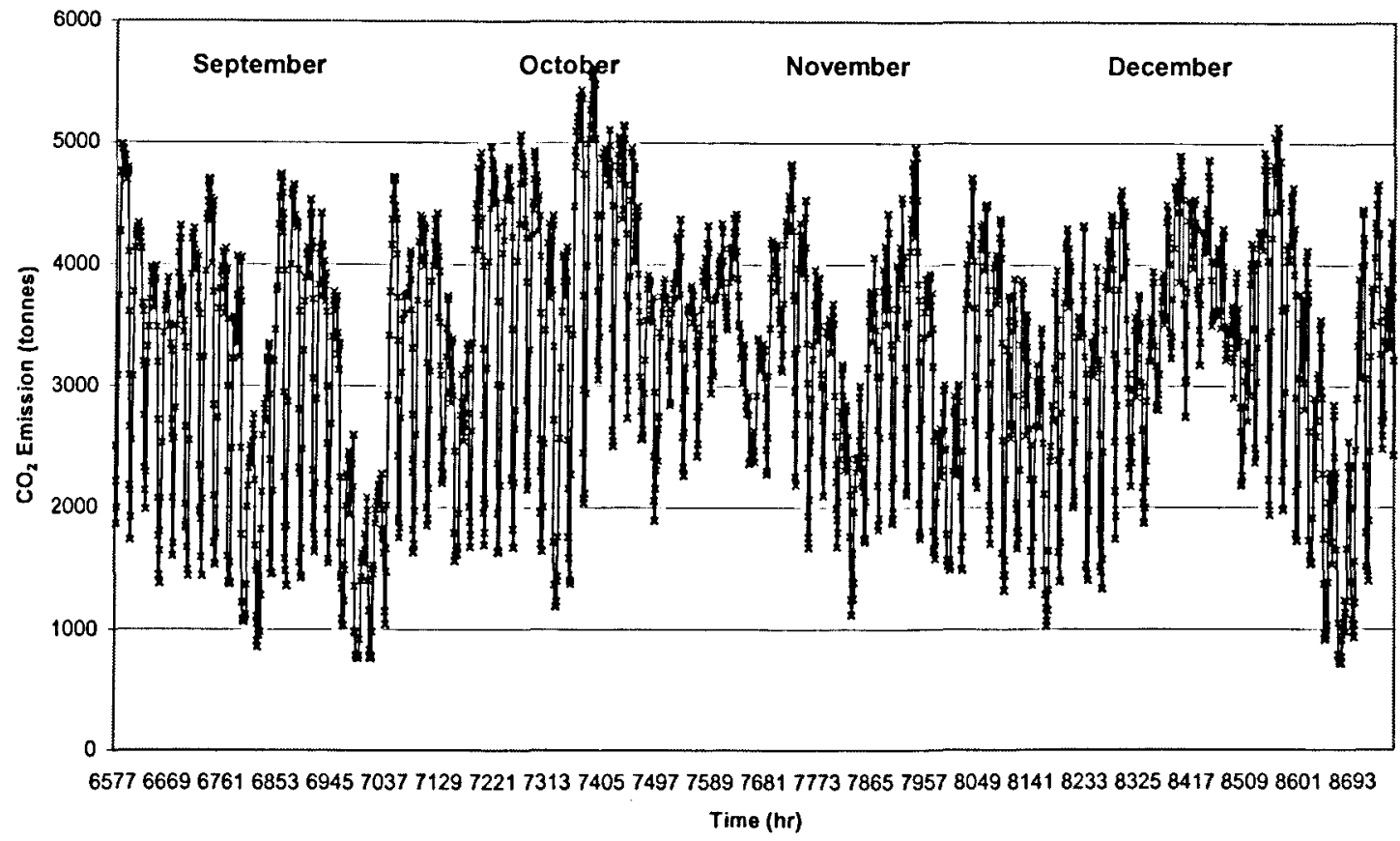

Figure 6-21: Hourly $\mathrm{CO}_{2}$ emissions - fall 2006 
Table 6-25 shows the total amount of GHG emissions for the falls of 2004, 2005, and 2006. It can be observed that $\mathrm{CO}_{2}$ emissions remained the same for 2004 and 2005, and decreased in by $20 \%$ in $2006 . \mathrm{SO}_{2}$ emissions increased by $18 \%$ in 2005 , but decreased by $48 \%$ in 2006 . NO emissions increased by $10 \%$ in 2005, but decreased by $9 \%$ in 2006 .

Table 6-25: GHG emissions from the power generation sector - fall 2004-2006

\begin{tabular}{|c|c|c|c|c|}
\hline \multicolumn{5}{|c|}{ Fall } \\
\hline \multirow{2}{*}{ Year } & \multicolumn{3}{|c|}{ Emissions (kt) } & Electricity Demand \\
\cline { 2 - 5 } & $\mathrm{CO}_{2}$ & $\mathrm{SO}_{2}$ & NO & (GWh) \\
\hline 2004 & 8844 & 32.19 & 8.01 & 37726 \\
\hline 2005 & 8879 & 39.03 & 8.93 & 37644 \\
\hline 2006 & 7072 & 20.16 & 8.16 & 36144 \\
\hline
\end{tabular}

\subsubsection{Fall Emission Factors}

Table 6-26 shows the average NGHGIF $_{\mathrm{A}}$ values for the falls of 2004, 2005, and 2006. The highest $\mathrm{CO}_{2}$ emission factor was in 2004, but decreased by $16 \%$ in 2005 and by $7.3 \%$ in 2006.

Table 6-26: Average Emission factors for fall 2004-2006

\begin{tabular}{|c|c|c|c|}
\hline \multicolumn{4}{|c|}{ Fall } \\
\hline \multirow{2}{*}{ Year } & \multicolumn{3}{|c|}{ NGHGIF $_{\mathrm{A}}$ (g/kWh) } \\
\cline { 2 - 4 } & $\mathrm{CO}_{\mathbf{2}}$ & SO $_{\mathbf{2}}$ & $\mathrm{NO}$ \\
\hline 2004 & 244 & 0.89 & 0.22 \\
\hline 2005 & 205 & 0.90 & 0.21 \\
\hline 2006 & 190 & 0.54 & 0.22 \\
\hline
\end{tabular}

Table 6-27 and Figure 6-22 show TDV emission factors for the falls of 2004, 2005, and 2006. Emission factors are highest during the afternoon and evening hours. 
Table 6-27: TDV emission factor comparison for fall 2004-2006

\begin{tabular}{|c|c|c|c|}
\hline \multicolumn{4}{|c|}{ Fall } \\
\hline \multicolumn{4}{|c|}{ TDV NGHGIF $\mathrm{A}(\mathrm{g}$ of $\mathrm{CO} 2 / \mathrm{kWh})$} \\
\hline Hour & 2004 & 2005 & 2006 \\
\hline 1 & 226.1 & 199.9 & 177.2 \\
\hline 2 & 213.2 & 193.4 & 165.1 \\
\hline 3 & 202.5 & 187.9 & 154.8 \\
\hline 4 & 200.2 & 185.7 & 153.8 \\
\hline 5 & 210.9 & 196.5 & 165.8 \\
\hline 6 & 231.7 & 205.0 & 184.0 \\
\hline 7 & 253.4 & 214.3 & 196.0 \\
\hline 8 & 268.7 & 226.4 & 211.0 \\
\hline 9 & 274.5 & 233.2 & 219.4 \\
\hline 10 & 278.8 & 238.4 & 223.4 \\
\hline 11 & 282.2 & 242.6 & 226.6 \\
\hline 12 & 284.2 & 244.4 & 228.5 \\
\hline 13 & 285.7 & 245.0 & 230.0 \\
\hline 14 & 283.5 & 243.8 & 229.1 \\
\hline 15 & 281.3 & 241.3 & 224.5 \\
\hline 16 & 277.4 & 236.3 & 221.8 \\
\hline 17 & 275.9 & 235.4 & 221.8 \\
\hline 18 & 281.7 & 241.4 & 227.3 \\
\hline 19 & 285.5 & 244.4 & 229.8 \\
\hline 20 & 285.4 & 241.8 & 227.1 \\
\hline 21 & 281.5 & 240.2 & 222.2 \\
\hline 22 & 274.0 & 233.9 & 216.1 \\
\hline 23 & 257.9 & 218.4 & 202.9 \\
\hline 24 & 239.2 & 206.1 & 187.5 \\
\hline
\end{tabular}

The TDV methodology assigns a value ( $\mathrm{g}$ of $\mathrm{CO}_{2} / \mathrm{kWh}$ ) to every hour of the year for a particular season. Table 6-27 shows that during the fall of 2006 at 4 p.m., for one $\mathrm{kWh}$ produced or reduced the emissions will be $221.8 \mathrm{~g}$ of $\mathrm{CO}_{2}$, while at $4 \mathrm{a}$.m. it would be 153.8 $\mathrm{g}$ of $\mathrm{CO}_{2}$, which shows a difference of $31 \%$ in just 12 hours. In addition, the maximum TDV values for years 2004,2005 , and 2006 occurred at 1 p.m. The corresponding $95 \%$ confidence interval was determined to be for each TDV hour \pm 11.63 , \pm 8.04 , and \pm 10.20 for the years 2004,2005 , and 2006, respectively. 


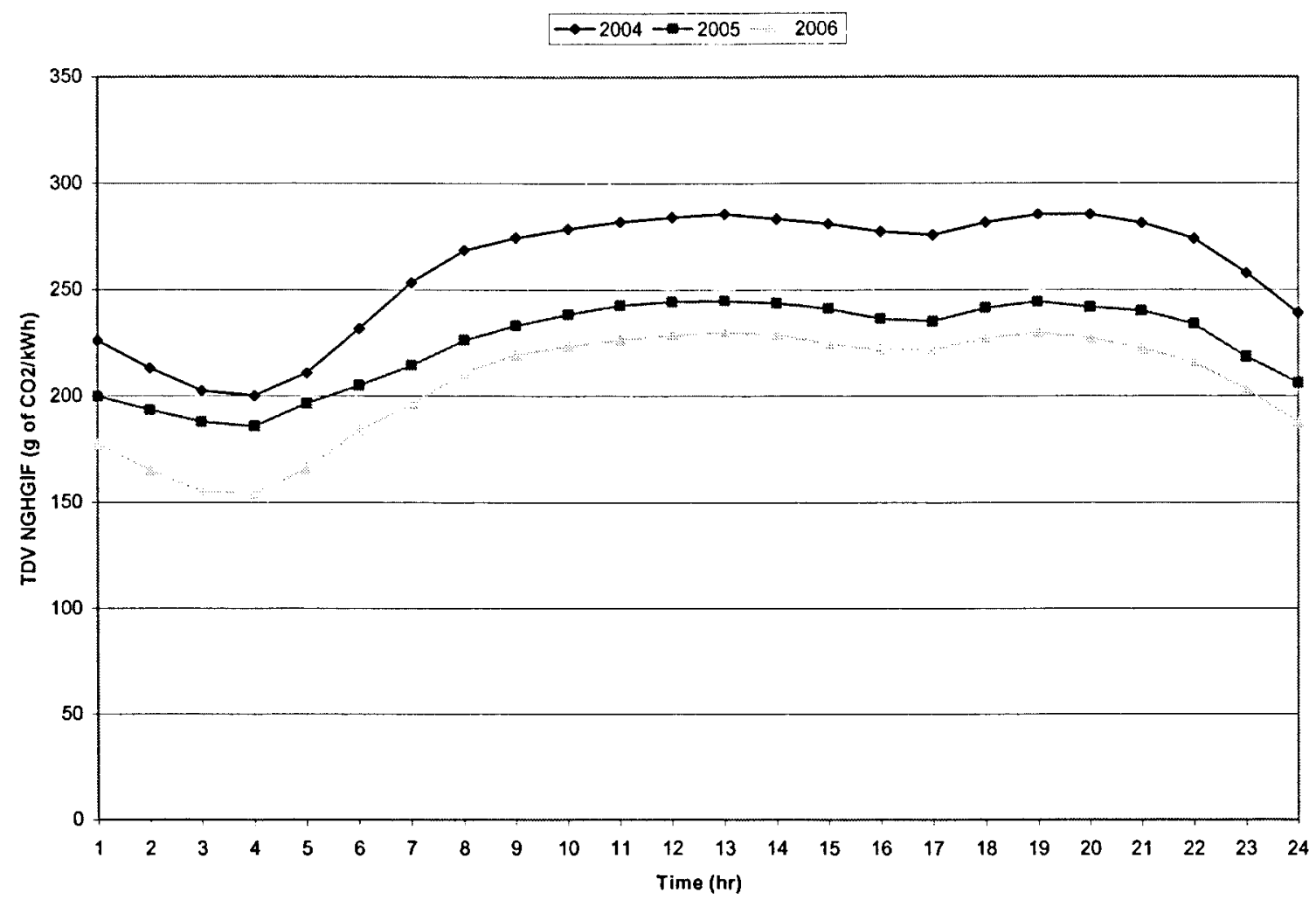

Figure 6-22: TDV emission factor profile comparison for fall 2004-2006

Monthly average GHG cost factors were developed for 2004, 2005, and 2006 based on flat rate, TOU, and wholesale pricing schemes as illustrated in Table 6-28, Table 6-29, and Table 6-30. Cost factors were the highest during October and November of 2006 for the flat rate electricity pricing scheme, TOU pricing scheme, and October, November, and December of 2005 for the wholesale pricing scheme.

Table 6-28 : Average GHG cost factors using flat rate pricing scheme 2004-2006

\begin{tabular}{|c|c|c|c|}
\hline \multicolumn{4}{|c|}{ NGHGCF $_{\text {A elec, flat }}$ (\$/kg of CO2) } \\
\hline Month & 2004 & 2005 & 2006 \\
\hline Oct & 0.405 & 0.547 & 0.579 \\
\hline Nov & 0.443 & 0.543 & 0.553 \\
\hline Dec & 0.525 & 0.507 & 0.507 \\
\hline
\end{tabular}


Table 6-29: Average GHG cost factors using TOU pricing scheme 2004-2006

\begin{tabular}{|c|c|c|c|}
\hline \multicolumn{4}{|c|}{ NGHGCF } \\
A elec, Tou (\$/kg of CO $_{2}$ ) \\
\hline Month & 2004 & 2005 & 2006 \\
\hline Oct & 0.383 & 0.507 & 0.540 \\
\hline Nov & 0.437 & 0.535 & 0.543 \\
\hline Dec & 0.526 & 0.495 & 0.497 \\
\hline
\end{tabular}

Table 6-30: Average GHG cost factors using wholesale pricing scheme 2004-2006

\begin{tabular}{|c|c|c|c|}
\hline \multicolumn{4}{|c|}{ NGHGCF $_{\text {A elec, wholesale }}$ (\$/kg of CO2) } \\
\hline Month & 2004 & 2005 & 2006 \\
\hline Oct & 0.189 & 0.364 & 0.212 \\
\hline Nov & 0.218 & 0.296 & 0.255 \\
\hline Dec & 0.252 & 0.363 & 0.187 \\
\hline
\end{tabular}

\subsubsection{Peak Day GHG Analysis for Fall 2004, 2005, and 2006}

Figure 6-23 shows the $\mathrm{CO}_{2}$ emissions for the fall peak days for 2004, 2005, and 2006. $\mathrm{CO}_{2}$ emissions were highest during the evening hours and in the morning of 2004.

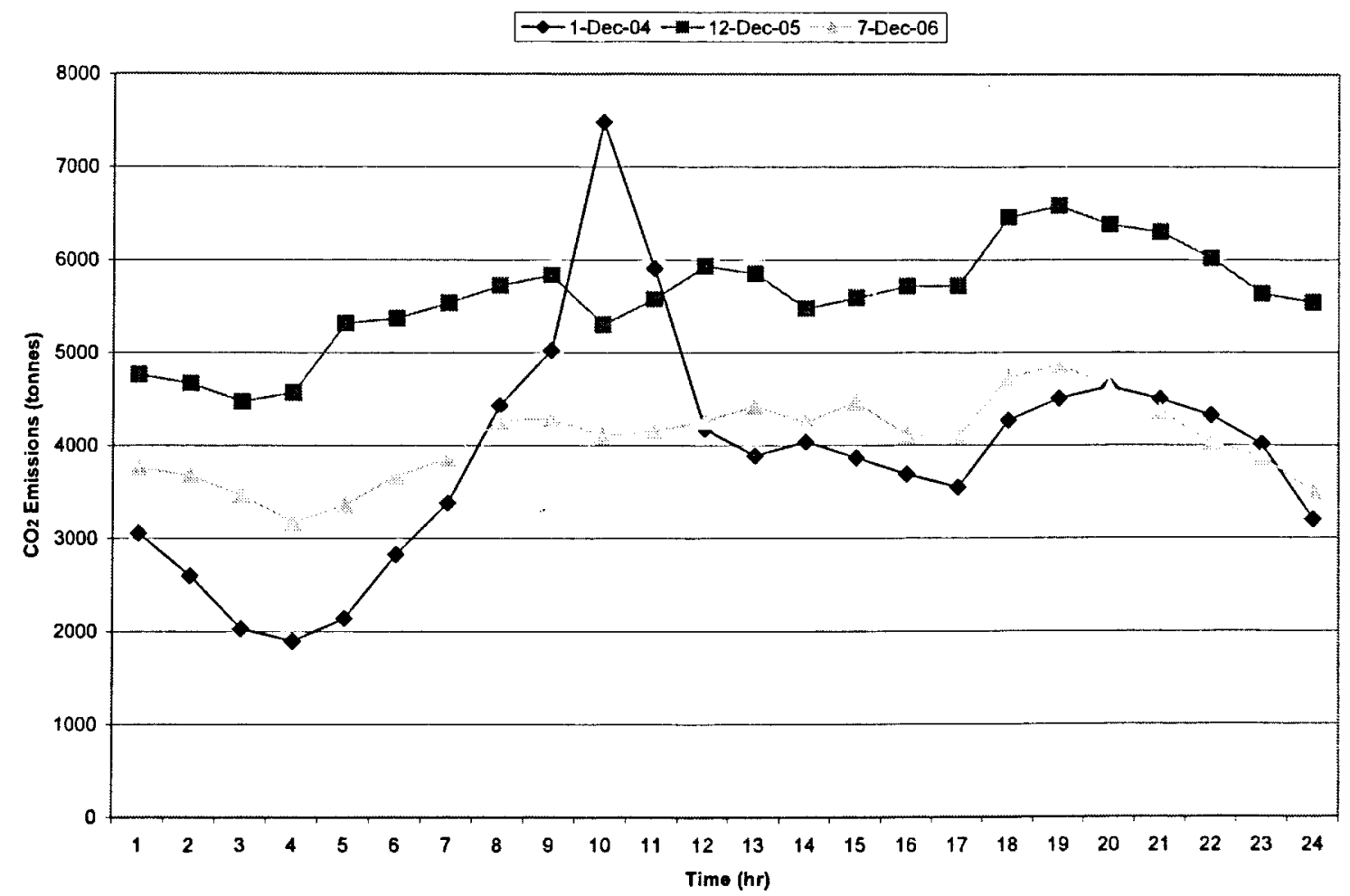

Figure 6-23: Hourly emissions during fall peak days for 2004, 2005, and 2006 
As illustrated in Table 6-31 $\mathrm{CO}_{2}$ emissions were the highest in 2005. $\mathrm{CO}_{2}$ emissions increased by $31 \%$ in 2005 , and decreased by $28 \%$ in 2006 .

Table 6-31: $\mathrm{CO}_{2}$ emissions during fall peak day for 2004, 2005, and 2006

\begin{tabular}{|c|c|c|}
\hline \multicolumn{3}{|c|}{ Fall } \\
\hline Year & Peak Day & Emissions (kt) \\
\hline 2004 & 1-Dec-04 & 93 \\
\hline 2005 & 12-Dec-05 & 134 \\
\hline 2006 & 7-Dec-06 & 97 \\
\hline
\end{tabular}

Figure 6-24 shows the $\mathrm{CO}_{2}$ emission factor profile for the summer peak days for 2004, 2005, and 2006. $\mathrm{CO}_{2}$ emission factors were constant throughout the day with the exception of 2004 where the emission factor varied considerably.

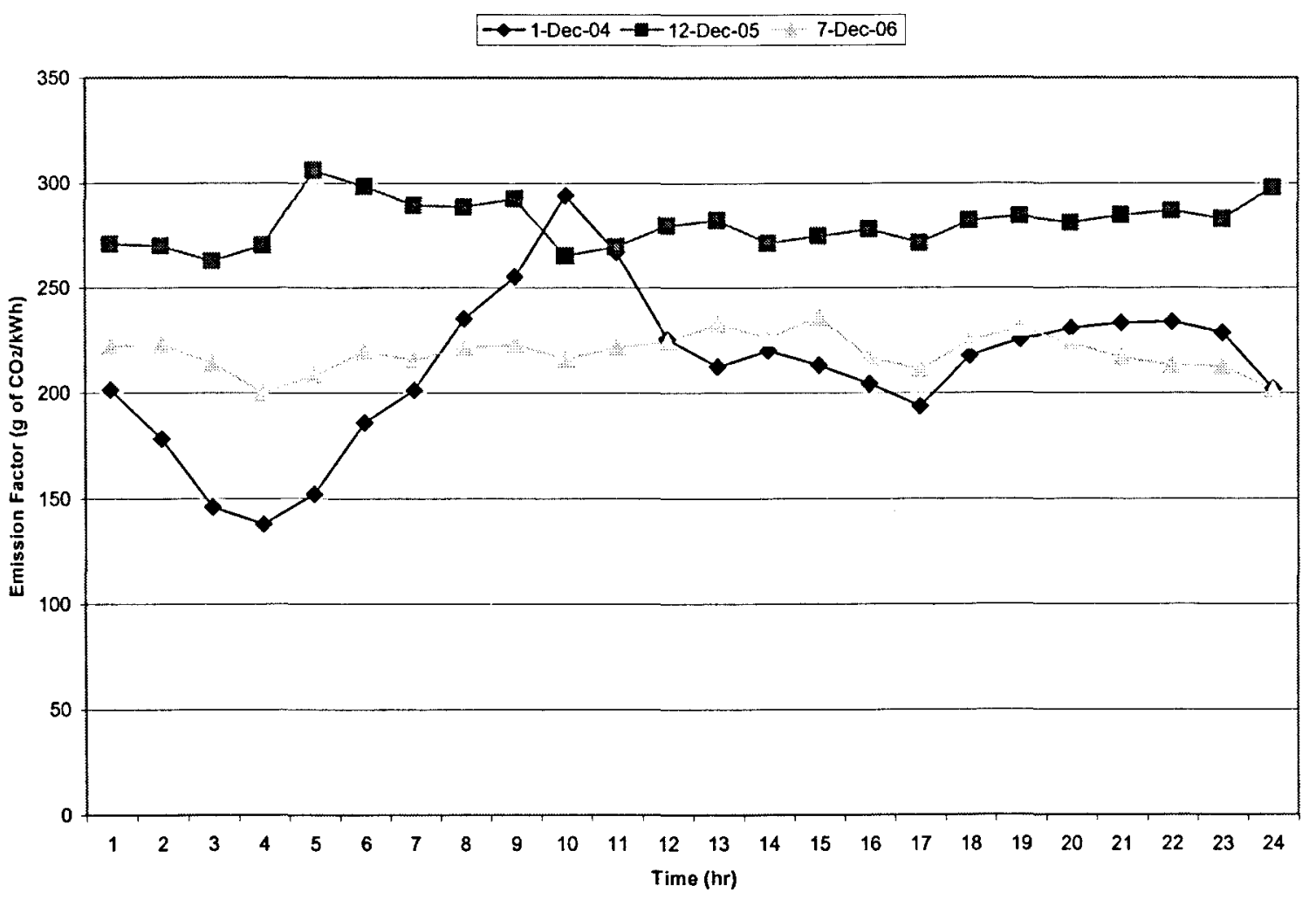

Figure 6-24: Hourly $\mathrm{CO}_{2}$ emission factors during peak fall day 2004-2006

As illustrated in Table 6-32 average emission factors for the peak summer day were the highest in 2005. 
Table 6-32 : Average emission factors during peak fall day 2004-2006

\begin{tabular}{|c|c|c|}
\hline \multicolumn{3}{|c|}{ Fall } \\
\hline Year & Peak Day & NGHGIF $_{\text {(g of CO2/kWh) }}$ \\
\hline 2004 & 1-Dec-04 & 212 \\
\hline 2005 & $12-D e c-05$ & 281 \\
\hline 2006 & $7-D e c-06$ & 219 \\
\hline
\end{tabular}

\subsection{Annual Emissions}

Figure 6-25, Figure 6-26, and Figure 6-27show hourly GHG emissions for the years 2004, 2005, and 2006. The highest GHG emissions occurred during January for 2004, and January and the summer for 2005 and 2006.

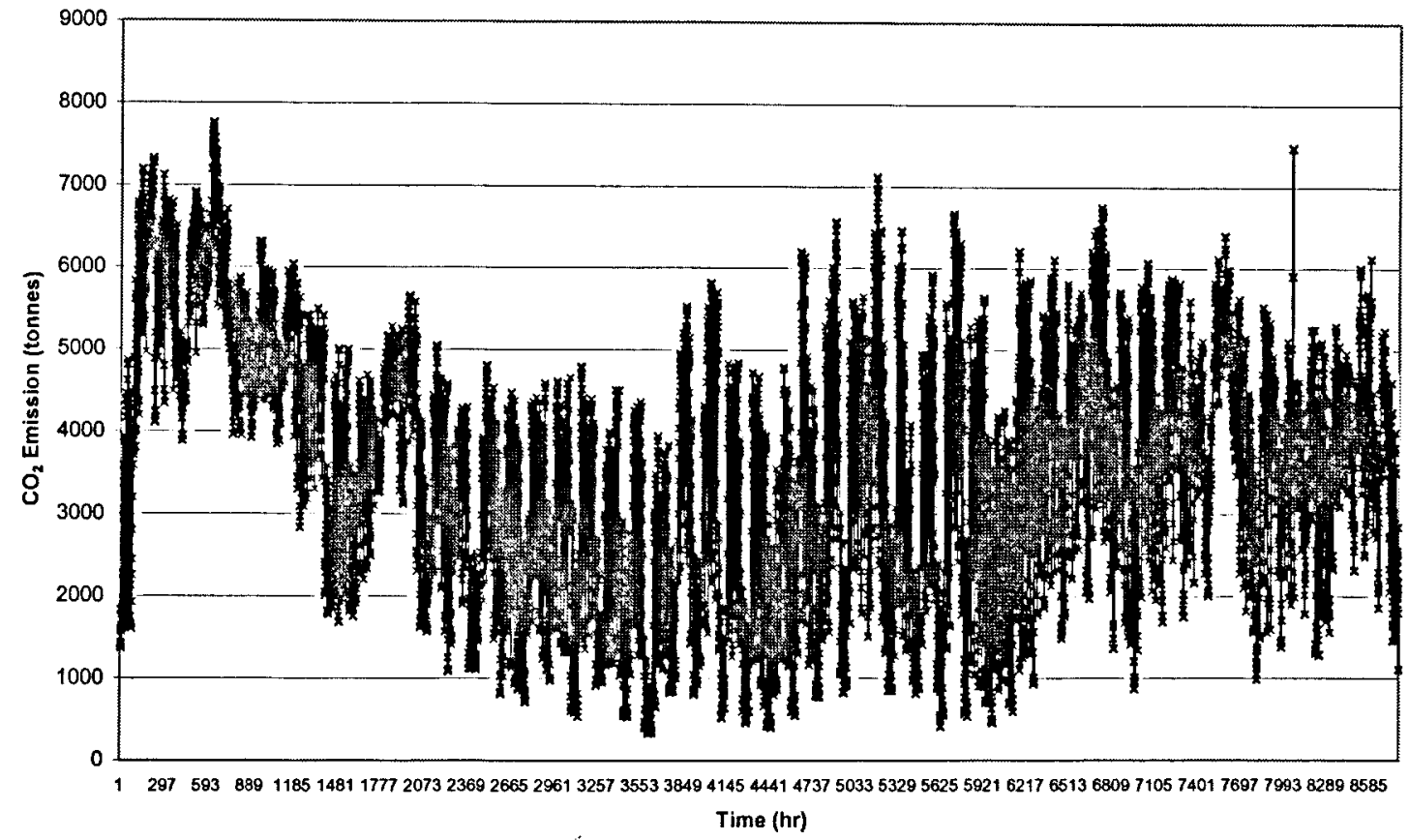

Figure 6-25: Hourly $\mathrm{CO}_{2}$ emissions - 2004 


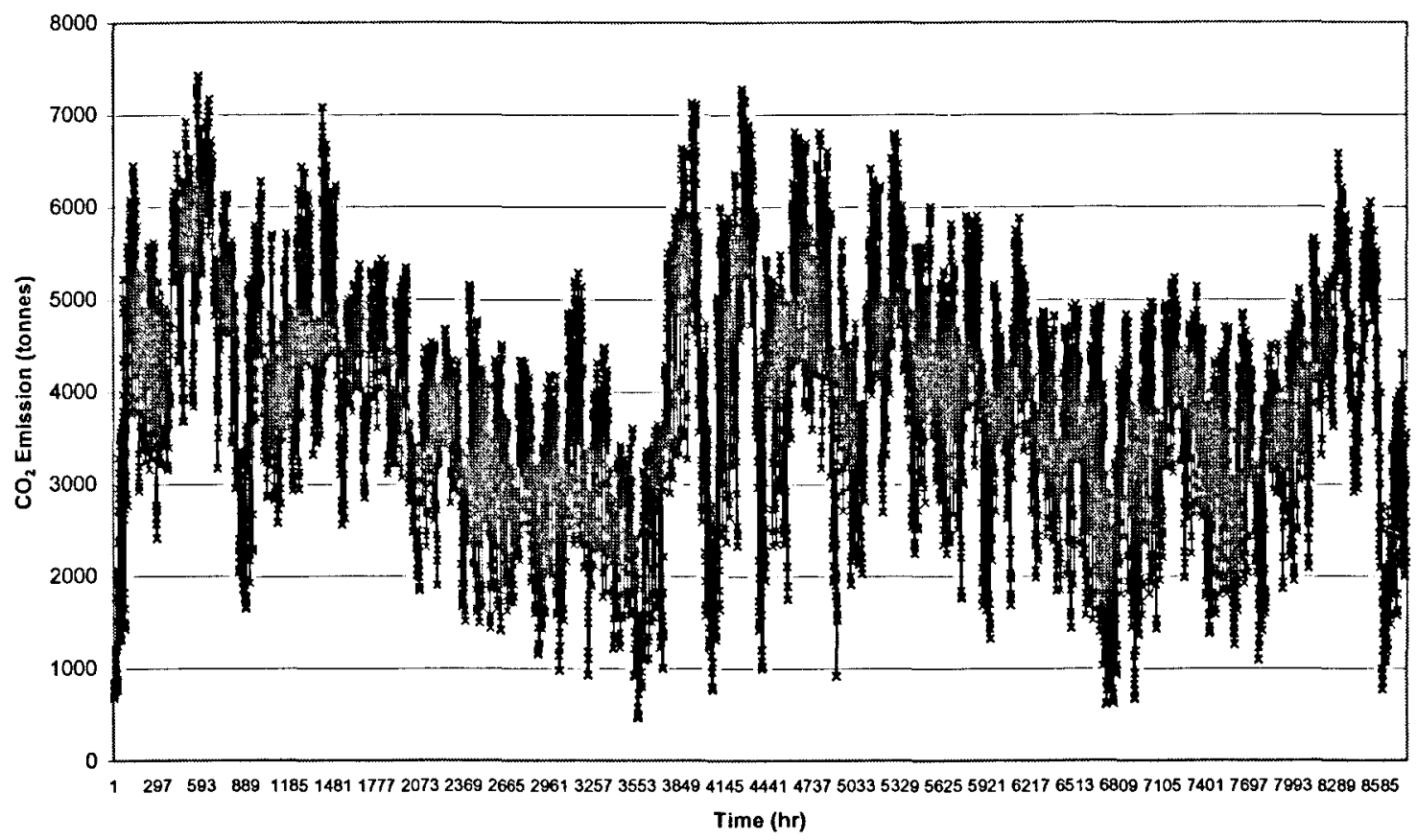

Figure 6-26: Hourly $\mathrm{CO}_{2}$ emissions - 2005

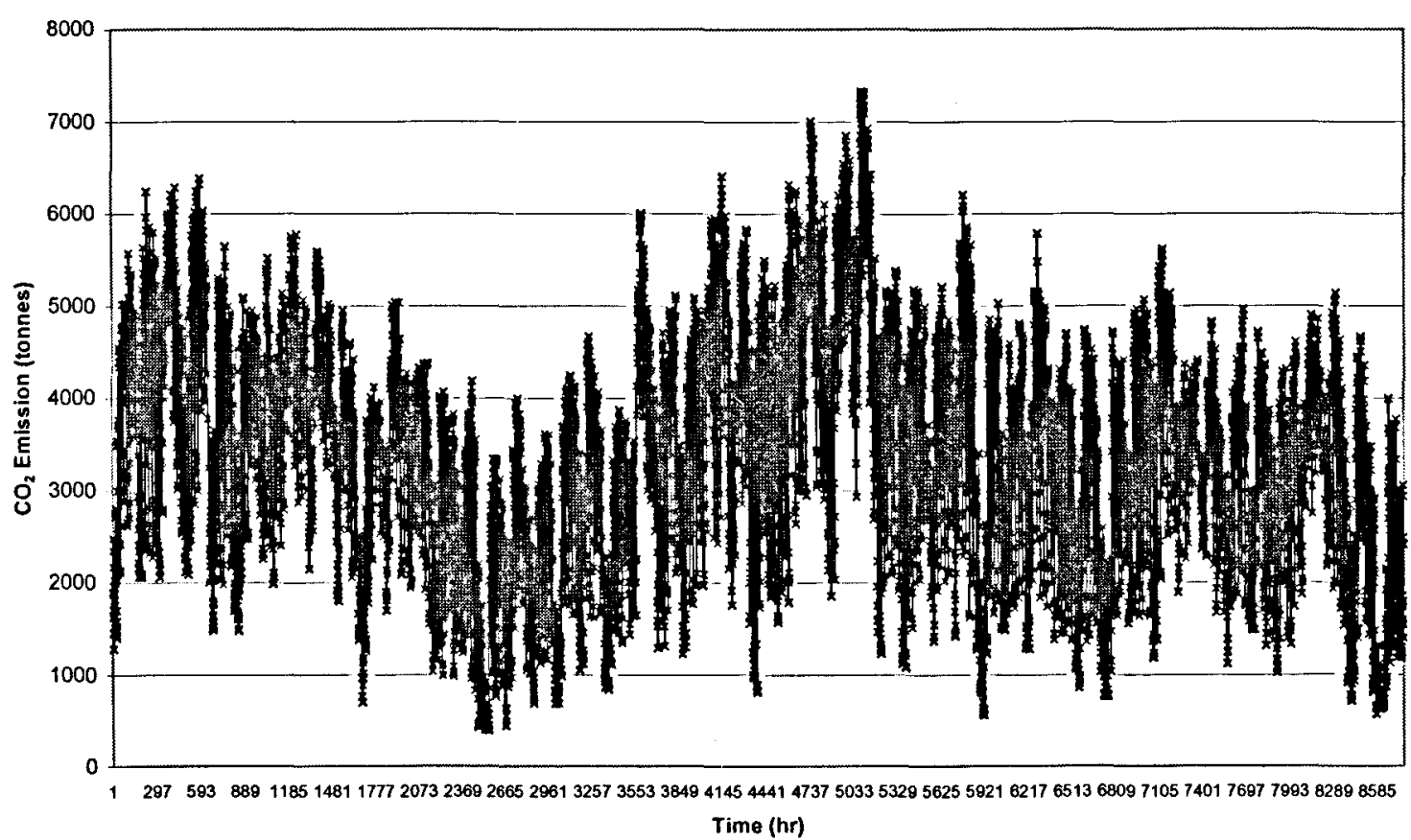

Figure 6-27: Hourly $\mathrm{CO}_{2}$ emissions - 2006 
Table 6-33 shows the total amount of GHG emissions for 2004. It can be observed that $\mathrm{CO}_{2}$ emissions were the highest during the winter and decreased by $37 \%$ during the spring, but increased by $9 \%$ and $22 \%$ during the summer and fall months, respectively. $\mathrm{SO}_{2}$ emissions also decreased by $41 \%$ during the spring, but increased by $12 \%$ and $22 \%$ during the summer and fall months, respectively. NO emissions decreased by $33 \%$ during the spring, and remained unchanged during the summer, but increased by $25 \%$ during the fall.

Table 6-33: GHG emissions from the power generation sector for 2004

\begin{tabular}{|c|c|c|c|}
\hline \multirow{2}{*}{2004} & \multicolumn{3}{|c|}{ Emissions (kt) } \\
\cline { 2 - 4 } & $\mathrm{CO}_{2}$ & $\mathrm{SO}_{2}$ & NO \\
\hline Winter & 10023 & 37 & 9 \\
\hline Spring & 6309 & 22 & 6 \\
\hline Summer & 6933 & 25 & 6 \\
\hline Fall & 8844 & 32 & 8 \\
\hline Total & 32109 & 116 & 29 \\
\hline
\end{tabular}

Table 6-34 shows the total amount of GHG emissions for 2005. It can be observed that $\mathrm{CO}_{2}$ emissions were the highest during the summer. Emissions decreased by $22 \%$ during the spring, but increased by $23 \%$ during the summer and decreased by $9.3 \%$ during the fall. $\mathrm{SO}_{2}$ emissions decreased by $20 \%$ during the spring, but increased and decreased by $25 \%$ and $11.3 \%$ during the summer and fall, respectively. NO emissions decreased by $11 \%$ during the spring, but increased by $20 \%$ during the summer, and decreased by $10 \%$ during the fall.

Table 6-34: GHG emissions from the power generation sector for 2005

\begin{tabular}{|c|c|c|c|}
\hline \multirow{2}{*}{2005} & \multicolumn{3}{|c|}{ Emissions (kt) } \\
\cline { 2 - 4 } & $\mathrm{CO}_{2}$ & $\mathbf{S O}_{2}$ & NO \\
\hline Winter & 9616 & 41 & 9 \\
\hline Spring & 7501 & 33 & 8 \\
\hline Summer & 9787 & 44 & 10 \\
\hline Fall & 8879 & 39 & 9 \\
\hline Total & 35783 & 157 & 36 \\
\hline
\end{tabular}

Table 6-35 shows the total amount of GHG emissions for 2006. It can be observed that $\mathrm{CO}_{2}$ emissions were the highest during the summer. Emissions decreased by $20 \%$ during the spring, but increased by $28 \%$ during the summer and decreased by $20 \%$ during the fall. $\mathrm{SO}_{2}$ emissions decreased by $31 \%$ during the spring, but increased and decreased by $31 \%$ and $23 \%$ 
during the summer and fall, respectively. NO emissions decreased by $22 \%$ during the spring, but increased by $30 \%$ during the summer, and decreased by $20 \%$ during the fall

Table 6-35: GHG emissions from the power generation sector for 2006

\begin{tabular}{|c|c|c|c|}
\hline \multirow{2}{*}{2006} & \multicolumn{3}{|c|}{ Emissions (kt) } \\
\cline { 2 - 4 } & $\mathrm{CO}_{2}$ & $\mathrm{SO}_{2}$ & $\mathrm{NO}$ \\
\hline Winter & 8049 & 26 & 9 \\
\hline Spring & 6416 & 18 & 7 \\
\hline Summer & 8881 & 26 & 10 \\
\hline Fall & 7072 & 20 & 8 \\
\hline Total & 30418 & 90 & 35 \\
\hline
\end{tabular}

Table 6-36 shows the total amount of GHG emissions for 2004, 2005, and 2006. It can be observed that $\mathrm{CO}_{2}$ emissions were the highest during 2005.

Table 6-36: GHG emissions from the power generation sector comparing 2004-2006

\begin{tabular}{|c|c|c|c|}
\hline \multicolumn{4}{|c|}{ Annual } \\
\hline \multirow{2}{*}{ Year } & \multicolumn{3}{|c|}{ Emissions (kt) } \\
\cline { 2 - 4 } & $\mathbf{C O}_{\mathbf{2}}$ & $\mathbf{S O}_{\mathbf{2}}$ & NO \\
\hline 2004 & 32109 & 116 & 29 \\
\hline 2005 & 35783 & 157 & 36 \\
\hline 2006 & 30418 & 90 & 35 \\
\hline
\end{tabular}

\subsubsection{Annual Emission Factors}

Annual and seasonal emission factors were developed for the years 2004, 2005, and 2006. Table 6-37 shows the average annual and seasonal NGHGIF $_{\mathrm{A}}$ values for 2004 . The highest emission factor was during the winter.

Table 6-37: Average Emission factors for 2004

\begin{tabular}{|c|c|c|c|}
\hline \multirow{2}{*}{2004} & \multicolumn{3}{|c|}{ NGHGIF $_{\mathrm{A}}(\mathrm{g} / \mathrm{kWh})$} \\
\cline { 2 - 4 } & $\mathrm{CO}_{2}$ & $\mathrm{SO}_{2}$ & NO \\
\hline Annual & 208 & 0.75 & 0.19 \\
\hline Winter & 248 & 0.91 & 0.23 \\
\hline Spring & 164 & 0.57 & 0.15 \\
\hline Summer & 174 & 0.62 & 0.16 \\
\hline Fall & 244 & 0.89 & 0.22 \\
\hline
\end{tabular}


Table 6-38 shows the average annual and seasonal NGHGIF ${ }_{A}$ values for 2005 . The highest emission factor was during the summer.

Table 6-38: Average Emission factors for 2005

\begin{tabular}{|c|c|c|c|}
\hline \multirow{2}{*}{2005} & \multicolumn{3}{|c|}{ NGHGIF $_{\mathrm{A}}(\mathrm{g} / \mathrm{kWh})$} \\
\cline { 2 - 4 } & $\mathrm{CO}_{2}$ & $\mathrm{SO}_{2}$ & NO \\
\hline Annual & 221 & 0.97 & 0.22 \\
\hline Winter & 231 & 0.99 & 0.23 \\
\hline Spring & 205 & 0.90 & 0.21 \\
\hline Summer & 241 & 1.08 & 0.25 \\
\hline Fall & 205 & 0.90 & 0.21 \\
\hline
\end{tabular}

Table 6-39 shows the average annual and seasonal NGHGIF $_{A}$ values for 2006. The highest emission factor was during the summer.

Table 6-39: Average Emission factors for 2006

\begin{tabular}{|c|c|c|c|}
\hline \multirow{2}{*}{2006} & \multicolumn{3}{|c|}{ NGHGIF $_{\mathbf{A}}(\mathrm{g} / \mathbf{k W h})$} \\
\cline { 2 - 4 } & $\mathrm{CO}_{\mathbf{2}}$ & $\mathrm{SO}_{\mathbf{2}}$ & NO \\
\hline Annual & 189 & 0.55 & 0.22 \\
\hline Winter & 196 & 0.63 & 0.23 \\
\hline Spring & 164 & 0.47 & 0.19 \\
\hline Summer & 214 & 0.63 & 0.25 \\
\hline Fall & 190 & 0.54 & 0.22 \\
\hline
\end{tabular}

Table 6-40 shows the average annual NGHGIF $_{\mathrm{A}}$ values for 2004,2005 , and 2006 . The highest emission factor was in 2005.

Table 6-40: Average Emission factors comparing 2004-2006

\begin{tabular}{|c|c|c|c|}
\hline \multirow{2}{*}{ Annual } & \multicolumn{3}{|c|}{ NGHGIF $_{\mathrm{A}}(\mathrm{g} / \mathbf{k W h})$} \\
\cline { 2 - 4 } & $\mathrm{CO}_{2}$ & $\mathrm{SO}_{2}$ & NO \\
\hline 2004 & 208 & 0.75 & 0.19 \\
\hline 2005 & 221 & 0.97 & 0.22 \\
\hline 2006 & 189 & 0.55 & 0.22 \\
\hline
\end{tabular}

Annual and seasonal TDV emission factors were developed for the years 2004, 2005, and 2006. Figure 6-28 shows the seasonal TDV NGHGIF A profile for 2004. The highest 
emission factors were in the fall during the afternoon and in the winter during the early morning hours.

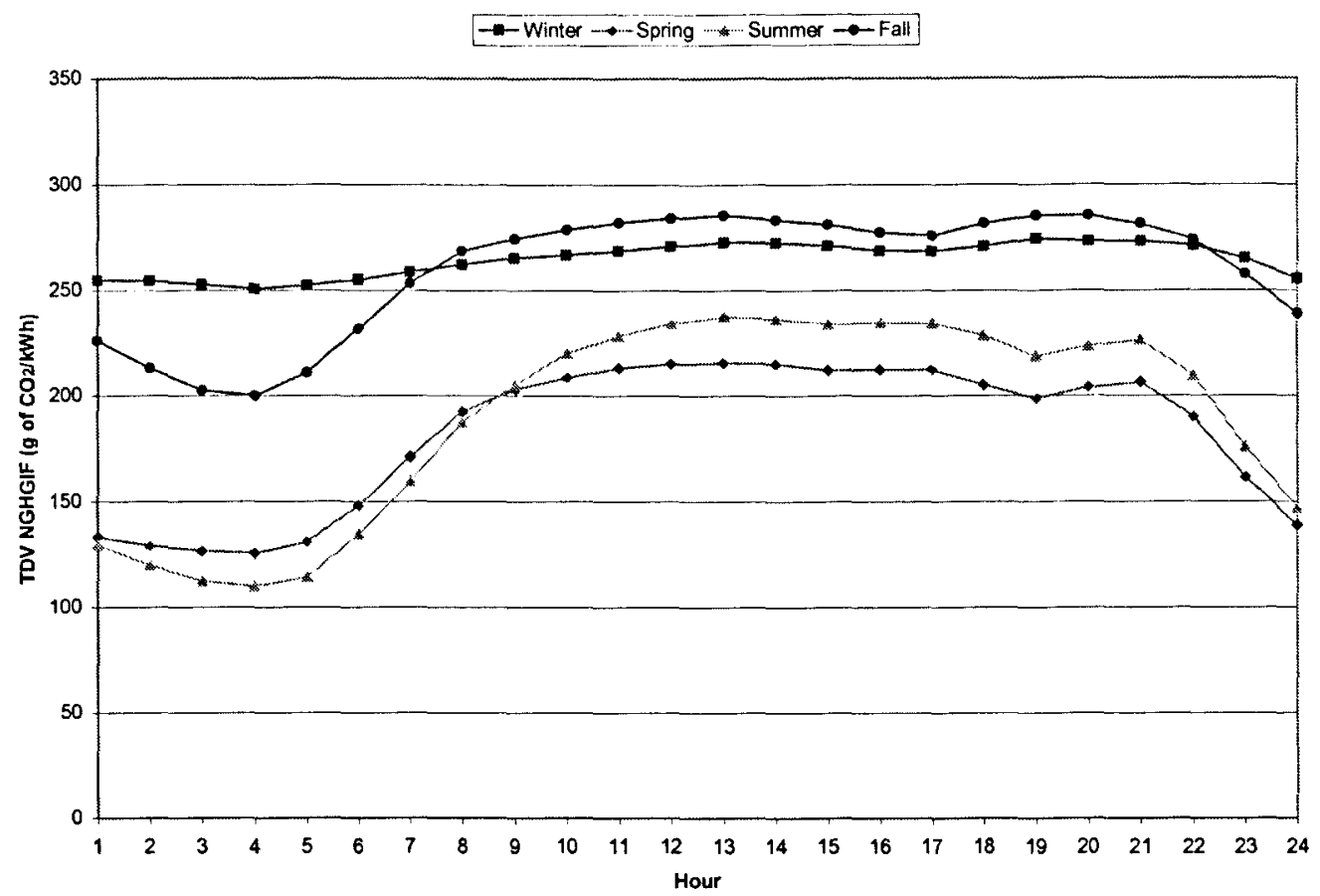

Figure 6-28: Seasonal TDV emission factor profile for 2004

Figure 6-29 shows the seasonal TDV NGHGIF A profile for 2005. The highest emission factors were in the summer during the afternoon and evening hours. 


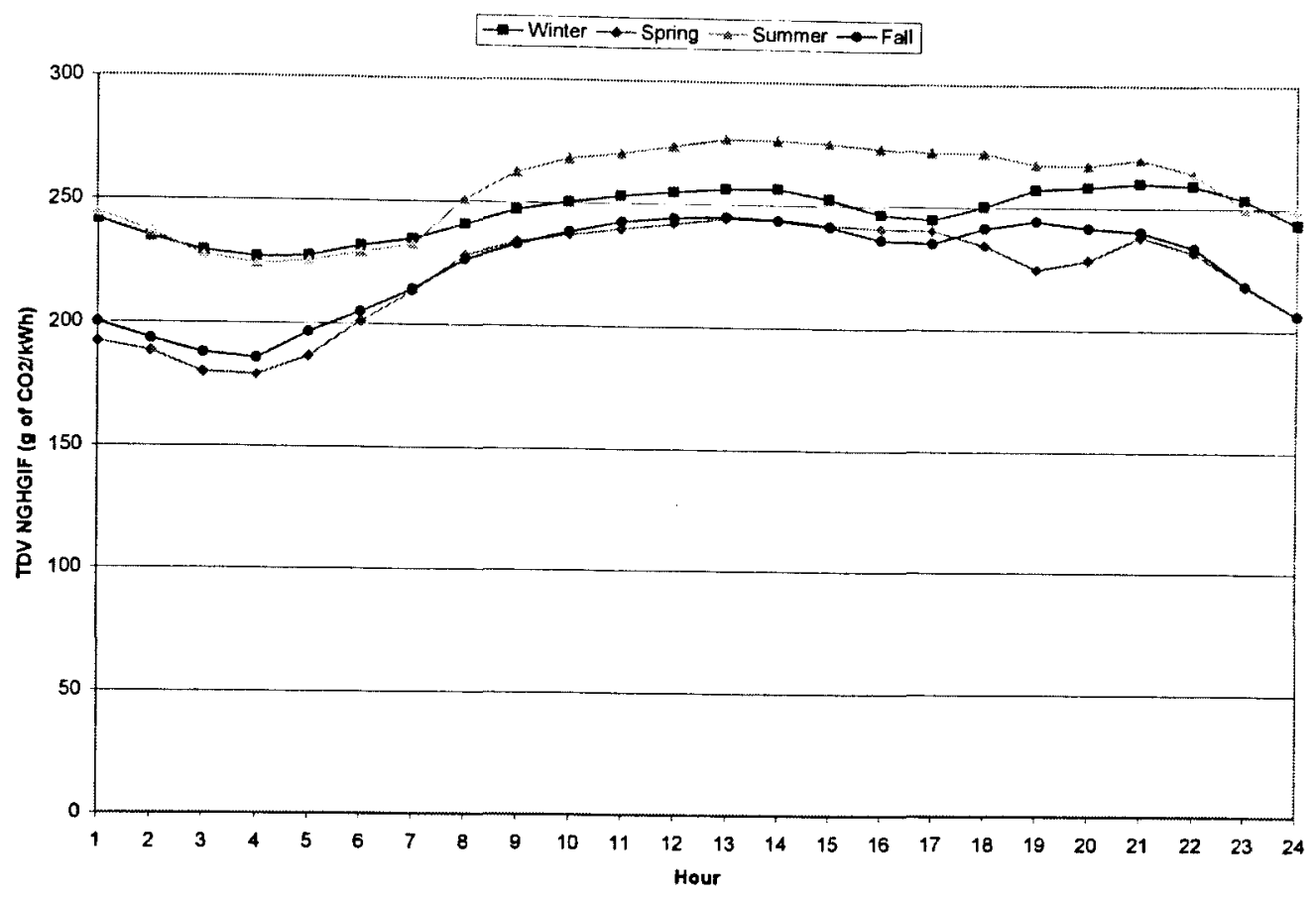

Figure 6-29: Seasonal TDV emission factor profile for 2005

Figure 6-30 shows the seasonal TDV NGHGIF A profile for 2006. The highest emission factors were in the summer during the afternoon and evening hours.

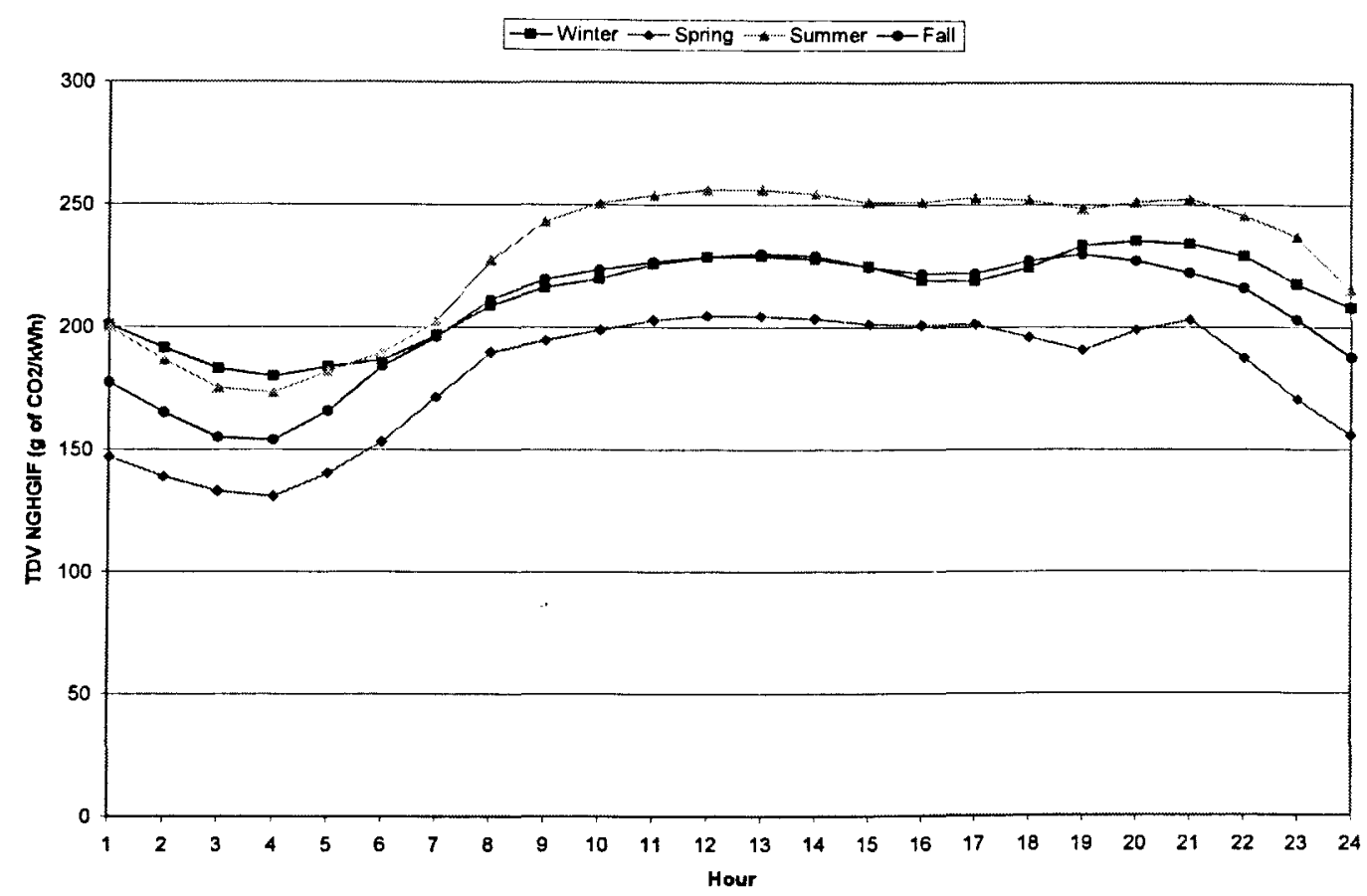

Figure 6-30: Seasonal TDV emission factor profile for 2006 
Table 6-41 and Figure 6-31 show TDV emission factors for 2004, 2005, and 2006. Emission factors were the highest in 2005 during the afternoon.

Table 6-41 shows the annual TDV emission factors. It can be observed that during the year 2006 at 4 p.m., for one $\mathrm{kWh}$ produced or reduced the emissions will be $223.3 \mathrm{~g}$ of $\mathrm{CO}_{2}$, while at 4 a.m. it would be $159.4 \mathrm{~g}$ of $\mathrm{CO}_{2}$, which shows a difference of $29 \%$ in just 12 hours. In addition, the maximum TDV values for years 2004, 2005, and 2006 occurred at 1 p.m. The corresponding $95 \%$ confidence interval was determined to be for each TDV hour $\pm 11.68, \pm 6.85$, and \pm 9.68 for the years 2004,2005 , and 2006 , respectively.

Table 6-41: Annual TDV emission factor comparison for 2004-2006

\begin{tabular}{|c|c|c|c|}
\hline \multicolumn{4}{|c|}{ Annual } \\
\hline \multicolumn{4}{|c|}{ TDV NGHGIF $_{\mathrm{A}}(\mathrm{g}$ of $\mathrm{CO} / \mathrm{kWh})$} \\
\hline Hour & 2004 & 2005 & 2006 \\
\hline 1 & 185.9 & 219.7 & 181.2 \\
\hline 2 & 179.2 & 213.3 & 170.5 \\
\hline 3 & 173.6 & 206.2 & 161.5 \\
\hline 4 & 171.6 & 203.9 & 159.4 \\
\hline 5 & 177.1 & 209.1 & 167.9 \\
\hline 6 & 192.5 & 216.8 & 178.3 \\
\hline 7 & 210.7 & 223.7 & 191.5 \\
\hline 8 & 227.8 & 236.7 & 209.1 \\
\hline 9 & 237.0 & 244.2 & 218.3 \\
\hline 10 & 243.6 & 248.5 & 223.1 \\
\hline 11 & 248.1 & 251.5 & 227.3 \\
\hline 12 & 251.1 & 253.6 & 229.5 \\
\hline 13 & 253.0 & 255.6 & 229.9 \\
\hline 14 & 252.0 & 255.2 & 228.7 \\
\hline 15 & 249.7 & 252.9 & 225.4 \\
\hline 16 & 248.4 & 249.3 & 223.3 \\
\hline 17 & 247.8 & 248.3 & 223.7 \\
\hline 18 & 246.5 & 249.6 & 224.9 \\
\hline 19 & 244.3 & 248.6 & 225.5 \\
\hline 20 & 246.6 & 249.0 & 228.1 \\
\hline 21 & 246.9 & 252.1 & 228.0 \\
\hline 22 & 236.4 & 247.3 & 219.5 \\
\hline 23 & 215.2 & 235.0 & 207.0 \\
\hline 24 & 195.0 & 226.0 & 191.4 \\
\hline
\end{tabular}




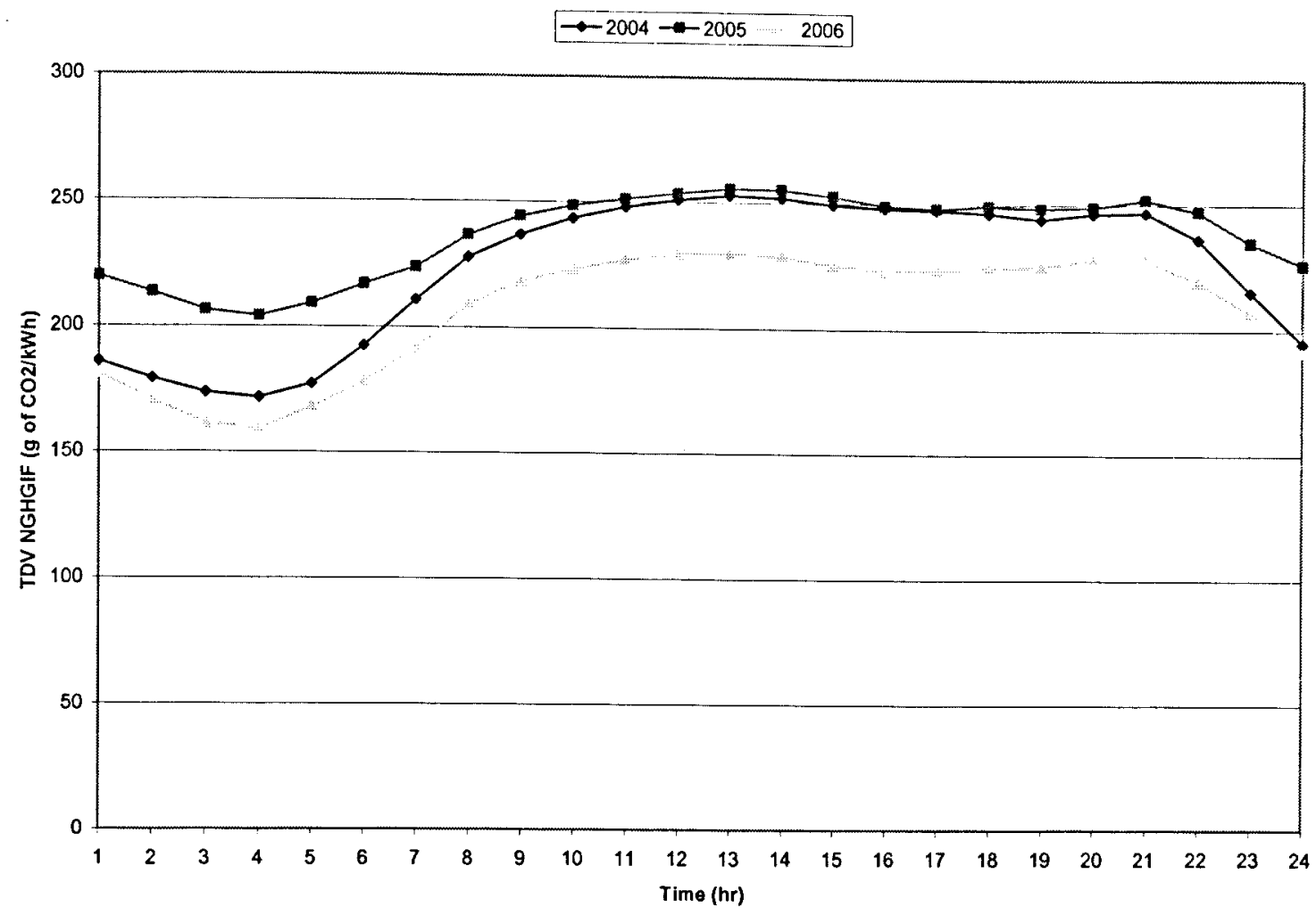

Figure 6-31: TDV emission factor profile comparison 2004-2006

Monthly average GHG cost factors were developed for 2004, 2005, and 2006 based on flat rate, TOU, and wholesale pricing schemes as illustrated in Table 6-42, Table 6-43, and Table 6-44. Cost factors were the highest during May for 2004 and 2005, and April for 2006 for the flat rate electricity pricing scheme, TOU pricing scheme, and wholesale pricing scheme. It should be noted that seasonal TDV cost factors did not vary as much in comparison to monthly values, thus it was determined that monthly values would give a better representation of the cost factor potential to assign a monetary value on greenhouse gases from the electricity generation sector. 
Table 6-42: Average GHG cost factors using flat rate pricing scheme 2004-2006

\begin{tabular}{|c|c|c|c|}
\hline \multicolumn{4}{|c|}{ TDV NGHGCF } \\
\hline Aelec, flat $(\$ / \mathbf{k g}$ of CO $)$ \\
\hline Month & $\mathbf{2 0 0 4}$ & $\mathbf{2 0 0 5}$ & $\mathbf{2 0 0 6}$ \\
\hline Jan & 0.372 & 0.467 & 0.494 \\
\hline Feb & 0.397 & 0.452 & 0.523 \\
\hline Mar & 0.495 & 0.443 & 0.587 \\
\hline Apr & 0.660 & 0.497 & 1.037 \\
\hline May & 0.916 & 0.606 & 0.686 \\
\hline Jun & 0.811 & 0.464 & 0.482 \\
\hline Jul & 0.777 & 0.444 & 0.459 \\
\hline Aug & 0.709 & 0.417 & 0.524 \\
\hline Sep & 0.599 & 0.468 & 0.614 \\
\hline Oct & 0.405 & 0.547 & 0.579 \\
\hline Nov & 0.443 & 0.543 & 0.553 \\
\hline Dec & 0.525 & 0.507 & 0.507 \\
\hline Annual & 0.592 & 0.488 & 0.587 \\
\hline
\end{tabular}

Table 6-43: Average GHG cost factors using TOU pricing scheme 2004-2006

\begin{tabular}{|c|c|c|c|}
\hline \multicolumn{4}{|c|}{ TDV NGHGCF } \\
\hline A elec, TOU $\left(\$ / \mathrm{kg}\right.$ of CO $_{2}$ ) \\
\hline Month & 2004 & $\mathbf{2 0 0 5}$ & $\mathbf{2 0 0 6}$ \\
\hline Jan & 0.363 & 0.448 & 0.481 \\
\hline Feb & 0.391 & 0.446 & 0.522 \\
\hline Mar & 0.490 & 0.439 & 0.579 \\
\hline Apr & 0.613 & 0.492 & 0.974 \\
\hline May & 0.818 & 0.571 & 0.646 \\
\hline Jun & 0.748 & 0.451 & 0.453 \\
\hline Jul & 0.712 & 0.423 & 0.440 \\
\hline Aug & 0.649 & 0.409 & 0.503 \\
\hline Sep & 0.555 & 0.453 & 0.566 \\
\hline Oct & 0.383 & 0.507 & 0.540 \\
\hline Nov & 0.437 & 0.535 & 0.543 \\
\hline Dec & 0.526 & 0.495 & 0.497 \\
\hline Annual & 0.557 & 0.473 & 0.562 \\
\hline
\end{tabular}


Table 6-44: Average GHG cost factors using wholesale pricing scheme 2004-2006

\begin{tabular}{|c|c|c|c|}
\hline \multicolumn{4}{|c|}{ TDV NGHGCF } \\
\hline A elec, wholesale $\left(\$ / k g\right.$ of CO$_{2}$ ) \\
\hline Month & 2004 & 2005 & 2006 \\
\hline Jan & 0.233 & 0.245 & 0.259 \\
\hline Feb & 0.203 & 0.219 & 0.242 \\
\hline Mar & 0.228 & 0.262 & 0.274 \\
\hline Apr & 0.274 & 0.294 & 0.353 \\
\hline May & 0.349 & 0.296 & 0.286 \\
\hline Jun & 0.312 & 0.272 & 0.210 \\
\hline Jul & 0.294 & 0.315 & 0.210 \\
\hline Aug & 0.260 & 0.347 & 0.251 \\
\hline Sep & 0.256 & 0.408 & 0.191 \\
\hline Oct & 0.189 & 0.364 & 0.212 \\
\hline Nov & 0.218 & 0.296 & 0.255 \\
\hline Dec & 0.252 & 0.363 & 0.187 \\
\hline Annual & 0.256 & 0.307 & 0.244 \\
\hline
\end{tabular}

\subsubsection{Annual Peak Day GHG Analysis for 2004, 2005, and 2006}

As illustrated in Table 6-45 $\mathrm{CO}_{2}$ emissions were highest during the peak winter day for 2004 . $\mathrm{CO}_{2}$ emissions decreased by $38 \%$ in the spring, increased by $11 \%$ in the summer and decreased by $22 \%$ in the fall.

Table 6-45: $\mathrm{CO}_{2}$ Emissions during seasonal peak days for 2004

\begin{tabular}{|c|c|}
\hline 2004 & Emissions (kt) \\
\hline Winter & 171 \\
\hline Spring & 106 \\
\hline Summer & 119 \\
\hline Fall & 93 \\
\hline
\end{tabular}

Figure 6-32 shows the seasonal emission factor profiles for 2004. Emission factors were highest during the winter. 


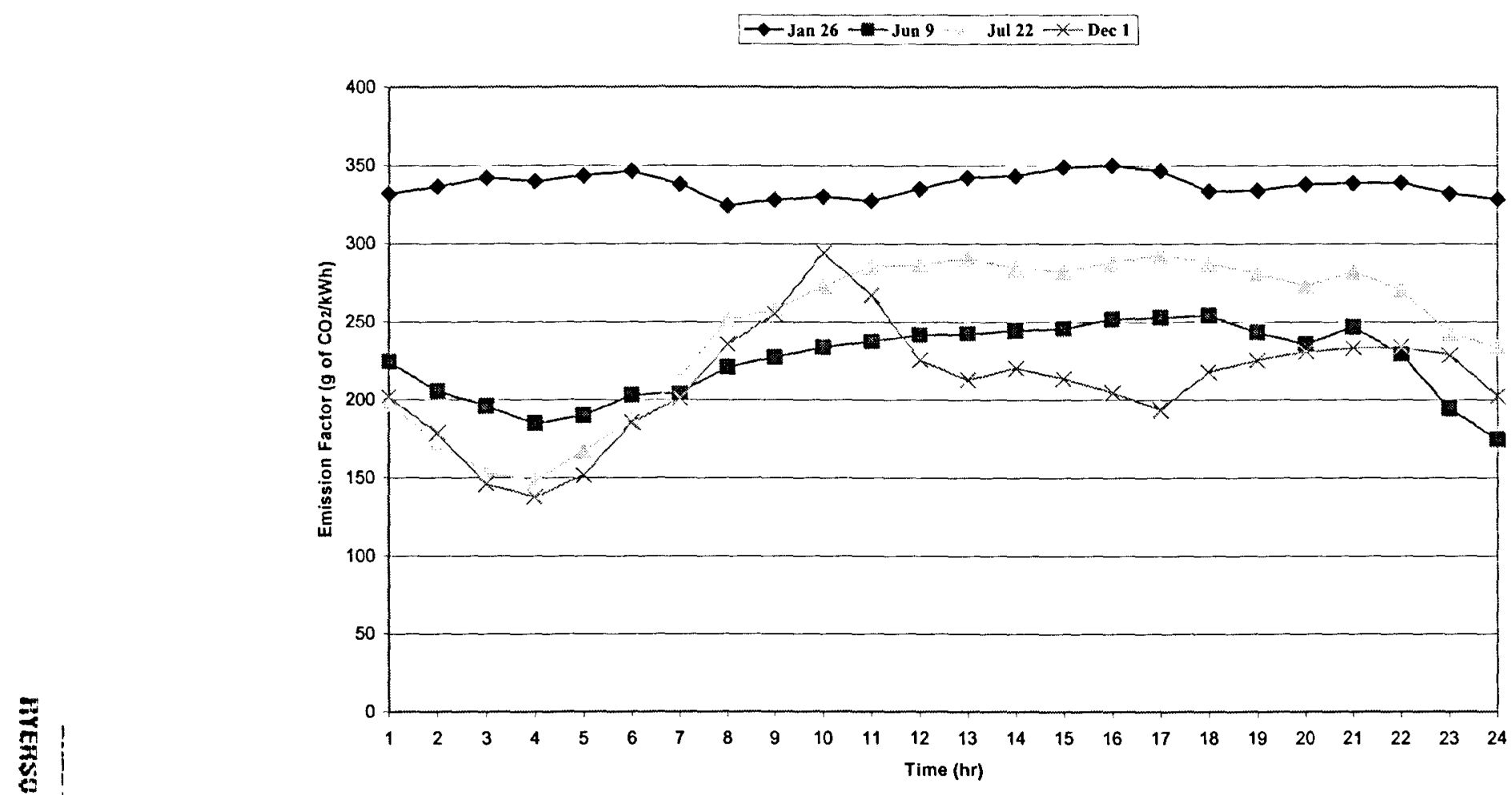

Figure 6-32: Hourly seasonal emission factors during peak days for 2004

As illustrated in Table 6-46 $\mathrm{CO}_{2}$ emissions were highest during the peak spring day for 2005. $\mathrm{CO}_{2}$ emissions increased by $4 \%$ in the spring, decreased by $5.6 \%$ in the summer and remained approximately the same in the fall.

Table 6-46: $\mathrm{CO}_{2}$ emissions during seasonal peak days for 2005

\begin{tabular}{|c|c|}
\hline 2005 & Emissions (kt) \\
\hline Winter & 137 \\
\hline Spring & 143 \\
\hline Summer & 135 \\
\hline Fall & 134 \\
\hline
\end{tabular}

Figure 6-33 shows the seasonal emission factor profiles for 2005. Emission factors were highest during the spring. 


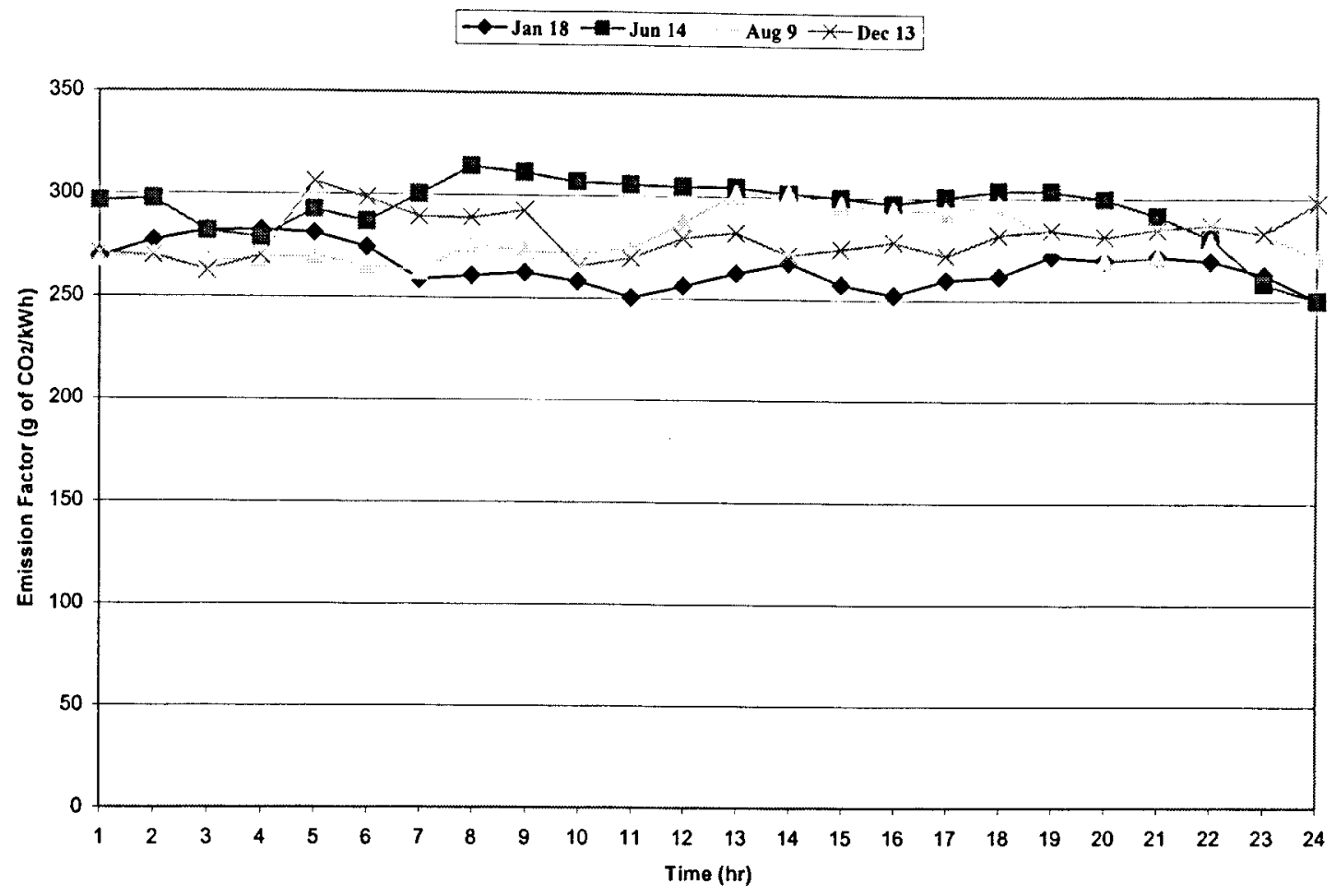

Figure 6-33: Hourly seasonal emission factors during peak days for 2005

As illustrated in Table 6-47 $\mathrm{CO}_{2}$ emissions were highest during the peak summer day for 2006. $\mathrm{CO}_{2}$ emissions decreased by $27 \%$ in the spring, increased by $37 \%$ in the summer and decreased by approximately the same in the fall.

Table 6-47: $\mathrm{CO}_{2}$ emissions during seasonal peak days for 2006

\begin{tabular}{|c|c|}
\hline 2006 & Emissions (kt) \\
\hline Winter & 131 \\
\hline Spring & 96 \\
\hline Summer & 153 \\
\hline Fall & 97 \\
\hline
\end{tabular}

Figure 6-34 shows the seasonal emission factor profiles for 2006. Emission factors were highest during the morning in the winter and afternoon in the summer. 


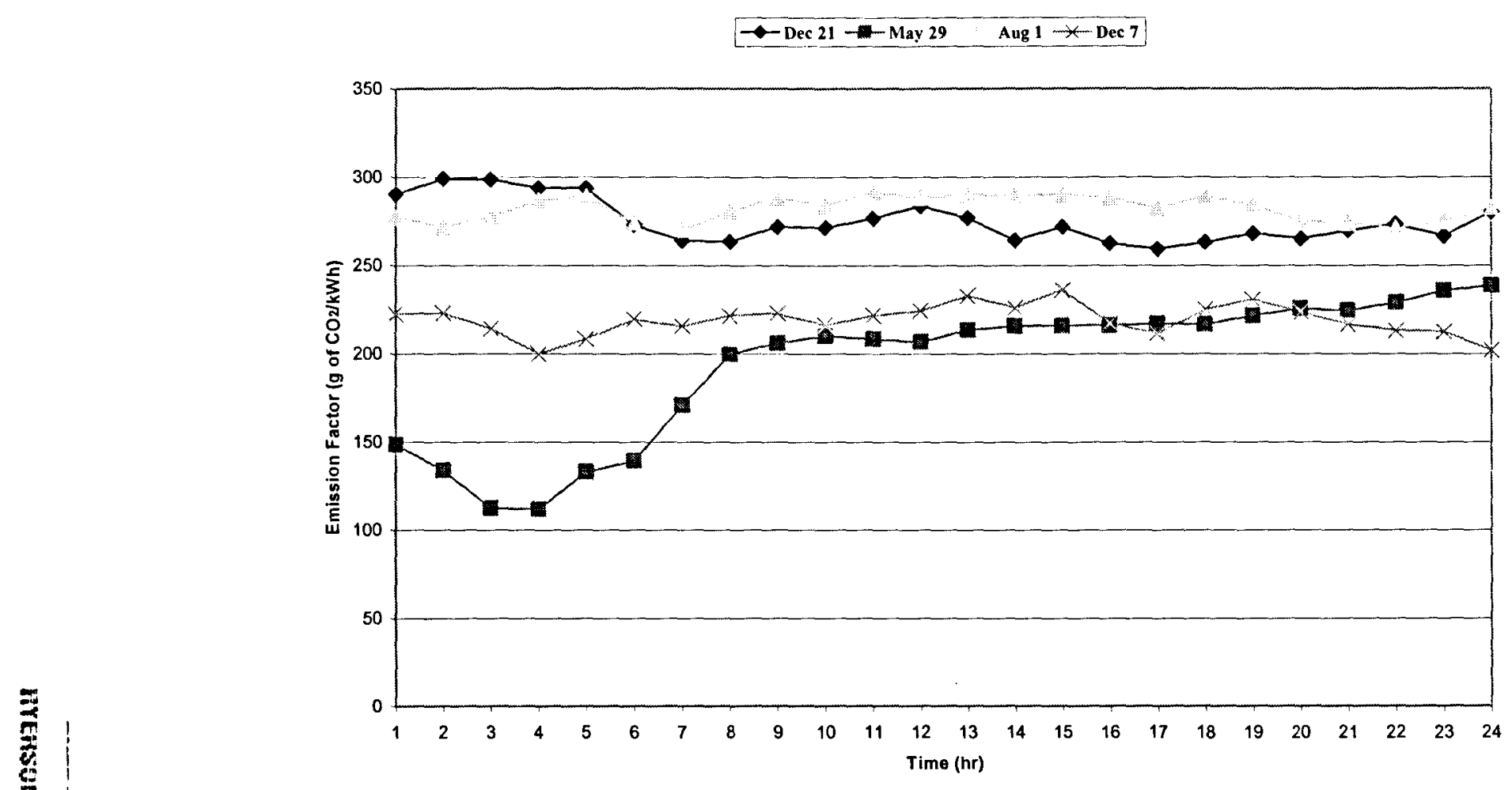

Figure 6-34: Hourly seasonal emission factors during peak days for 2006

The next chapter shows three case studies using the emission factors developed in this chapter. 


\section{Test-Case Scenarios}

\subsection{Introduction}

In recent years, the correlation between increasing greenhouse gas (GHG) emissions, resulting from humankind's unwavering demand for energy, and global climate change has been the subject of worldwide concern. While much of the science behind climatic shifts remains unexplained, it has become increasingly difficult to disregard the reductions of GHG achievable through utilization of renewable energy technologies. The offset cyclical relationship, daily and yearly, between electricity generated by a photovoltaic (PV) system, its solar source, and varying electrical demand is commonly considered unfavourable. However the alignment between off-peak residential demand and high solar availability suitable for PV generation presents a possibly lucrative opportunity. An Ontario government initiative offers compensation in the form of 42 cents/kWh to PV generated electricity supplied to the grid. This thesis will investigate a residential PV and a micro-wind turbine system for comparison, to determine both the economic feasibility and GHG reduction potential in the Province of Ontario by employing the model of a test-case model house in Toronto, using building energy simulation software. All test cases are described in Section 3.8.

The estimates for GHG emission reductions from three scenarios presented in this chapter illustrate the impact on the use of the different GHG emission factors developed in Chapter 6. Depending on which emission factor is used the actual GHG emissions can vary considerably.

\subsection{Electricity Generation}

\subsubsection{Case Study 1}

The electricity generated by the PV and micro-wind turbine simulations performed for the entire year is shown in Figure 7-1 and Figure 7-2 (Syed et al., 2007). Clearly PV output is the highest during early summer and micro-wind during early spring. 


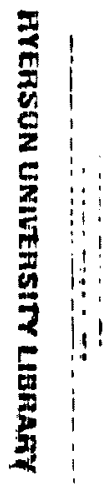

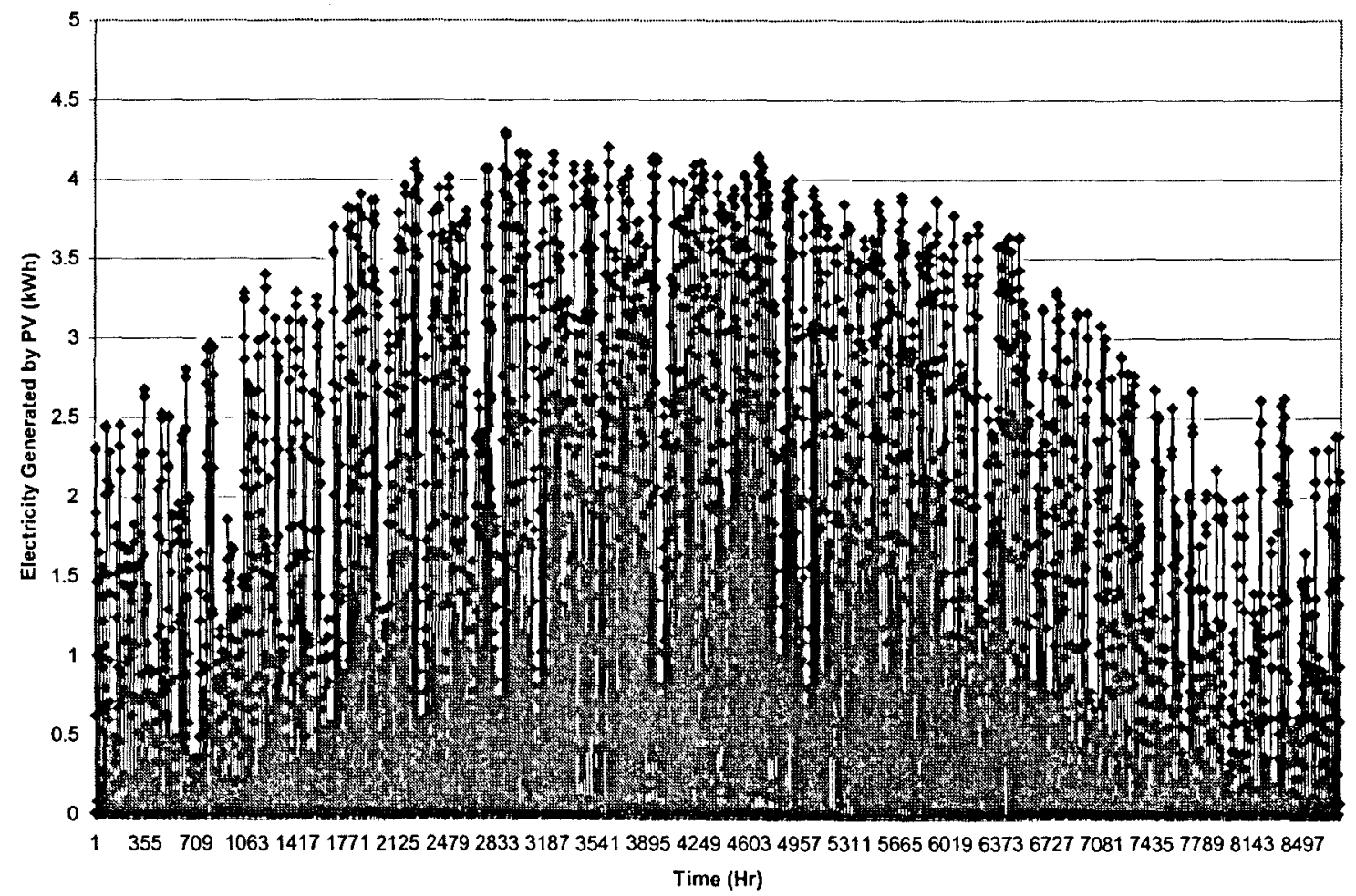

Figure 7-1: PV output profile for test-case study 1 in Toronto

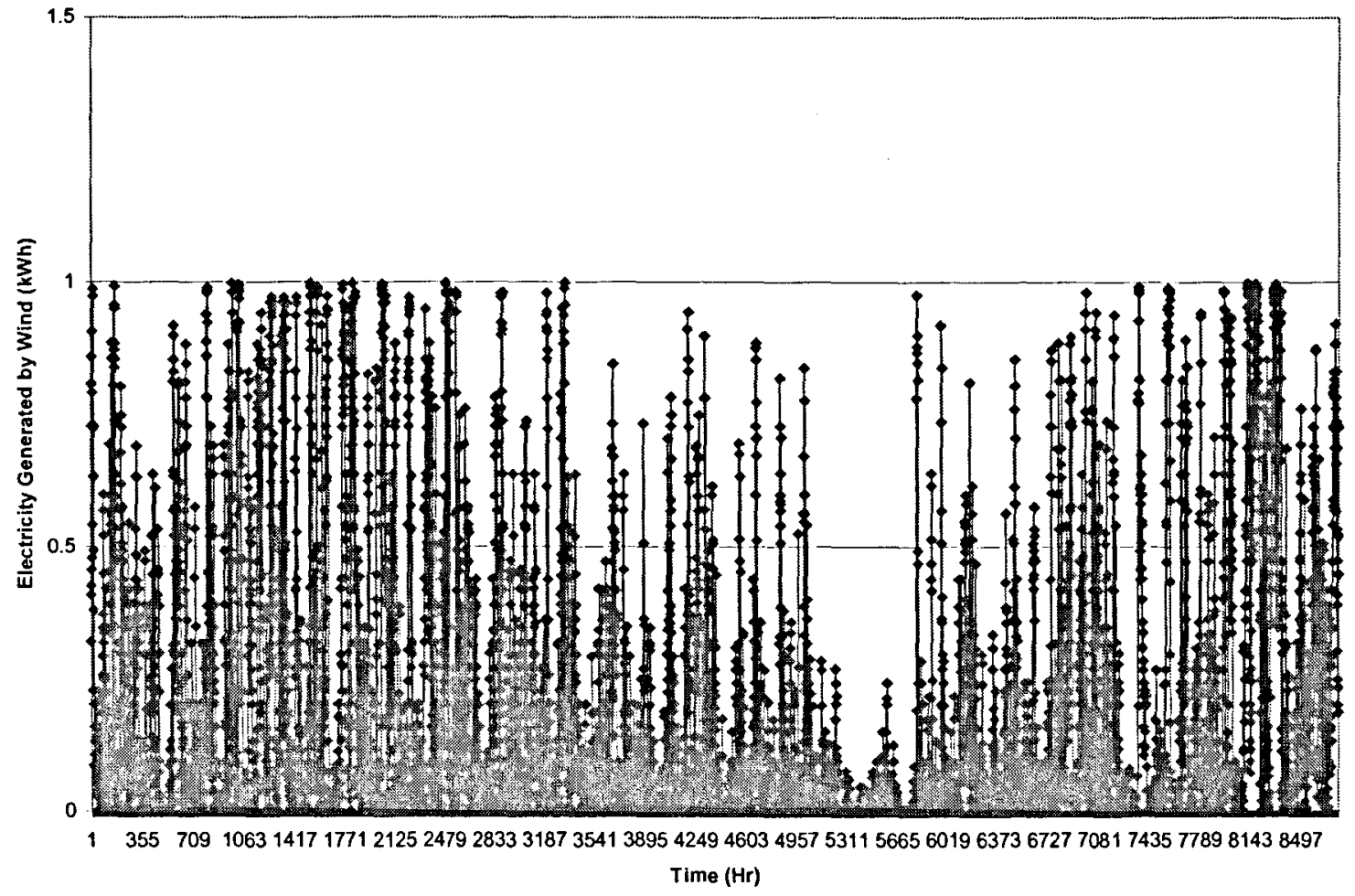

Figure 7-2: Micro-wind turbine output profile for test-case study 1 in Toronto 
Table 7-1 shows the total electric power generated by PV and micro-wind turbine for the entire year. It can be observed that PV generated $76 \%$ more electricity than micro-wind turbine. It should be noted that the installed capacities for PV $(5 \mathrm{~kW})$ and micro-wind turbine $(1 \mathrm{~kW})$ are different. Therefore, the results are specific to this simulation only.

Table 7-1: Annual electricity generated by PV and micro-wind turbine for test-case study 1

\begin{tabular}{|c|c|}
\hline \multicolumn{2}{|c|}{ Electricity Generated (kWh) } \\
\hline Photovoltaic & Micro-Wind Turbine \\
\hline 7047 & 1686 \\
\hline
\end{tabular}

Figure 7-3 shows the total monthly electric power generated by PV and micro-wind turbine. Electricity generation was highest during July and December for PV and micro-wind turbine, respectively. It should be noted that the results are highly dependent on the weather data in a given simulation year.

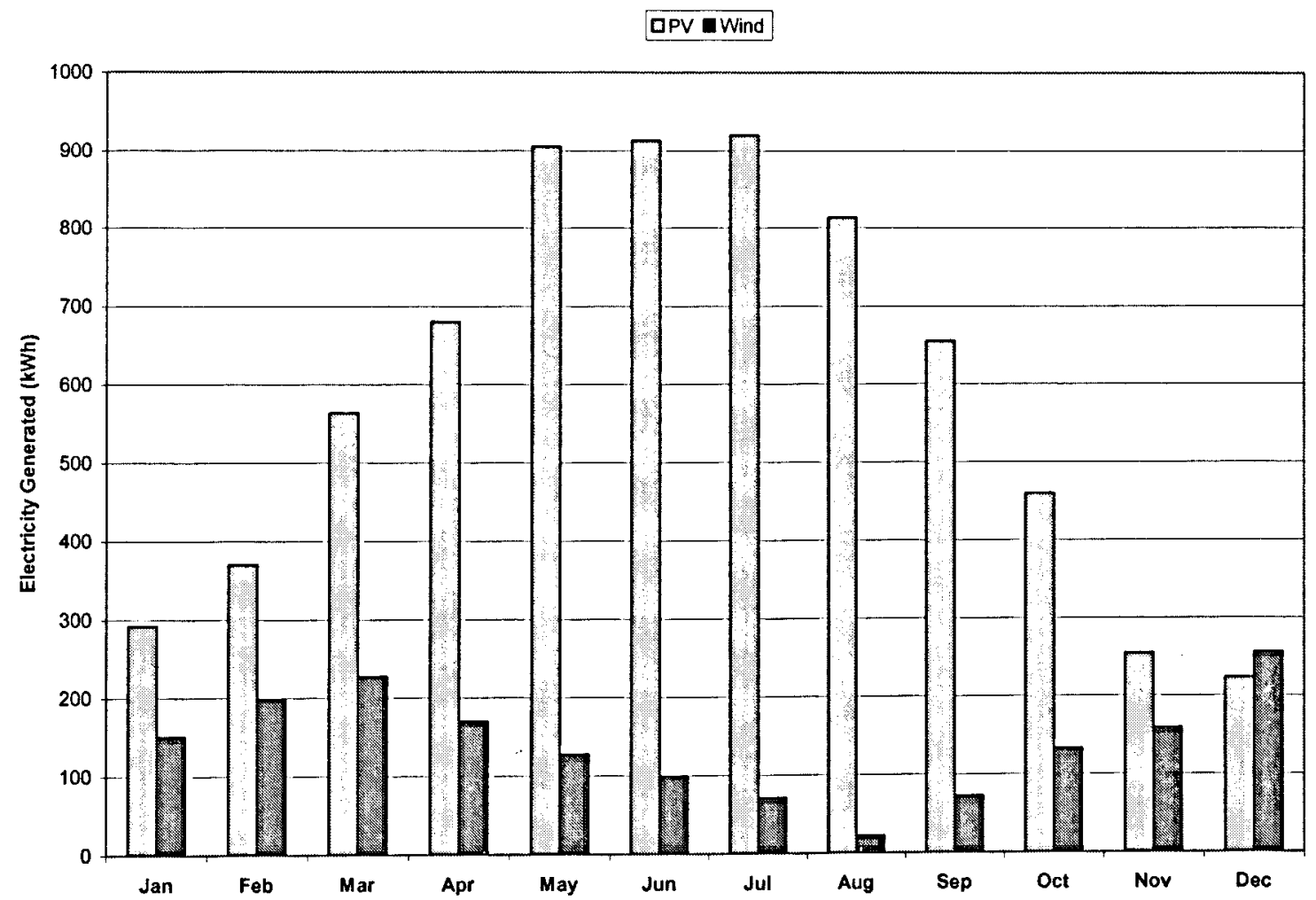

Figure 7-3: Monthly electricity generated by PV and micro-wind turbine for test-case study 1 


\subsubsection{Case Study 2}

The electricity generated by the PV simulation performed for a typical summer and winter week is illustrated in Figure 7-4 (Good et al., 2006). It can be observed that PV output is highest during the middle of the week in the summer. The results are specific to the weeks in study.

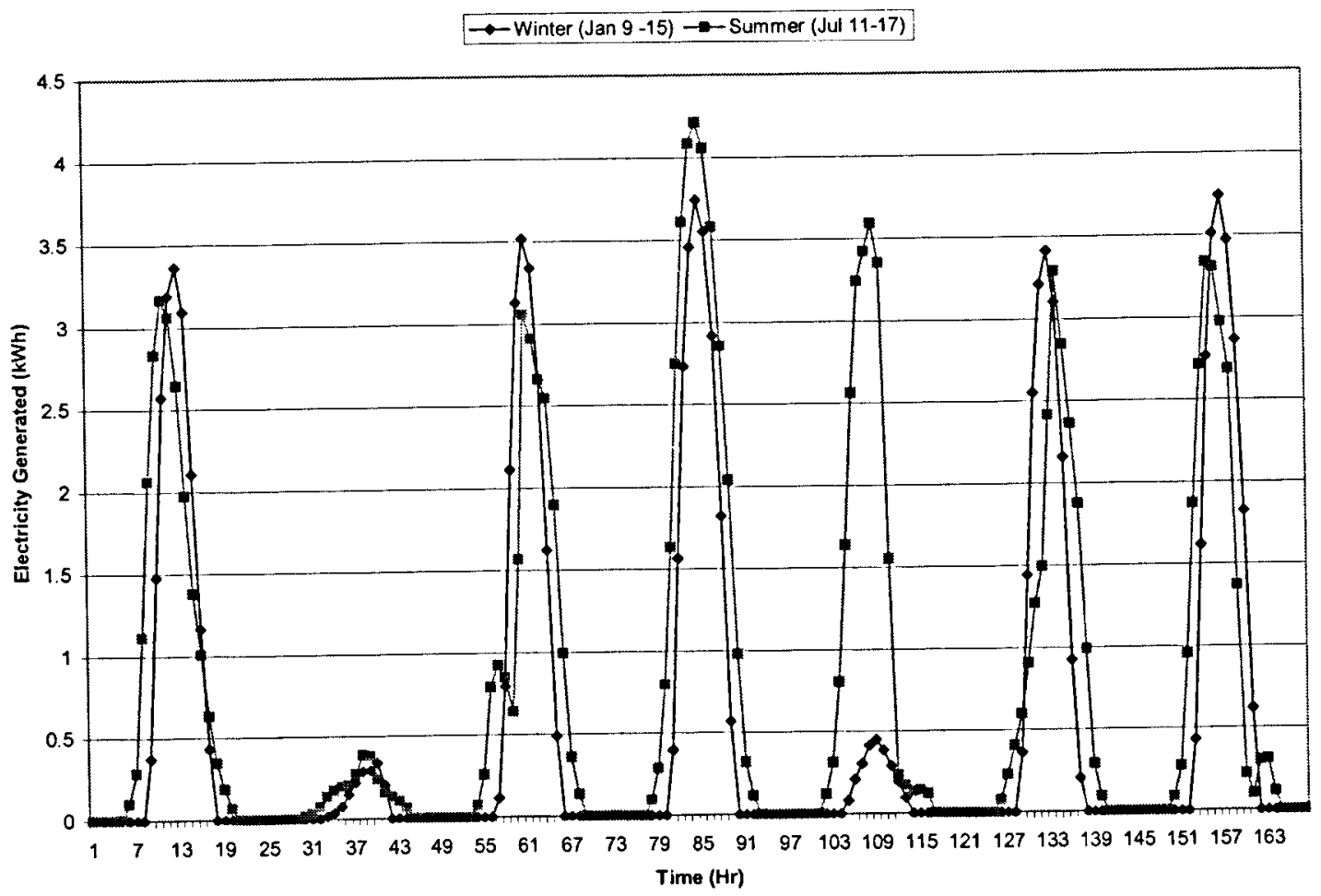

Figure 7-4: PV output profile for test-case study 2 in Ottawa

Table 7-2 shows the total electric power generated by PV for a typical summer and winter week. It can be observed that PV in the summer generated $20 \%$ more electricity than in the winter.

Table 7-2: Annual electricity generated by PV for test-case study 2

\begin{tabular}{|c|c|}
\hline \multicolumn{2}{|c|}{ Photovoltaic } \\
\hline Electricity Generated (kWh) \\
\hline Winter & Summer \\
\hline 109 & 136 \\
\hline
\end{tabular}

Figure 7-5 shows the total daily electric power generated by PV. Electricity generation was highest on Wednesday and Monday for the summer and winter, respectively. 


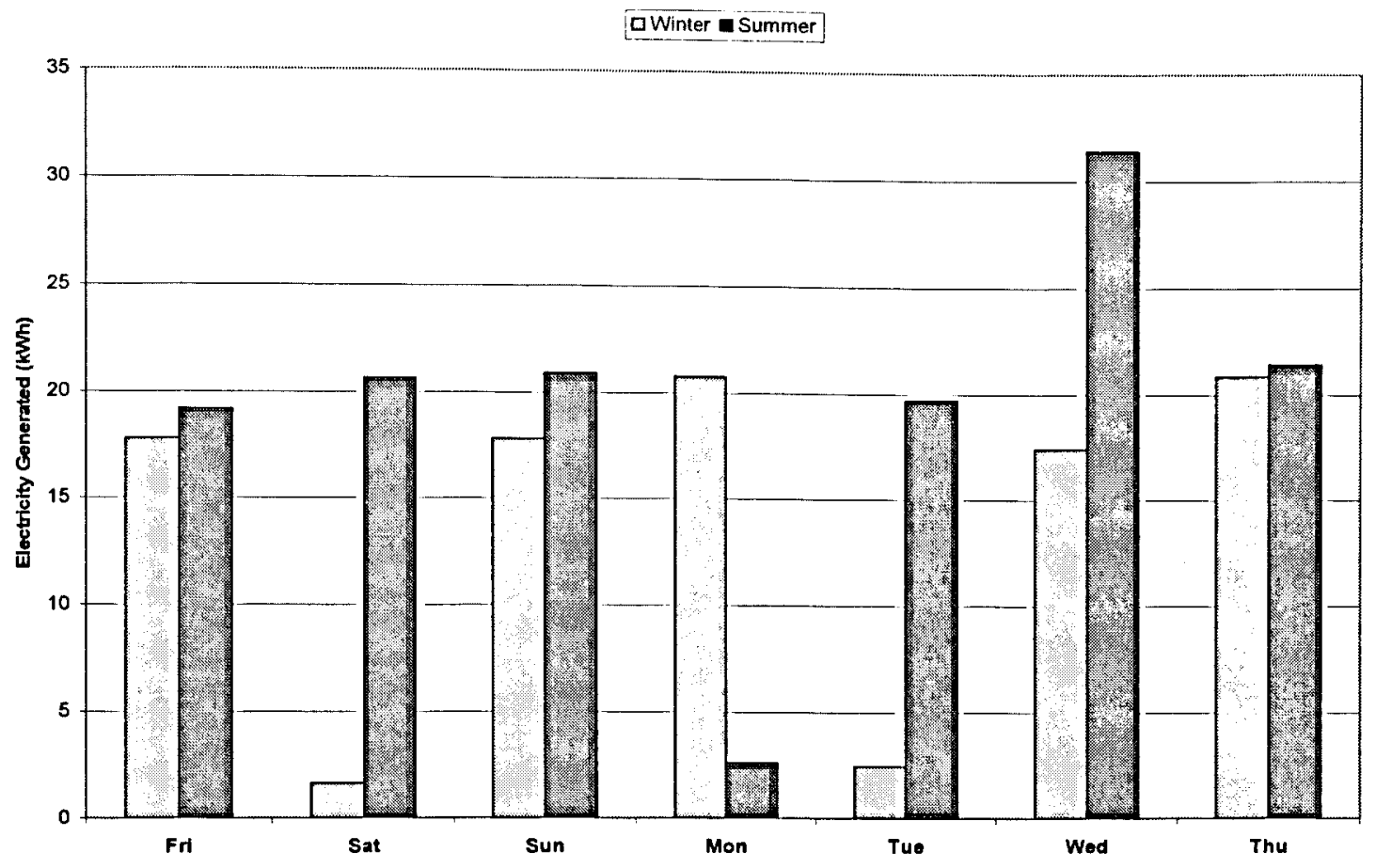

Figure 7-5: Daily electricity generated by PV for test-case study 2

\subsubsection{Case Study 3}

The electricity generated by the PV simulation performed for 2005 is illustrated in Figure 7-6 (Tse et al., 2008). It can be observed that PV output is highest during the summer.

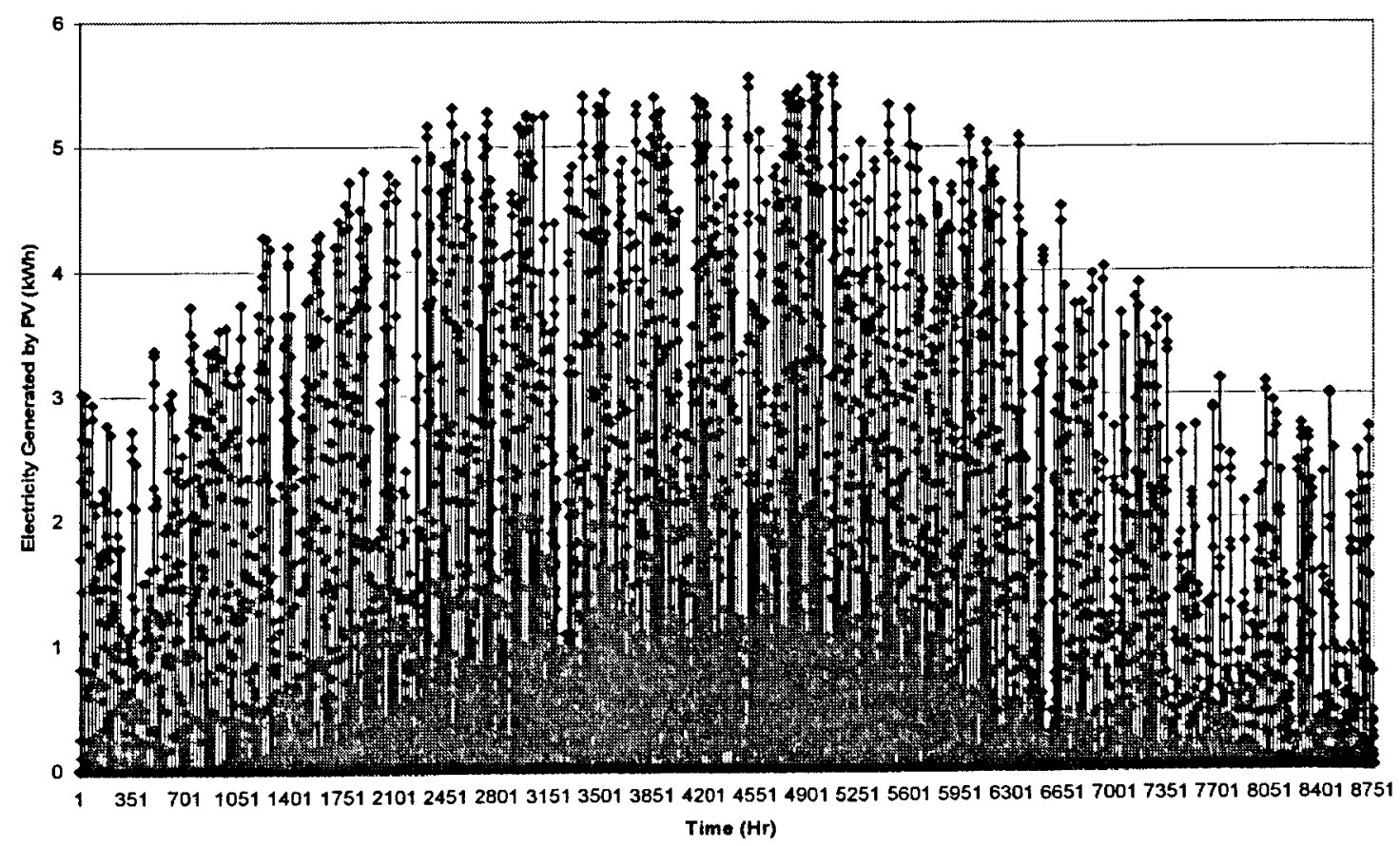

Figure 7-6: PV output profile for test-case study 3 in Toronto 
Table 7-3 shows the total electric power generated by PV for the entire year. It can be observed that PV generated $7767 \mathrm{kWh}$ during 2005 for the test-case townhouse located in the Annex part of Toronto.

Table 7-3: Total electricity generated by PV for test-case study 3

\begin{tabular}{|c|}
\hline Photovoltaic \\
\hline Electricity Generated $(\mathrm{kWh})$ \\
\hline 7767 \\
\hline
\end{tabular}

Figure 7-7 shows the total monthly electric power generated by the PV system for the year 2005. Electricity generation was the highest during July and throughout the summer.

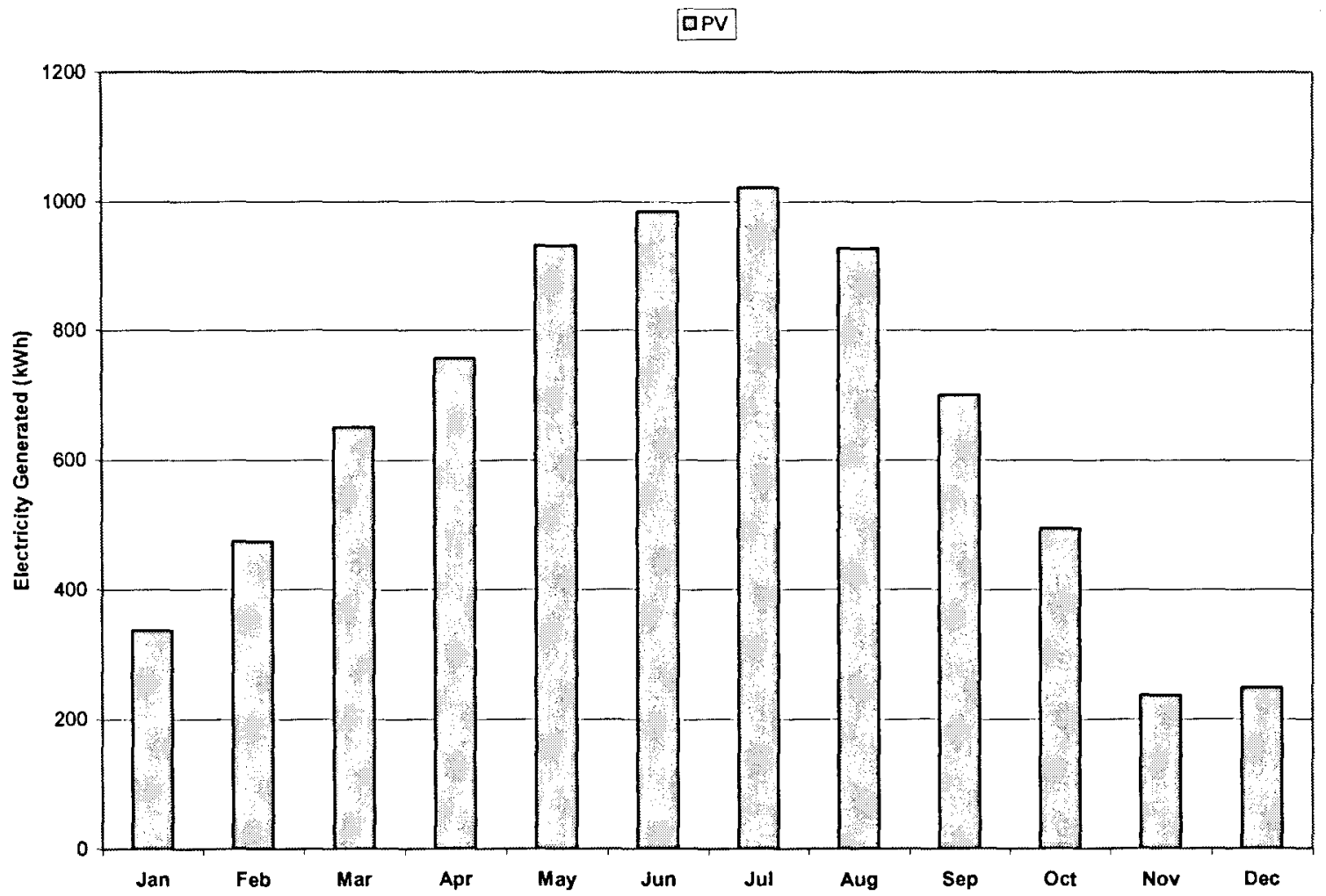

Figure 7-7: Monthly electricity generated by PV for test-case study 3 


\subsection{GHG Analysis}

In order to calculate the $\mathrm{CO}_{2}$ emission reduction for the electricity generated by $\mathrm{PV}$ and micro-wind technologies, electricity emission factors were developed in chapter 6 . The $\mathrm{CO}_{2}$ emission reduction potential was calculated by multiplying the hourly electricity by the different emission factors for the province as defined in equations 7.1, 7.2, 7.3, and 7.4. Four estimates of the GHG emissions are given using the various intensity electricity emission factors as discussed in chapter 3 .

$$
G H G_{\text {el,HNGHGIF }}=\sum\left[\left(\text { Generated }_{\text {el,hourly }}\right)\left(N H G H G I F_{A}\right)\right]
$$

Where,

$G H G_{\text {el.HNGHGF}}=$ Annual GHG emission reduction using the new hourly emission factor ( $\mathrm{g}$ of $\mathrm{CO}_{2}$ )

Generated $_{\text {el,hourly }}=$ Hourly electricity generated by renewable technology for test case house (kWh)

NHGHGIF $F_{A}=$ New Hourly Greenhouse Gas Intensity Factor $\left(\mathrm{g} \mathrm{CO}_{2} / \mathrm{kWh}\right)$

$$
G H G_{\text {el.SNGHGIFA }}=\sum\left[\left(\text { Generated }_{\text {el,hourly }}\right)\left(\operatorname{SANGHGIF}_{A}\right)\right]
$$

Where,

$G H G_{\text {el,SANGHGIF }}=$ Annual GHG emission reductions using the seasonal average emission factor $\left(\mathrm{g}\right.$ of $\left.\mathrm{CO}_{2}\right)$

Generated $_{\text {el,hourly }}=$ Hourly electricity generated by renewable technology for test case house (kWh)

$\operatorname{SANGHGIF}_{A}=$ Seasonal Average New Greenhouse Gas Intensity Factor (g $\left.\mathrm{CO}_{2} / \mathrm{kWh}\right)$

$$
G H_{\text {el, AANGHCIF }_{A}}=\sum\left[\left(\text { (enerated }_{\text {el, hourly }}\right)\left(A A N G H G I F_{A}\right)\right]
$$


Where,

$G H G_{e l, A A N G H G I F_{A}}=$ Annual GHG emission reductions using the annual average emission factor $\left(\mathrm{g}\right.$ of $\left.\mathrm{CO}_{2}\right)$

Generated $_{\text {el,hourly }}=$ Hourly electricity generated by renewable technology for test case house $(\mathrm{kWh})$

$A A N G H G I F_{A}=$ Annual Average New Greenhouse Gas Intensity Factor (g $\left.\mathrm{CO}_{2} / \mathrm{kWh}\right)$

$G H G_{e l, T D V N G H G I F_{A}}=\sum\left[\left(\right.\right.$ Generated $\left.\left._{\text {el,hourly }}\right)\left(T D V N G H G I F_{A}\right)\right]$

Where,

$G H G_{e l, T D V N G H G I F_{A}}=$ Annual GHG emission reductions using the seasonal time dependent valuation new greenhouse gas intensity factor $\left(\mathrm{g} \mathrm{CO}_{2} / \mathrm{kWh}\right)$

Generated $_{\text {el.hourly }}=$ Hourly electricity generated by renewable technology for test case house $(\mathrm{kWh})$

$T D V N G H G I F_{A}=$ Seasonal Time Dependent Valuation New Greenhouse Gas Intensity Factor $\left(\mathrm{g} \mathrm{CO}_{2} / \mathrm{kWh}\right)$

\subsubsection{Case Study 1}

The total emission reductions by PV and micro-wind turbine using the new hourly emission factor were:

PV GHG $G_{e l, H N G H G I F_{A}}=1657 \mathrm{~kg}$ of $\mathrm{CO}_{2}$

Micro-wind turbine $G H G_{e l, H N G H G I F_{A}}=376 \mathrm{~kg}$ of $\mathrm{CO}_{2}$

The total emission reductions by PV and micro-wind turbine using the seasonal average emission factor were:

$\mathrm{PV} \mathrm{GHG}_{\text {el.SANGHGIF }}=1559 \mathrm{~kg}$ of $\mathrm{CO}_{2}$ 
Micro-wind turbine $G H G_{e l, S A N G H G I F_{A}}=365 \mathrm{~kg}$ of $\mathrm{CO}_{2}$

The total emission reductions by PV and micro-wind turbine using the annual average emission factor were:

$\mathrm{PVGHG}_{e l, A A N G H G I F_{A}}=1557 \mathrm{~kg}$ of $\mathrm{CO}_{2}$

Micro-wind turbine $G H G_{e l, A A N G H G I F_{A}}=373 \mathrm{~kg}$ of $\mathrm{CO}_{2}$

The total emission reductions by PV and micro-wind turbine using the seasonal time dependent valuation new greenhouse gas intensity factor were:

PV GHG $G_{e l, T D V N G H G I F_{A}}=1767 \mathrm{~kg}$ of $\mathrm{CO}_{2}$

Micro-wind turbine $G H G_{e l, T D V N G H G I F_{A}}=403 \mathrm{~kg}$ of $\mathrm{CO}_{2}$

Table 7-4 summarizes the total emission reduction results by using the different emission factors. The upper limit of $\mathrm{CO}_{2}$ emission reduction was obtained by using the TDV emission factor for both PV and micro-wind turbine. The lower limit was obtained by using the annual and seasonal average emission factors for PV and micro-wind turbine, respectively.

Table 7-4: Emission reduction comparison for test-case study 1

\begin{tabular}{|l|c|c|}
\hline \multirow{2}{*}{ Emission Factor Type } & Emission Reduction Potential (kg of CO2) \\
\cline { 2 - 3 } & Photovoltaic & Micro-Wind Turbine \\
\hline Hourly & 1657 & 376 \\
\hline Seasonal Average & 1559 & 365 \\
\hline Annual Average & 1557 & 373 \\
\hline Seasonal TDV & 1767 & 403 \\
\hline
\end{tabular}

The potential reductions in $\mathrm{CO}_{2}$ emissions using the seasonal average, annual average and seasonal TDV emission factors compared to using hourly emission factor is shown in Table 7-5. It can be observed that higher and lower emission reductions by PV and micro-wind turbine are obtained by using the seasonal TDV and annual average emission factor, respectively. 
Table 7-5: Different emission factor types vs. hourly emission factor for test-case study 1

\begin{tabular}{|c|cc|}
\hline \multirow{2}{*}{ Emission Factor Type } & \multicolumn{2}{|c|}{ \% Difference } \\
\cline { 2 - 3 } & PV & Wind \\
\hline Seasonal Average & -5.93 & -2.92 \\
\hline Annual Average & -6.05 & -0.79 \\
\hline Seasonal TDV & 6.62 & 7.18 \\
\hline
\end{tabular}

Figure 7-8 shows the total monthly emission reduction potential by PV and micro-wind turbine. Emission reductions were the highest in June for PV and December for micro-wind, respectively. Conversely, the lowest emission reductions were during December and August for PV and micro-wind, respectively.

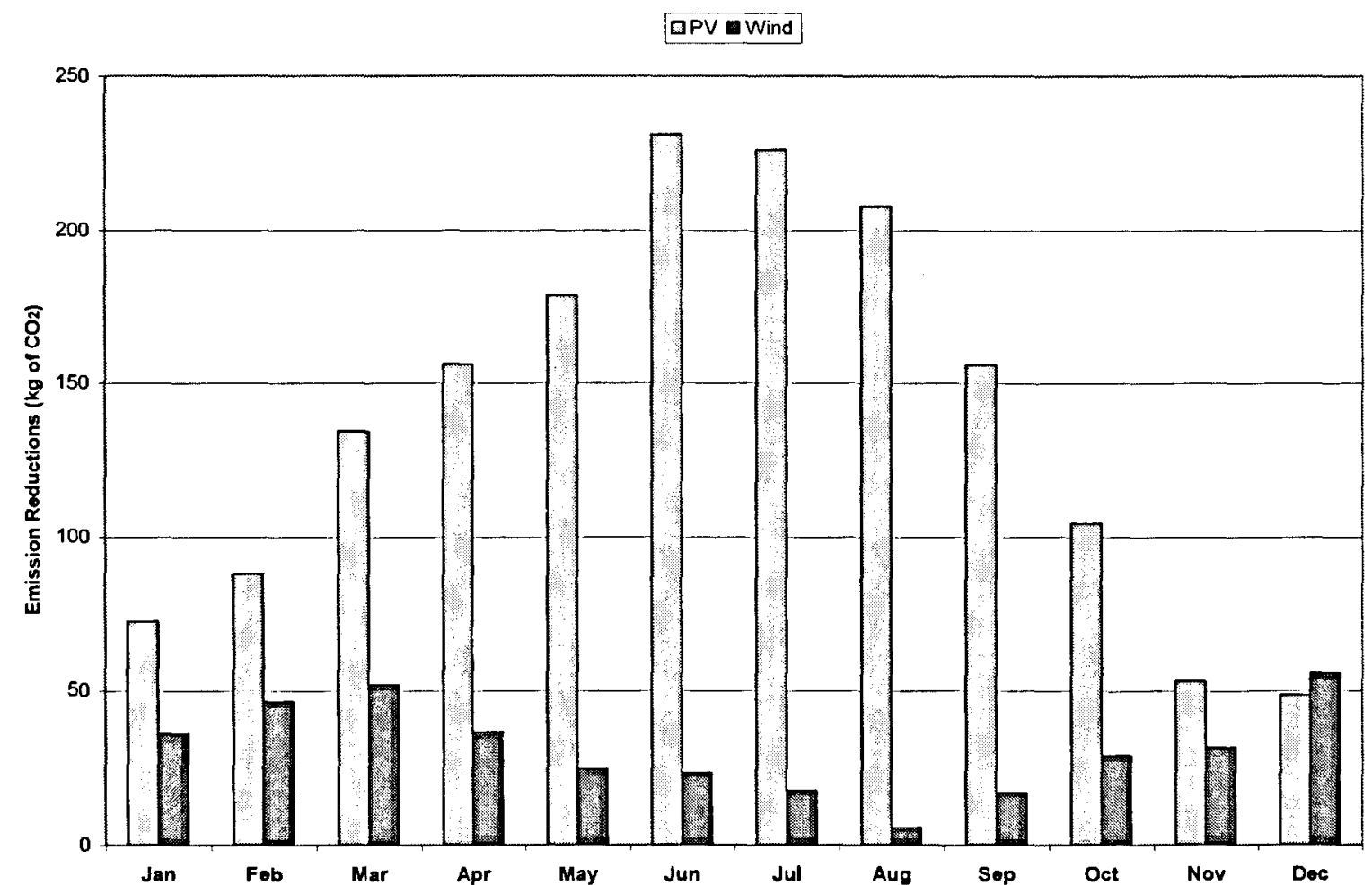

Figure 7-8: Monthly emission reductions for PV and micro-wind turbine test-case study 1

\subsubsection{Case Study 2}

Similarly to Case Study 1 the total emission reductions by PV using the new hourly emission factor for a typical summer and winter week were: 
Winter PV GHG $G_{e l, H N G H G I F_{A}}=30 \mathrm{~kg}$ of $\mathrm{CO}_{2}$

Summer PV GHG el.HNGHIF $_{4}=26 \mathrm{~kg}$ of $\mathrm{CO}_{2}$

The total emission reductions by PV using the seasonal average emission factor for a typical summer and winter week were:

Winter PV GHG el,SANGHGIF $_{A}=25 \mathrm{~kg}$ of $\mathrm{CO}_{2}$

Summer PVGHG el,SANGHGIFA $_{A}=24 \mathrm{~kg}$ of $\mathrm{CO}_{2}$

The total emission reductions by PV using the annual average emission factor for a typical summer and winter week were:

Winter PV GHG $G_{\text {el,AANGHGIF }}=21 \mathrm{~kg}$ of $\mathrm{CO}_{2}$

Summer PVGHG el,AANGHGIF $_{4}=28 \mathrm{~kg}$ of $\mathrm{CO}_{2}$

The total emission reductions by PV using the seasonal time dependent valuation new greenhouse gas intensity factor for a typical summer and winter week were:

Winter PV GHG el,TDVNGHCIF $_{4}=27 \mathrm{~kg}$ of $\mathrm{CO}_{2}$

Summer PV GHG $G_{\text {el,TDVNGHGIF }}=31 \mathrm{~kg}$ of $\mathrm{CO}_{2}$

Table 7-6 summarizes the total emission reduction results by using the different emission factors. The upper limit of $\mathrm{CO}_{2}$ emission reduction was obtained by using the hourly and TDV emission factor for the winter and summer, respectively. The lower limit was obtained by using the annual and seasonal average emission factors for the winter and summer, respectively. 
Table 7-6: Emission reduction comparison for test-case study 2

\begin{tabular}{|l|c|c|}
\hline \multirow{2}{*}{ Emission Factor Type } & \multicolumn{2}{|c|}{ Photovoltaic } \\
\cline { 2 - 3 } & Emission Reduction Potential (kg of CO2) \\
\cline { 2 - 3 } & Winter & Summer \\
\hline Hourly & 30 & 26 \\
\hline Seasonal Average & 25 & 24 \\
\hline Annual Average & 21 & 28 \\
\hline Seasonal TDV & 27 & 31 \\
\hline
\end{tabular}

The potential reductions in $\mathrm{CO}_{2}$ emissions using the seasonal average, annual average and seasonal TDV emission factors compared to using hourly emission factor is shown in Table 7-7. It can be observed that for the winter week emission reductions are lower in comparison to using hourly emission factors. As for the summer, higher and lower emission reductions are obtained by using the seasonal TDV and seasonal average emission factor, respectively. It should also be noted that during the summer the seasonal TDV emission factor resulted in a positive value compared to the winter. This might be attributed to the smaller period (one week) of this case study.

Table 7-7: Different emission factor types vs. hourly emission factor for test-case study 2

\begin{tabular}{|l|c|c|}
\hline \multicolumn{3}{|c|}{ \% Difference } \\
\hline Emission Factor Type & Winter & Summer \\
\hline Seasonal Average & -16.29 & -9.11 \\
\hline Annual Average & -31.33 & 8.65 \\
\hline Seasonal TDV & -10.61 & 18.96 \\
\hline
\end{tabular}

Figure 7-9 shows the total daily emission reduction potential by PV. Emission reductions were the highest on Monday and Wednesday for winter and summer, respectively. Conversely, the lowest emission reductions were on Saturday and Monday for winter and summer, respectively. 


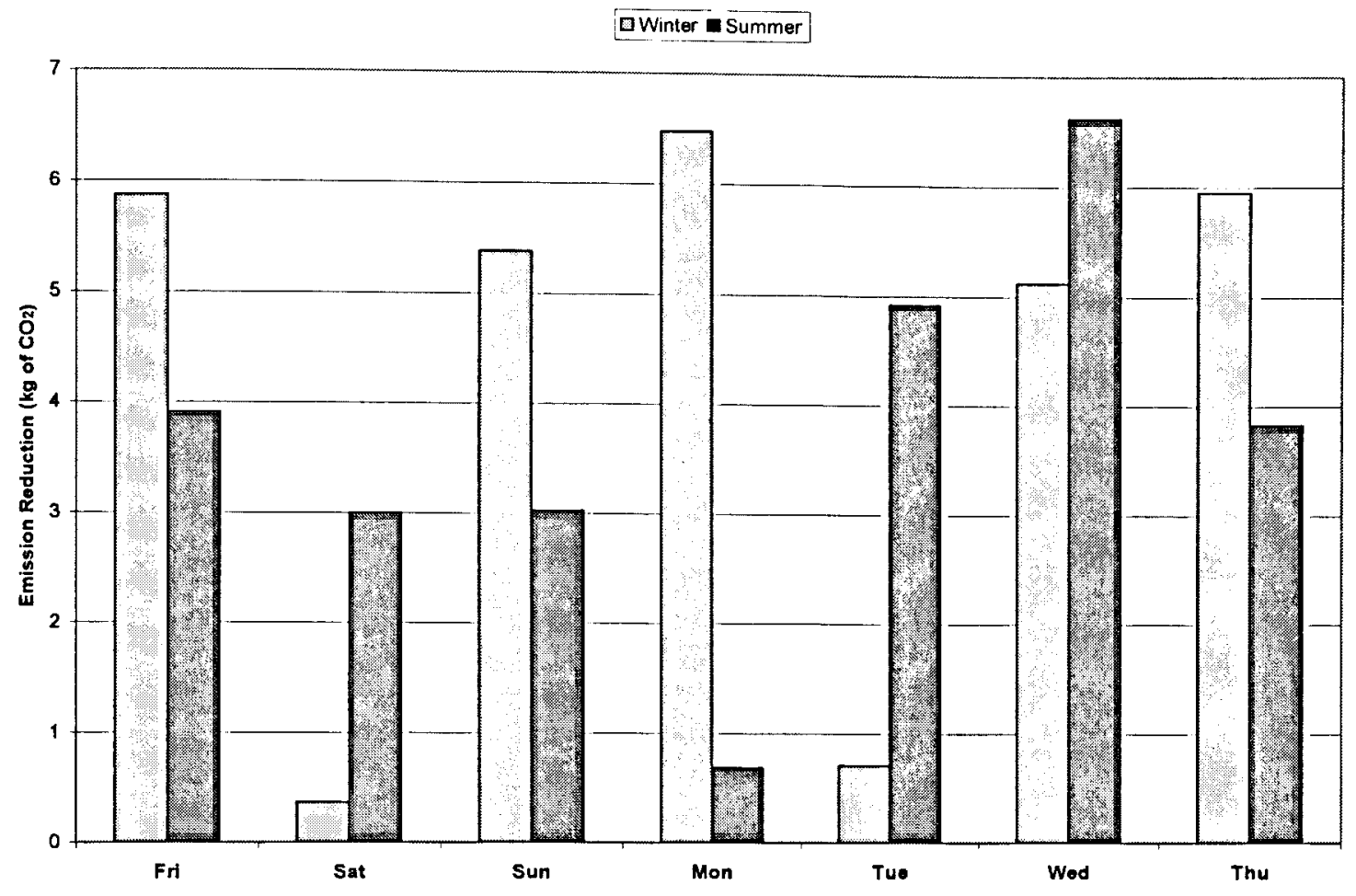

Figure 7-9: Daily emission reductions for PV test-case study 2

\subsubsection{Case Study 3}

Similarly to Case Study 2 the total emission reductions by PV using the new hourly emission factor were:

$\mathrm{PVGHG}_{\text {el.HNGHGIF}}=1856 \mathrm{~kg}$ of $\mathrm{CO}_{2}$

The total emission reductions by PV using the seasonal average emission factor were:

$\mathrm{PVGHG}_{\text {el, } \text { SANGHGIF }_{4}}=1727 \mathrm{~kg}$ of $\mathrm{CO}_{2}$

The total emission reductions by PV using the annual average emission factor were:

$\mathrm{PVGHG}_{\text {el,AANGHGIF }}=1716 \mathrm{~kg}$ of $\mathrm{CO}_{2}$ 
The total emission reductions by PV using the seasonal time dependent valuation new greenhouse gas intensity factor were:

Winter PVGHG ${ }_{e l . T D V N G H G I F}=1974 \mathrm{~kg}$ of $\mathrm{CO}_{2}$

Table 7-8 summarizes the total emission reduction results by using the different emission factors. The upper limit of $\mathrm{CO}_{2}$ emission reduction was obtained by using the TDV emission factor and the lower limit was obtained by using the annual average emission factor.

Table 7-8: Emission reduction comparison for test-case study 3

\begin{tabular}{|l|c|}
\hline \multirow{2}{*}{ Emission Factor Type } & Photovoltaic \\
\cline { 2 - 2 } & Emission Reduction Potential (kg of CO2) \\
\hline Hourly & 1856 \\
\hline Seasonal Average & 1727 \\
\hline Annual Average & 1716 \\
\hline Seasonal TDV & 1974 \\
\hline
\end{tabular}

The potential reductions in $\mathrm{CO}_{2}$ emissions using the seasonal average, annual average and seasonal TDV emission factors compared to using hourly emission factor is shown in Table 7-9. It can be observed that higher and lower emission reductions are obtained by using the seasonal TDV and annual average emission factor, respectively.

Table 7-9: Different emission factor types vs. hourly emission factor for test-case study 3

\begin{tabular}{|c|c|}
\hline Emission Factor Type & $\%$ Difference \\
\hline Seasonal Average & -6.97 \\
\hline Annual Average & -7.54 \\
\hline Seasonal TDV & 6.36 \\
\hline
\end{tabular}

Figure 7-10 shows the total daily emission reduction potential by PV. Emission reductions were the highest in June and July and the lowest in November and December. 


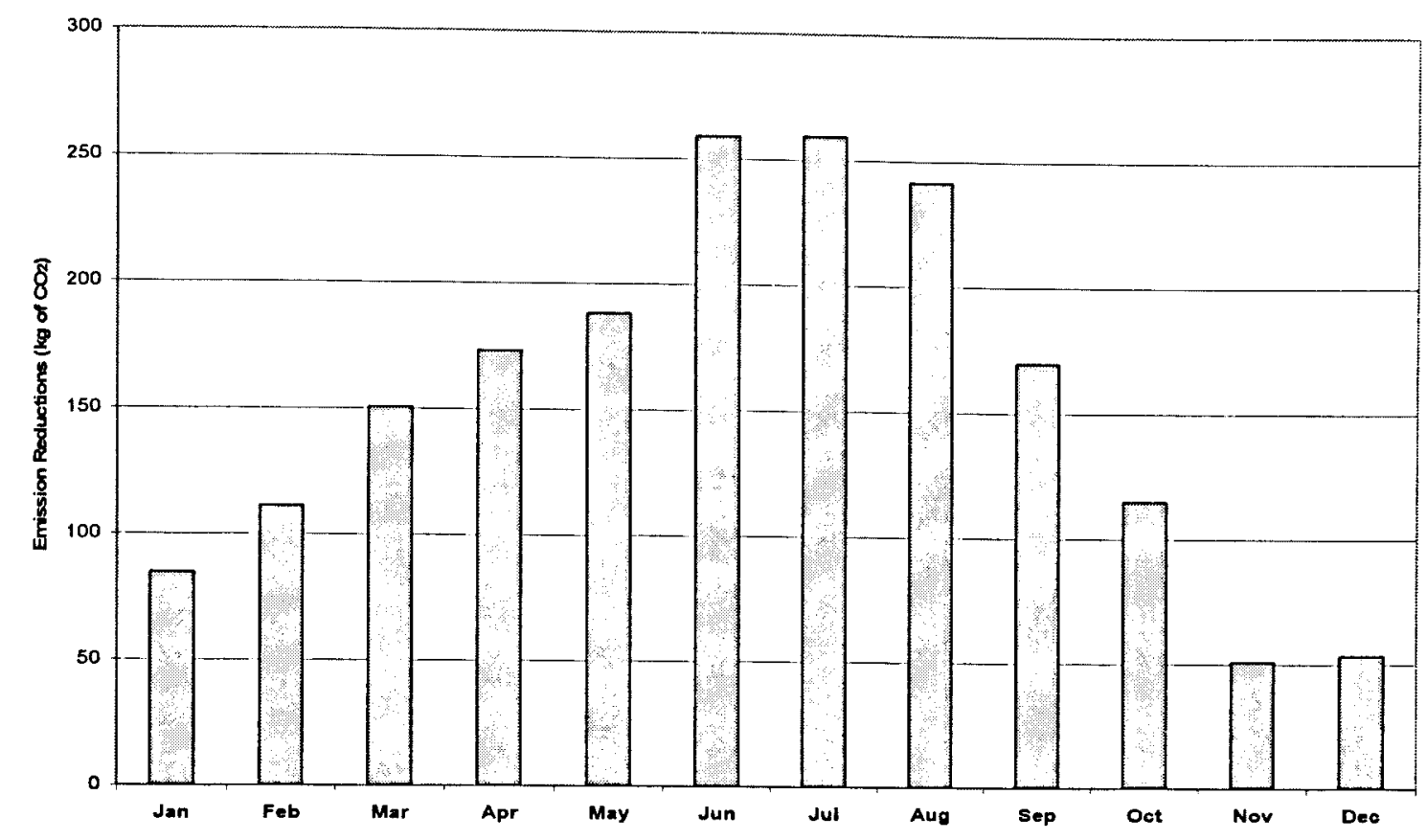

Figure 7-10: Monthly emission reductions for PV test-case study 3

\subsection{Revenue Generated by Test-Cases}

The credit of selling all of the PV and micro-wind turbine generated electricity to the local grid is calculated by using the Province of Ontario initiative price plan to pay $42 \mathrm{cent} / \mathrm{kWh}$. It should be noted that micro-wind turbine revenue from the above government incentive was hypothetically explored in order to compare the revenue generated between the two technologies.

\subsubsection{Case Study 1}

The total revenue generated by PV and micro-wind turbine is shown in Table 7-10. It can be observed that PV generated an additional $76 \%$ compared to micro-wind turbine. It should be noted that the capacities for the PV $(5 \mathrm{~kW})$ and micro-wind turbine $(1 \mathrm{~kW})$ are different and there the results are specific to this case only.

Table 7-10: Revenue generated from PV and micro-wind turbine technologies for case-study 1

\begin{tabular}{|c|c|}
\hline \multicolumn{2}{|c|}{ Revenue Generated (CAD\$) } \\
\hline Photovoltaic & Micro-Wind Turbine \\
\hline 2960 & 708 \\
\hline
\end{tabular}




\subsubsection{Case Study 2}

The total revenue generated by PV for winter and summer weeks is shown in Table 7-11. It can be observed that an additional $16 \mathrm{CAD}$ was generated during the summer.

Table 7-11: Revenue generated from PV for case-study 2

\begin{tabular}{|c|c|}
\hline \multicolumn{2}{|c|}{ Photovoltaic } \\
\hline \multicolumn{2}{|c|}{ Revenue Generated (CAD\$) } \\
\hline Winter & Summer \\
\hline 41 & 57 \\
\hline
\end{tabular}

\subsubsection{Case Study 3}

The total revenue generated by PV is shown in Table 7-12. It can be observed that PV generated 3262 CAD during 2005 for the test-case townhouse located in the Annex district of Toronto.

Table 7-12: Revenue generated from PV for case-study 3

\begin{tabular}{|c|}
\hline Photovoltaic \\
\hline Revenue Generated (CAD\$) \\
\hline 3262 \\
\hline
\end{tabular}

\subsection{Greenhouse Gas Cost Factor Analysis}

Greenhouse Gas Cost Factors (NGHGCF $)$ were developed in order to place a monetary value on emissions from the electricity generation sector as discussed in chapter 6 . The cost of emissions was determined using a flat rate, time-of-use, and wholesale price scheme in order to provide flexibility for the user to assign either a charge or rebate for the cost of emissions to the appropriate sector. The cost of emissions was calculated by multiplying the hourly emission reduction values from renewable technologies by the different emission cost factors for the province as defined in equations 7.5, 7.6, 7.7, 7.8, 7.9, and 7.10. Two estimates of the cost of emissions are given using the various emission cost factor methodology as discussed in chapter 3 . 


$$
G H G C_{\text {el. HGHGCFel, lat }}=\sum\left[\left(E R_{\text {em, hourrly }}\right)\left(H G H G C F_{\text {ele,flat }}\right)\right]
$$

Where,

$G H G C_{e l, H G H G C F_{e l, f a t}}=$ Annual cost of emissions using the hourly emission cost factor for the flat rate pricing scheme (CAD\$)

$E R_{\text {em.hourly }}=$ Hourly emission reduction by renewable technology for test case house (g of $\mathrm{CO}_{2}$ )

$H G H G C F_{\text {ele,flat }}=$ Hourly Greenhouse Gas Cost Factor using flat rate pricing scheme $\left(\mathrm{CAD} \$ / \mathrm{g}\right.$ of $\left.\mathrm{CO}_{2}\right)$

$G H G C_{e l, T D V G H G C F_{e l, \text { sat }}}=\sum\left[\left(E R_{e m, h o u r l y}\right)\left(T D V G H G C F_{\text {ele,flat }}\right)\right]$

Where,

$G H G C_{e l, T D V G H G F_{e l, f a t}}=$ Annual cost of emissions using the seasonal time dependent valuation emission cost factor for the flat rate pricing scheme (CAD\$)

$E R_{e m, h o u r l y}=$ Hourly emission reduction by renewable technology for test case house ( $\mathrm{g}$ of $\left.\mathrm{CO}_{2}\right)$

$T D V H G H G C F_{\text {ele,fat }}=$ Monthly Time Dependent Valuation Hourly Greenhouse Gas Cost Factor using flat rate pricing scheme (CAD $\$ / g$ of $\left.\mathrm{CO}_{2}\right)$

$G H G C_{e l, H G H G C F_{\text {el,Tou }}}=\sum\left[\left(E R_{\text {em,hourly }}\right)\left(H G H G C F_{\text {ele,Tou }}\right)\right]$

Where,

$G H G C_{e l, H G H G C F_{e l, T O U}}=$ Annual cost of emissions using the hourly emission cost factor for the TOU pricing scheme (CAD\$)

$E R_{e m, h o u r l y}=$ Hourly emission reduction by renewable technology for test case house ( $\mathrm{g}$ of $\mathrm{CO}_{2}$ ) 
$H G H G C F_{\text {ele.TOU }}=$ Hourly Greenhouse Gas Cost Factor using TOU pricing scheme $\left(\mathrm{CAD} \$ / \mathrm{g}\right.$ of $\left.\mathrm{CO}_{2}\right)$

$$
G H G C_{e l . T D V G H G C F_{\text {el, TOU }}}=\sum\left[\left(E R_{\text {em.hourly }}\right)\left(T D V G H G C F_{\text {ele }, T O U}\right)\right]
$$

Where,

$G H G C_{e l, T D V G H G C F_{e l, T o u}}=$ Annual cost of emissions using the seasonal time dependent valuation emission cost factor for the TOU pricing scheme (CAD\$)

$E R_{\text {em.hourly }}=$ Hourly emission reduction by renewable technology for test case house $\left(\mathrm{g}\right.$ of $\left.\mathrm{CO}_{2}\right)$

TDVHGHGCF $F_{\text {ele }, T O U}=$ Monthly Time Dependent Valuation Greenhouse Gas Cost Factor using TOU pricing scheme $\left(\mathrm{CAD} \$ / \mathrm{g}\right.$ of $\left.\mathrm{CO}_{2}\right)$

$G H G C_{e l, H G H G C F_{\text {el,Wholesale }}}=\sum\left[\left(E R_{\text {em, hourly }}\right)\left(H G H G C F_{\text {ele, Wholesale }}\right)\right]$

Where,

$G H G C_{e l, H G H G C F_{e l, \text { Hholesale }}}=$ Annual cost of emissions using the hourly emission cost factor for the wholesale pricing scheme (CAD\$)

$E R_{e m, h o u r l y}=$ Hourly emission reduction by renewable technology for test case house ( $\mathrm{g}$ of $\mathrm{CO}_{2}$ )

$H G H G C F_{\text {ele,wholesale }}=$ Hourly Greenhouse Gas Cost Factor using wholesale pricing scheme $\left(\mathrm{CAD} \$ / \mathrm{g}\right.$ of $\left.\mathrm{CO}_{2}\right)$

$G H G C_{\text {el,TDVGHGCF el,wholesale }}=\sum\left[\left(E R_{\text {em,hourly }}\right)\left(T D V G H G C F_{\text {ele, wholesale }}\right)\right]$ 
Where,

GHGC $_{\text {el.TDVGHGCF }}$ el,Wwotesate $=$ Annual cost of emissions using the seasonal time dependent valuation emission cost factor for the wholesale pricing scheme (CAD\$) $E R_{e m, h o w l y}=$ Hourly emission reduction by renewable technology for test case house $\left(\mathrm{g}\right.$ of $\left.\mathrm{CO}_{2}\right)$

TDVHGHGCF $F_{\text {ele,wholesale }}=$ Monthly Time Dependent Valuation Greenhouse Gas Cost Factor using wholesale pricing scheme (CAD $\$ / g$ of $\left.\mathrm{CO}_{2}\right)$

\subsubsection{Case Study 1}

The total emission costs by PV and micro-wind turbine using the hourly emission cost factor for the flat rate pricing scheme were:

$\mathrm{PV} \mathrm{GHGC}_{e l, H G H G C F_{e l, \pi a t}}=705 \mathrm{CAD} \$$

Micro-wind turbine $G H G C_{e l, H G H G C F_{e l, f a t}}=169 \mathrm{CAD} \$$

The total emission costs by PV and micro-wind turbine using the monthly time dependent valuation greenhouse gas cost factor for the flat rate pricing scheme were:

$\mathrm{PVGHGC}_{\text {el,TDVGHGCFel,Jat }}=729 \mathrm{CAD} \$$

Micro-wind turbine $G H G C_{e l . T D V G H C C F_{e l, f a t}}=178 \mathrm{CAD} \$$

The total emission costs by PV and micro-wind turbine using the hourly emission cost factor for the TOU pricing scheme were:

$\mathrm{PV} \mathrm{GHGC}_{\text {el,HGHGCFel,Tou }}=805 \mathrm{CAD} \$$

Micro-wind turbine $G H G C_{e l, H G H G C F_{e l, \pi v U}}=179 \mathrm{CAD} \$$

The total emission costs by PV and micro-wind turbine using the monthly time dependent valuation greenhouse gas cost factor for the TOU pricing scheme were: 
$\mathrm{PV} \mathrm{GHGC} C_{\text {el.TDVGHGCFel, } 0 u}=818 \mathrm{CAD} \$$

Micro-wind turbine $G H G C_{\text {el.TDVGHGCF } F_{l, T U v}}=181 \mathrm{CAD} \$$

The total emission costs by PV and micro-wind turbine using the hourly emission cost factor for the wholesale pricing scheme were:

$\mathrm{PV} \mathrm{GHGC}_{\text {el,HGHGCFel, whlessate }}=583 \mathrm{CAD} \$$

Micro-wind turbine $G H G C_{e l, H G H G C F_{l, l \text {,Holesul }}}=117 \mathrm{CAD} \$$

The total emission costs by PV and micro-wind turbine using the monthly time dependent valuation greenhouse gas cost factor for the wholesale pricing scheme were:

PV GHGC $C_{e l, T D V G H G C F_{e l, \text { Yholesale }}}=585 \mathrm{CAD} \$$

Micro-wind turbine $G H G C_{e l, T D V G H G C F_{e l, \text { woleseal }}}=117 \mathrm{CAD} \$$

Table 7-13 and Table 7-14 summarize the total emission cost results by using the different pricing schemes and emission cost factors. Since PV and micro-wind turbine are renewable technologies, the emission cost becomes an emission rebate. Depending on which pricing scheme is used the rebate may vary. The maximum emission rebate was obtained by using the TOU pricing scheme for both PV and micro-wind turbine. The minimum emission rebate was obtained by using the wholesale pricing scheme for electricity. It should be noted that using TDV emission cost factor resulted in a higher emission rebate.

Table 7-13: Hourly emissions cost comparison using the different pricing schemes test-case study 1

\begin{tabular}{|c|c|c|c|}
\hline \multirow{2}{*}{ Technology Type } & \multicolumn{3}{|c|}{ Hourly NGHGCF NCAD\$) $^{\text {No, }}$} \\
\cline { 2 - 4 } & elec, flat & elec, TOU & elec, wholesale \\
\hline PV & 705 & 805 & 583 \\
\hline Micro-Wind Turbine & 169 & 179 & 117 \\
\hline
\end{tabular}


Table 7-14: TDV emissions cost comparison using the different pricing schemes test-case study 1

\begin{tabular}{|c|c|c|c|}
\hline \multirow{2}{*}{ Technology Type } & \multicolumn{3}{|c|}{ TDV NGHGCF (CAD\$) } \\
\cline { 2 - 4 } & elec, flat & elec, TOU & elec, wholesale \\
\hline PV & 729 & 818 & 585 \\
\hline Micro-Wind-Turbine & 178 & 181 & 117 \\
\hline
\end{tabular}

Figure 7-11 shows the total monthly emission rebate by PV and micro-wind turbine using the TOU pricing scheme. Emission rebates were the highest in June for PV and December for micro-wind turbine, respectively. Conversely, the lowest emission rebates were during December and August for PV and micro-wind turbine, respectively.

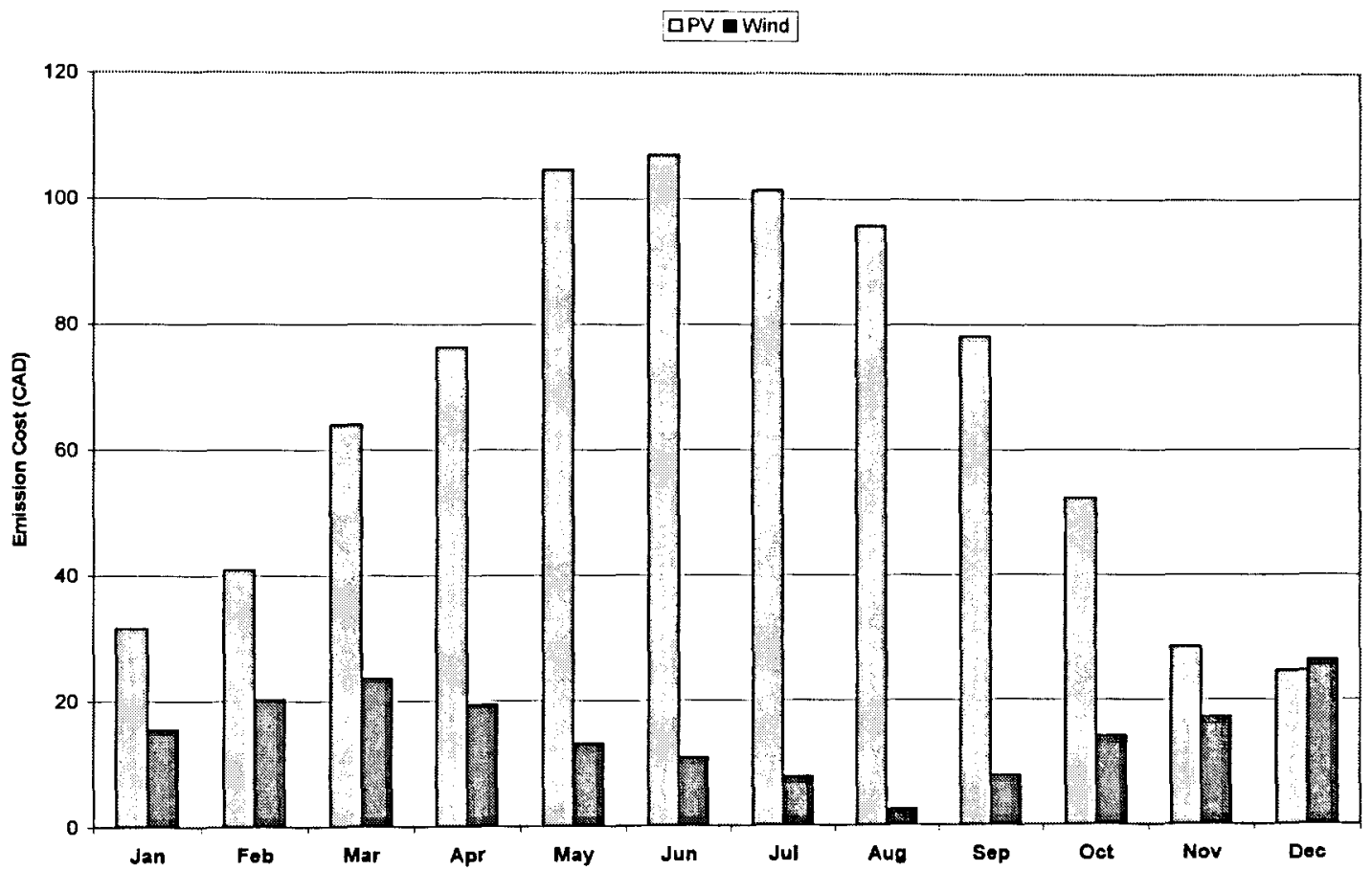

Figure 7-11: Monthly emission cost for PV and micro-wind turbine test-case study 1

\subsubsection{Case Study 2}

The total emission costs by PV using the hourly emission cost factor for the flat rate pricing scheme were:

Winter PV GHGC $C_{e l, H G H G C F_{\text {el, }, \text { aa }}}=9.86 \mathrm{CAD} \$$

Summer PV GHGC $C_{e l, H G H G C F_{e l, f a t}}=13.58 \mathrm{CAD} \$$ 
The total emission costs by PV using the monthly time dependent valuation greenhouse gas cost factor for the flat rate pricing scheme were:

$$
\begin{aligned}
& \text { Winter PV GHGC } C_{e l, T D V G H G C F_{e l, f a t}}=11.01 \mathrm{CAD} \$ \\
& \text { Summer PV GHGC } \\
& {\text { el,TDVGHGCF } F_{e l, \text { Aat }}}=14.14 \mathrm{CAD} \$
\end{aligned}
$$

The total emission costs by PV using the hourly emission cost factor for the TOU pricing scheme were:

$$
\begin{aligned}
& \text { Winter PV GHGC } C_{e l, H G H G C F_{e l, T O U}}=11.06 \mathrm{CAD} \$ \\
& \text { Summer PV GHGC } \\
& e l, H G H G C F_{e l, T O U}=15.01 \mathrm{CAD} \$
\end{aligned}
$$

The total emission costs by PV using the monthly time dependent valuation greenhouse gas cost factor for the TOU pricing scheme were:

$$
\begin{aligned}
& \text { Winter PV GHGC } C_{e l, T D V G H G C F_{e l, T O U}}=11.41 \mathrm{CAD} \$ \\
& \text { Summer PV GHGC } C_{e l, T D V G H G C F_{e l, r o u}}=14.80 \mathrm{CAD} \$
\end{aligned}
$$

The total emission costs by PV using the hourly emission cost factor for the wholesale pricing scheme were:

$$
\begin{aligned}
& \text { Winter PV GHGC } C_{e l, H G H G C F_{\text {el, wholesal }}}=7.87 \mathrm{CAD} \$ \\
& \text { Summer PV GHGC } C_{e l, H G H G C F_{\text {el,Hholesale }}}=7.63 \mathrm{CAD} \$
\end{aligned}
$$

The total emission costs by PV using the monthly time dependent valuation greenhouse gas cost factor for the wholesale pricing scheme were:

$$
\begin{aligned}
& \text { Winter PV GHGC } C_{e l, T D V G H G C F_{\text {el, Wholesale }}}=7.85 \mathrm{CAD} \$ \\
& \text { Summer PV GHGC } C_{e l, T D V G H G C F_{\text {el,Hholesale }}}=7.56 \mathrm{CAD} \$
\end{aligned}
$$


Table 7-15 and Table 7-14 summarize the total emission cost results by using the different pricing schemes and emission cost factors. Since PV is a renewable technology, the emission cost becomes an emission rebate. Depending on which pricing scheme is used the rebate may vary. The maximum emission rebate was obtained by using the TOU pricing scheme. The minimum emission rebate was obtained by using the wholesale pricing scheme for electricity. It should be noted that using TDV emission cost factor resulted in a higher emission rebate and that since the simulation results were for one week only the difference between pricing schemes is smaller in comparison to total yearly values.

Table 7-15: Hourly emissions cost comparison using the different pricing schemes test-case study 2

\begin{tabular}{|c|c|c|c|}
\hline \multirow{2}{*}{ Technology Type } & \multicolumn{3}{|c|}{ Hourly NGHGCF (CAD\$) } \\
\cline { 2 - 4 } & elec, flat & elec, TOU & elec, wholesale \\
\hline Jan $9-15$ & 9.86 & 11.06 & 7.87 \\
\hline July $11-17$ & 13.58 & 15.01 & 7.63 \\
\hline
\end{tabular}

Table 7-16: TDV emissions cost comparison using the different pricing schemes test-case study 2

\begin{tabular}{|c|c|c|c|}
\hline \multirow{2}{*}{ Technology Type } & \multicolumn{3}{|c|}{ TDV NGHGCF (CAD\$) } \\
\cline { 2 - 4 } & elec, flat & elec, TOU & elec, wholesale \\
\hline Jan $9-15$ & 11.01 & 11.41 & 7.85 \\
\hline July $11-17$ & 14.14 & 14.80 & 7.56 \\
\hline
\end{tabular}

Figure 7-12 shows the total daily emission rebate by PV using the TOU pricing scheme. Emission rebates were the highest on Monday and Thursday during the winter and on Wednesday during the summer. Conversely, the lowest emission rebates were on Saturday and Monday during the winter and summer weeks, respectively. 


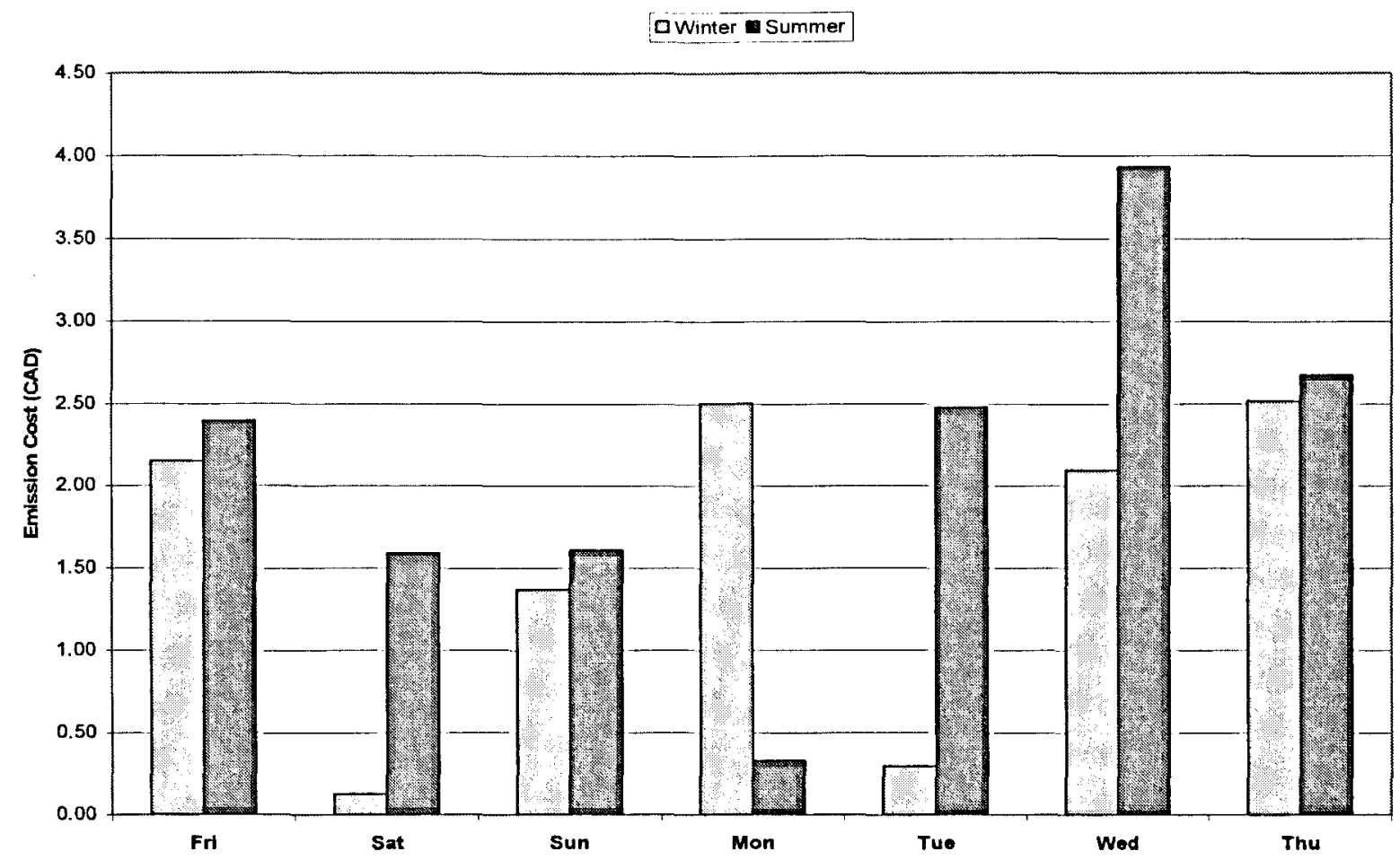

Figure 7-12: Daily emission cost for PV test-case study 2

\subsubsection{Case Study 3}

The total emission costs by PV using the hourly emission cost factor for the flat rate pricing scheme were:

PV GHGC $C_{e l, H G H G C F_{e l, f u}}=777 \mathrm{CAD} \$$

The total emission costs by PV using the monthly time dependent valuation greenhouse gas cost factor for the flat rate pricing scheme were:

PVGHGC $C_{e l, T D V G H G C F_{e l, \text {,ar }}}=800 \mathrm{CAD} \$$

The total emission costs by PV using the hourly emission cost factor for the TOU pricing scheme were:

$\mathrm{PV} \mathrm{GHGC} C_{e l, H G H G C F_{e l, \text { OOU }}}=898 \mathrm{CAD} \$$ 
The total emission costs by PV using the monthly time dependent valuation greenhouse gas cost factor for the TOU pricing scheme were:

PV GHGC $C_{e l, T D V G H G C F_{e l, T O U}}=908 \mathrm{CAD} \$$

The total emission costs by PV using the hourly emission cost factor for the wholesale pricing scheme were:

PV GHGC $C_{e l, H G H G C F_{e l, \text { Hhotesale }}}=685 \mathrm{CAD} \$$

The total emission costs by PV using the monthly time dependent valuation greenhouse gas cost factor for the wholesale pricing scheme were:

PV GHGC $C_{\text {el.TDVGHGCF el, wholesale }}=677$ CAD\$

Table 7-17 and Table 7-18 summarize the total emission cost results by using the different pricing schemes and emission cost factors. Since PV is a renewable technology and does not emit any emissions, the emission cost becomes an emission rebate. Depending on which pricing scheme is used the rebate may vary. The maximum emission rebate was again obtained by using the TOU pricing scheme for PV. The minimum emission rebate was again obtained by using the wholesale pricing scheme for electricity. It should be noted that using TDV emission cost factor resulted in a higher emission rebate.

Table 7-17: Hourly emissions cost comparison using the different pricing schemes test-case study 3

\begin{tabular}{|c|c|c|c|}
\hline \multirow{2}{*}{ Technology Type } & \multicolumn{3}{|c|}{ Hourly NGHGCF (CAD\$) } \\
\cline { 2 - 4 } & elec, flat & elec, TOU & elec, wholesale \\
\hline PV & 777 & 898 & 685 \\
\hline
\end{tabular}

Table 7-18: TDV emissions cost comparison using the different pricing schemes test-case study 3

\begin{tabular}{|c|c|c|c|}
\hline \multirow{2}{*}{ Technology Type } & \multicolumn{3}{|c|}{ TDV NGHGCF $_{\mathrm{A}}$ (CAD\$) } \\
\cline { 2 - 4 } & elec, flat & elec, TOU & elec, wholesale \\
\hline PV & 800 & 908 & 677 \\
\hline
\end{tabular}


Figure 7-13 shows the total monthly emission rebate by PV using the TOU pricing scheme. Emission rebates were the highest in June for PV. Conversely, the lowest emission rebates were during December.

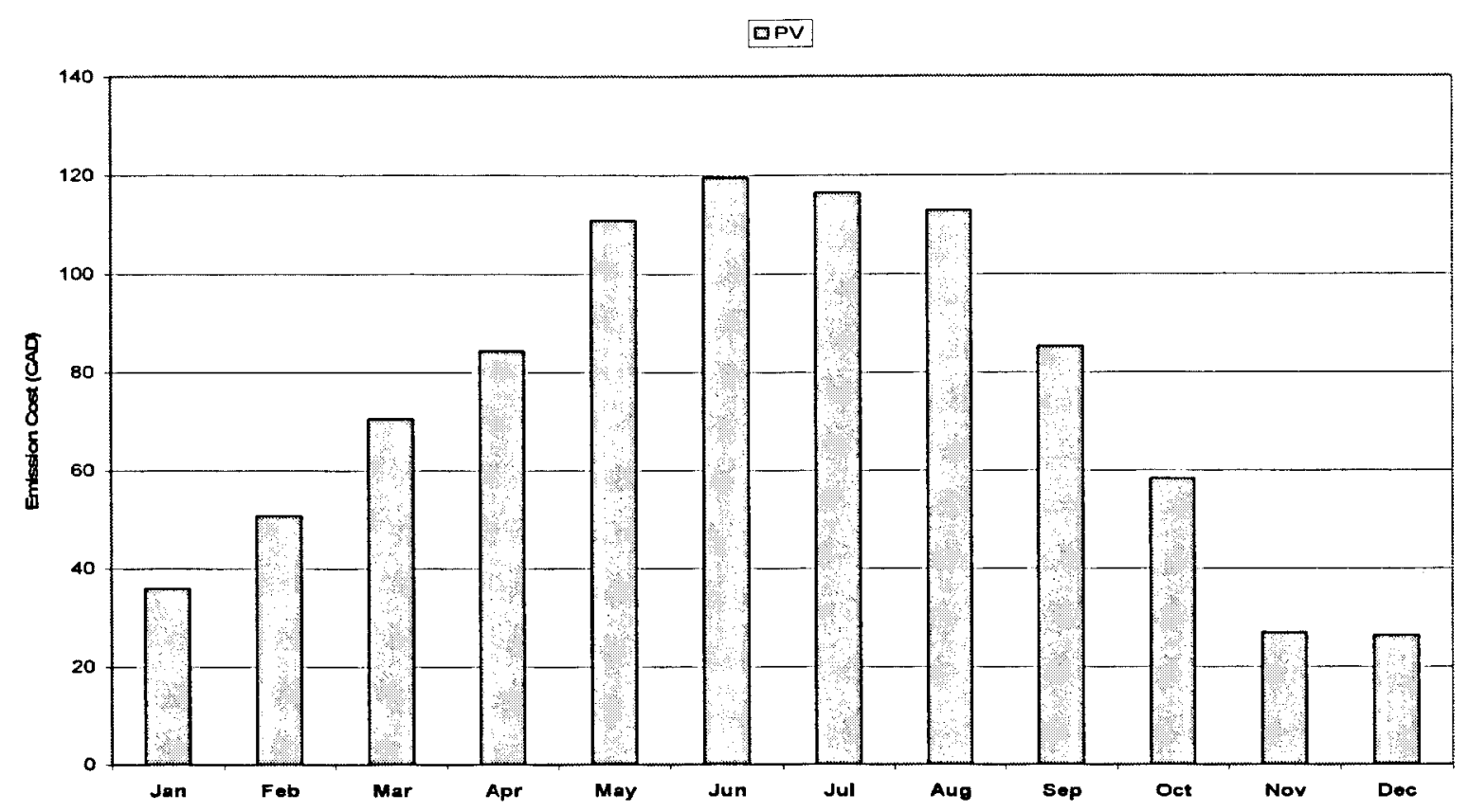

Figure 7-13: Monthly emission cost for PV and micro-wind turbine test-case study 3

In conclusion, all three case studies demonstrated that the TDV emission cost factor placed a higher monetary value on emissions and that the wholesale emission cost placed a lower monetary value. Depending on whether the emissions are generated or reduced the emission cost value can be either a levy on emitters or a rebate for reducers of greenhouse gases. It should be noted that by employing the aforementioned methodology more people will invest in renewable technologies for their homes.

The next chapter will show the results associated with the neural network models. 


\section{$8 \quad$ Neural Network Results}

\subsection{Overview}

In this chapter, an evaluation of the NN models developed in this study will be conducted by comparing their predicting performance with actual data, as well as comparing their estimates with each other. Comparisons are carried out for the following networks:

- Hourly electricity demand

- Percentage mix from generation type (methodology 1)

- Hourly Emission Factor (methodology 2)

\subsection{Hourly Electricity Demand Forecasting}

The performance of the developed NN model for load forecasting has been tested using the actual load (IESO, 2006) and weather data (Environment Canada, 2004) (for the year 2004) for Toronto. The results are presented in Table 8-1. The $\mathrm{R}^{2}$ and correlation values for the training, validation, and testing data are close to 1 which is a good performance indicator of the network.

Table 8-1: Prediction performance of NN model - load forecasting

\begin{tabular}{|c|c|c|}
\hline Subset & $\mathbf{R}^{\mathbf{2}}$ & Correlation \\
\hline Training & 0.962 & 0.981 \\
\hline Validation & 0.952 & 0.977 \\
\hline Testing & 0.954 & 0.978 \\
\hline
\end{tabular}

The correlation of a network is a statistical measure of strength of the relationship between the actual values and network outputs. The correlation coefficient can range from -1 to +1 . The closer it is to 1 , the stronger the positive relationship, and the closer it is to -1 , the stronger the negative relationship. It should be noted that when the correlation coefficient is near 0 there is no relationship. 
The estimates for the NN models are plotted along with the actual electricity demand data for Ontario as shown in Figures C-1 to C-3 in Appendix C. The NN model was able to predict the hourly electricity demand of most hours for 2004. When the inputs were examined, it was found that most of the predicted values where close to their corresponding values in the testing dataset.

The error distribution for the network is shown in Figure 8-1. It can be observed that the majority of the errors are lower than $1300 \mathrm{MWh}$. These errors are small when compared to the electricity demand for a typical day in the Province of Ontario is $23000 \mathrm{MWh}$.

\section{Errox Cistribution}

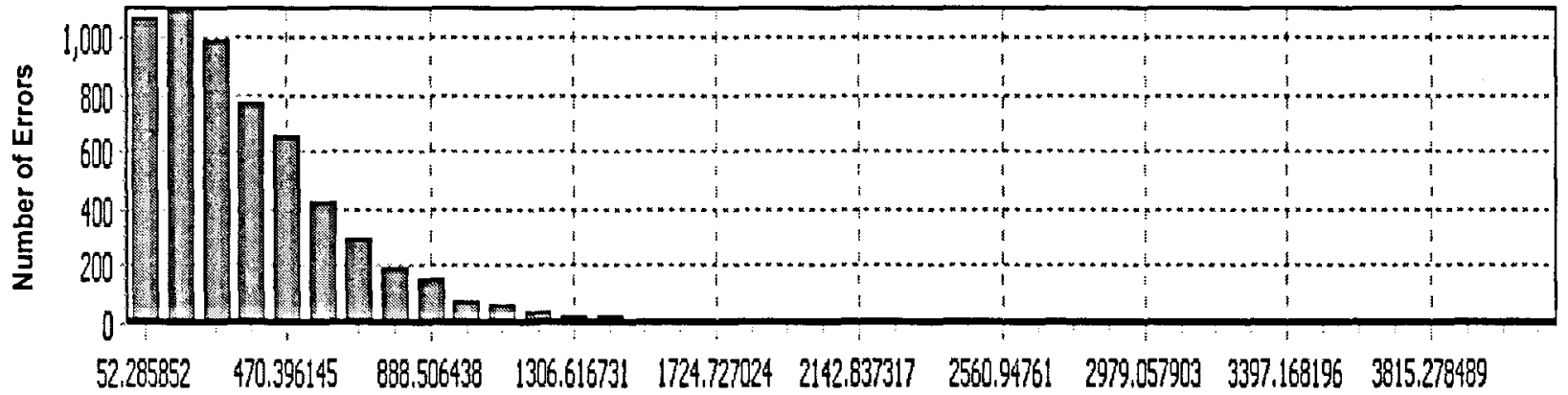

Figure 8-1: Error distribution for the load forecasting NN

The importance of the types of inputs for the network is illustrated in Figure 8-2. Several input categories have a significant effect on the electricity demand for the Province of Ontario. It can be observed that the electricity demand is heavily dependent on the month which is directly related to weather. 


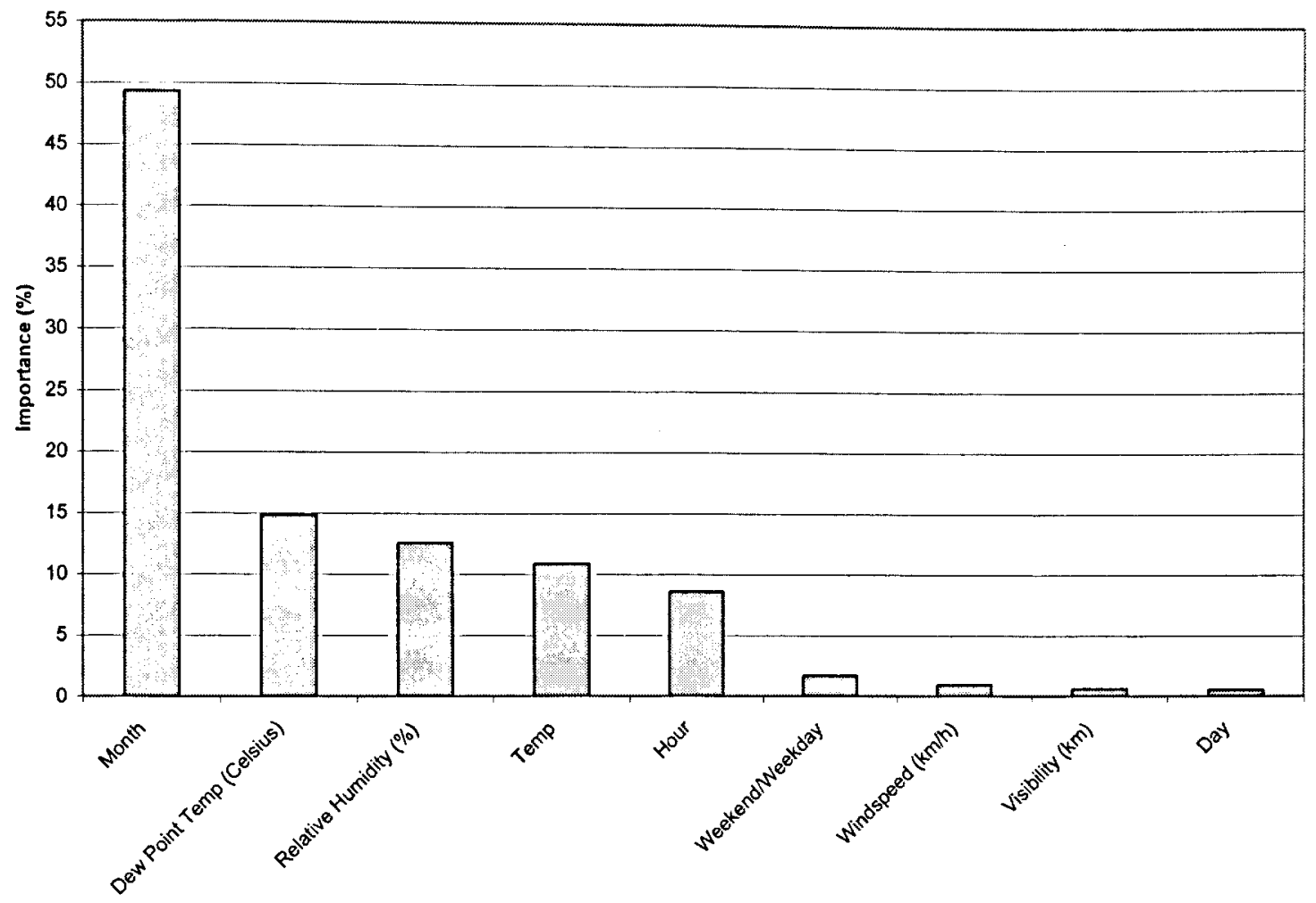

Figure 8-2: Input importance percentage for the load forecasting NN

The statistical results are presented in Table 8-2 for the training, validation and testing subsets. Given the MAPE values, the factors affecting the electricity demand are closely represented by the inputs selected in Chapter 4 . The validation and testing subsets have the highest value of MAPE with $2.37 \%$, whereas the training subset has the lowest with $2.12 \%$. The definition of MAPE can be found in Appendix A.

Table 8-2: NN load forecasting statistics

\begin{tabular}{|c|c|c|c|}
\hline & \multicolumn{3}{|c|}{ MAPE (\%) } \\
\cline { 2 - 4 } & Training & Validation & Testing \\
\hline Mean & 2.12 & 2.37 & 2.37 \\
\hline Std Dev & 1.83 & 2.08 & 2.01 \\
\hline Min & 0.00002 & 0.00030 & 0.00004 \\
\hline Max & 22.40 & 18.19 & 20.76 \\
\hline
\end{tabular}

\subsubsection{Test Case Using Load Forecasting NN Model}

In this case, the target is to predict the hourly peak load for each season for 2005. The NN model was developed using data from 2004 and as shown above it could predict the hourly 
electricity demand accurately with an average MAPE of $2.12 \%$. Load and weather data for 2005 was divided into winter, spring, summer, and fall in order to compare the NN predictive performance across the seasons. Table 8-3 shows the average MAPE values for 2005. The highest MAPE value occurred in the summer which indicates loads during the summer fluctuate a lot more than the other seasons. The lowest MAPE values occurred during the winter and fall which demonstrates that there is less fluctuation in temperature during the winter and fall. The seasonal MAPE profiles for the test case are presented in Figures C-4 to C-7 in Appendix C.

Table 8-3: Average MAPE values for test case - 2005

\begin{tabular}{|c|c|}
\hline \multicolumn{2}{|c|}{2005} \\
\hline Season & MAPE (\%) \\
\hline Winter & 3.24 \\
\hline Spring & 4.83 \\
\hline Summer & 7.27 \\
\hline Fall & 3.26 \\
\hline Average & 4.65 \\
\hline
\end{tabular}

The NN model which was trained using 2004 load and weather data continued to be quite accurate for 2005 . It was observed that the winter months were easier to predict and summer months were the hardest. Yearly retraining of the NN should improve the predictive performance.

\subsection{Hourly Percentage Mix from Generation Sources NN Model}

The hourly percentage mix $N N$ was developed by creating four models due to the complexity and difficulty in developing a multiple output model and software limitations.

\subsubsection{Percentage Nuclear NN}

The performance of the developed NN model for percentage nuclear forecasting is presented in Table 8-4. The $\mathrm{R}^{2}$ and correlation values for the training, validation, and testing data were close to 1 which is a good performance indicator of the network. 
Table 8-4: Prediction performance of NN model - \% nuclear

\begin{tabular}{|c|c|c|}
\hline Subset & $\mathbf{R}^{2}$ & Correlation \\
\hline Training & 0.967 & 0.984 \\
\hline Validation & 0.967 & 0.984 \\
\hline Testing & 0.966 & 0.984 \\
\hline
\end{tabular}

The estimates for the NN models are plotted along with the percentage nuclear data for Ontario as shown in Figures C-8 to C-10 in Appendix C. The NN model was able to predict the percentage share from nuclear most hours for the year 2005. When the inputs were examined, it was found that most of the predicted values where close to their corresponding values in the testing dataset.

The error distribution for the network is shown in Figure 8-3. It can be observed that the majority of the errors are lower than $3.5 \%$. These errors are small when compared to the percentage share from nuclear for a typical day in the Province of Ontario which is approximately $50 \%$.

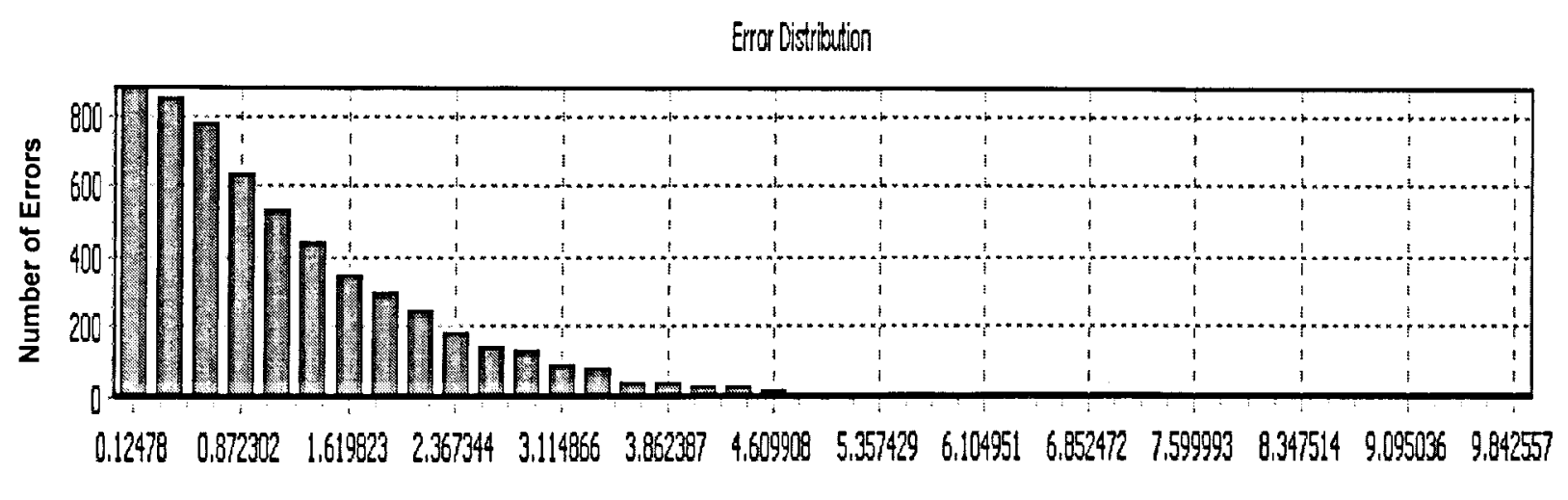

Figure 8-3: Error distribution for the \% nuclear NN

The importance of the types of inputs for the network is illustrated in Figure 8-4. Several input categories have a significant effect on the percentage share of nuclear. It can be observed that the percentage share from nuclear is heavily dependent on the dew point temperature on the far right of the figure, as well as the month, temperature and the electricity generated in the province. It should be noted that the hour had no significant effect on the network. This was identified in Chapter 4. 


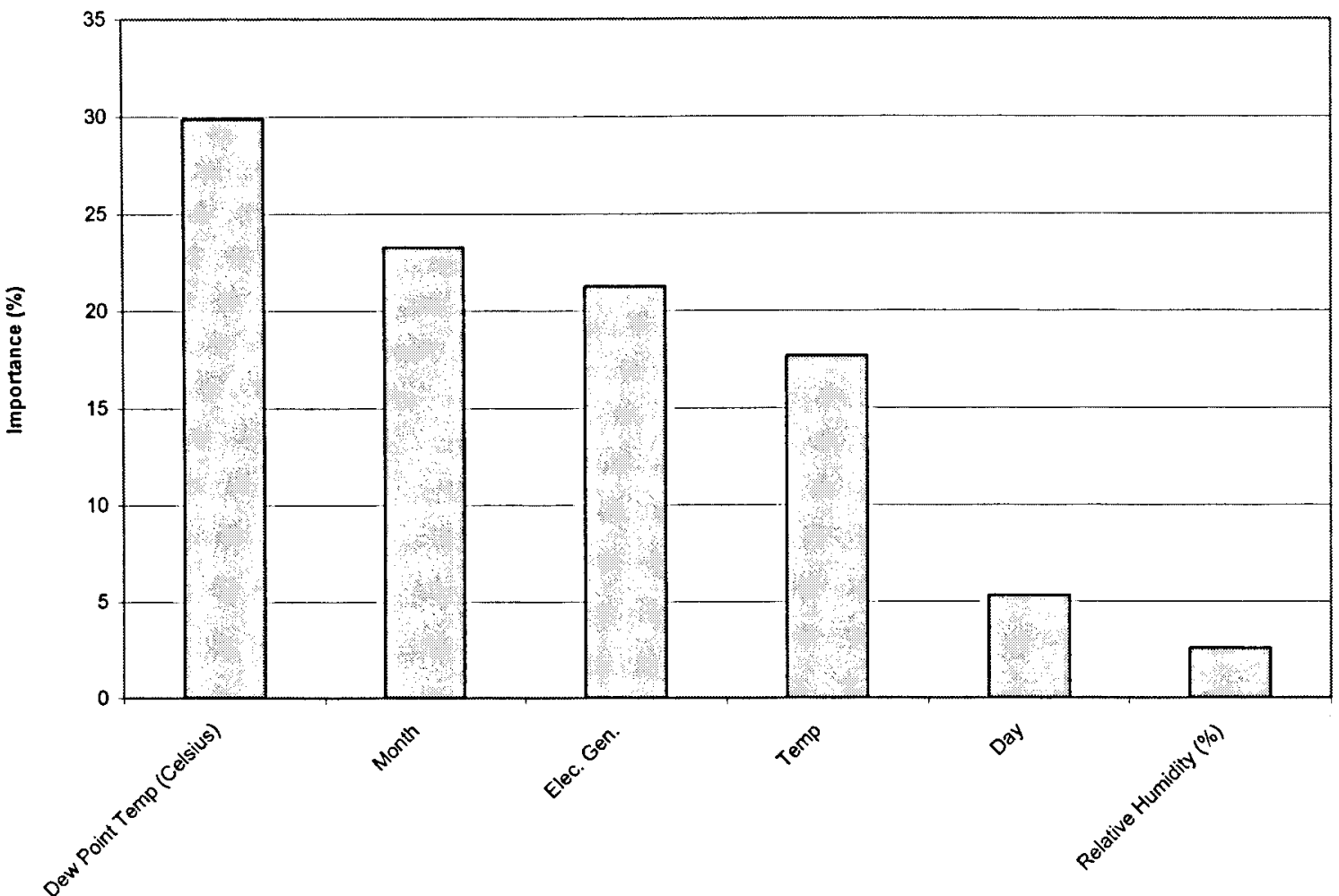

Figure 8-4: Input importance percentage for the \% nuclear NN

The statistical results are presented in Table 8-5 for the training, validation and testing subsets. This NN model is very accurate given the MAPE values, the factors affecting the percentage share from nuclear are closely represented by the inputs selected in Chapter 4 . The validation and testing subsets have the highest values for the MAPE of $1.95 \%$ and $1.92 \%$, respectively, whereas the training subset has the lowest value of $1.90 \%$. The maximum MAPE value was the highest in the validation subset.

Table 8-5: NN \% nuclear training statistics

\begin{tabular}{|c|c|c|c|}
\hline \multirow{2}{*}{} & \multicolumn{3}{|c|}{ MAPE (\%) } \\
\cline { 2 - 4 } & Training & Validation & Testing \\
\hline Mean & 1.90 & 1.95 & 1.92 \\
\hline Std Dev & 1.78 & 1.77 & 1.83 \\
\hline Min & 0.0007 & 0.001 & 0.0008 \\
\hline Max & 23.65 & 14.90 & 14.51 \\
\hline
\end{tabular}




\subsubsection{Test Case Using Percent Nuclear NN Model}

In this case, the target is to predict the percent share from nuclear for each season for 2006. The NN model was developed using data from 2005 and as shown above it could predict the percent share from nuclear accurately with an average MAPE of $1.90 \%$. Percent share from power generation and weather data for 2006 was divided into winter, spring, summer, and fall in order to compare the NN predictive performance across the seasons for the year 2006. Table 8-6 shows the average MAPE values for 2006. The highest MAPE value occurred in the spring which indicates that the percent share from nuclear during the spring fluctuates considerably in comparison to the other seasons. The lowest MAPE values occurred during the winter, summer and fall. The high MAPE value for the spring could be attributed to either weather variability or inability to predict within accuracy during that season. The seasonal MAPE profiles for the test case are presented in Figures C-11 to C14 in Appendix C.

Table 8-6: Average MAPE values for test case - 2005

\begin{tabular}{|c|c|}
\hline \multicolumn{2}{|c|}{2006} \\
\hline Season & MAPE (\%) \\
\hline Winter & 8.60 \\
\hline Spring & 21.38 \\
\hline Summer & 8.50 \\
\hline Fall & 8.14 \\
\hline Average & 11.66 \\
\hline
\end{tabular}

The NN model which was trained using 2005 data was not as accurate for 2006. It was observed that the winter, summer, and fall months were easier to predict with a MAPE of approximately $8 \%$ and the spring was considered to be the hardest season to predict due to its high MAPE value of $21.38 \%$. This high MAPE could be explained by unusual temperature changes. However the average MAPE for the entire year was $11.66 \%$. Yearly retraining of the NN should improve the predictive performance.

\subsubsection{Percentage Hydro NN}

The performance of the developed NN model for percentage hydro forecasting is presented in Table 8-7. The $\mathrm{R}^{2}$ and correlation values for the training, validation, and testing data were really close to 1 which is a good performance indicator of the network. 
Table 8-7: Prediction performance of NN model - \% hydro

\begin{tabular}{|c|c|c|}
\hline Subset & $\mathbf{R}^{\mathbf{2}}$ & Correlation \\
\hline Training & 0.933 & 0.968 \\
\hline Validation & 0.915 & 0.959 \\
\hline Testing & 0.920 & 0.962 \\
\hline
\end{tabular}

The estimates for the NN models are plotted along with the percentage hydro data for Ontario as shown in Figure C-15 to C-17 in Appendix C. The NN model was able to predict the percentage share from hydro for most hours for the year 2005. When the inputs were examined, it was found that most of the predicted values where close to their corresponding values in the testing dataset.

The error distribution for the network is shown in Figure 8-5. It can be observed that the majority of the errors are lower than $3.5 \%$.

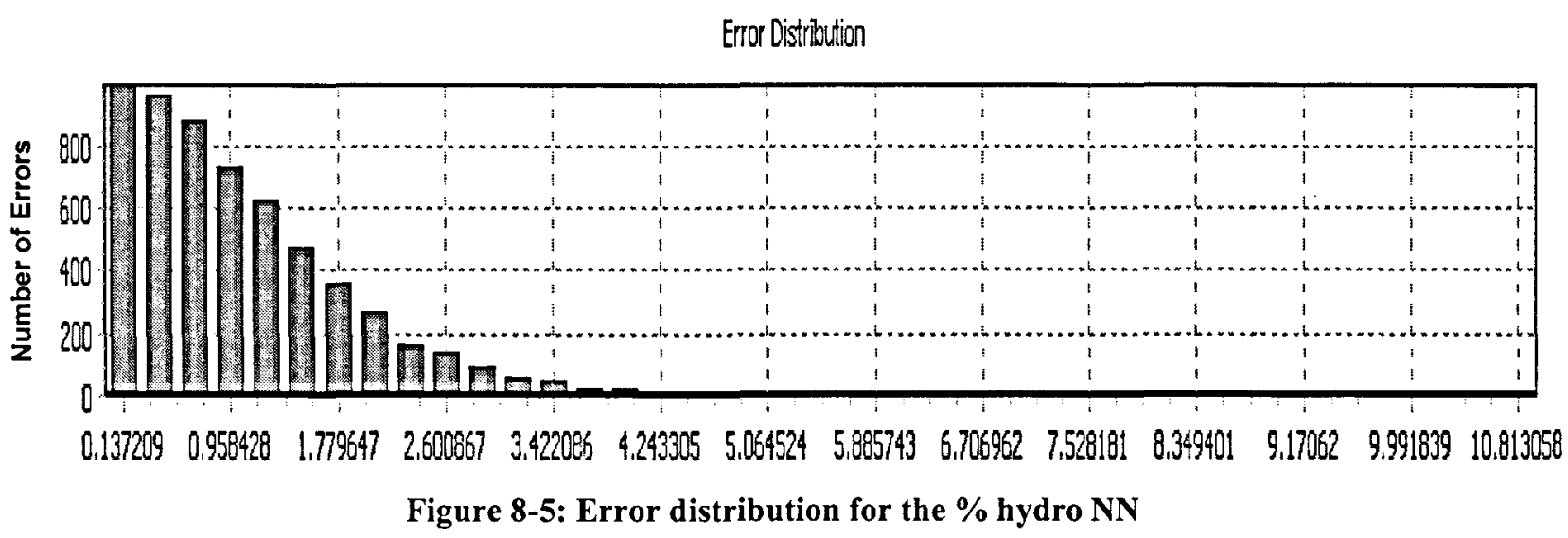

The importance of the types of inputs for the network is illustrated in Figure 8-6. Several input categories have a significant effect on the percentage share of hydro. It can be observed that the percentage share from hydro is heavily dependent on the dew point temperature, the month, and the relative humidity on the left of the figure. It should be noted that the other inputs had a relatively smaller effect on the predicting power of the network. This clearly indicates that hydro is highly dependent on the weather. 


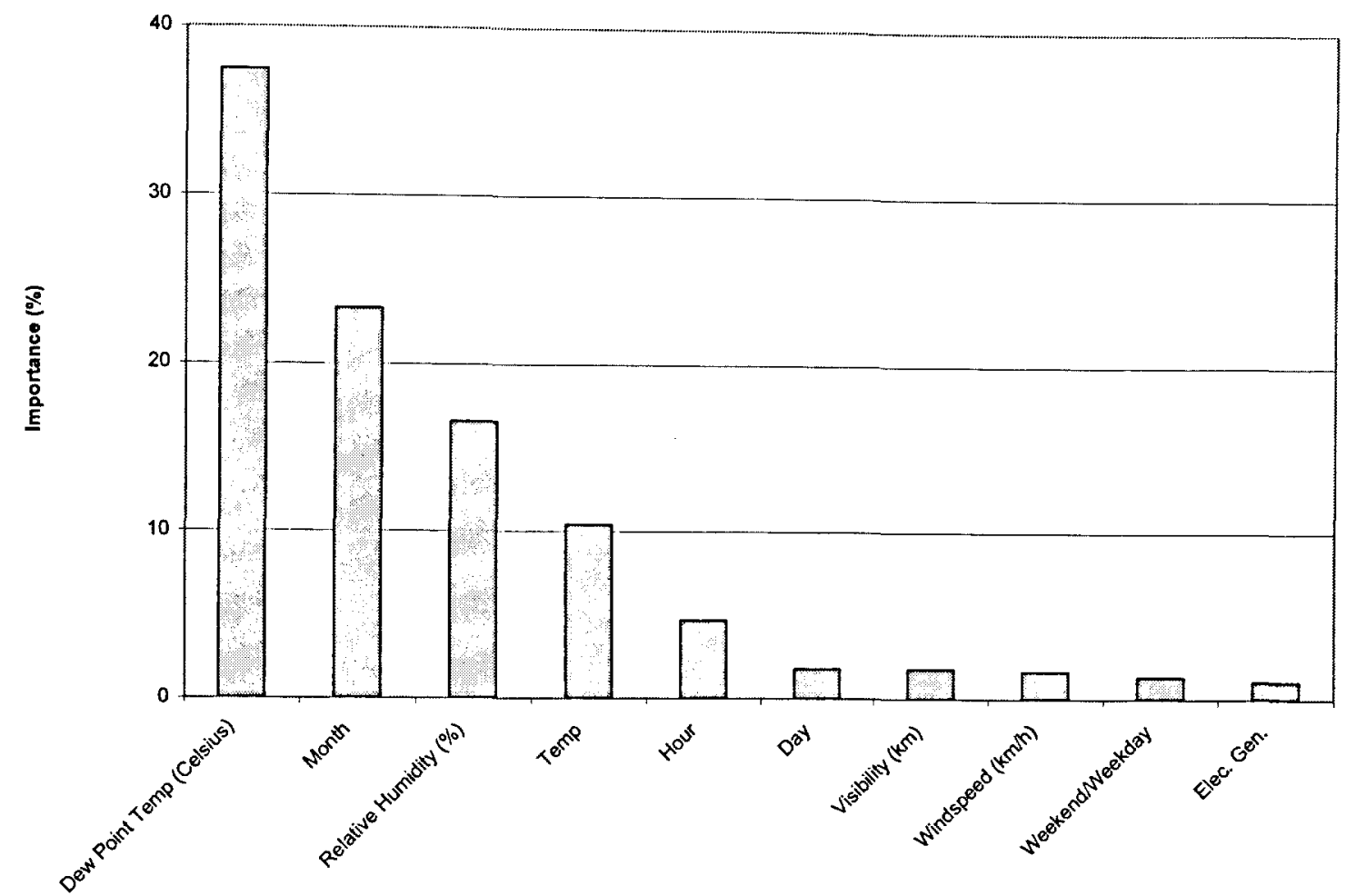

Figure 8-6: Input importance percentage for the \% hydro NN

The statistical results are presented in Table 8-8 for the training, validation and testing subsets. This NN model is very accurate given the MAPE values, the factors affecting the percentage share from hydro are closely represented by the inputs selected in Chapter 4 . The validation and testing subsets have the highest values for the MAPE of $5.81 \%$ and $5.78 \%$, respectively, whereas the training subset has the lowest value of $5.23 \%$. The maximum MAPE value was the highest in the validation subset.

Table 8-8: NN \% hydro training statistics

\begin{tabular}{|c|c|c|c|}
\hline & \multicolumn{3}{|c|}{ MAPE (\%) } \\
\cline { 2 - 4 } & Training & Validation & Testing \\
\hline Mean & 5.23 & 5.81 & 5.78 \\
\hline Std Dev & 4.79 & 5.51 & 5.29 \\
\hline Min & 0.0013 & 0.0031 & 0.0060 \\
\hline Max & 53.74 & 52.63 & 45.28 \\
\hline
\end{tabular}




\subsubsection{Test Case Using Percent Hydro NN Model}

In this case, the target is to predict the percent share from hydro for each season for 2006 . The NN model was developed using data from 2005 and as shown above it could predict the percent share from hydro accurately with an average MAPE of $5.23 \%$. Percent share from power generation and weather data for 2006 was divided into winter, spring, summer, and fall in order to compare the NN predictive performance across the seasons for the year 2006. Table 8-9 shows the average MAPE values for 2006. The highest MAPE value occurred in the fall which indicates that the percent share from hydro during the fall fluctuates considerably in comparison to the other seasons. The lowest MAPE value occurred during the winter. The seasonal MAPE profiles for the test case are presented in Figures C-18 to C-21 in Appendix C.

Table 8-9: Average MAPE values for $\%$ hydro test case - 2006

\begin{tabular}{|c|c|}
\hline \multicolumn{2}{|c|}{2006} \\
\hline Season & MAPE (\%) \\
\hline Winter & 8.67 \\
\hline Spring & 9.62 \\
\hline Summer & 11.03 \\
\hline Fall & 12.23 \\
\hline Average & 10.39 \\
\hline
\end{tabular}

The NN model which was trained using 2005 data was not as accurate for 2006 . The NN models developed are for short term forecasting only. However, it was observed that long term forecasting for the winter had the lowest MAPE of $8.67 \%$ in 2006. In addition, the spring and summer months resulted in a MAPE of $9.62 \%$ and $11.03 \%$, respectively. In addition, the fall was considered to be the hardest season to predict due to its high MAPE value of $12.23 \%$. However the average MAPE for the entire year was $10.39 \%$. Yearly retraining of the NN should improve the predictive performance.

\subsubsection{Percentage Coal NN}

The performance of the developed NN model for percentage coal forecasting is presented in Table 8-10. The $\mathrm{R}^{2}$ and correlation values for the training, validation, and testing data were really close to 1 which is a good performance indicator of the network. 
Table 8-10: Prediction performance of NN model - \% coal

\begin{tabular}{|c|c|c|}
\hline Subset & $\mathbf{R}^{2}$ & Correlation \\
\hline Training & 0.938 & 0.970 \\
\hline Validation & 0.934 & 0.968 \\
\hline Testing & 0.931 & 0.966 \\
\hline
\end{tabular}

The estimates for the NN models are plotted along with the percentage coal data for Ontario as shown in Figures C-22 to C-24 in Appendix C. The NN model was able to predict the percentage share from coal most hours for the year 2005. When the inputs were examined, it was found that most of the predicted values where close to their corresponding values in the testing dataset.

The error distribution for the network is shown in Figure 8-7. It can be observed that the majority of the errors are lower than $4.6 \%$.

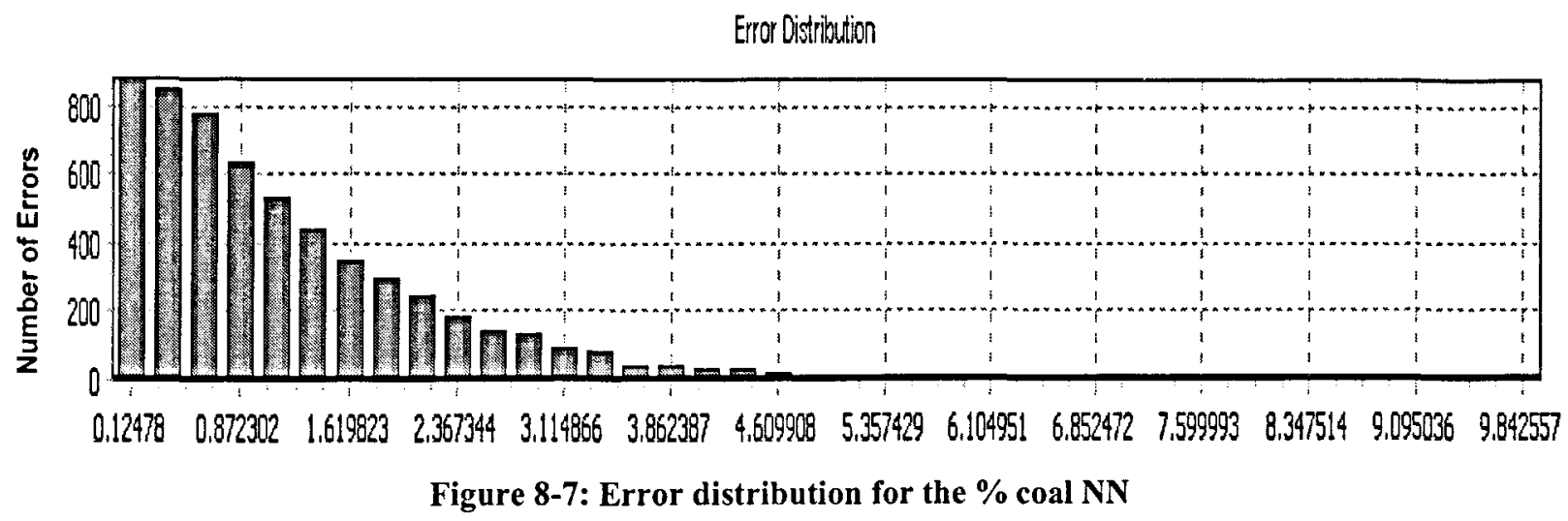

The importance of the types of inputs for the network is illustrated in Figure 8-8. Several input categories have a significant effect on the percentage share of coal. It can be observed that the percentage share from coal is heavily dependent on the percentage share from Hydro on the far left of the figure, as well as percentage share from nuclear. It should be noted that the other inputs had little effect on the predicting power of the network. This clearly indicates that the electricity market regulators attempt to use hydro and nuclear before using coal. 


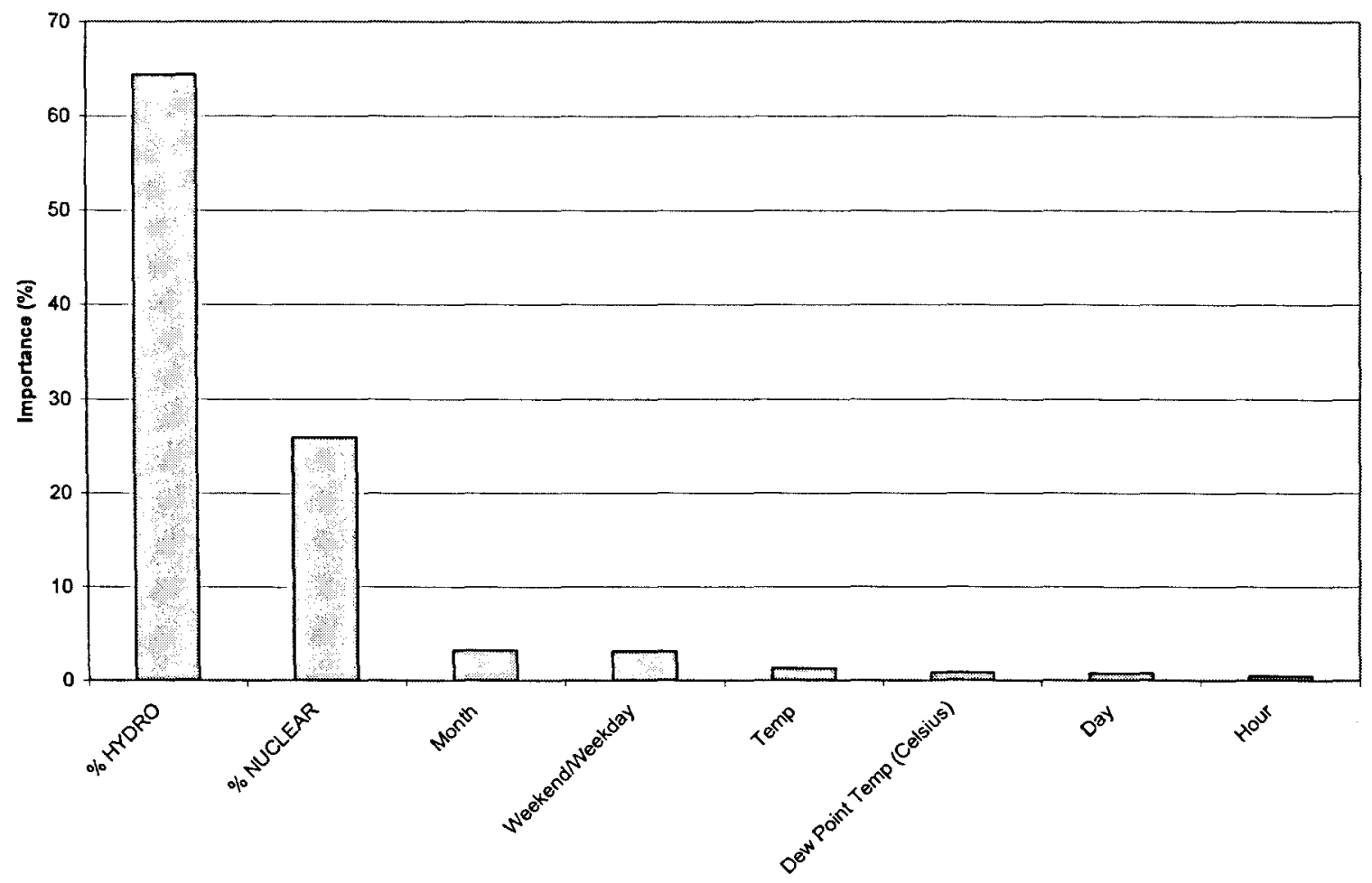

Figure 8-8: Input importance percentage for the \% coal NN

The statistical results are presented in Table 8-11 for the training, validation and testing subsets. This NN model is very accurate given the MAPE values, the factors affecting the percentage share from coal are closely represented by the inputs selected in Chapter 4 . The validation and testing subsets have the highest values for the MAPE of $4.71 \%$ and $4.64 \%$, respectively, whereas the training subset has the lowest value of $4.45 \%$. The maximum MAPE value was the highest in the validation subset.

Table 8-11: NN \% coal training statistics

\begin{tabular}{|c|c|c|c|}
\hline & \multicolumn{3}{|c|}{ MAPE (\%) } \\
\cline { 2 - 4 } & Training & Validation & Testing \\
\hline Mean & 4.45 & 4.71 & 4.64 \\
\hline Std Dev & 4.15 & 4.35 & 4.29 \\
\hline Min & 0.0005 & 0.0027 & 0.0043 \\
\hline Max & 48.91 & 40.23 & 37.51 \\
\hline
\end{tabular}




\subsubsection{Test Case Using Percent Coal NN Model}

In this case, the target is to predict the percent share from coal for each season for 2006. The NN model was developed using data from 2005 and as shown above it could predict the percent share from coal accurately with an average MAPE of $4.45 \%$. Percent share from power generation and weather data for 2006 was divided into winter, spring, summer, and fall in order to compare the NN predictive performance across the seasons for the year 2006. Table 8-12 shows the average MAPE values for 2006. The highest MAPE value occurred in the winter which indicates that the percent share from coal during the winter fluctuates considerably in comparison to the other seasons. The lowest MAPE value occurred during the summer. The seasonal MAPE profiles for the test case are presented in Figures C-25 to C-28 in Appendix C.

Table 8-12: Average MAPE values for \% coal test case - 2006

\begin{tabular}{|c|c|}
\hline \multicolumn{2}{|c|}{2006} \\
\hline Season & MAPE (\%) \\
\hline Winter & 13.53 \\
\hline Spring & 12.84 \\
\hline Summer & 7.23 \\
\hline Fall & 12.87 \\
\hline Average & 11.62 \\
\hline
\end{tabular}

The NN model which was trained using 2005 data was not as accurate for 2006. The NN models developed are for short term forecasting only. However, it was observed that long term forecasting for the summer had the highest MAPE of $7.23 \%$ in 2006 . In addition, the spring and fall months resulted in a MAPE of approximately $12.8 \%$ and the winter was considered to be the hardest season to predict due to its high MAPE value of $13.53 \%$. However the average MAPE for the entire year was $11.62 \%$. Yearly retraining of the NN should improve the predictive performance.

\subsubsection{Percentage Other NN}

The performance of the developed NN model for percentage other forecasting is presented in Table 8-13. The $\mathrm{R}^{2}$ and correlation values for the training, validation, and testing data were approximately $80 \%$ and $90 \%$, respectively. It should be recognized that the percent share from "other" is difficult to predict since it is dependent on the market. 


\subsubsection{Test Case Using Percent Coal NN Model}

In this case, the target is to predict the percent share from coal for each season for 2006. The NN model was developed using data from 2005 and as shown above it could predict the percent share from coal accurately with an average MAPE of $4.45 \%$. Percent share from power generation and weather data for 2006 was divided into winter, spring, summer, and fall in order to compare the NN predictive performance across the seasons for the year 2006. Table 8-12 shows the average MAPE values for 2006. The highest MAPE value occurred in the winter which indicates that the percent share from coal during the winter fluctuates considerably in comparison to the other seasons. The lowest MAPE value occurred during the summer. The seasonal MAPE profiles for the test case are presented in Figures C-25 to C-28 in Appendix C.

Table 8-12: Average MAPE values for \% coal test case - 2006

\begin{tabular}{|c|c|}
\hline \multicolumn{2}{|c|}{2006} \\
\hline Season & MAPE (\%) \\
\hline Winter & 13.53 \\
\hline Spring & 12.84 \\
\hline Summer & 7.23 \\
\hline Fall & 12.87 \\
\hline Average & 11.62 \\
\hline
\end{tabular}

The NN model which was trained using 2005 data was not as accurate for 2006 . The NN models developed are for short term forecasting only. However, it was observed that long term forecasting for the summer had the highest MAPE of 7.23\% in 2006. In addition, the spring and fall months resulted in a MAPE of approximately $12.8 \%$ and the winter was considered to be the hardest season to predict due to its high MAPE value of $13.53 \%$. However the average MAPE for the entire year was $11.62 \%$. Yearly retraining of the NN should improve the predictive performance.

\subsubsection{Percentage Other NN}

The performance of the developed NN model for percentage other forecasting is presented in Table 8-13. The $\mathrm{R}^{2}$ and correlation values for the training, validation, and testing data were approximately $80 \%$ and $90 \%$, respectively. It should be recognized that the percent share from "other" is difficult to predict since it is dependent on the market. 
Table 8-13: Prediction performance of NN model - \% other

\begin{tabular}{|c|c|c|}
\hline Subset & $\mathbf{R}^{\mathbf{2}}$ & Correlation \\
\hline Training & 0.839 & 0.928 \\
\hline Validation & 0.814 & 0.912 \\
\hline Testing & 0.797 & 0.909 \\
\hline
\end{tabular}

The estimates for the NN models are plotted along with the percentage "other" data for Ontario as shown in Figures C-29 to C-31 in Appendix C. The NN model was able to predict the percentage share from "other" for the year 2005. When the inputs were examined, it was found that some of the predicted values where close to their corresponding values in the testing dataset.

The error distribution for the network is shown in Figure 8-9. It can be observed that the majority of the errors are lower than $3.2 \%$.

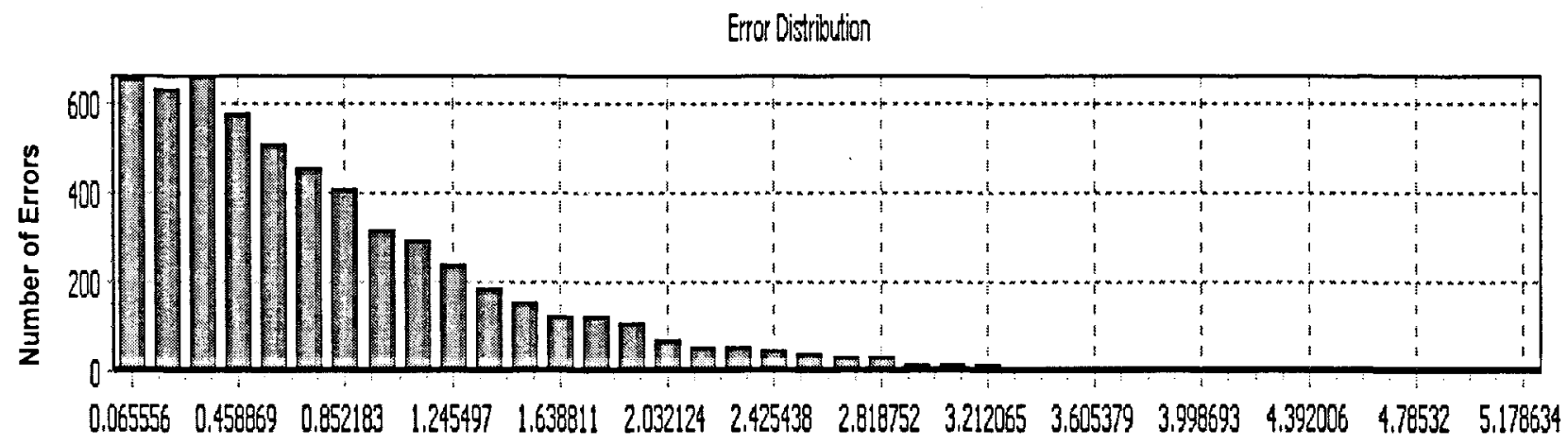

Figure 8-9: Error distribution for the \% other NN

The importance of the types of inputs for the network is illustrated in Figure 8-10. Several input categories have a significant effect on the percentage share of "other". It can be observed that the percentage share from "other" is heavily dependent on the day of the week, the electricity generated in the Province of Ontario, the month, and the temperature. It should be noted that the other inputs had a relatively smaller effect on the predicting power of the network. This clearly indicates that other is highly dependent on day of the week. 


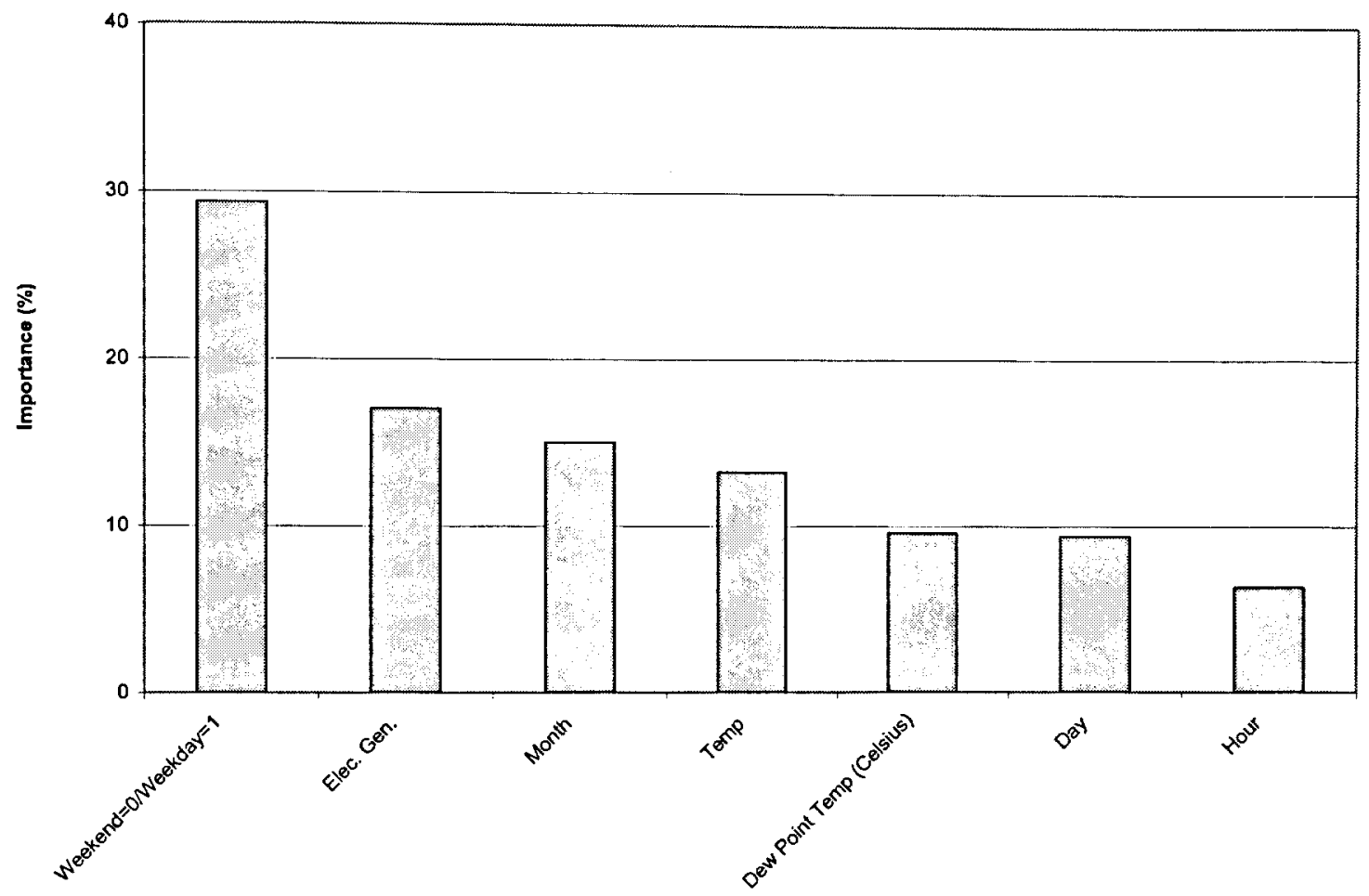

Figure 8-10: Input importance percentage for the \%other NN

The statistical results are presented in Table 8-14 for the training, validation and testing subsets. This NN model is less accurate than the other networks, the factors affecting the percentage share from "other" are somewhat represented by the inputs selected in Chapter 4. The validation and testing subsets have the highest values for the MAPE of $11.86 \%$ and $12.17 \%$, respectively, whereas the training subset has the lowest value of $10.89 \%$. The maximum MAPE value was the highest in the testing subset.

Table 8-14: NN \% other training statistics

\begin{tabular}{|c|c|c|c|}
\hline & \multicolumn{3}{|c|}{ MAPE (\%) } \\
\cline { 2 - 4 } & Training & Validation & Testing \\
\hline Mean & 10.89 & 11.86 & 12.17 \\
\hline Std Dev & 10.06 & 10.35 & 11.13 \\
\hline Min & 0.0002 & 0.0012 & 0.0042 \\
\hline Max & 109.09 & 89.74 & 114.31 \\
\hline
\end{tabular}


In this case, the target is to predict the percent share from "other" for each season for 2006. The NN model was developed using data from 2005 and as shown above it could predict the percent share from "other" somewhat accurately with an average MAPE of $10.89 \%$. Percent share from power generation and weather data for 2006 was divided into winter, spring, summer, and fall in order to compare the NN predictive performance across the seasons for the year 2006. Table 8-15 shows the average MAPE values for 2006. The highest MAPE value occurred in the fall and the lowest MAPE value occurred during the winter. Given the high MAPE values the predictive performance of the "other" network is not valid for 2006. The seasonal MAPE profiles for the test case are presented in Figures C-32 to C35 in Appendix C.

Table 8-15: Average MAPE values for \% other test case - 2006

\begin{tabular}{|c|c|}
\hline \multicolumn{2}{|c|}{2006} \\
\hline Season & MAPE (\%) \\
\hline Winter & 27.70 \\
\hline Spring & 21.24 \\
\hline Summer & 23.52 \\
\hline Fall & 28.05 \\
\hline Average & 25.13 \\
\hline
\end{tabular}

The NN model which was trained using 2005 data was not as accurate for 2006. The NN models developed are for short term forecasting only. However, it was observed that long term forecasting for the fall had the highest MAPE of $28.05 \%$ in 2006 . In addition, the spring and summer months resulted in a MAPE of $21.24 \%$ and $23.52 \%$, respectively. In addition, the fall was considered to be the hardest season to predict due to its high MAPE value of $28.05 \%$ and average MAPE for the entire year was $25.13 \%$. This network is the most difficult to predict due to the electricity market regulations and fuel costs. Other mainly uses natural gas, and wood chips to produce electricity. However, the nuclear, coal and hydro networks were quite accurate and since they produce approximately $94 \%$ of the electricity, the less accurate network such as "other" does not have a huge impact on the total percentage share predictions. 


\subsection{Emission Factor Forecasting using Neural Networks}

This section presents the use of neural networks developed in previous sections to predict the $\mathrm{NGHGIF}_{\mathrm{A}}$ for the Province of Ontario. Two methodologies were explored, one that uses the neural networks developed in previous sections and another one that has its own NN to predict the hourly emission factor.

\subsubsection{Methodology 1}

In order to predict the emission factor for the first case, the total hourly electricity generated, and the hourly electricity generated by coal and "other" for the Province of Ontario had to be predicted for the year 2005 using the networks developed in Sections 8.2, and 8.3. The following process is defined in Equations 8.1, 8.2, 8.3, 8.4 and 8.5

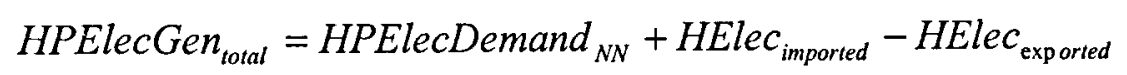

Where,

HPElecGen $_{\text {total }}=$ Hourly Predicted Total Electricity Generated by the Province of Ontario $(\mathrm{kWh})$

HPElecDemand $_{N N}=$ Hourly Predicted Electricity Demand by NN for the Province of Ontario (kWh)

HElec $_{\text {imported }}=$ Hourly Electricity imported by the Province of Ontario (kWh)

$H E l e c_{\text {exp orted }}=$ Hourly Electricity exported by the Province of Ontario $(\mathrm{kWh})$

$$
\text { HPElec }_{\text {coal }}=\left(\frac{H P \% \text { Coal }_{N N} \times H P E l e c G e n_{\text {total }}}{100}\right)
$$

Where,

HPElec $_{\text {coal }}=$ Hourly Predicted Electricity generated by coal for the Province of Ontario $(\mathrm{kWh})$

$H P \%$ Coal $_{N N}=$ Hourly Predicted Percentage from Coal by NN for the Province of Ontario $(\mathrm{kWh})$ 
HPElecGen $_{\text {total }}=$ Hourly Predicted Total Electricity Generated by the Province of Ontario $(\mathrm{kWh})$

HPElec $_{\text {other }}=\left(\frac{H P \% \text { Other }_{N N} \times \text { HPElecGen }}{\text { total }}\right)$

Where,

HPElec $_{\text {other }}=$ Hourly Predicted Electricity generated by other for the Province of Ontario (kWh)

$H P \%$ Other $_{N N}=$ Hourly Predicted Percentage from Other by NN for the Province of Ontario (kWh)

HPElecGen $_{\text {total }}=$ Hourly Predicted Total Electricity Generated by the Province of Ontario (kWh)

$\mathrm{HPCO}_{2}=(i)\left(\right.$ HPElec $\left._{\text {coal }}\right)+(j)\left(\right.$ HPElec $\left._{\text {other }}\right)$

Where,

$\mathrm{HPCO}_{2}=$ Hourly Predicted $\mathrm{CO}_{2}$ production $(\mathrm{g})$

HPElec $_{\text {coal }}=$ Hourly Predicted Electricity generated by other for the Province of Ontario (kWh)

HPElec $_{\text {other }}=$ Hourly Predicted Electricity generated by coal for the Province of Ontario (kWh)

$i=\mathrm{OPG} \mathrm{CO} 2$ emission factor $\left(0.974 \mathrm{~g}\right.$ of $\mathrm{CO}_{2} / \mathrm{kWh}$ for the year 2005)

$j=$ Environment Canada natural gas emission factor $\left(0.432 \mathrm{~g}\right.$ of $\mathrm{CO}_{2} / \mathrm{kWh}$ for the year 2005) (Environment Canada (2005))

$H P N G H G I F_{A}=\frac{\mathrm{HPCO}_{2}}{H P E l e c G e n_{\text {total }}}$ 
Where,

$H_{P N G H G I F}=$ Hourly Predicted New Greenhouse Gas Intensity Factor (g of $\left.\mathrm{CO}_{2} / \mathrm{kWh}\right)$

$\mathrm{HPCO}_{2}=$ Hourly Predicted $\mathrm{CO}_{2}$ production (g)

HPElecGen $_{\text {total }}=$ Hourly Predicted Total Electricity Generated by the Province of Ontario (kWh)

\subsubsection{Test Case Using Methodology 1}

In this case, the target is to predict the $\mathrm{NGHGIF}_{\mathrm{A}}$ for each season for 2005 . The model was developed using data from 2005. As described in the previous section, NN predictions for the electricity generated and percent share from power generation for Ontario data for 2005 was divided into winter, spring, summer, and fall in order to compare the predicted and actual emission factor. Table 8-16 shows the average MAPE values for 2005. The highest MAPE value occurred in the summer and the lowest MAPE value occurred during the spring. The MAPE values were not as low as desired, however the predictive performance of the emission factor network is still valid for 2005. The seasonal MAPE profiles for the test case presented in Figures C-36 to C-39 in Appendix C correspond to the initial methodology and not to the alternate method.

Table 8-16: Average seasonal MAPE values comparing actual and predicted NGHGIF $_{A}-2005$

\begin{tabular}{|c|c|}
\hline \multicolumn{2}{|c|}{2005} \\
\hline Season & MAPE (\%) \\
\hline Winter & 13.58 \\
\hline Spring & 12.94 \\
\hline Summer & 15.72 \\
\hline Fall & 15.06 \\
\hline Average & 14.32 \\
\hline
\end{tabular}

It should be noted that the predicted emission factor is dependent on the predicted electricity demand for the Province of Ontario. An alternate method was explored by using the actual electricity demand instead of the predicted electricity demand in the predicted percentage mix values. However, the predicted electricity demand was still used to calculate 
the emission factor as show in Equation 8.5. Table 8-17 shows the average MAPE values for 2005 using the alternative methodology which is beyond the scope of this thesis.

Table 8-17: Average seasonal MAPE values comparing actual and predicted NGHGIF $_{\mathrm{A}}$ using alternate methodology $\mathbf{- 2 0 0 5}$

\begin{tabular}{|c|c|}
\hline \multicolumn{2}{|c|}{2005} \\
\hline Season & MAPE (\%) \\
\hline Winter & 6.27 \\
\hline Spring & 8.04 \\
\hline Summer & 5.47 \\
\hline Fall & 7.35 \\
\hline Average & 6.78 \\
\hline
\end{tabular}

The NN model which was trained using 2005 data was not as accurate as expected. This might be due to carried errors from the other predictive models. The NN models developed are for short term forecasting only. However, it was observed that long term forecasting for the spring had the lowest MAPE of $12.94 \%$ and the winter and fall months resulted in a MAPE of $13.58 \%$ and $15.06 \%$, respectively. The summer had the highest MAPE of $15.72 \%$ and was considered to be the hardest season to predict due to grid fluctuations related to weather change in the city of Toronto. In addition, the overall average MAPE for the entire year was $14.32 \%$ which is a good performance indicator for this methodology. This methodology will be compared to methodology 2 in the next section.

\subsubsection{Methodology 2}

For the second case a neural network model was developed to estimate the hourly emission factor based on the total electricity demand and weather for the Province of Ontario.

The performance of the developed $N N$ model for emission factor $(E F)$ forecasting is presented in Table 8-18. The $\mathrm{R}^{2}$ and correlation values for the training, validation, and testing data were close to 1 which is a good performance indicator of the network. 
Table 8-18: Prediction performance of NN model - emission factor

\begin{tabular}{|c|c|c|}
\hline Subset & $\mathbf{R}^{2}$ & Correlation \\
\hline Training & 0.806 & 0.915 \\
\hline Validation & 0.782 & 0.906 \\
\hline Testing & 0.790 & 0.912 \\
\hline
\end{tabular}

The estimates for the NN models are plotted along with the EF data for Ontario as shown in Figures C-40 to C-42 in Appendix C. The NN model was able to predict the EF for the year 2005. When the inputs were examined, it was found that most of the predicted values where close to their corresponding values in the testing dataset.

The error distribution for the network is shown in Figure 8-11. It can be observed that the errors for the network are lower than $53 \mathrm{~g}$ of $\mathrm{CO}_{2} / \mathrm{kWh}$, and that the majority of these errors corresponding to the predicted EF are within 0.848277 and $15 \mathrm{~g}$ of $\mathrm{CO}_{2} / \mathrm{kWh}$ from the actual EF value.

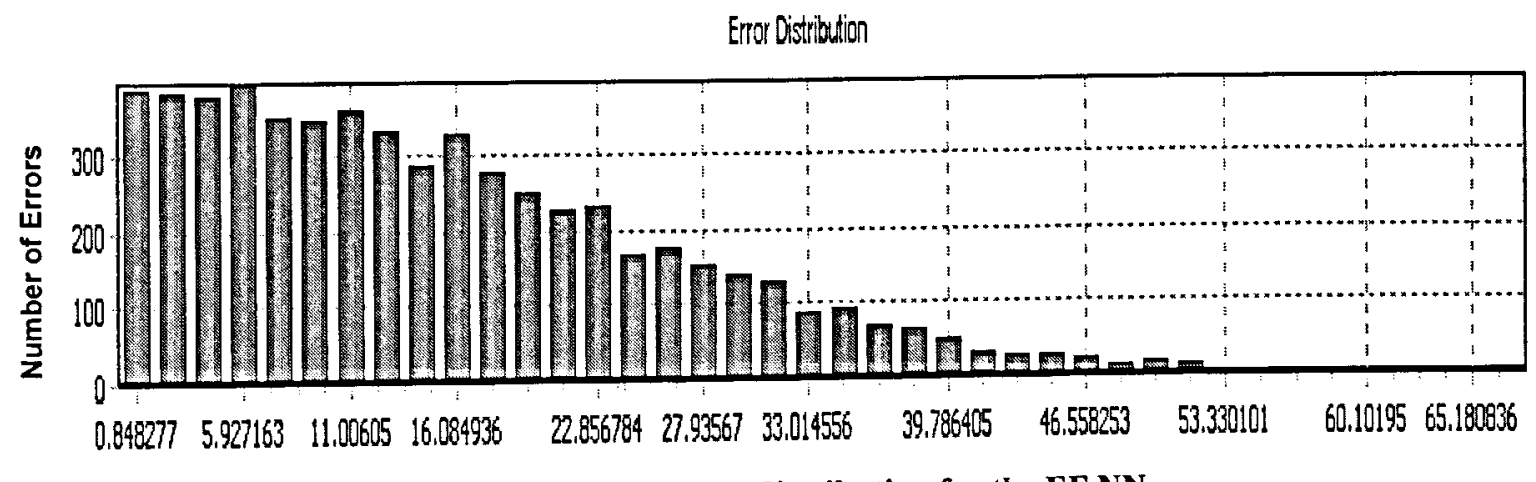

Figure 8-11: Error distribution for the EF NN

The importance of the types of inputs for the network is illustrated in Figure 8-12. Several input categories have a significant effect on the emission factor for the Province of Ontario. It can be observed that the emission factor is heavily dependent on the electricity demand. 


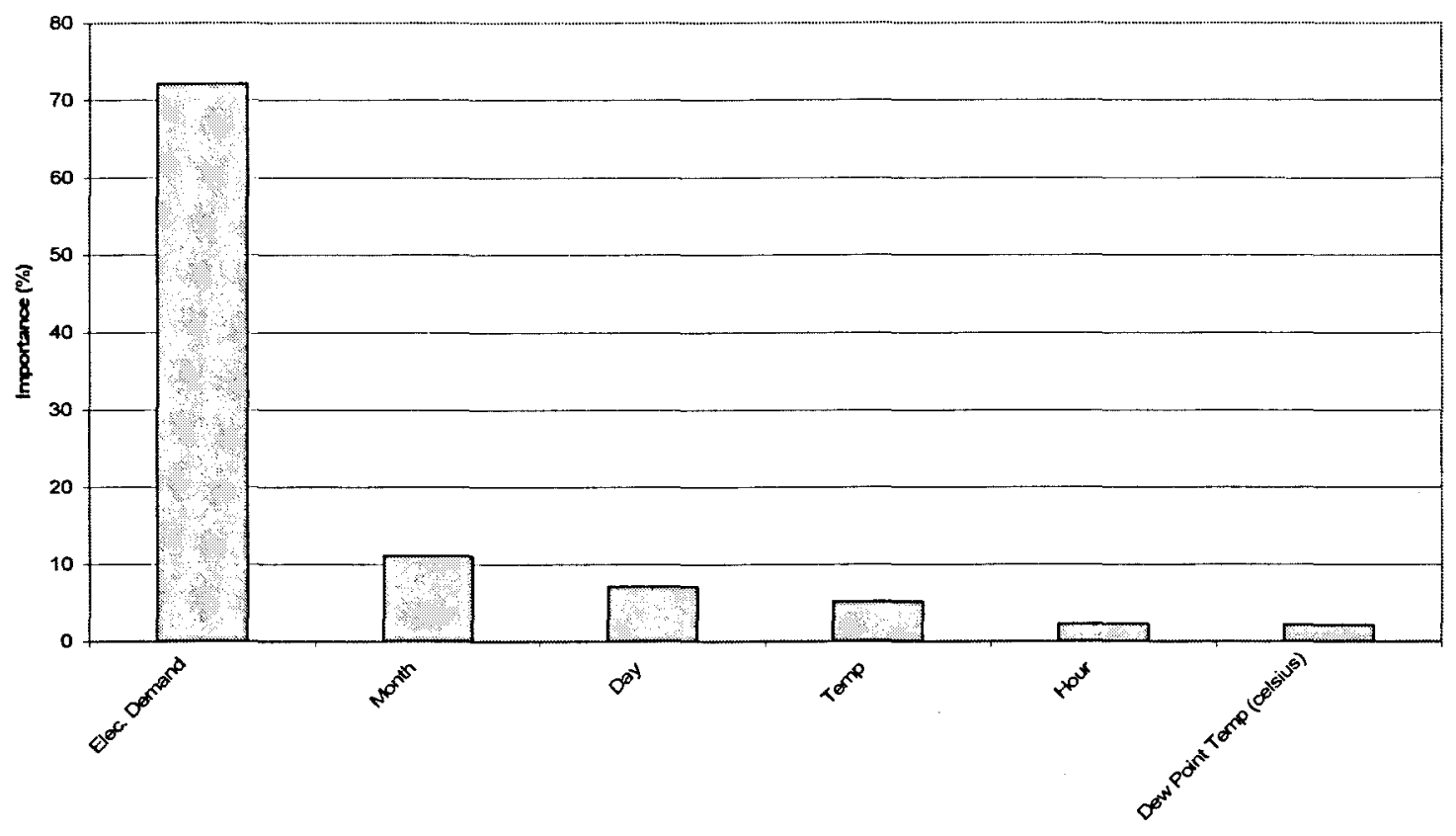

Figure 8-12: Input importance percentage for the EF NN

The statistical results are presented in Table 8-19 for the training, validation and testing subsets. Given the MAPE values, the factors affecting the emission factor are closely represented by the inputs selected in Chapter 4 . The validation and testing subsets have the highest values of MAPE with $8.09 \%$ and $8.31 \%$, respectively, whereas the training subset has the lowest with $7.85 \%$.

Table 8-19: NN EF training statistics

\begin{tabular}{|c|c|c|c|}
\hline & \multicolumn{3}{|c|}{ MAPE (\%) } \\
\cline { 2 - 4 } & Training & Validation & Testing \\
\hline Mean & 7.85 & 8.09 & 8.31 \\
\hline Std Dev & 7.55 & 8.39 & 8.20 \\
\hline Min & 0.002 & 0.016 & 0.0126 \\
\hline Max & 87.63 & 77.96 & 69.25 \\
\hline
\end{tabular}

\subsubsection{Comparison of Emission Factor Methodologies}

Two methodologies were developed in order to estimate the emission factor for the Province of Ontario. It is clear that methodology 1 is more complex due to the several inputs and steps that are required in order to estimate the emission factor, whereas methodology 2 is simpler and is highly dependent on the electricity demand and does not 


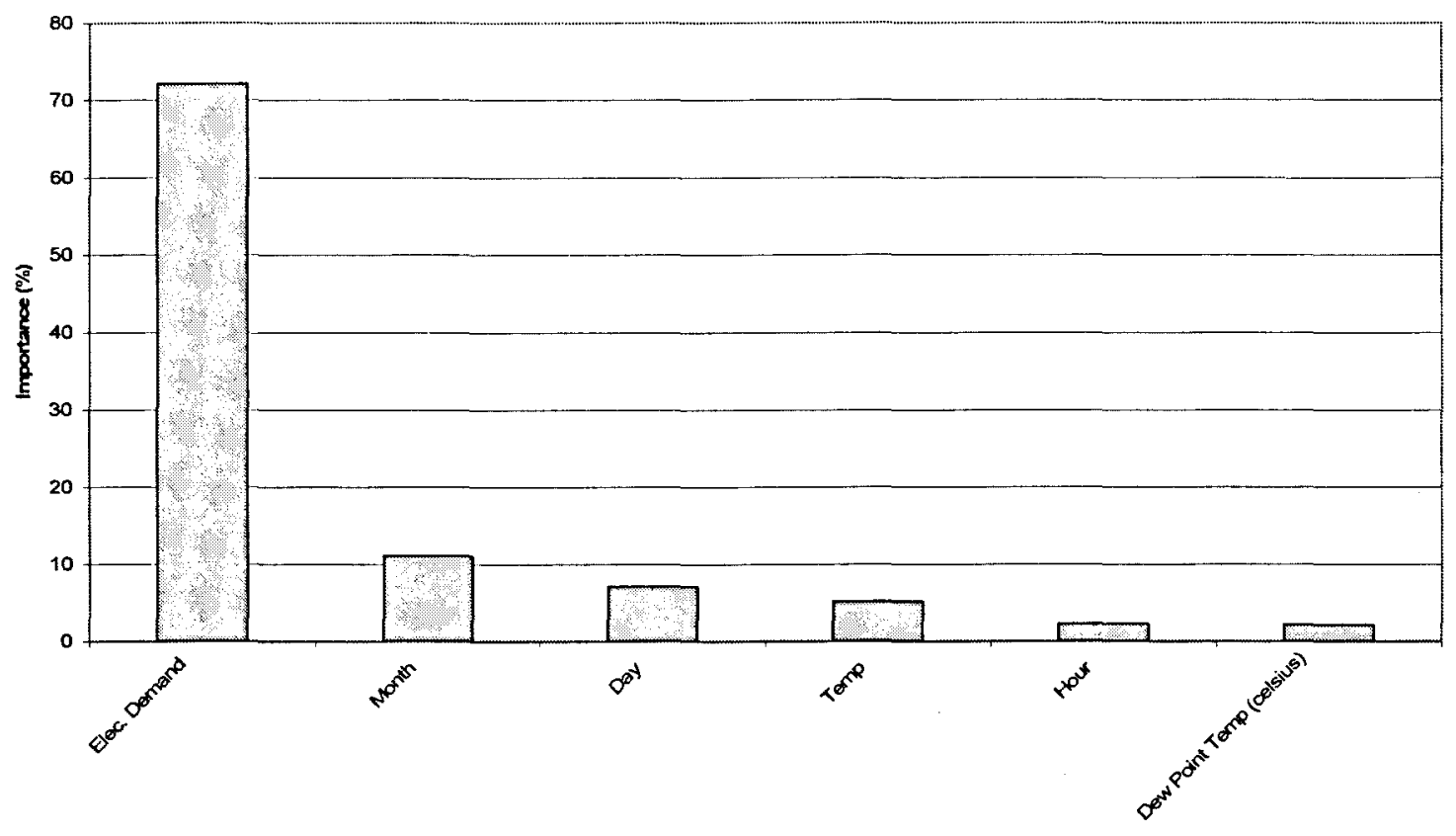

Figure 8-12: Input importance percentage for the EF NN

The statistical results are presented in Table 8-19 for the training, validation and testing subsets. Given the MAPE values, the factors affecting the emission factor are closely represented by the inputs selected in Chapter 4 . The validation and testing subsets have the highest values of MAPE with $8.09 \%$ and $8.31 \%$, respectively, whereas the training subset has the lowest with $7.85 \%$.

Table 8-19: NN EF training statistics

\begin{tabular}{|c|c|c|c|}
\hline & \multicolumn{3}{|c|}{ MAPE (\%) } \\
\cline { 2 - 4 } & Training & Validation & Testing \\
\hline Mean & 7.85 & 8.09 & 8.31 \\
\hline Std Dev & 7.55 & 8.39 & 8.20 \\
\hline Min & 0.002 & 0.016 & 0.0126 \\
\hline Max & 87.63 & 77.96 & 69.25 \\
\hline
\end{tabular}

\subsubsection{Comparison of Emission Factor Methodologies}

Two methodologies were developed in order to estimate the emission factor for the Province of Ontario. It is clear that methodology 1 is more complex due to the several inputs and steps that are required in order to estimate the emission factor, whereas methodology 2 is simpler and is highly dependent on the electricity demand and does not 
take into consideration the percentage mix from the different sources that make up the electricity generation sector. It should be noted that methodology 2 resulted in a lower MAPE. However, the alternate methodology 1 performed better than methodology 2 because it did not use the predicted electricity value developed in Section 8.2, but instead used the actual value. Also, methodology 1 used the predicted electricity values for 2005 developed by the electricity demand network based on 2004 data, which was not as accurate for 2005. This might have been one of the contributing factors to the lower performance of the network developed by the first methodology. 


\section{Conclusions and Recommendations}

\subsection{Conclusions}

As stated in Section 1.5, the objectives of this work were: firstly, to study the supply and demand of electricity and associated GHG emissions for the Province of Ontario and to develop GHG emission factors for the years 2004, 2005, and 2006; secondly, to develop seasonal Time Dependent Valuation (TDV) emission and monthly cost factors in order to estimate and place a monetary value on emissions produced by the electricity generation sector; thirdly, these emission and cost factors were applied to simulation results from ESP-r for the different archetypes and cities; lastly, NN models were developed to predict the electricity demand, emissions, and emission factor for the Province of Ontario. The aforementioned objectives were successfully achieved as follows:

- Emissions from the electricity generation sector were analyzed and different emission factors were developed in order to represent the true reduction potential of $\mathrm{CO}_{2}$ by using renewable energy technologies. $\mathrm{CO}_{2}$ emissions were the highest during the winter in 2004, but were higher during the summer months in 2005 and 2006. The year with the highest emissions was 2005. However, emissions in 2006 were the lowest between 2004 and 2006. Once again, electricity generated by coal plants is being reduced unless some unplanned event affects the other generating plants.

- Several emission factors were developed for the years 2004,2005 , and 2006 . The hourly emission factor proved to be the most accurate. In addition, depending on the type of analysis conducted it might be practical but not as accurate to employ seasonal, time dependent valuation (TDV), and annual averages emission factors to estimate $\mathrm{CO}_{2}$ emissions. It was observed that TDV and seasonal average emission factors were more accurate than using the annual average value. It should also be mentioned, that monthly TDV emission factors might prove to be as accurate as using hourly values. However, it should be noted that TDV values for 2005 were quite different from those of the years 2004 and 2006. This difference might be 
attributed to unexpected events for 2005 due to either unplanned outages for plants or variability in temperature.

- Greenhouse Gas Cost Factors (GHGCF) were developed in order to place a monetary value on emissions from fossil plants. The cost factors were developed for three pricing schemes: flat rate, time-of-use (TOU), and wholesale. It was determined that the flat rate pricing scheme placed a higher monetary value on emissions compared to using a TOU pricing scheme. In addition, the cost factor based on the wholesale pricing scheme was developed to charge generators a price for the amount of emissions produced from fossil plants. Clearly, the money collected from generators could be used as a rebate for customers using renewable technologies emitting zero operating emissions.

- The potential reduction of GHG emissions using the different emission factors was performed on each of the test case house models. Using the hourly, seasonal average, annual average and TDV emission factors for the Province of Ontario, the total $\mathrm{CO}_{2}$ emission reduction potential for each test case was estimated and compared to using the hourly emission factor. For all test cases, the highest and lowest emission reduction potential was obtained by using the seasonal TDV and annual average emission factor, respectively. The hourly emission factor is usually in between the two limits. It is clear that there is a need for hourly emission factors in order to accurately estimate the true potential reduction in greenhouse gases. The use of regionally specific climate-modeled factors, such as those identified, allows for a more accurate representation of the benefits associated with GHG reducing technologies.

- The development of NN models was conducted in order to speed up the process in estimating emission factors. Initially, a neural network model was developed in order to predict the electricity demand and percentage mix from each generating source for the Province of Ontario by using hourly data obtained from the IESO and weather data from Environment Canada. Two methodologies were developed in this thesis: 1) using the aforementioned networks to predict the emission factor or 2) developing a specific neural network that could predict the emission factor in one step. It was determined that both methodologies are accurate, but the second method proved to be better at estimating the emission factor with a MAPE of $7.85 \%$ compared to a 
MAPE of $14.32 \%$ using the first methodology. Two things were discovered during the simulations: Firstly, it was determined that by using the actual electricity demand data instead of the predicted values increased the MAPE value by almost $45 \%$. Secondly, the predicted electricity demand network was developed using data from 2004 to predict the electricity demand for 2005 . Both of these factors contributed to lower MAPE values. This approach could be used in other provinces where electricity generation data are not readily available. However, it should be noted that the NN model is limited to changes in both the environment and electricity consumption; thus, it should be updated periodically.

\subsection{Recommendations}

In this thesis, average hourly, seasonal and annual emission factors were developed in order to show the time of day and time of year variations of the electricity generation sector. However, monthly emission factors could be developed to provide better accuracy. It should be noted that the emission factors developed were based on the total electricity generated from all sources in the Province of Ontario. Perhaps peak and marginal emission factors could be developed in order to have a middle and upper limit reduction potential of emissions. However, these emission factors should not be used to estimate the reduction potential of $\mathrm{CO}_{2}$ by using renewable technologies in the residential sector due to their overestimating quality. 
In addition, an $\mathrm{NN}$ model was developed using the learning algorithms and activation functions of the NeuroIntelligence software. Other NN software with different learning algorithms and activation functions could be tested to increase the prediction performance of the model in order to reduce training time. Another potential improvement to the NN model would be to increase the database size of the environmental factors and electricity demand values. Fuel based methods only estimate an annual average and do not reflect the cyclic behaviour of emission factors throughout the day. The model can detcrmine the environmental impacts on when energy is consumed. Thus, the NN model can predict the hour-by-hour electricity demand for the Province of Ontario which can then be used to estimate GHG emission factors. This method of analysis would allow for a more accurate representation of the potential reduction of GHGs by using renewable technologies. However, it was determined that all the neural network models should be trained for the same year due to their short term predictive power. 


\section{References}

Akaike, H., (1974), A New Look At The Statistical Model Identification. IEEE Transaction of Automatic Control, 19, pp. 723.

Alfares, H.K., and Nazeeruddin, M., (1999), Regression-Based Methodology for Daily Peak Load Forecasting. Proceedings of the 2nd International Conference on Operations and Quantitative Management, Ahmedabad, India, 3-6 January, pp. 468-471.

AlFuhaid, A.S., El-Sayed, M.A., Mahmoud, M.S., (1997), Cascaded Artificial Neural Networks for Short-term Load Forecasting, IEEE Transactions on Power Systems, Vol. 12, No. 4, pp. 1524-1529.

Alyuda (2007), NeuroIntelligence Software and Manual, [online] Available: http://www.alyuda.com

Anstett, M., and Kreider, J.F., (1993), Application of Neural Networking Models to Predict Energy Use, ASHRAE Transactions, Vol. 99, Part 1, pp. 505-517.

Amjady, N., (2001), Short-Term Hourly Load Forecasting using Time-Series Modeling with Peak Load Estimation Capability, IEEE Transaction on Power Systems, Vol. 16, No. 3, pp.498-505.

Asar, A. \& McDonald, R. (1994). A Specification of Neural Network Applications in the Load Forecasting Problem. IEEE Transactions on Control Systems Technology, 2, 135-141.

Bertsekas, D. P. (1995), Nonlinear Programming, Belmont, MA: Athena Scientific, ISBN 1886529-14-0.

Bruce, A., Jurke, S., and Thomson, P. (1994). Forecasting Load-Duration Curves, J. Forecasting 13. 
Canadian Manufacturers \& Exporters (CME), Pain Without Gain: Canada and the Kyoto Protocol, 2003 [online]

Available: http://www.cme-mec.ca/kyoto/documents/kyoto_release.pdf

Chow, T.W.S \& Leung, C.T. (1996). Neural Network Based Short-Term Load Forecasting System using Weather Compensation. IEEE Transactions on Power Systems, 11, 1736-1742.

Christiaanse, W.R. (1971). Short-Term Load Forecasting Using General Exponential Smoothing, IEEE Transactions on Power Apparatus and Systems, PAS-90, pp. 900-902.

City of Toronto, Population Statistics, (2005) [online]

Available: http://www.toronto.ca/toronto_facts/diversity.htm

Environment Canada. Hourly Weather Report, (2004) [online]

Available:http://climate.weatheroffice.ec.gc.ca/climateData/hourlydata_e.html?timeframe= $1 \&$ Prov $=$ XX\&StationID $=5097 \&$ Year $=2006 \&$ Month $=1 \&$ Day $=1$

Environment Canada. Hourly Weather Report, (2005) [online] Available:http://climate.weatheroffice.ec.gc.ca/climateData/hourlydata_e.html?timeframe= $1 \&$ Prov $=$ XX\&StationID $=5097 \&$ Year $=2006 \&$ Month $=1 \&$ Day $=1$

Environment Canada. Hourly Weather Report, (2006) [online] Available:http://climate.weatheroffice.ec.gc.ca/climateData/hourlydata_e.html?timeframe= $1 \&$ Prov $=$ XX $\&$ StationID $=5097 \&$ Year $=2006 \&$ Month $=1 \&$ Day $=1$

Environment Canada, Trends in GHG Sources and Sinks in Canada 1990-2004, Greenhouse Gas Division, October 2007

Feuston, B.P., and Thurtell, J.H., (1994), Generalized Nonlinear Regression with Ensemble of Neural Nets: The Great Energy Predictor Shootout, ASHRAE Transactions, Vol. 100, No. 2, pp. 1075-1080. 
Good, J, Modelling and technical feasibility analysis of a low emission hybrid residential energy system. MASc Thesis, Dalhousie University, Halifax, Nova Scotia, Canada, 2005.

Guler, B., Ugursal, V. I., Fung, A.S. and Aydinalp-Koksal, M., Impact of energy efficiency upgrade retrofits on the residential energy consumption and Greenhouse Gas emissions in Canada, Int. J. Environmental Technology and Management, In press.

Ho, K.L., Hsu, Y.Y., and Yang, C.C., (1992), Short-Term Load Forecasting Using a Multi Layer Neural Network with an Adaptive Learning algorithm. IEEE Transactions on Power Systems, 7, pp. 141-149.

Independent Electricity System Operator (IESO), Market Data 2006 [online] Available: http://www.ieso.ca/imoweb/marketdata/marketData.asp (2006a)

Independent Electricity System Operator (IESO), 2005 Year in Review [online] Available: http://www.ieso.ca/imoweb/pubs/corp/IESO_2005AnnualReview.pdf (2006b)

Independent Electricity System Operator (IESO), 2007 Today's Market [online] http://www.ieso.ca/imoweb/marketdata/marketToday.asp

Intergovernmental Panel on Climate Change (IPCC), National Greenhouse Gas Inventories Program, 1997 [online]

Available: http://www.ipcc-nggip.iges.or.jp/public/gl/invs1.html

Kiartzis, S.J., Bakirtzis, A.G., and Petridis, V., (1995), Short-term Forecasting Using NNs, Electric Power Systems Research, Vol. 33, pp. 1-6.

Lee, K.Y., and Park, J.H., (1992), Short-Term Load Forecasting Using an Artificial Neural Network, IEEE Transactions on Power Systems, 7, pp. 124-130. 
Lonergan, T. and Ringwood, J. V., (1995), Linguistic Modeling of Short-Timescale Electricity Consumption using Fuzzy Modeling Techniques, Proceedings of Irish DSP and Control Colloquium (IDSPCC'95), Belfast.

MacCracken, M, California's Title 24 \& Cool Storage, ASHRAE Journal Vol. 48, 2006.

NRCan, The State of Energy Efficiency in Canada, Report 2006, Natural Resources of Canada, Ottawa, 2007.

Neocleous, C., Schizas, C. (1995), Artificial Neural Networks in Marine Propeller Design, ICNN’95, International Conference on Neural Networks, vol. 2, pp.1098-1102, New York, IEEE Computer Society Press

Ontario Power Generation, Sustainable Development Report (2004) [online] Available: http://www.opg.com/safety/sustainable/index.asp

Ontario Power Generation, Sustainable Development Report (2005) [online] Available: http://www.opg.com/safety/sustainable/index.asp

Ontario Power Generation, Sustainable Development Report (2006) [online] Available: http://www.opg.com/safety/sustainable/index.asp

OPG hotline (2006a). Personal Communication via phone, April, 2006

Ortiz-Arroyo, D., Skov, M.K., Huynh, Q., (2001), Accurate Electricity Load Forecasting with Artificial Neural Networks, Aalborg University Esbjerg Paper, Denmark.

Park, D.C., El-Sharkawai, M.A., Marks II, R.J., Atlas, L.E., Damborg, M.J., (1991), Electric Load Forecasting Using an Artificial Neural Network, IEEE Transactions on Power Systems, vol. 6, no. 2, pp. $442-449$. 
Perry, C. (1999), Short-Term Load Forecasting Using Multiple Regression Analysis. Rural Electric Power Conference, 1999

Roweis, S. (2001), Levenberg-Marquardt Optimization [online]

Available: http://www.cs.toronto.edu/\%7Eroweis/notes/lm.pdf

Rumelhart, D.E., and McClelland, J.L., (1986), Parallel Distributed Processing, The

MIT Press, Cambridge, Massachusetts, USA.

RWE AG, World Energy Report 2005 [online]

Available: http://www.rwe.com/generator.aspx/konzern/worldenergyreport-2005.pdf

Shewchuk, J., An Introduction to the Conjugate Gradient Method Without the Agonizing Pain

Available: http://www.cs.cmu.edu/ jrs/jrspapers.html

Srinivasan, D., Liew, A.C., and Chen, S.P.J., (1991), A Novel Approach to Electric Load Forecasting Based on Neural Networks. IEEE International Joint Conference on Neural Networks, Singapore, 18-21 November, pp. 1172-1177.

Statistics Canada, Population and dwelling counts, for Canada, provinces and territories, and census subdivisions (municipalities), 2006 and 2001 censuses [online]. Available: http://www12.statcan.ca/english/census06/data/popdwell/Tables.cfm

Sunpowered, How PV works, 2007 [online]

Available: http://sunpowered.co.uk/about-pv-how-pv-works-

c5_12_13.html?zenid=6cb98f34a914f34c3968005a7209d9b9

Syed, A.M., Fung, A.S., Ugursal, V.I. (2007), Analysis of Renewable Energy Potential in The Residential Sector Through High Resolution Building Energy Simulation, MASc Thesis, department of Mechanical Engineering, Dalhousie University, Halifax, Canada. 
Taylor, J.W. \& Buizza R. (2003). Using Weather Ensemble Predictions in Electricity Demand Forecasting. International Journal of Forecasting, 19, 57-70.

Tse, H., and Fung, A.S., (2008), Simulation and Analysis of a Net-Zero Energy Townhome in Toronto, Solar Buildings Research Network Conference, Fredericton, New Brunswick.

United Nations Framework Convention on Climate Change (UNFCC), Greenhouse Gas Inventory Data, 1999 [online]

Available: http://unfccc.int/ghg_data/ghg_data_unfccc/items/4146.php

United Nations Framework Convention on Climate change (UNFCC), Kyoto Protocol Thermometer, 2003 [online]

Available: http://unfccc.int/resource/kpthermo.html

Wojczynski, A Canadian Utilities response to Climate Change, 2002 [online] Available: http://www.energyfoundation.org/documents/Manitoba\%20_Hydro.pdf 


\section{Appendix A: Neural Network Algorithms and Performance}

\section{A.1 Learning Algorithms}

This section will explain the most common learning algorithms used for the training of neural networks.

\section{Levenberg-Marquardt}

Levenberg-Marquardt (Roweis, 2001) is an advanced non-linear optimization algorithm. It is the fastest algorithm available for multi-layer perceptrons. However, it has the following restrictions:

- It can only be used on networks with a single output unit.

- It can only be used with small networks (a few hundred weights) because its memory requirements are proportional to the square of the number of weights in the network.

It is only defined for the sum of squared error function and therefore it is only appropriate for regression problems.

\section{Quasi-Newton}

The network training algorithm based on Newton's method (Bertsekas, 1995) is an approximate Hessian matrix that is computed for each iteration of the algorithm based on the gradients.

\section{Conjugate Gradient Descent}

This is an advanced method for training multi-layer neural networks (Shewchuk, 1994). It is based on the linear search usage in the line of an optimal network weights' change. The correction of weights is conducted once per iteration. In most cases, this method works faster than Back Propagation and provides more precise forecasting results.

\section{Back-Propagation Algorithms}

The back-propagation algorithm was introduced by Rumelhart and McClelland (1986) and is the most commonly used learning algorithm. Back-propagation is the best known training algorithm for multi-layer neural networks. It defines rules of propagating the network error back from network output to network input units and adjusting network weights along with 
this back-propagation. It requires lower memory resources than most learning algorithms and usually gets an acceptable result, although it can be too slow to reach the error minimum.

There is no single best training algorithm for neural networks. You need to choose a training algorithm based on the characteristics of the problem. The following simple rules proved to be quite effective for most practical purposes (Alyuda, 2007):

- If the network has a small number of weights (usually, up to 300), LevenbergMarquardt algorithm is efficient. Levenberg-Marquardt often performs considerably faster than other algorithms and finds better optima than other algorithms. But its memory requirements are proportional to the square of the number of weights. Another Levenberg-Marquardt limitation is that it is specifically designed to minimize the sum of square errors and cannot be used for other types of network error.

- If the network has a moderate number of weights, Quasi-Newton and Limited Memory Quasi-Newton algorithms are efficient. But their memory requirements are also proportional to the square of the number of weights.

- If the network has a large number of weights, it is recommended that a Conjugate Gradient Descent algorithm be used. Conjugate Gradient Descent has nearly the convergence speed of second-order methods, while avoiding the need to compute and store the Hessian matrix. Its memory requirements are proportional to the number of weights.

- Conjugate Gradient Descent and Quick Propagation are general-purpose training algorithms of choice.

- It is also possible to use incremental and batch-back propagation for networks of any size. Back-propagation algorithm is the most popular algorithm for training of multilayer perceptrons and is often used by researchers and practitioners. The main drawbacks of back-propagation are: slow convergence, need to adjust the learning rate and momentum parameters, and high probability of getting caught in local minima. Incremental back-propagation can be efficient for large datasets if learning rate properly selected. 



\section{(c) Error calculation:}

The output of the network, i.e. its prediction, and the output (target) parameter are used to compute the network error. The error is used to compute the necessary changes of the weights and biases to minimize the error of the network.

\section{(d) Online backward propagation:}

The weights and biases are adjusted in a way that minimizes the error, and steps from (a) to (d) are repeated until the desired R-squared error is achieved, at which point the slope of the testing dataset will become constant. However, if the testing and training datasets begin to diverge this is an indication that the network has been overtrained. The R-squared value is the relative predictive power of a model, and it is a descriptive measure between 0 and 1 . The closer it is to one, the better the model's predicting ability. In addition, the correlation value is also considered since it is a statistical measure of strength of the relationship between the actual values and network outputs. The correlation coefficient can range from 1 to +1 . The closer it is to 1 , the stronger the positive linear relationship, and the closer it is to -1 , the stronger the negative linear relationship. Once the network is complete, it is used to predict the desired output. 


\section{Appendix B: Neural Network Model Development}

Figures B-1 - B-3 show the minimum error values for the networks developed in this thesis.

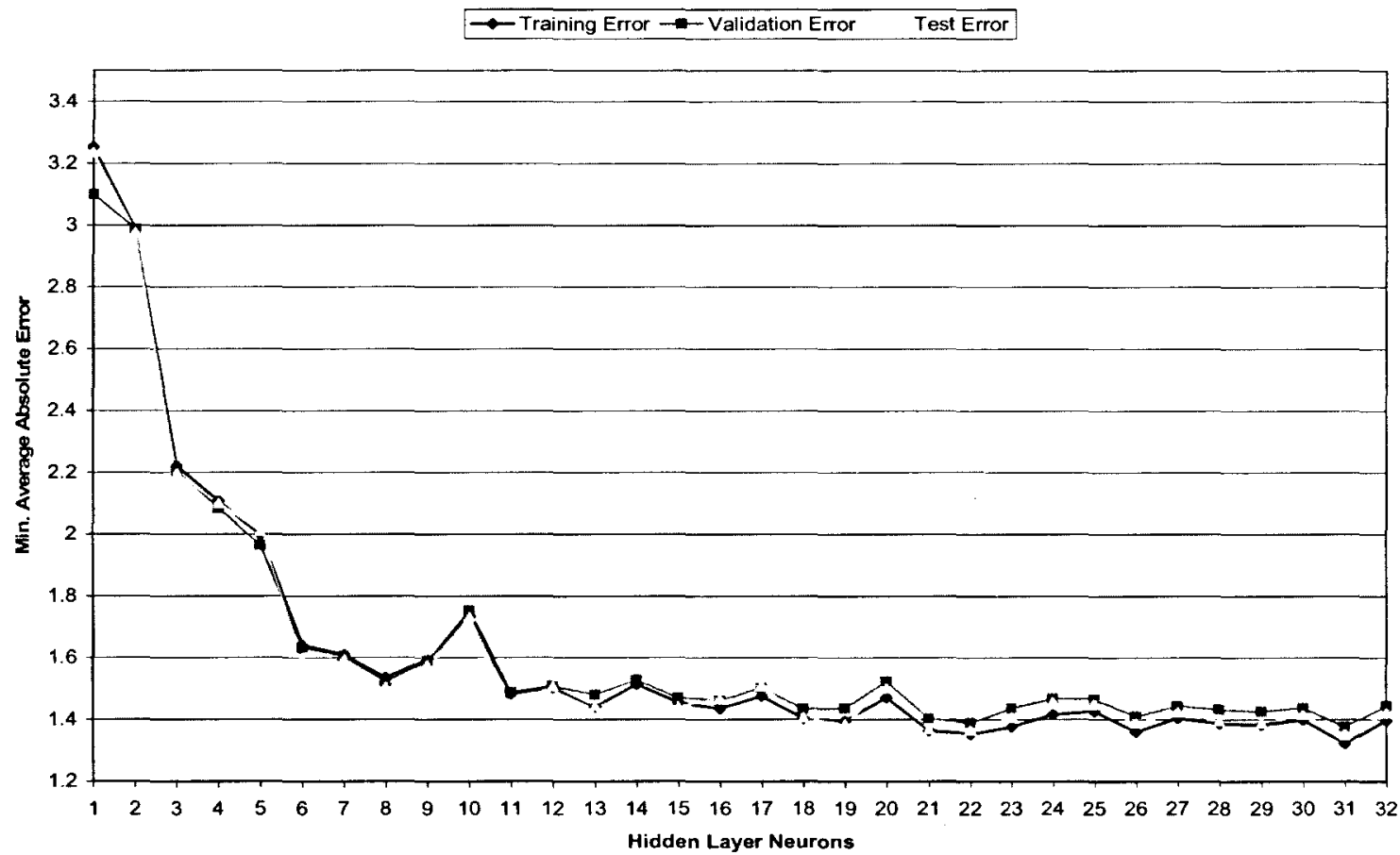

Figure B-1: Minimum error values for the percentage from hydro NN

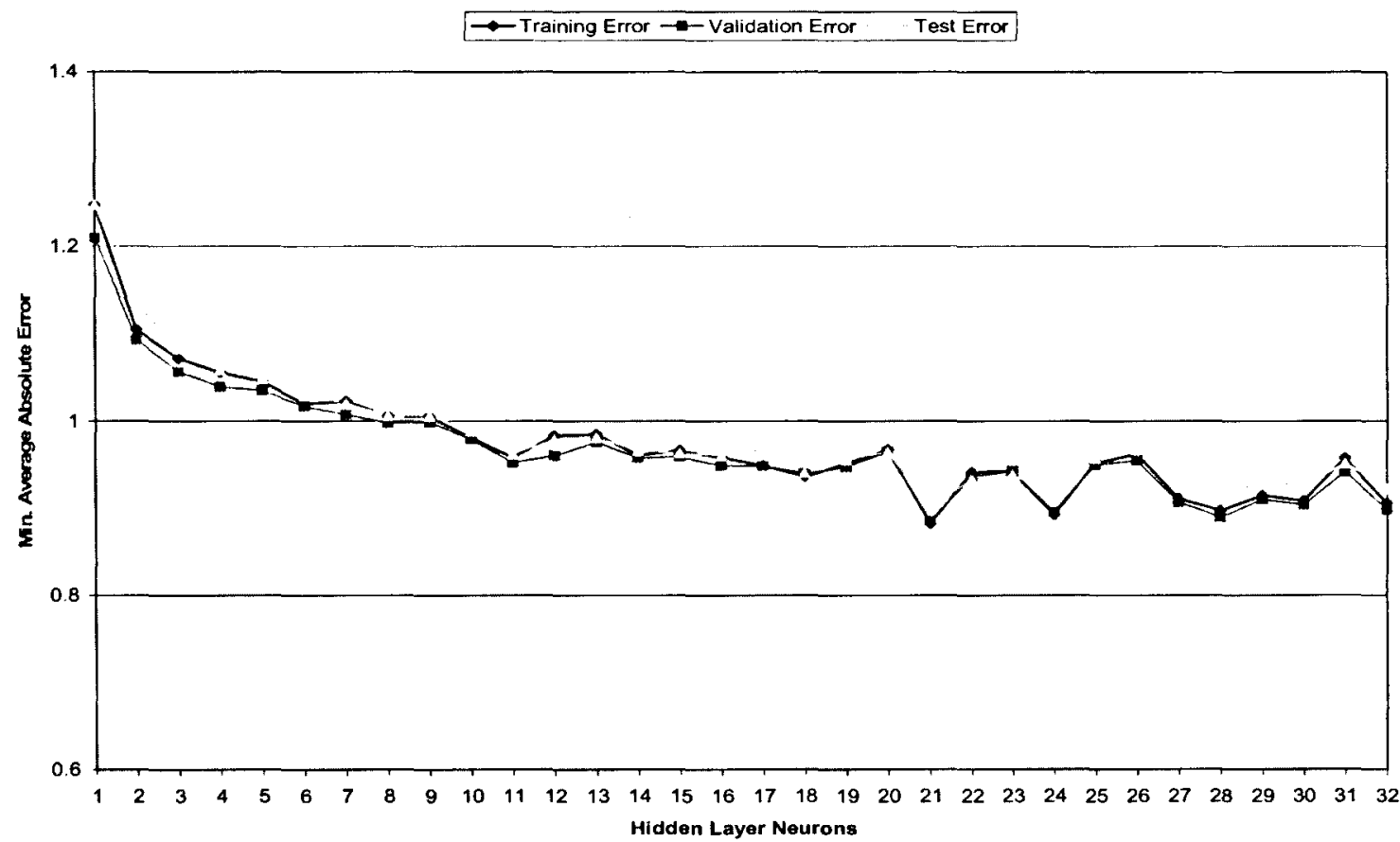

Figure B-2: Minimum error values for the percentage from coal NN 


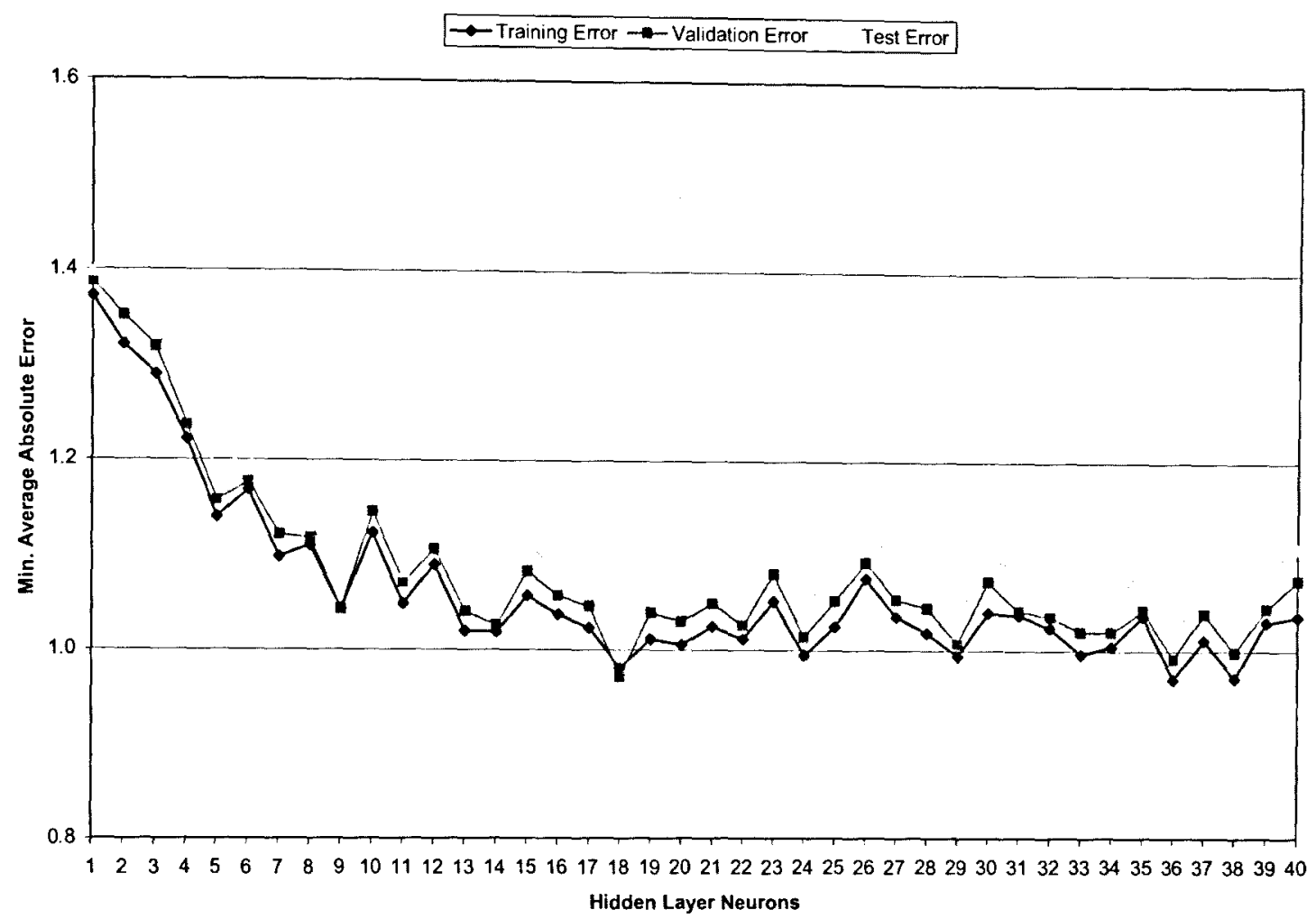

Figure B-3: Minimum error values for the percentage from other NN

Figures B-4 - B-6 show the AIC for the trained networks.

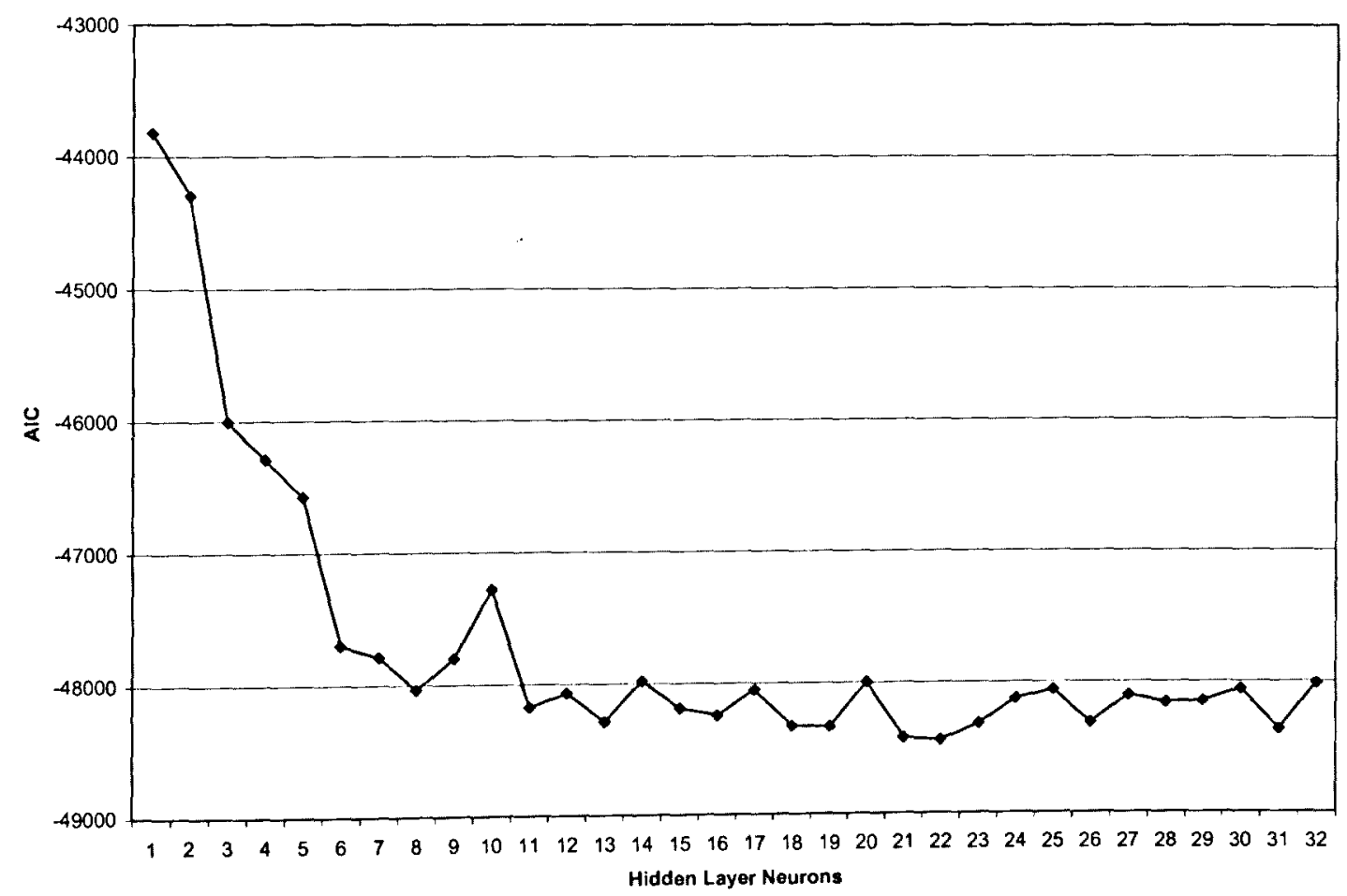

Figure B-4: Akaike's Information Criterion for the percentage from hydro NN 


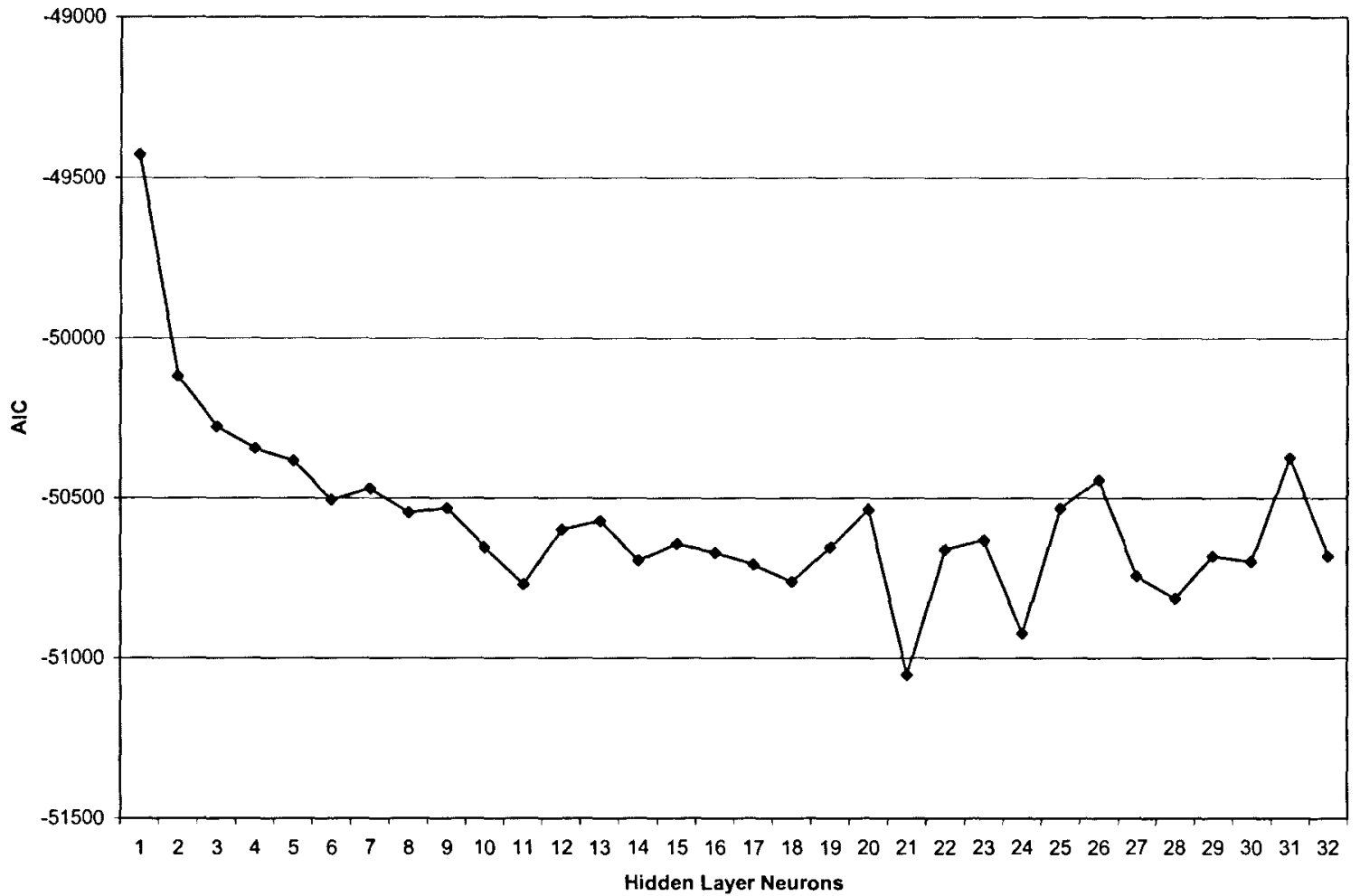

Figure B-5: Akaike's Information Criterion for the percentage from coal NN

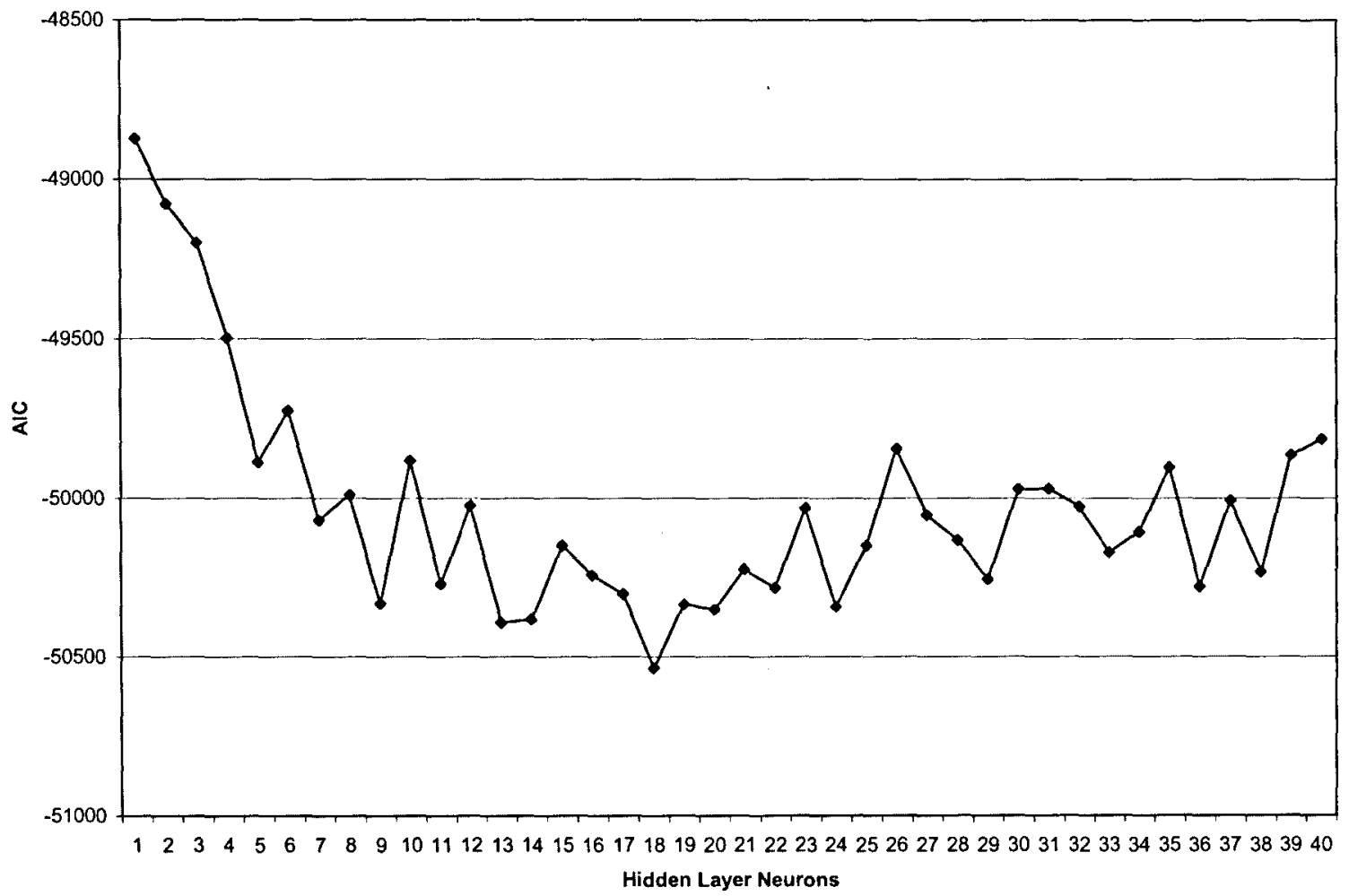

Figure B-6: Akaike's Information Criterion for the percentage from other NN 
Tables B-1 - B-6 show the architectural performance results for the networks.

Table B-1: Performance of the hourly electricity demand network with different architectures

\begin{tabular}{|c|c|c|c|c|c|c|}
\hline Architecture & Train Error & Validation Error & Test Error & AIC & Correlation & $\mathbf{R}^{2}$ \\
\hline$[9-1-1]$ & 1329 & 1341 & 1327 & -8822 & 0.728 & 0.531 \\
\hline [9-2-1] & 1060 & 1063 & 1058 & -10141 & 0.834 & 0.691 \\
\hline [9-3-1] & 820 & 812 & 810 & -11635 & 0.902 & 0.813 \\
\hline [9-4-1] & 664 & 661 & 662 & -12867 & 0.933 & 0.871 \\
\hline [9-5-1] & 785 & 806 & 804 & -11855 & 0.908 & 0.825 \\
\hline$[9-6-1]$ & 679 & 686 & 685 & -12689 & 0.929 & 0.864 \\
\hline$[9-7-1]$ & 618 & 627 & 623 & -13225 & 0.943 & 0.890 \\
\hline [9-8-1] & 652 & 666 & 658 & -12889 & 0.939 & 0.881 \\
\hline [9-9-1] & 602 & 622 & 615 & -13337 & 0.948 & 0.898 \\
\hline [9-10-1] & 614 & 636 & 617 & -13194 & 0.945 & 0.893 \\
\hline [9-11-1] & 600 & 612 & 619 & -13313 & 0.946 & 0.896 \\
\hline [9-12-1] & 600 & 616 & 609 & -13293 & 0.948 & 0.899 \\
\hline [9-13-1] & 591 & 604 & 604 & -13360 & 0.949 & 0.901 \\
\hline [9-14-1] & 582 & 596 & 587 & -13423 & 0.951 & 0.904 \\
\hline [9-15-1] & 581 & 602 & 593 & -13411 & 0.951 & 0.905 \\
\hline [9-16-1] & 605 & 625 & 611 & -13155 & 0.947 & 0.896 \\
\hline [9-17-1] & 562 & 583 & 585 & -13567 & 0.955 & 0.911 \\
\hline [9-18-1] & 540 & 554 & 546 & -13776 & 0.957 & 0.916 \\
\hline [9-19-1] & 619 & 633 & 625 & -12951 & 0.945 & 0.893 \\
\hline$[9-20-1]$ & 557 & 579 & 563 & -13554 & 0.955 & 0.911 \\
\hline$[9-21-1]$ & 559 & 574 & 575 & -13513 & 0.955 & 0.911 \\
\hline$[9-22-1]$ & 578 & 596 & 589 & -13289 & 0.952 & 0.907 \\
\hline [9-23-1] & 576 & 602 & 588 & -13292 & 0.952 & 0.907 \\
\hline$[9-24-1]$ & 561 & 591 & 572 & -13421 & 0.955 & 0.912 \\
\hline [9-25-1] & 554 & 577 & 562 & -13479 & 0.956 & 0.913 \\
\hline [9-26-1] & 552 & 577 & 559 & -13480 & 0.957 & 0.915 \\
\hline [9-27-1] & 569 & 585 & 580 & -13277 & 0.954 & 0.910 \\
\hline$[9-28-1]$ & 576 & 586 & 583 & -13183 & 0.952 & 0.906 \\
\hline [9-29-1] & 588 & 606 & 598 & -13033 & 0.951 & 0.905 \\
\hline [9-30-1] & 565 & 598 & 583 & -13253 & 0.955 & 0.911 \\
\hline$[9-31-1]$ & 531 & 555 & 542 & -13597 & 0.959 & 0.919 \\
\hline [9-32-1] & 552 & 585 & 568 & -13338 & 0.956 & 0.915 \\
\hline
\end{tabular}


Table B-2: Performance of the percentage from nuclear network with different architectures

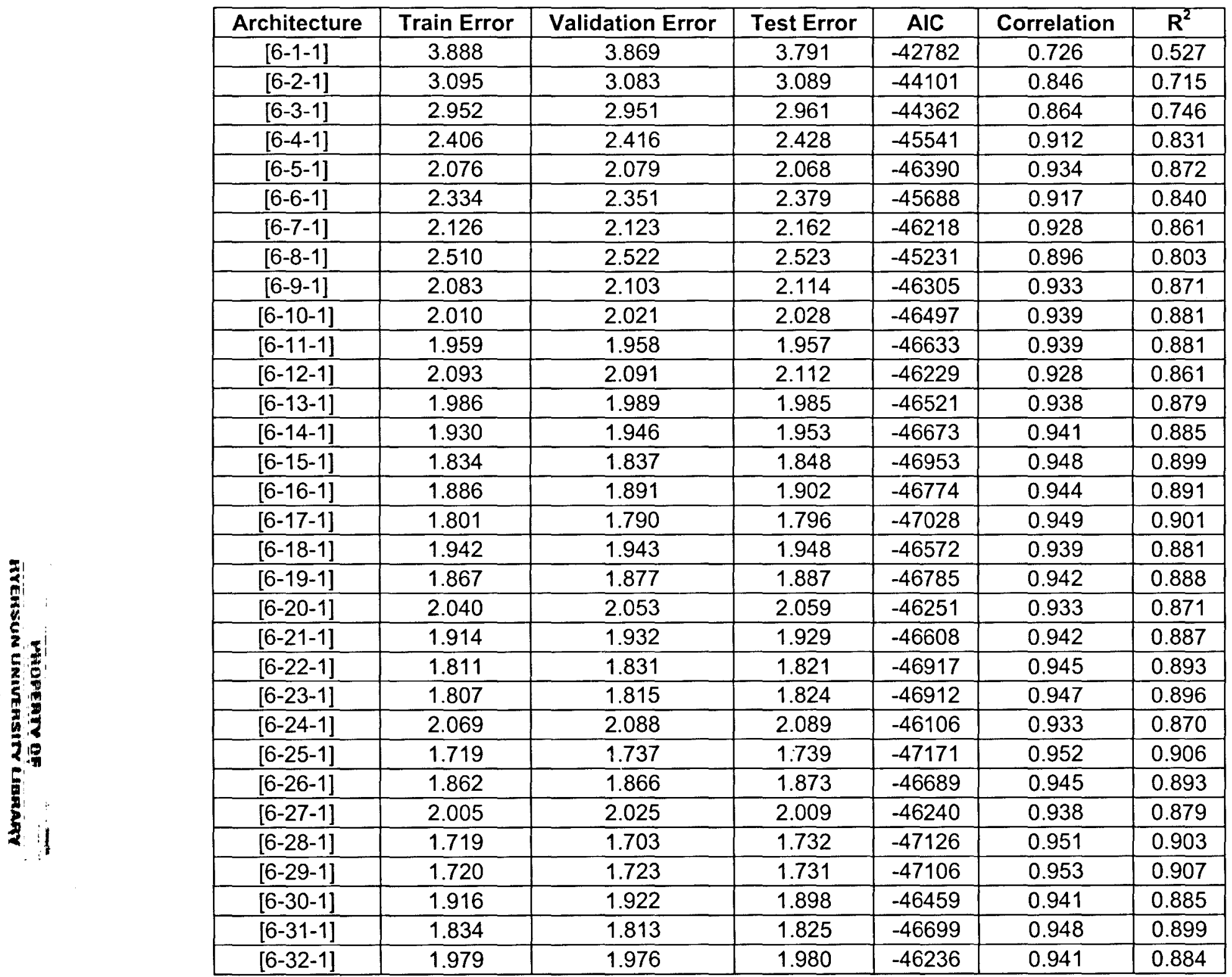


Table B-3: Performance of the percentage from hydro network with different architectures

\begin{tabular}{|c|c|c|c|c|c|c|}
\hline Architecture & Train Error & Validation Error & Test Error & AIC & Correlation & $\mathbf{R}^{2}$ \\
\hline$[10-1-1]$ & 3.251 & 3.099 & 3.236 & -43821 & 0.612 & 0.375 \\
\hline$[10-2-1]$ & 2.986 & 2.987 & 2.978 & -44294 & 0.710 & 0.503 \\
\hline$[10-3-1]$ & 2.221 & 2.204 & 2.196 & -46002 & 0.849 & 0.721 \\
\hline$[10-4-1]$ & 2.106 & 2.085 & 2.101 & -46288 & 0.863 & 0.744 \\
\hline$[10-5-1]$ & 1.998 & 1.964 & 2.009 & -46573 & 0.871 & 0.759 \\
\hline$[10-6-1]$ & 1.641 & 1.632 & 1.593 & -47702 & 0.922 & 0.850 \\
\hline$[10-7-1]$ & 1.609 & 1.605 & 1.594 & -47791 & 0.924 & 0.854 \\
\hline$[10-8-1]$ & 1.536 & 1.522 & 1.504 & -48039 & 0.932 & 0.869 \\
\hline$[10-9-1]$ & 1.593 & 1.590 & 1.578 & -47804 & 0.927 & 0.859 \\
\hline$[10-10-1]$ & 1.734 & 1.754 & 1.733 & -47281 & 0.909 & 0.827 \\
\hline$[10-11-1]$ & 1.482 & 1.488 & 1.447 & -48177 & 0.937 & 0.878 \\
\hline$[10-12-1]$ & 1.503 & 1.509 & 1.510 & -48072 & 0.935 & 0.874 \\
\hline$[10-13-1]$ & 1.442 & 1.481 & 1.444 & -48289 & 0.940 & 0.884 \\
\hline$[10-14-1]$ & 1.513 & 1.529 & 1.476 & -47983 & 0.933 & 0.871 \\
\hline$[10-15-1]$ & 1.454 & 1.472 & 1.441 & -48192 & 0.938 & 0.880 \\
\hline$[10-16-1]$ & 1.435 & 1.462 & 1.468 & -48246 & 0.941 & 0.884 \\
\hline$[10-17-1]$ & 1.476 & 1.504 & 1.510 & -48057 & 0.936 & 0.876 \\
\hline$[10-18-1]$ & 1.403 & 1.436 & 1.407 & -48330 & 0.943 & 0.888 \\
\hline$[10-19-1]$ & 1.395 & 1.437 & 1.387 & -48338 & 0.943 & 0.889 \\
\hline$[10-20-1]$ & 1.471 & 1.524 & 1.502 & -48003 & 0.937 & 0.877 \\
\hline$[10-21-1]$ & 1.363 & 1.404 & 1.369 & -48426 & 0.946 & 0.894 \\
\hline$[10-22-1]$ & 1.353 & 1.390 & 1.366 & -48445 & 0.947 & 0.896 \\
\hline$[10-23-1]$ & 1.377 & 1.438 & 1.408 & -48320 & 0.944 & 0.891 \\
\hline$[10-24-1]$ & 1.417 & 1.468 & 1.458 & -48129 & 0.942 & 0.886 \\
\hline$[10-25-1]$ & 1.426 & 1.467 & 1.451 & -48064 & 0.941 & 0.886 \\
\hline$[10-26-1]$ & 1.361 & 1.410 & 1.388 & -48317 & 0.946 & 0.895 \\
\hline$[10-27-1]$ & 1.404 & 1.444 & 1.423 & -48109 & 0.943 & 0.888 \\
\hline$[10-28-1]$ & 1.385 & 1.432 & 1.395 & -48163 & 0.944 & 0.891 \\
\hline$[10-29-1]$ & 1.383 & 1.427 & 1.388 & -48150 & 0.944 & 0.891 \\
\hline$[10-30-1]$ & 1.398 & 1.438 & 1.414 & -48060 & 0.943 & 0.889 \\
\hline$[10-31-1]$ & 1.322 & 1.376 & 1.351 & -48366 & 0.949 & 0.901 \\
\hline$[10-32-1]$ & 1.398 & 1.445 & 1.421 & -48014 & 0.944 & 0.891 \\
\hline & & & & & & \\
\hline & & & & & & \\
\hline
\end{tabular}


Table B-4: Performance of the percentage from coal network with different architectures

\begin{tabular}{|c|c|c|c|c|c|c|}
\hline Architecture & Train Error & Validation Error & Test Error & AIC & Correlation & $\mathbf{R}^{2}$ \\
\hline$[8-1-1]$ & 1.247 & 1.210 & 1.248 & -49429 & 0.928 & 0.861 \\
\hline [8-2-1] & 1.105 & 1.093 & 1.135 & -50118 & 0.942 & 0.888 \\
\hline$[8-3-1]$ & 1.072 & 1.057 & 1.082 & -50277 & 0.945 & 0.892 \\
\hline$[8-4-1]$ & 1.056 & 1.039 & 1.059 & -50345 & 0.947 & 0.897 \\
\hline$[8-5-1]$ & 1.045 & 1.035 & 1.049 & -50384 & 0.950 & 0.903 \\
\hline$[8-6-1]$ & 1.020 & 1.017 & 1.030 & -50506 & 0.951 & 0.905 \\
\hline [8-7-1] & 1.023 & 1.008 & 1.021 & -50471 & 0.951 & 0.904 \\
\hline [8-8-1] & 1.006 & 0.998 & 1.007 & -50546 & 0.953 & 0.907 \\
\hline [8-9-1] & 1.005 & 0.999 & 1.006 & -50532 & 0.953 & 0.908 \\
\hline$[8-10-1]$ & 0.981 & 0.979 & 0.989 & -50653 & 0.956 & 0.913 \\
\hline [8-11-1] & 0.958 & 0.953 & 0.963 & -50770 & 0.957 & 0.915 \\
\hline [8-12-1] & 0.983 & 0.960 & 0.980 & -50599 & 0.955 & 0.912 \\
\hline$[8-13-1]$ & 0.985 & 0.976 & 0.981 & -50571 & 0.956 & 0.914 \\
\hline$[8-14-1]$ & 0.961 & 0.958 & 0.966 & -50695 & 0.957 & 0.915 \\
\hline [8-15-1] & 0.966 & 0.959 & 0.963 & -50643 & 0.957 & 0.915 \\
\hline$[8-16-1]$ & 0.958 & 0.949 & 0.961 & -50670 & 0.957 & 0.916 \\
\hline [8-17-1] & 0.949 & 0.949 & 0.967 & -50708 & 0.958 & 0.918 \\
\hline [8-18-1] & 0.937 & 0.941 & 0.941 & -50762 & 0.959 & 0.919 \\
\hline [8-19-1] & 0.951 & 0.948 & 0.956 & -50654 & 0.958 & 0.917 \\
\hline [8-20-1] & 0.967 & 0.965 & 0.965 & -50537 & 0.957 & 0.916 \\
\hline [8-21-1] & 0.883 & 0.886 & 0.903 & -51051 & 0.964 & 0.928 \\
\hline [8-22-1] & 0.940 & 0.936 & 0.933 & -50662 & 0.959 & 0.919 \\
\hline [8-23-1] & 0.942 & 0.942 & 0.938 & -50631 & 0.959 & 0.919 \\
\hline [8-24-1] & 0.893 & 0.896 & 0.921 & -50923 & 0.964 & 0.928 \\
\hline [8-25-1] & 0.952 & 0.951 & 0.958 & -50532 & 0.958 & 0.917 \\
\hline [8-26-1] & 0.963 & 0.955 & 0.967 & -50444 & 0.957 & 0.916 \\
\hline [8-27-1] & 0.912 & 0.907 & 0.927 & -50744 & 0.962 & 0.925 \\
\hline [8-28-1] & 0.898 & 0.890 & 0.912 & -50813 & 0.963 & 0.927 \\
\hline [8-29-1] & 0.915 & 0.910 & 0.932 & -50682 & 0.961 & 0.924 \\
\hline [8-30-1] & 0.909 & 0.904 & 0.925 & -50700 & 0.962 & 0.925 \\
\hline [8-31-1] & 0.958 & 0.942 & 0.952 & -50376 & 0.957 & 0.916 \\
\hline [8-32-1] & 0.906 & 0.899 & 0.923 & -50681 & 0.962 & 0.925 \\
\hline
\end{tabular}


Table B-5: Performance of the percentage from other network with different architectures

\begin{tabular}{|c|c|c|c|c|c|c|}
\hline Architecture & Train Error & Validation Error & Test Error & AIC & Correlation & $\mathbf{R}^{2}$ \\
\hline$[7-1-1]$ & 1.372 & 1.387 & 1.397 & -48873 & 0.780 & 0.607 \\
\hline$[7-2-1]$ & 1.321 & 1.352 & 1.373 & -49077 & 0.794 & 0.631 \\
\hline [7-3-1] & 1.290 & 1.319 & 1.336 & -49200 & 0.808 & 0.653 \\
\hline [7-4-1] & 1.222 & 1.236 & 1.269 & -49499 & 0.829 & 0.687 \\
\hline [7-5-1] & 1.140 & 1.158 & 1.188 & -49887 & 0.848 & 0.719 \\
\hline [7-6-1] & 1.168 & 1.177 & 1.209 & -49726 & 0.839 & 0.704 \\
\hline$[7-7-1]$ & 1.098 & 1.122 & 1.139 & -50069 & 0.857 & 0.735 \\
\hline [7-8-1] & 1.110 & 1.118 & 1.132 & -49989 & 0.855 & 0.730 \\
\hline [7-9-1] & 1.043 & 1.043 & 1.080 & -50332 & 0.867 & 0.751 \\
\hline$[7-10-1]$ & 1.123 & 1.145 & 1.184 & -49883 & 0.854 & 0.729 \\
\hline [7-11-1] & 1.048 & 1.071 & 1.082 & -50269 & 0.870 & 0.757 \\
\hline$[7-12-1]$ & 1.090 & 1.106 & 1.137 & -50023 & 0.869 & 0.755 \\
\hline [7-13-1] & 1.020 & 1.041 & 1.056 & -50392 & 0.877 & 0.770 \\
\hline [7-14-1] & 1.019 & 1.027 & 1.059 & -50382 & 0.879 & 0.772 \\
\hline$[7-15-1]$ & 1.057 & 1.083 & 1.115 & -50148 & 0.873 & 0.761 \\
\hline$[7-16-1]$ & 1.037 & 1.058 & 1.080 & -50240 & 0.877 & 0.768 \\
\hline$[7-17-1]$ & 1.024 & 1.046 & 1.087 & -50300 & 0.880 & 0.774 \\
\hline$[7-18-1]$ & 0.980 & 0.972 & 1.020 & -50534 & 0.889 & 0.791 \\
\hline$[7-19-1]$ & 1.011 & 1.040 & 1.083 & -50334 & 0.883 & 0.779 \\
\hline$[7-20-1]$ & 1.005 & 1.031 & 1.061 & -50350 & 0.882 & 0.777 \\
\hline [7-21-1] & 1.025 & 1.049 & 1.070 & -50222 & 0.881 & 0.775 \\
\hline [7-22-1] & 1.011 & 1.026 & 1.071 & -50280 & 0.886 & 0.785 \\
\hline [7-23-1] & 1.052 & 1.081 & 1.105 & -50031 & 0.874 & 0.763 \\
\hline [7-24-1] & 0.995 & 1.014 & 1.051 & -50342 & 0.887 & 0.786 \\
\hline$[7-25-1]$ & 1.025 & 1.053 & 1.075 & -50149 & 0.880 & 0.774 \\
\hline [7-26-1] & 1.076 & 1.094 & 1.129 & -49845 & 0.868 & 0.753 \\
\hline [7-27-1] & 1.036 & 1.054 & 1.098 & -50051 & 0.878 & 0.770 \\
\hline$[7-28-1]$ & 1.018 & 1.045 & 1.065 & -50131 & 0.882 & 0.778 \\
\hline$[7-29-1]$ & 0.994 & 1.008 & 1.034 & -50253 & 0.890 & 0.791 \\
\hline$[7-30-1]$ & 1.040 & 1.074 & 1.100 & -49970 & 0.876 & 0.767 \\
\hline$[7-31-1]$ & 1.037 & 1.042 & 1.087 & -49969 & 0.878 & 0.771 \\
\hline$[7-32-1]$ & 1.024 & 1.036 & 1.064 & -50026 & 0.880 & 0.774 \\
\hline$[7-33-1]$ & 0.996 & 1.020 & 1.041 & -50170 & 0.886 & 0.784 \\
\hline$[7-34-1]$ & 1.004 & 1.020 & 1.048 & -50105 & 0.885 & 0.784 \\
\hline [7-35-1] & 1.036 & 1.043 & 1.089 & -49903 & 0.875 & 0.766 \\
\hline [7-36-1] & 0.969 & 0.992 & 1.012 & -50276 & 0.893 & 0.797 \\
\hline$[7-37-1]$ & 1.012 & 1.040 & 1.070 & -50008 & 0.884 & 0.781 \\
\hline [7-38-1] & 0.971 & 0.999 & 1.021 & -50230 & 0.893 & 0.797 \\
\hline$[7-39-1]$ & 1.030 & 1.045 & 1.087 & -49864 & 0.879 & 0.772 \\
\hline$[7-40-1]$ & 1.036 & 1.075 & 1.109 & -49814 & 0.877 & 0.769 \\
\hline
\end{tabular}


Table B-6: Performance of the hourly emission factor network with different architectures

\begin{tabular}{|c|c|c|c|c|c|c|}
\hline Architecture & Train Error & Validation Error & Test Error & AIC & Correlation & $\mathrm{R}^{2}$ \\
\hline$[6-1-1]$ & 25 & 25 & 26 & -31883 & 0.736 & 0.542 \\
\hline [6-2-1] & 24 & 24 & 25 & -32039 & 0.749 & 0.561 \\
\hline [6-3-1] & 24 & 24 & 25 & -32045 & 0.753 & 0.567 \\
\hline [6-4-1] & 24 & 24 & 24 & -32122 & 0.766 & 0.587 \\
\hline$[6-5-1]$ & 23 & 23 & 24 & -32237 & 0.780 & 0.608 \\
\hline$[6-6-1]$ & 22 & 22 & 23 & -32521 & 0.804 & 0.646 \\
\hline$[6-7-1]$ & 22 & 22 & 22 & -32552 & 0.808 & 0.653 \\
\hline [6-8-1] & 22 & 23 & 23 & -32461 & 0.801 & 0.641 \\
\hline$[6-9-1]$ & 21 & 22 & 22 & -32650 & 0.815 & 0.664 \\
\hline$[6-10-1]$ & 21 & 22 & 22 & -32717 & 0.821 & 0.673 \\
\hline$[6-11-1]$ & 20 & 21 & 21 & -32933 & 0.840 & 0.705 \\
\hline$[6-12-1]$ & 21 & 22 & 22 & -32715 & 0.828 & 0.686 \\
\hline [6-13-1] & 21 & 22 & 22 & -32633 & 0.820 & 0.671 \\
\hline$[6-14-1]$ & 21 & 22 & 22 & -32694 & 0.825 & 0.681 \\
\hline [6-15-1] & 20 & 20 & 20 & -32904 & 0.835 & 0.697 \\
\hline [6-16-1] & 21 & 22 & 22 & -32617 & 0.819 & 0.671 \\
\hline [6-17-1] & 21 & 22 & 21 & -32693 & 0.829 & 0.686 \\
\hline [6-18-1] & 20 & 21 & 21 & -32825 & 0.835 & 0.696 \\
\hline [6-19-1] & 20 & 21 & 20 & -32906 & 0.842 & 0.708 \\
\hline$[6-20-1]$ & 20 & 21 & 21 & -32778 & 0.838 & 0.703 \\
\hline$[6-21-1]$ & 21 & 21 & 21 & -32549 & 0.825 & 0.680 \\
\hline$[6-22-1]$ & 21 & 22 & 22 & -32522 & 0.820 & 0.672 \\
\hline$[6-23-1]$ & 19 & 20 & 20 & -33062 & 0.856 & 0.732 \\
\hline [6-24-1] & 20 & 21 & 21 & -32696 & 0.833 & 0.694 \\
\hline$[6-25-1]$ & 19 & 20 & 20 & -33005 & 0.856 & 0.732 \\
\hline [6-26-1] & 20 & 20 & 20 & -32935 & 0.850 & 0.722 \\
\hline [6-27-1] & 21 & 21 & 22 & -32471 & 0.824 & 0.679 \\
\hline$[6-28-1]$ & 21 & 21 & 21 & -32600 & 0.833 & 0.694 \\
\hline [6-29-1] & 20 & 21 & 21 & -32620 & 0.832 & 0.691 \\
\hline [6-30-1] & 20 & 21 & 21 & -32703 & 0.842 & 0.709 \\
\hline [6-31-1] & 20 & 20 & 21 & -32724 & 0.841 & 0.707 \\
\hline$[6-32-1]$ & 19 & 19 & 19 & -33102 & 0.864 & 0.745 \\
\hline$[6-33-1]$ & 20 & 20 & 20 & -32694 & 0.843 & 0.711 \\
\hline [6-34-1] & 20 & 21 & 21 & -32563 & 0.834 & 0.696 \\
\hline$[6-35-1]$ & 20 & 20 & 20 & -32635 & 0.839 & 0.704 \\
\hline [6-36-1] & 19 & 20 & 20 & -32831 & 0.852 & 0.726 \\
\hline [6-37-1] & 20 & 20 & 21 & -32570 & 0.839 & 0.704 \\
\hline [6-38-1] & 20 & 21 & 21 & -32501 & 0.834 & 0.696 \\
\hline [6-39-1] & 21 & 21 & 22 & -32362 & 0.830 & 0.689 \\
\hline [6-40-1] & 20 & 21 & 21 & -32492 & 0.837 & 0.700 \\
\hline
\end{tabular}


Tables B-7 - B-10 show the architectural performance results for the networks.

Table B-7: Performance of hydro network trained using five different learning algorithms

\begin{tabular}{|c|c|c|c|c|}
\hline Architecture & Training algorithm & AIC & Correlation & $\mathbf{R}^{\mathbf{2}}$ \\
\hline$[10-31-1]$ & Quick Propagation & -49748 & 0.968 & 0.933 \\
\hline$[10-31-1]$ & Conjugate Gradient Descent & -46220 & 0.891 & 0.794 \\
\hline$[10-31-1]$ & Quasi-Newton & -47094 & 0.921 & 0.849 \\
\hline$[10-31-1]$ & Levenberg-Marquardt & -48068 & 0.947 & 0.896 \\
\hline$[10-31-1]$ & Online Back Propagation & -41929 & 0.271 & 0.007 \\
\hline
\end{tabular}

Table B-8: Performance of the coal network trained using five different learning algorithms

\begin{tabular}{|c|c|c|c|c|}
\hline Architecture & Training algorithm & AIC & Correlation & $\mathbf{R}^{2}$ \\
\hline$[8-21-1]$ & Quick Propagation & -51510 & 0.970 & 0.936 \\
\hline$[8-21-1]$ & Conjugate Gradient Descent & -50147 & 0.949 & 0.900 \\
\hline$[8-21-1]$ & Quasi-Newton & -50117 & 0.949 & 0.901 \\
\hline$[8-21-1]$ & Levenberg-Marquardt & -50164 & 0.956 & 0.913 \\
\hline$[8-21-1]$ & Online Back Propagation & -50019 & 0.947 & 0.897 \\
\hline
\end{tabular}

Table B-9: Performance of other network trained using five different learning algorithms

\begin{tabular}{|c|c|c|c|c|}
\hline Architecture & Training algorithm & AIC & Correlation & $\mathbf{R}^{\mathbf{2}}$ \\
\hline$[7-36-1]$ & Quick Propagation & -51286 & 0.928 & 0.862 \\
\hline$[7-36-1]$ & Conjugate Gradient Descent & -48869 & 0.819 & 0.671 \\
\hline$[7-36-1]$ & Quasi-Newton & -49799 & 0.872 & 0.761 \\
\hline$[7-36-1]$ & Levenberg-Marquardt & -49070 & 0.851 & 0.720 \\
\hline$[7-36-1]$ & Online Back Propagation & -49253 & 0.846 & 0.712 \\
\hline
\end{tabular}




\section{Appendix C: Neural Network Model Results}

\section{C.1 Load Forecasting NN}

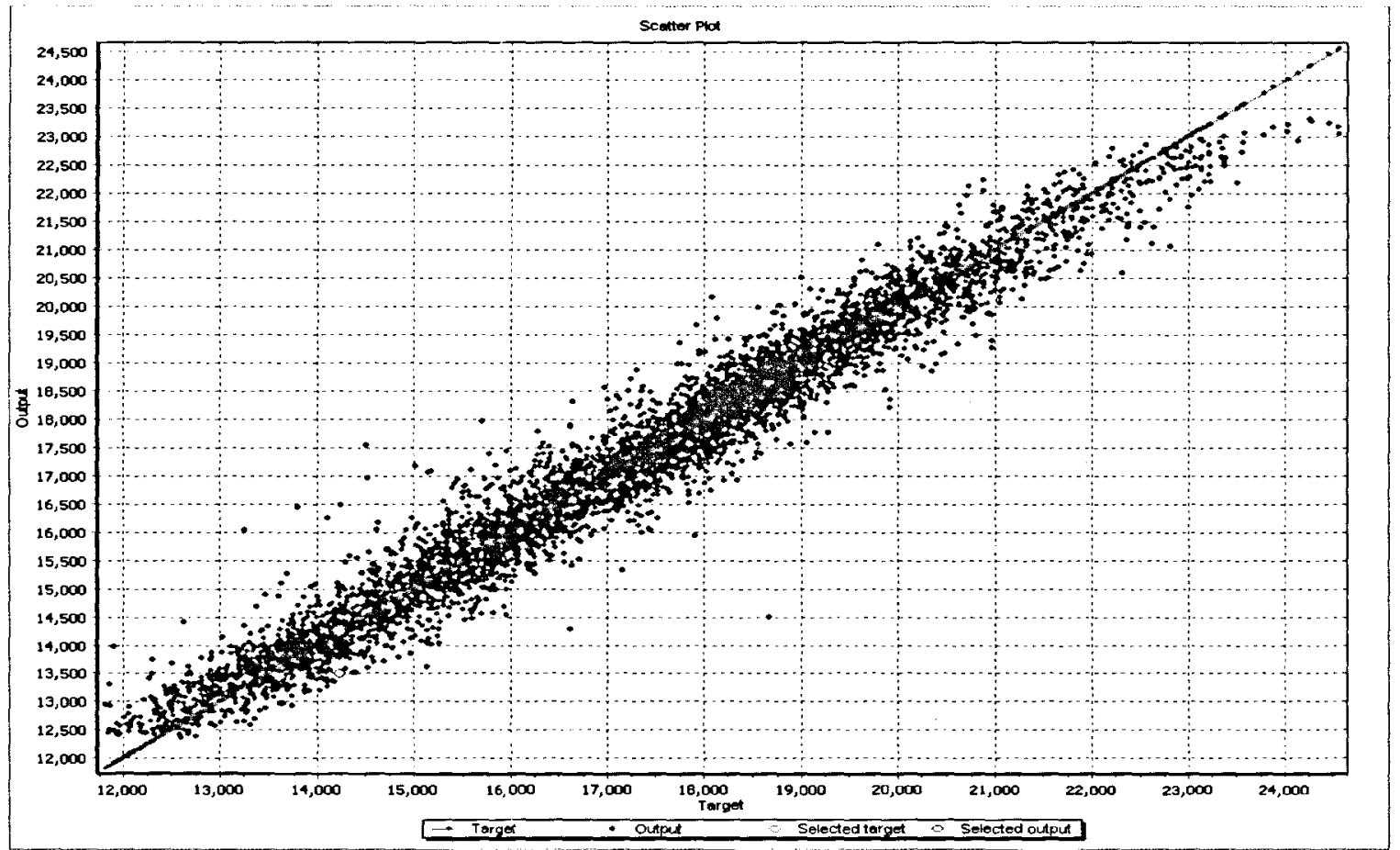

Figure C-1: Scatter plot comparing actual vs. predicted values for the training of the network

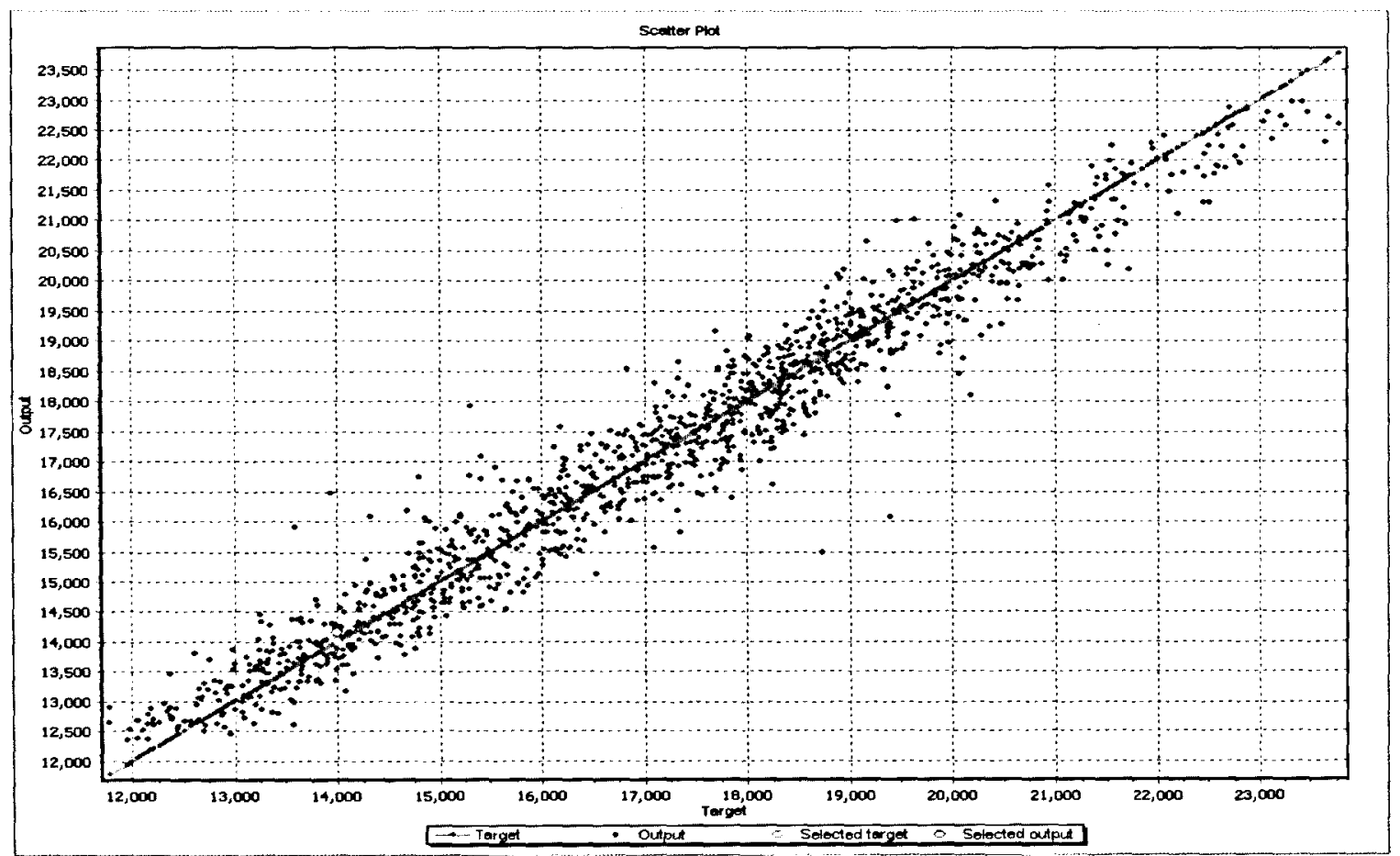

Figure C-2: Scatter plot comparing actual vs. predicted values for the validation of the network 


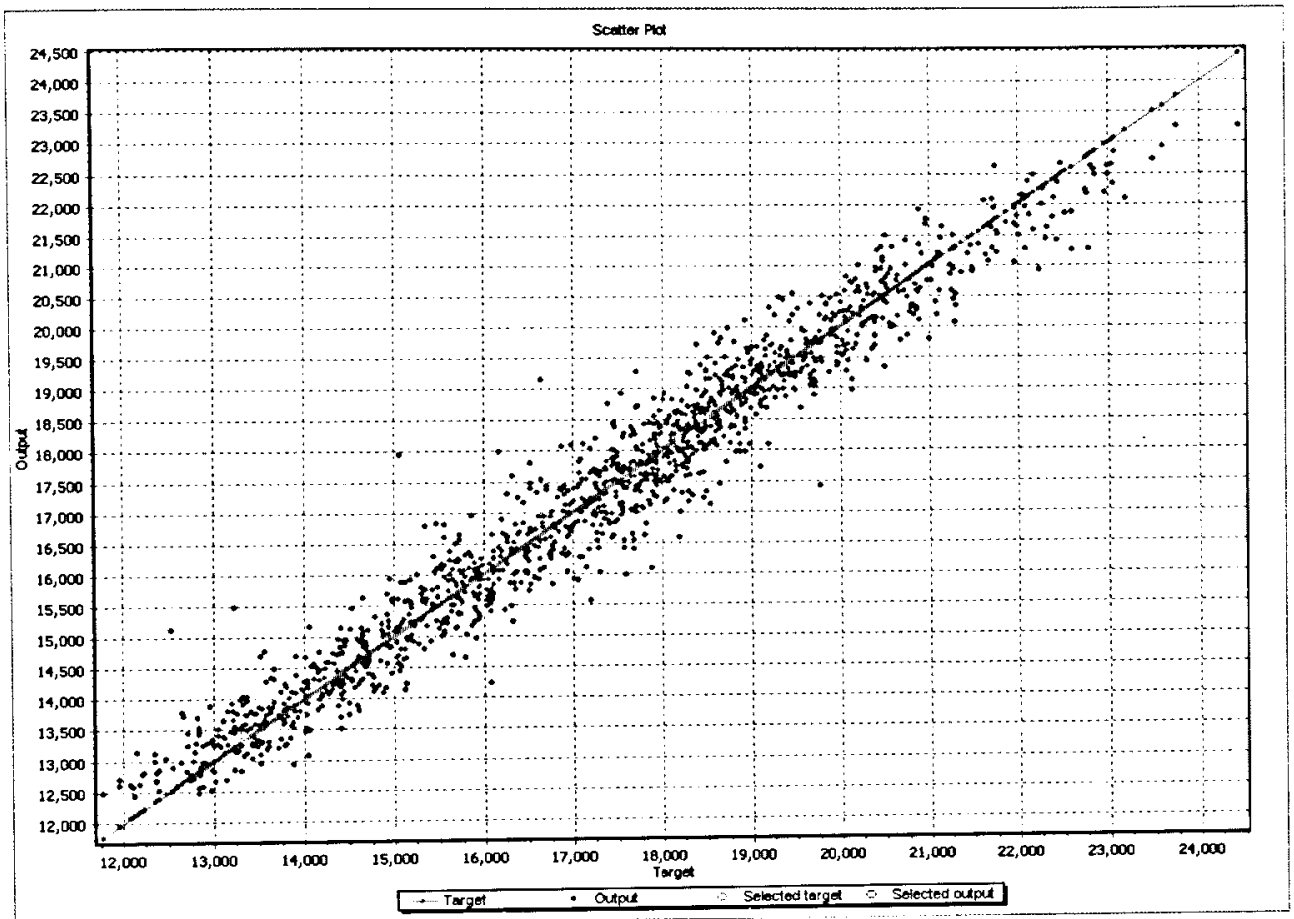

Figure C-3: Scatter plot comparing actual vs. predicted values for the testing of the network

\section{Test Case Result}

Figure C-4 shows the MAPE profile for the winter of 2005. The MAPE was the highest during January.

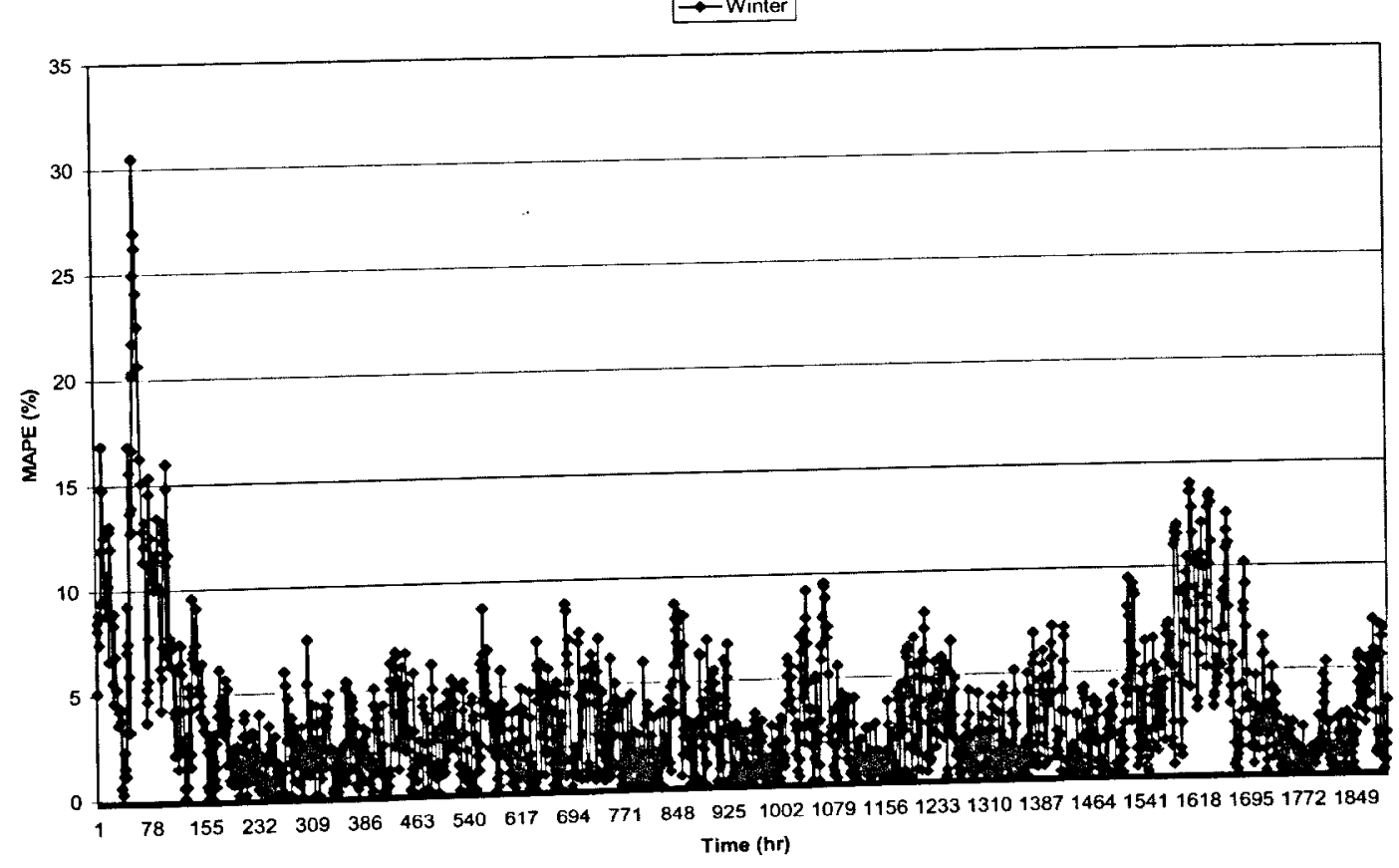

Figure C-4: MAPE profile for winter test case - load forecasting network 
Figure C-5 shows the MAPE profile for the spring of 2005. The MAPE was the highest during April and June.

Spring
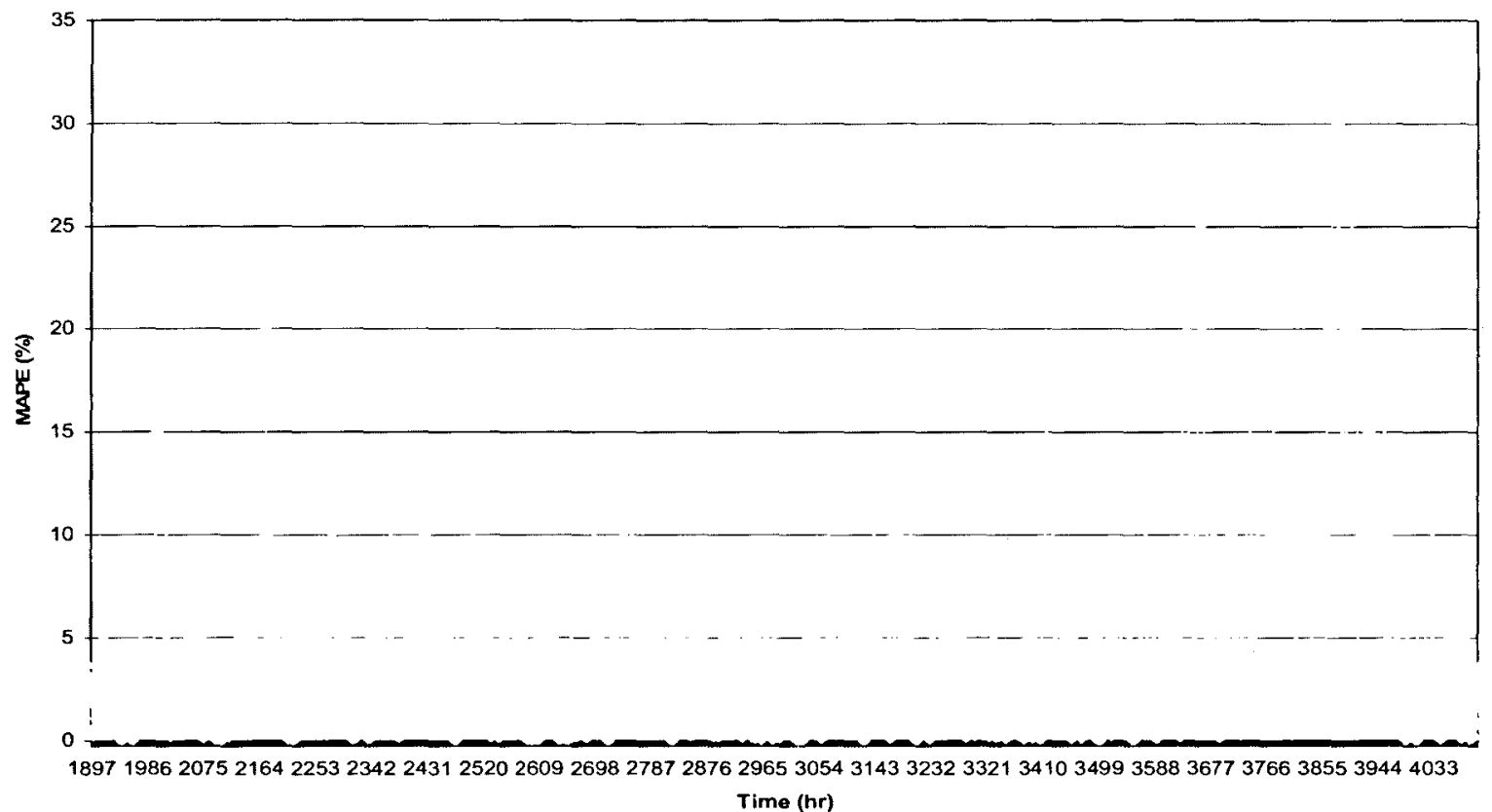

Figure C-5: MAPE profile for spring test case - load forecasting network

Figure C-6 shows the MAPE profile for the summer of 2005. The MAPE fluctuated throughout the summer.

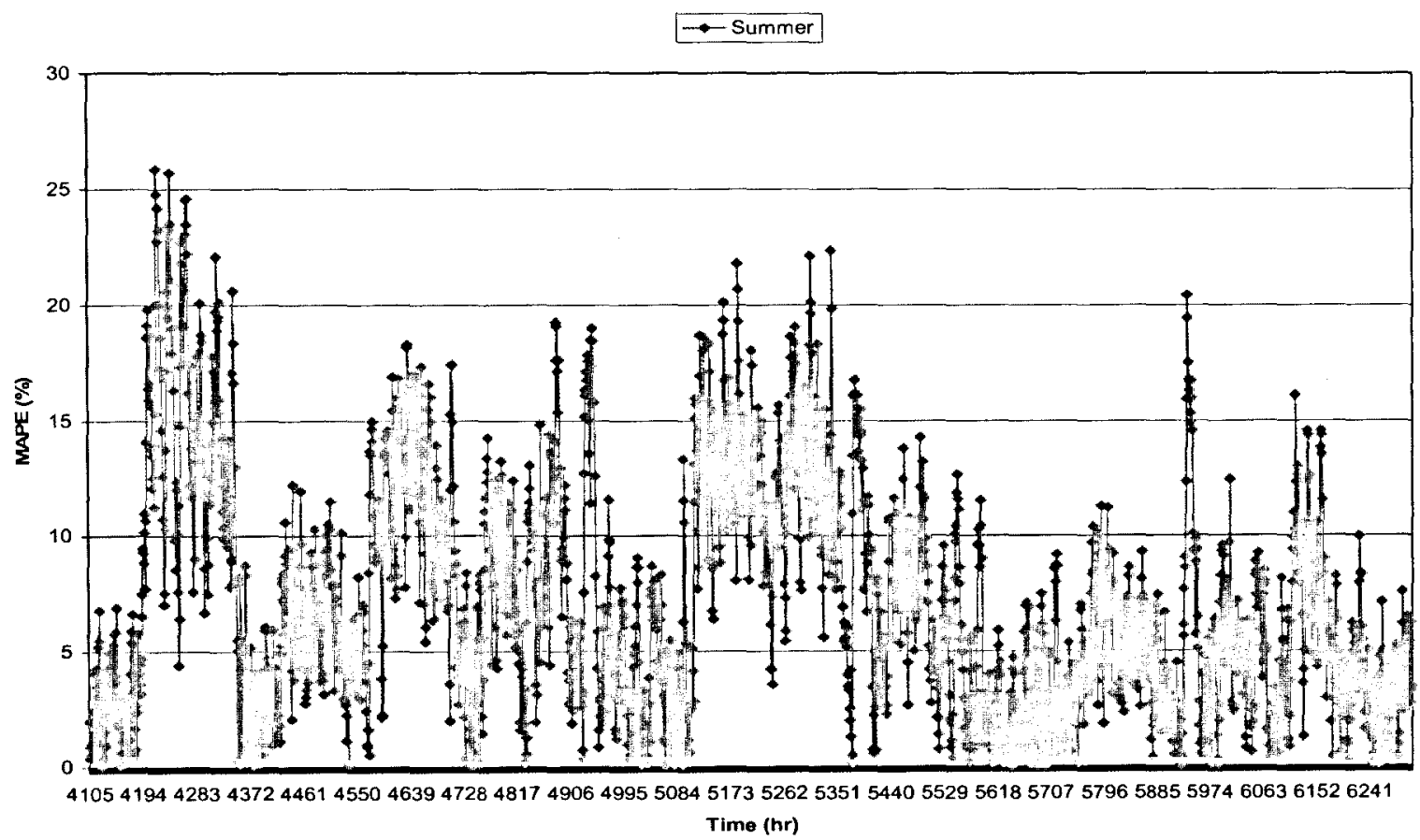

Figure C-6: MAPE profile for summer test case - load forecasting network 
Figure C-7 shows the MAPE profile for the fall of 2005. The MAPE was the highest during October. However fluctuations were visible during the fall.

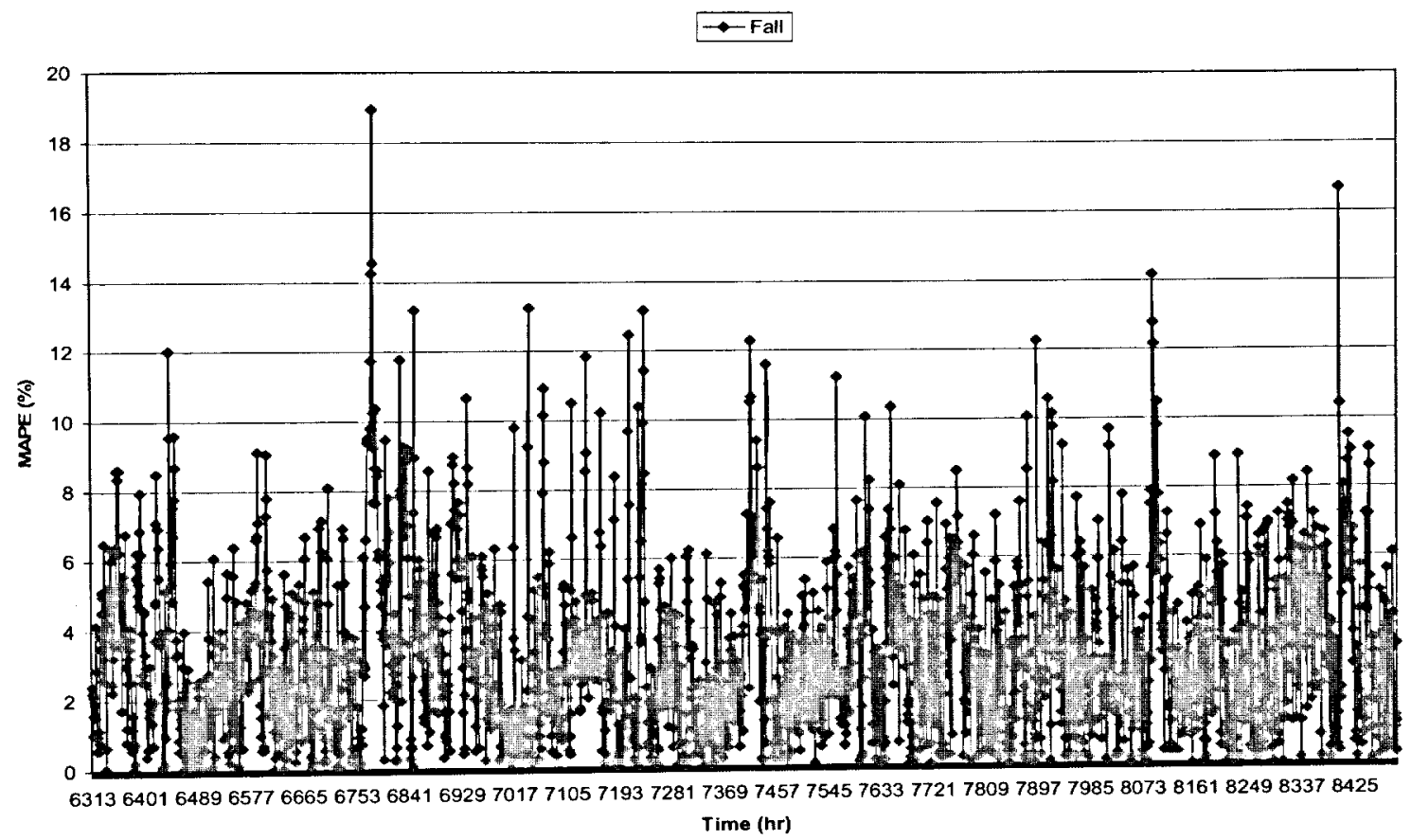

Figure C-7: MAPE profile for fall test case - load forecasting network

\section{C.2 Percentage Mix from Nuclear Network}

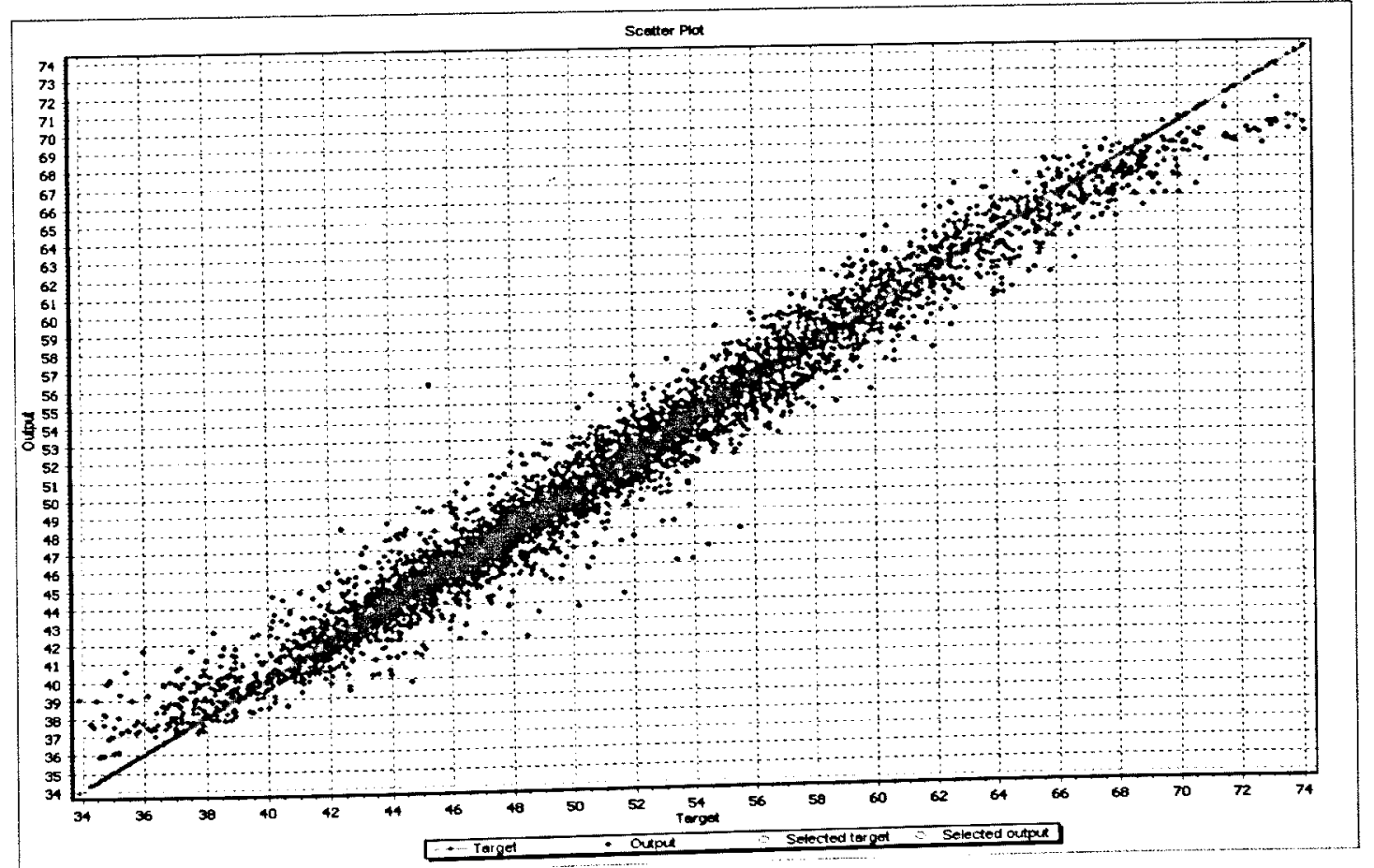

Figure C-8: Scatter plot comparing actual vs. predicted values for the training of the $\%$ nuclear NN 


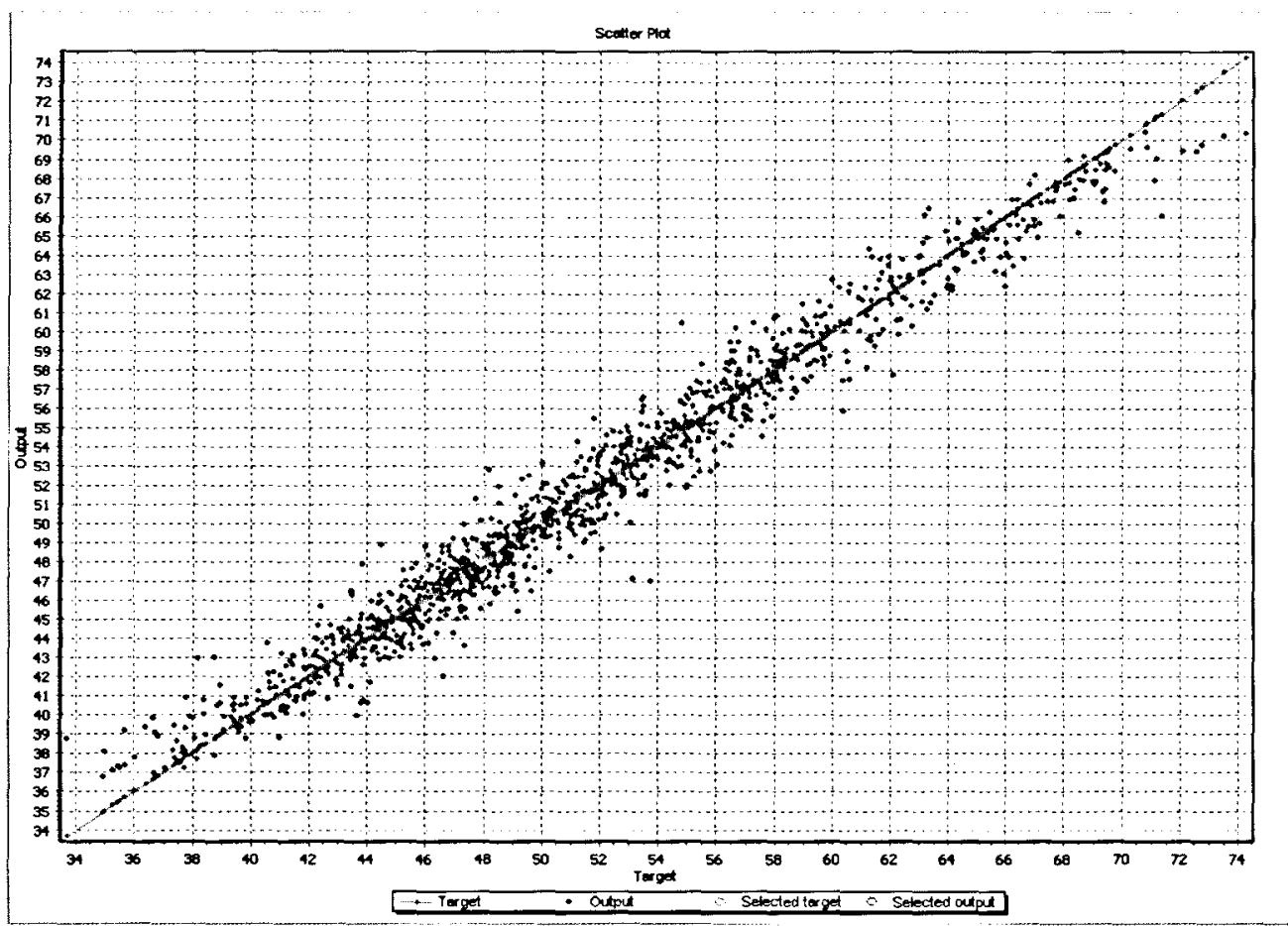

Figure C-9: Scatter plot comparing actual vs. predicted values for the validation of the \% nuclear

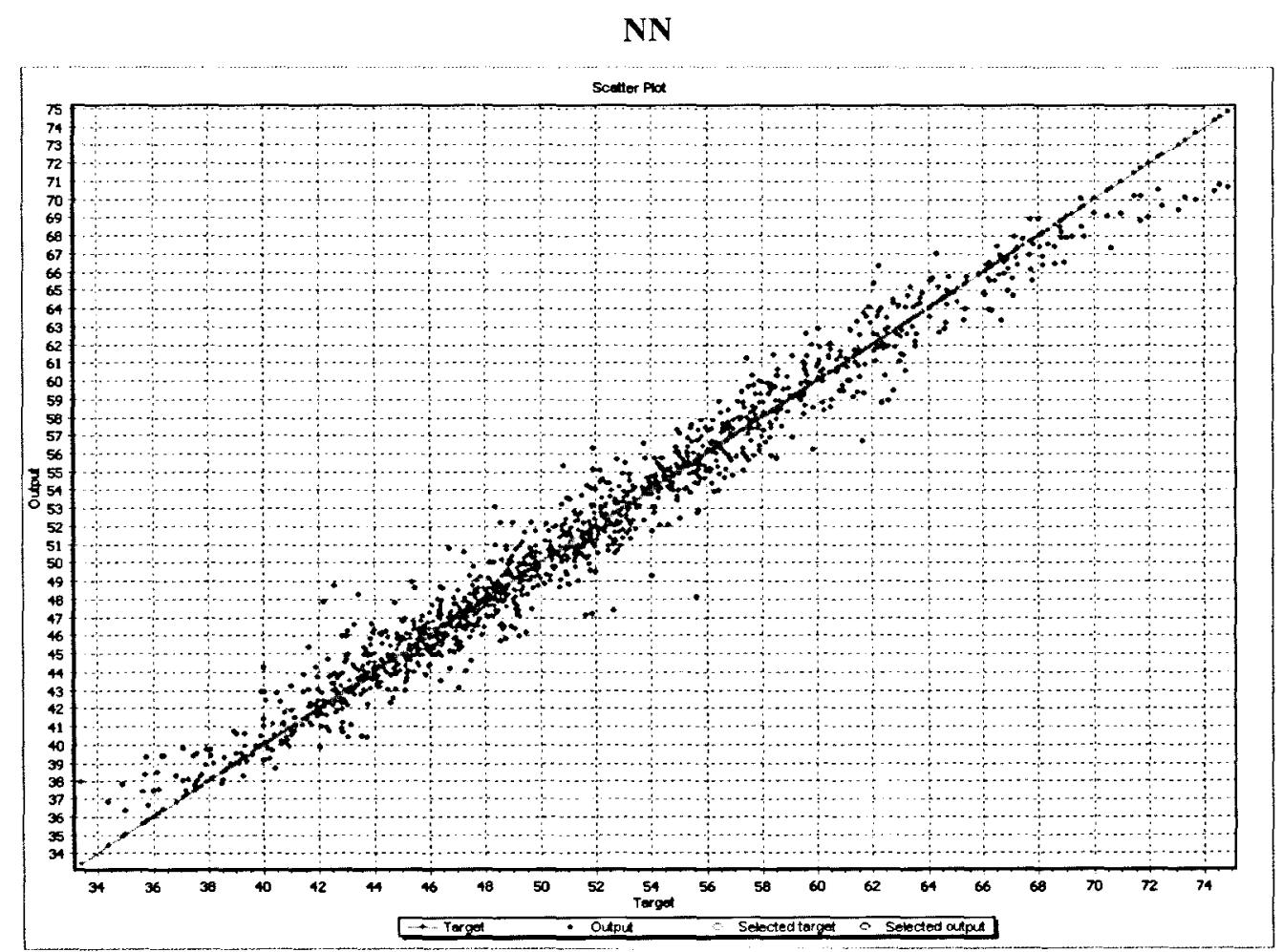

Figure C-10: Scatter plot comparing actual vs. predicted values for the testing of the \% nuclear NN 


\section{Test Case Results}

Figure C-11 shows the MAPE profile for the winter of 2006. The MAPE is shown fluctuating in sync.

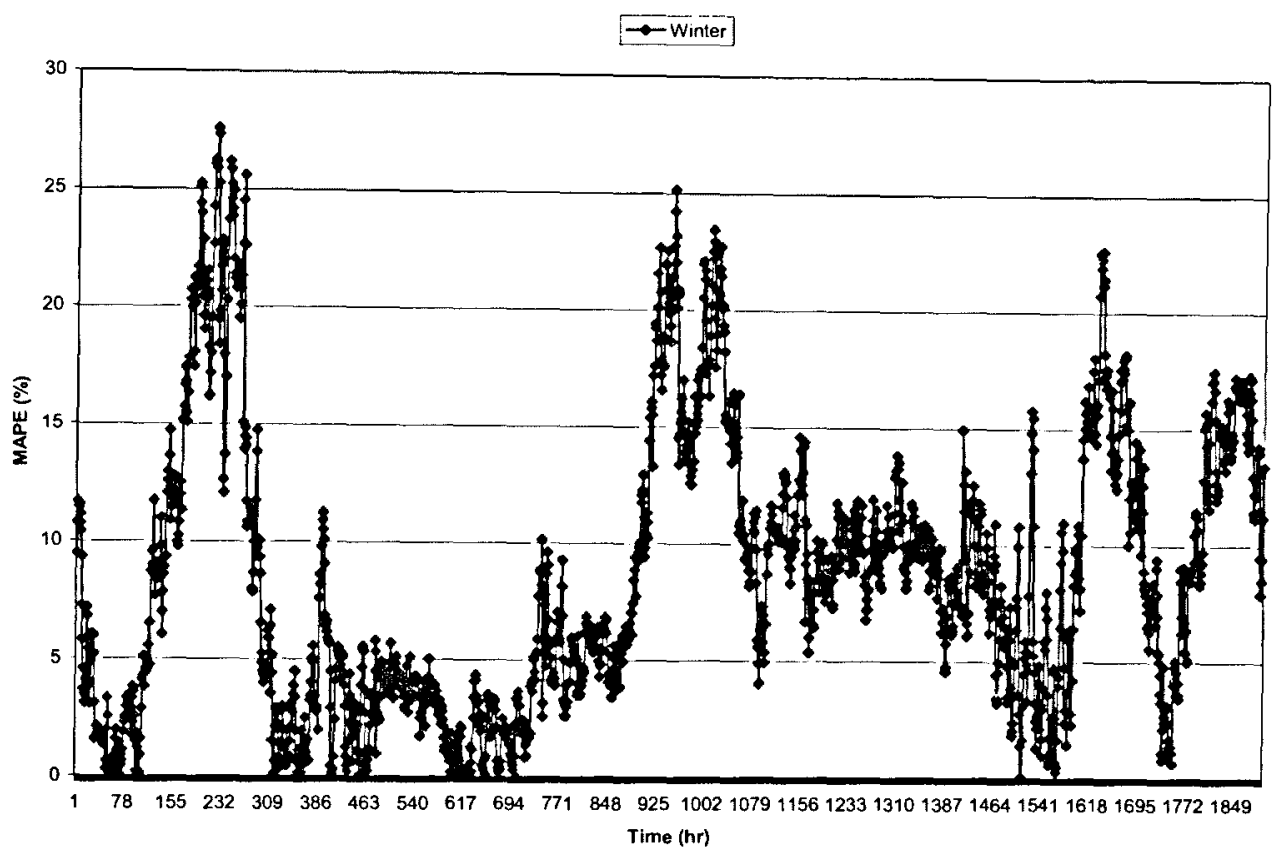

Figure C-11: MAPE profile for winter \% nuclear test case

Figure C-12 shows the MAPE profile for the spring of 2006. The MAPE was the highest during April and early May.

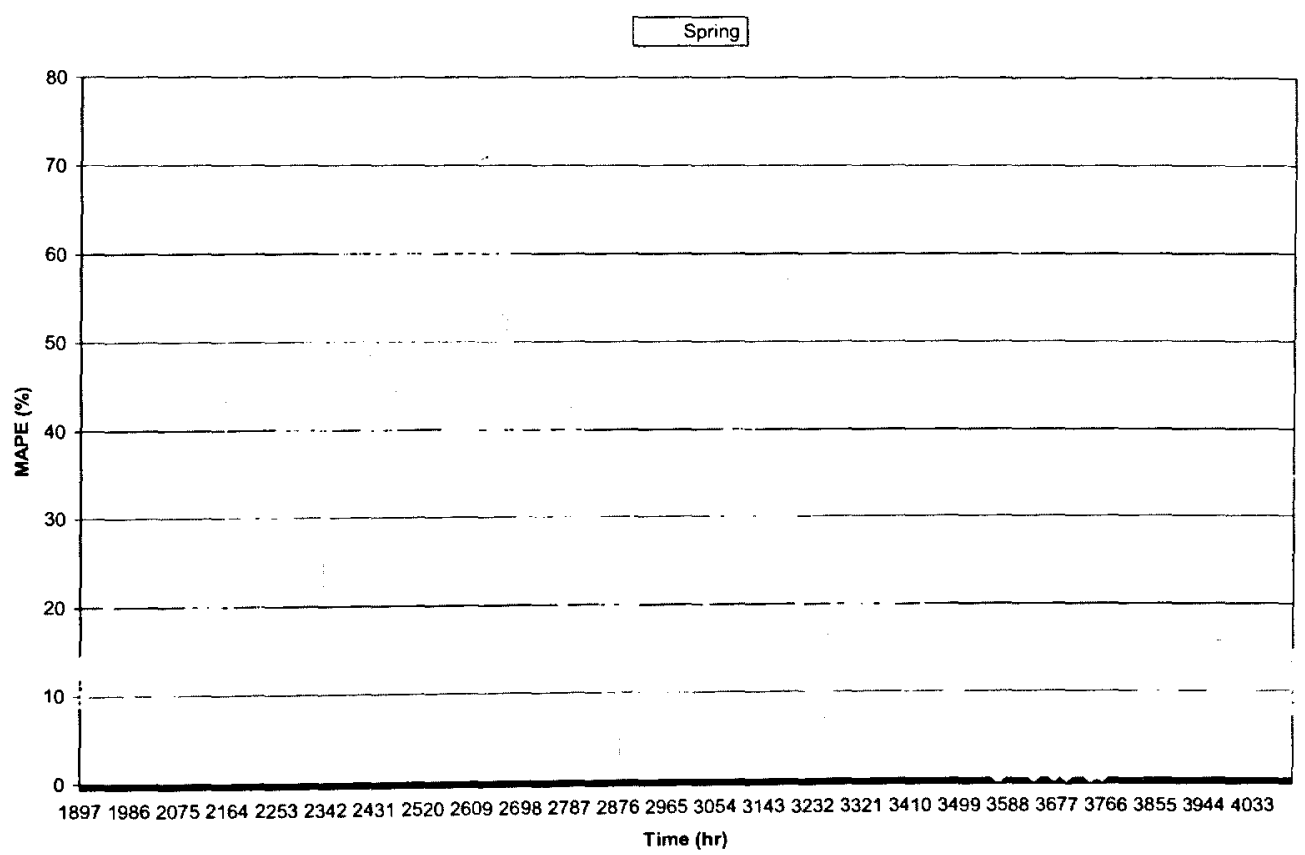

Figure C-12: MAPE profile for spring \% nuclear test case 
Figure C-13 shows the MAPE profile for the summer of 2006. The MAPE fluctuated throughout the summer.

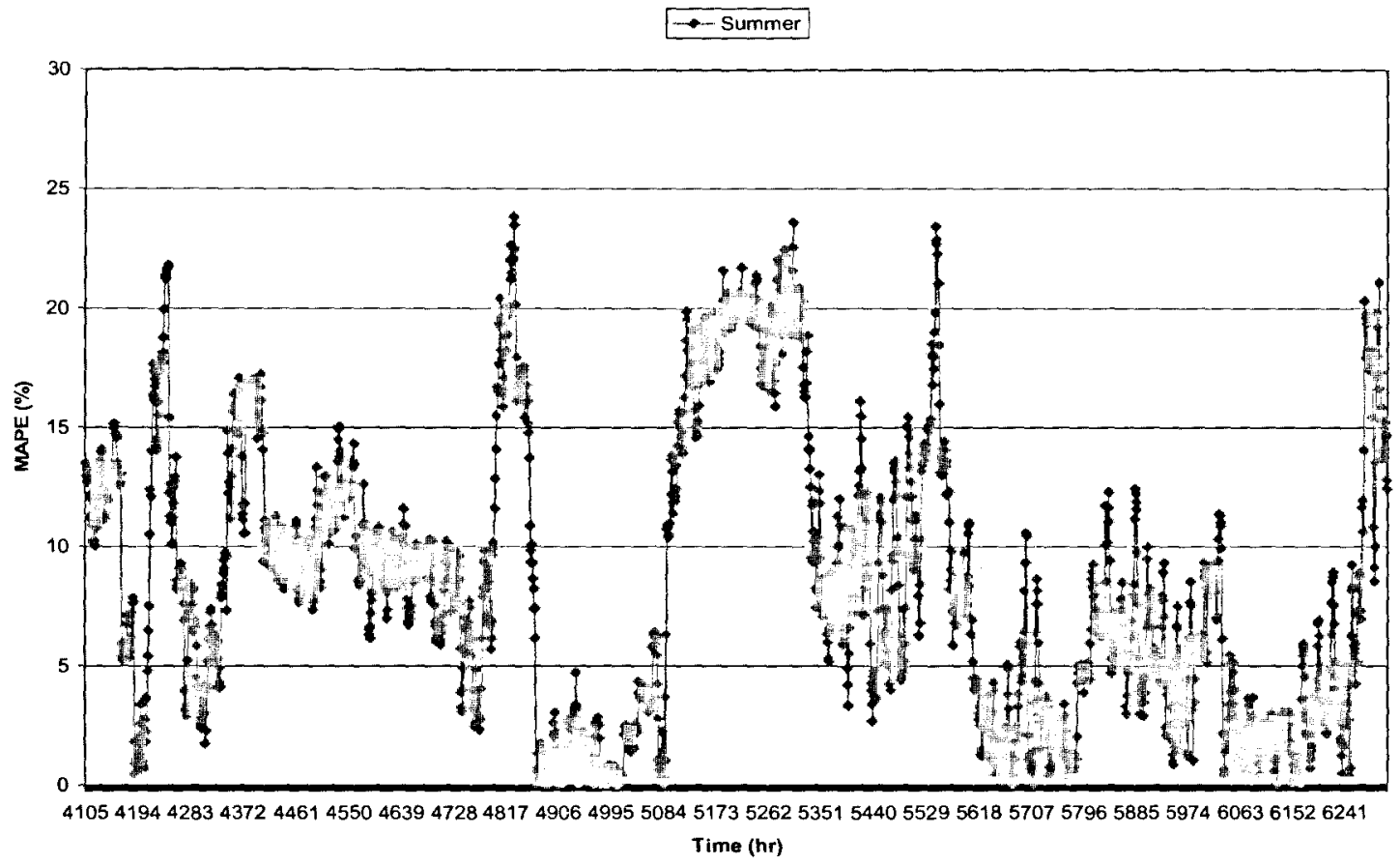

Figure C-13: MAPE profile for summer \% nuclear test case

Figure C-14 shows the MAPE profile for the fall of 2006. The MAPE was the highest during October. In addition, the second highest point occurred near the end of December.

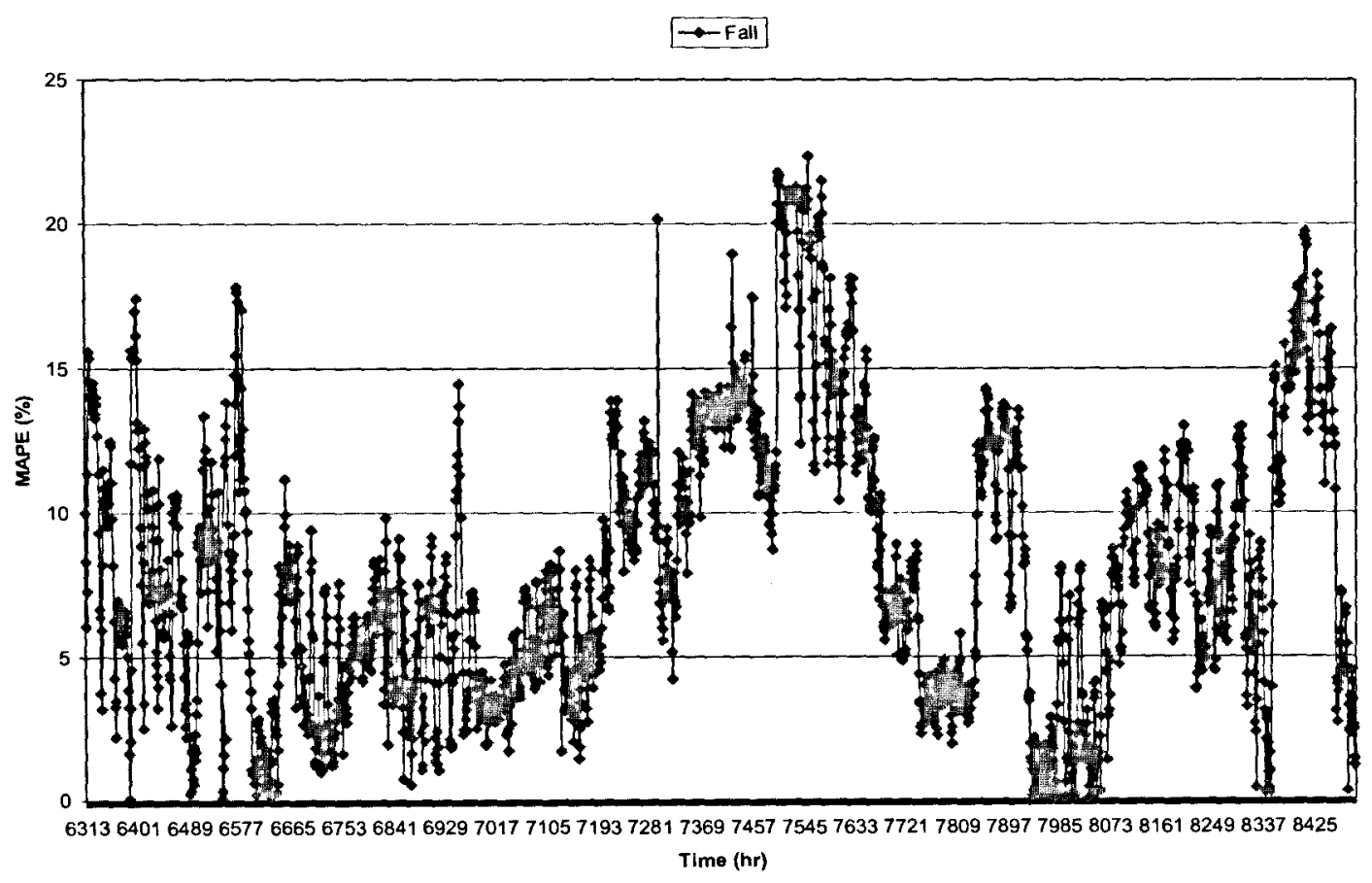

Figure C-14: MAPE profile for fall \% nuclear test case 


\section{C.3 Percentage Mix from Hydro Network}

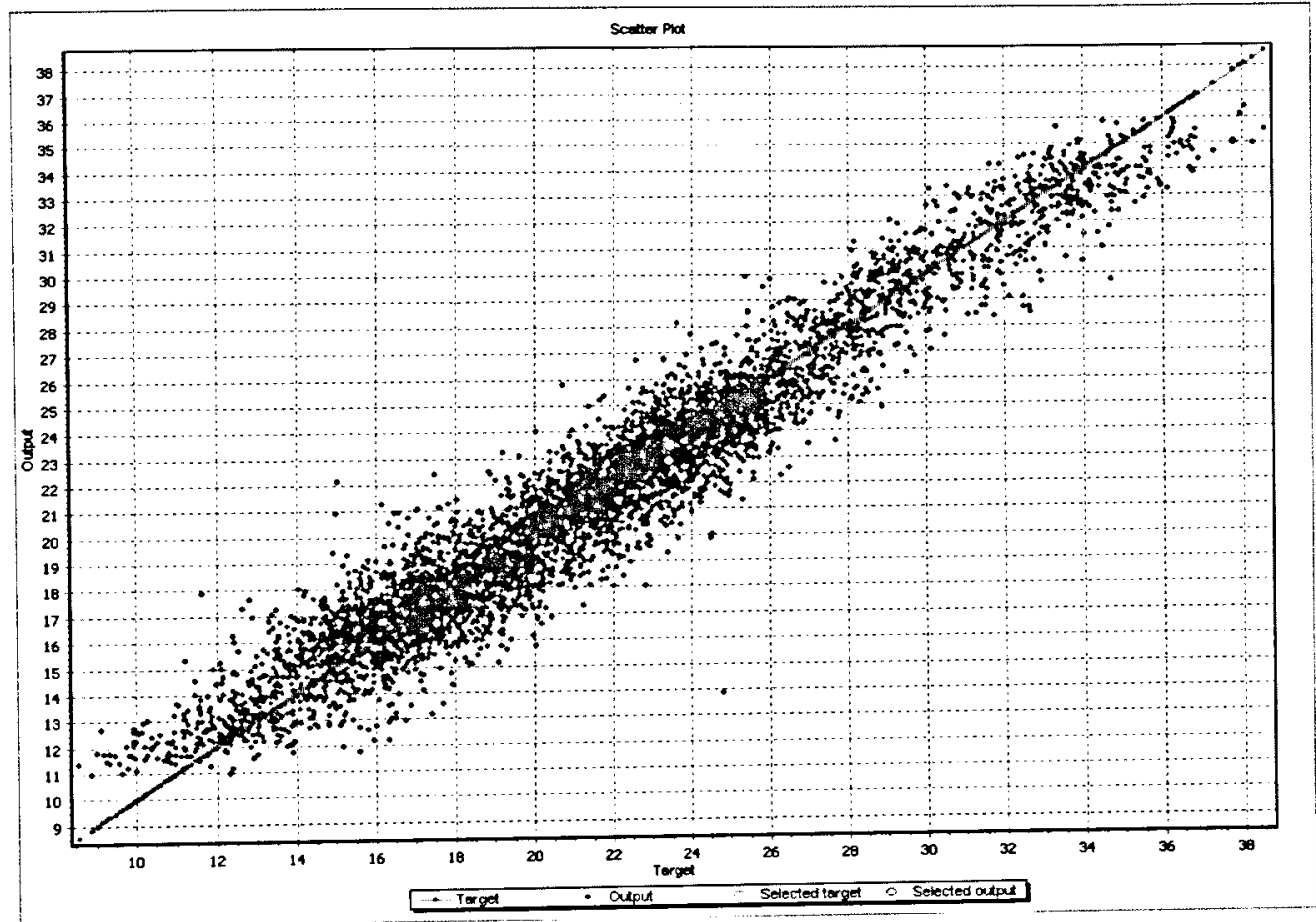

Figure C-15: Scatter plot comparing actual vs. predicted values for the training of the \% hydro NN

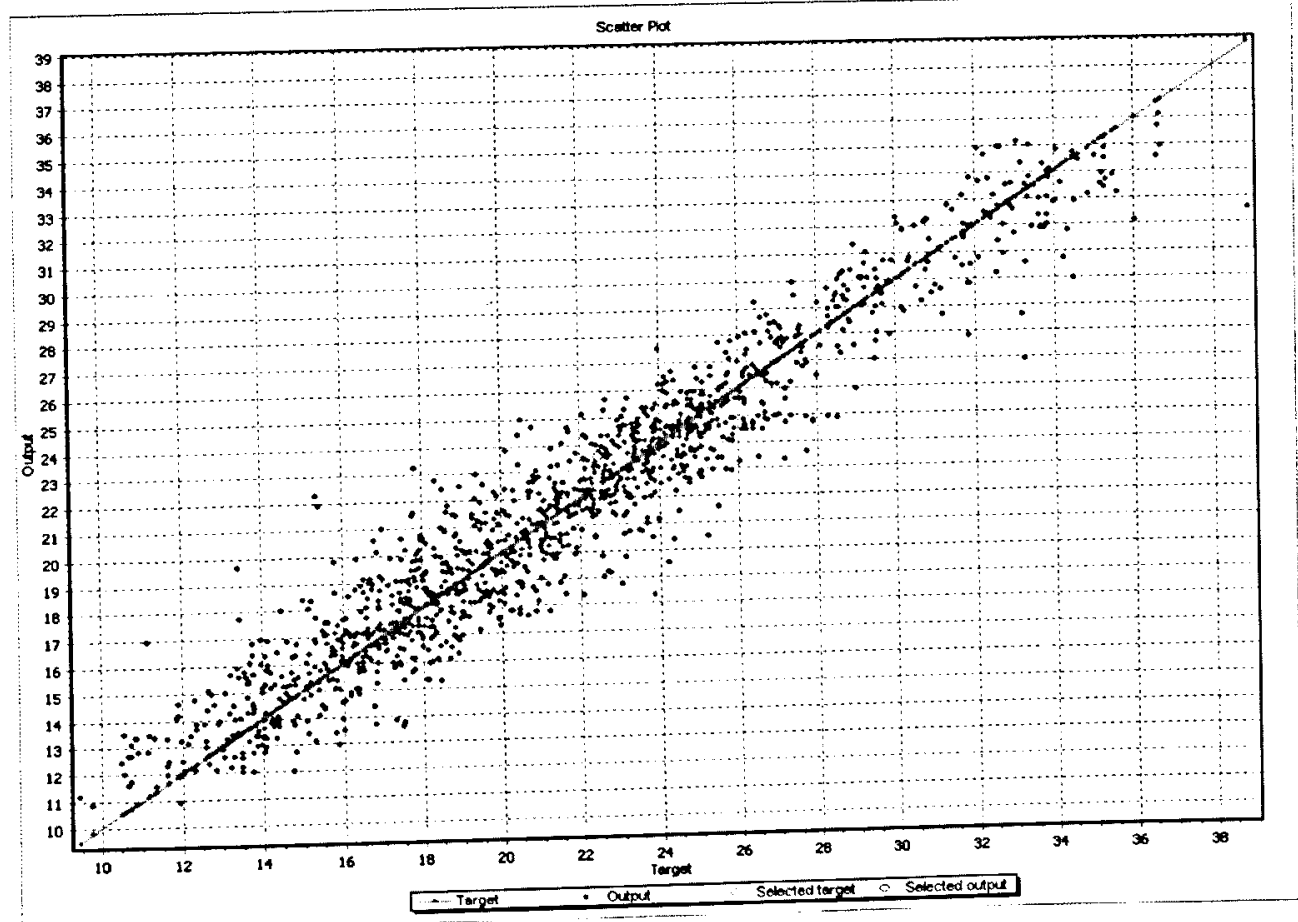

Figure C-16: Scatter plot comparing actual vs. predicted values for the validation of the $\%$ hydro $\mathrm{NN}$ 


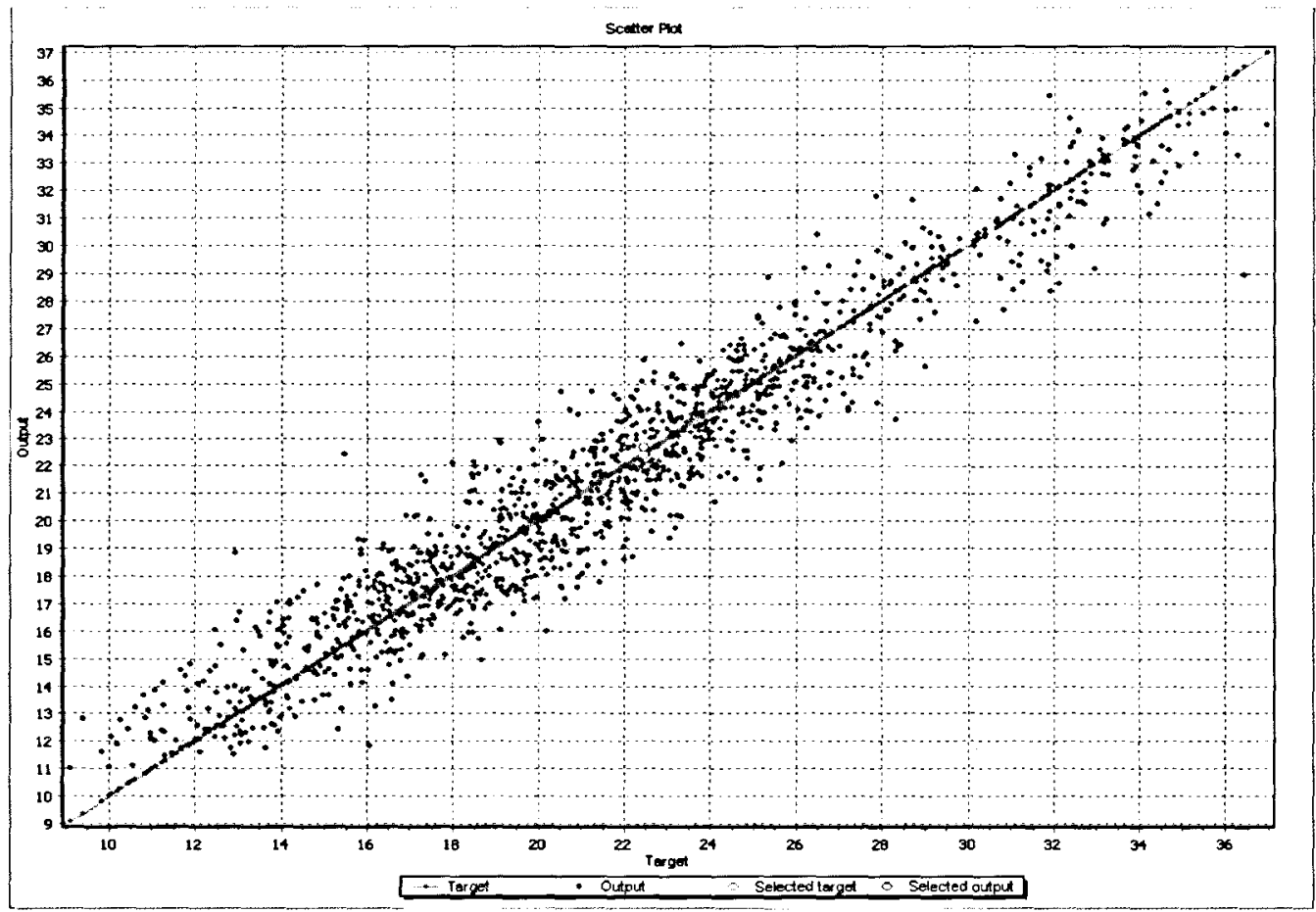

Figure C-17: Scatter plot comparing actual vs. predicted values for the testing of the \% hydro NN

\section{Test Case Results}

Figure C-18 shows the MAPE profile for the winter of 2006. The MAPE fluctuated the most during February.

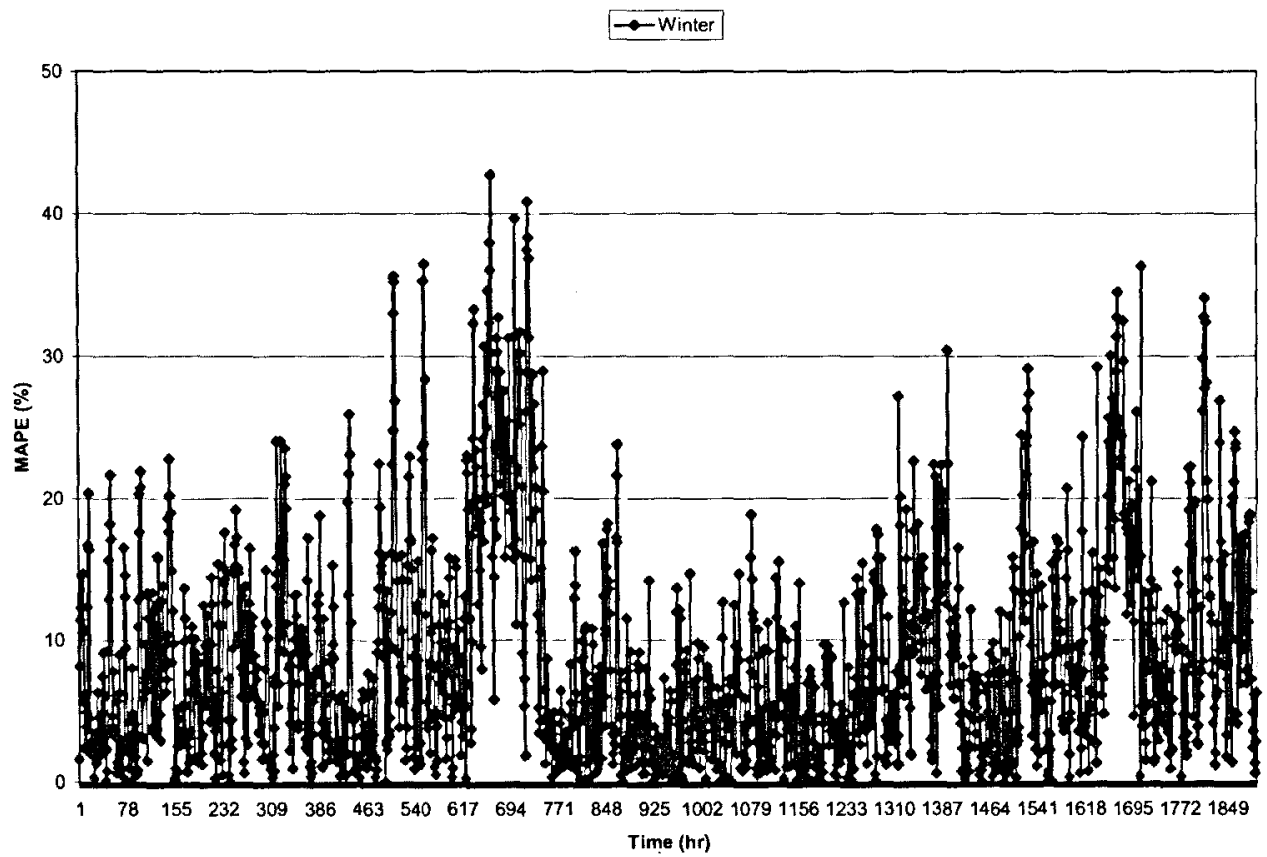

Figure C-18: MAPE profile for winter \% hydro test case 
Figure C-19 shows the MAPE profile for the spring of 2006. The MAPE was the highest during late May and early June.

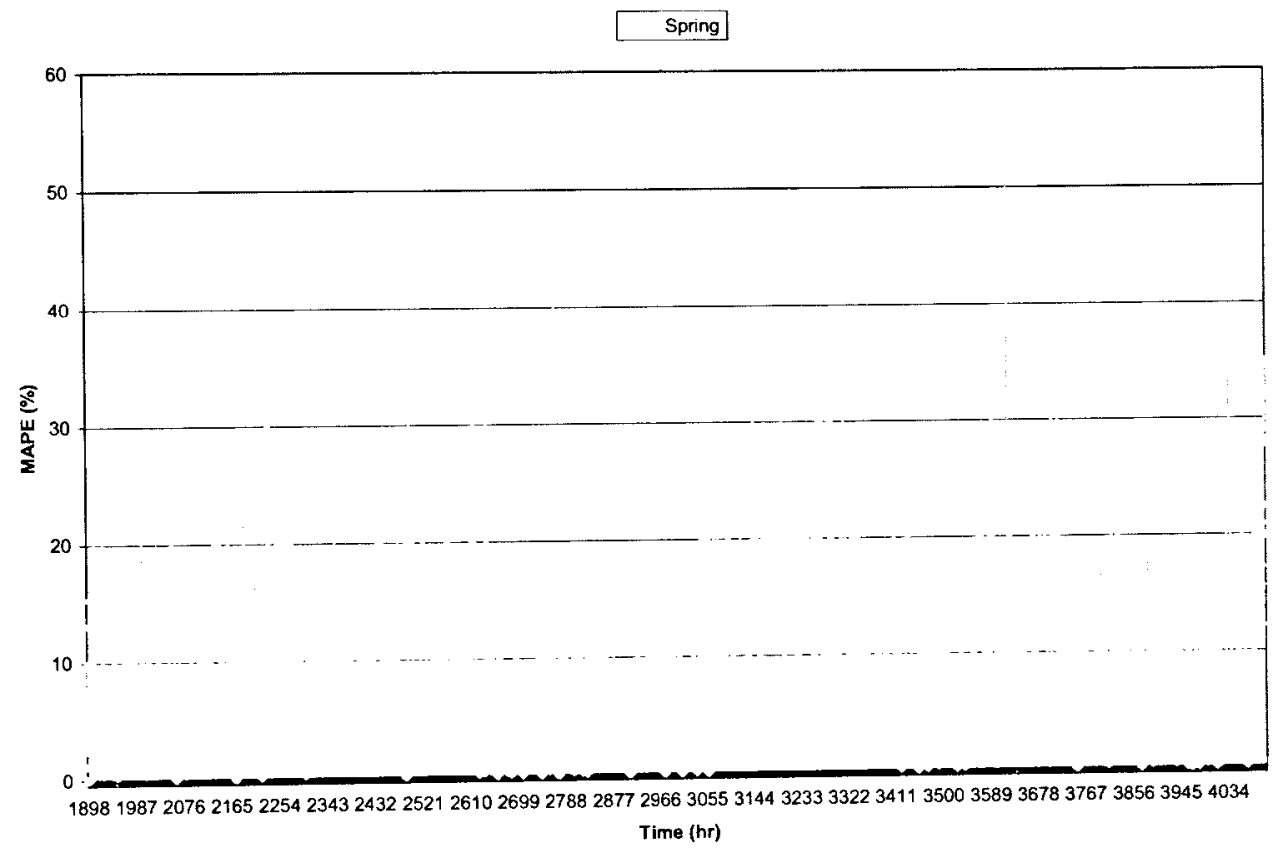

Figure C-19: MAPE profile for spring \% hydro test case

Figure C-20 shows the MAPE profile for the summer of 2006. The MAPE was highest in early July and in mid September.

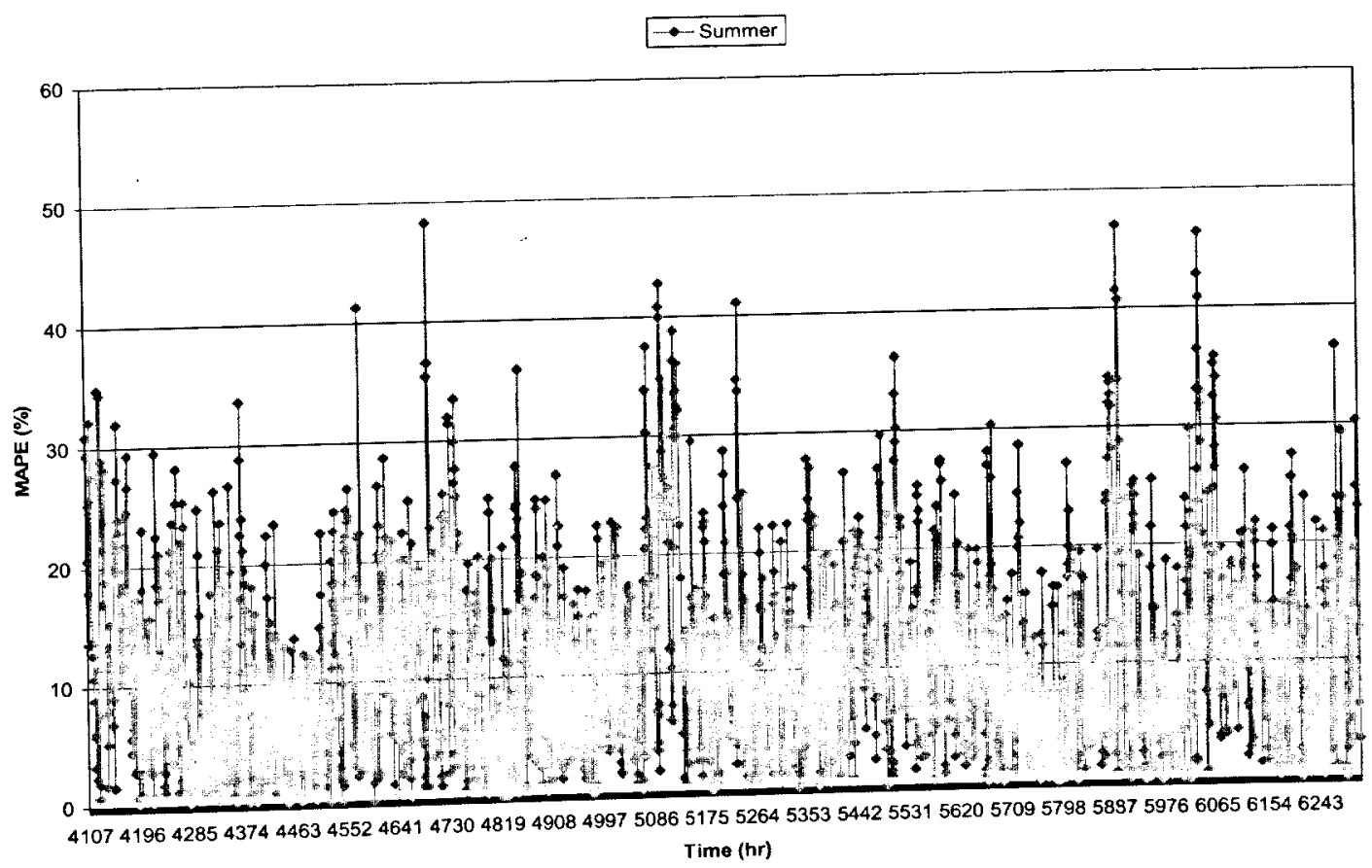

Figure C-20: MAPE profile for summer \% hydro test case 
Figure C-21 shows the MAPE profile for the fall of 2006. The MAPE was the highest during early November.

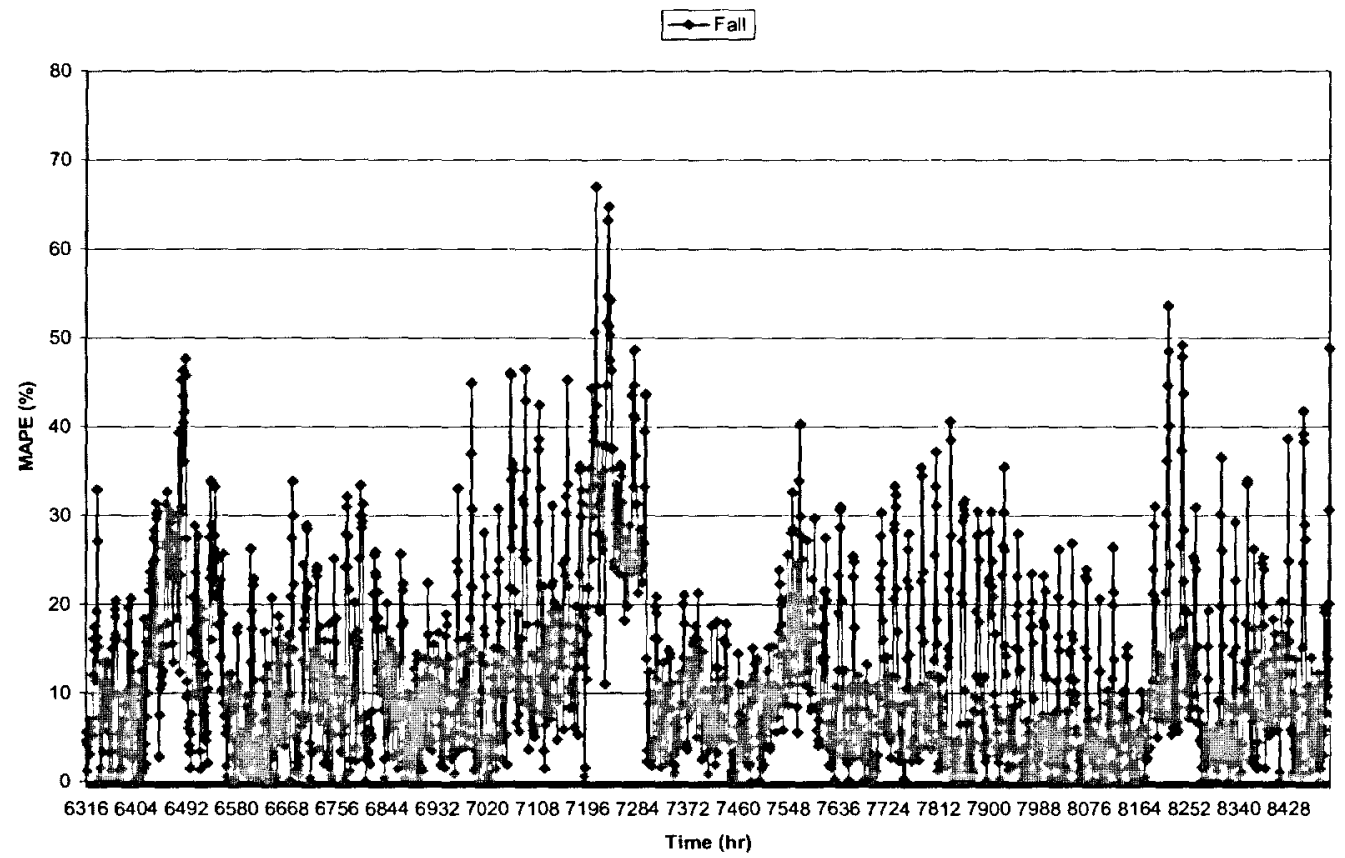

Figure C-21: MAPE profile for fall \% hydro test case

\section{C.4 Percentage Mix from Coal Network}

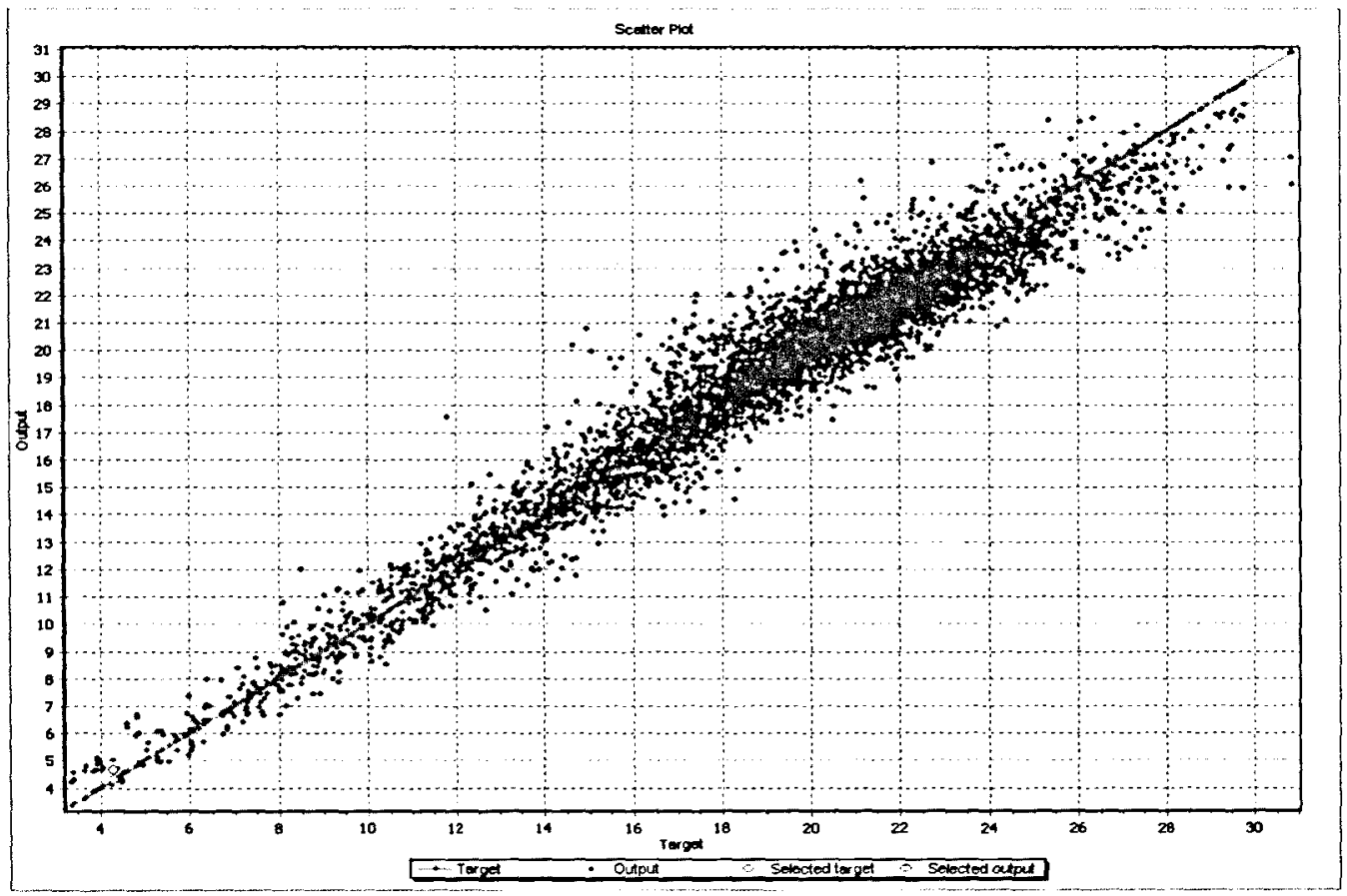

Figure C-22: Scatter plot comparing actual vs. predicted values for the training of the $\%$ coal $N N$ 


\section{Test Case Results}

Figure C-25 shows the MAPE profile for the winter of 2006. The MAPE fluctuated the most during mid-winter.

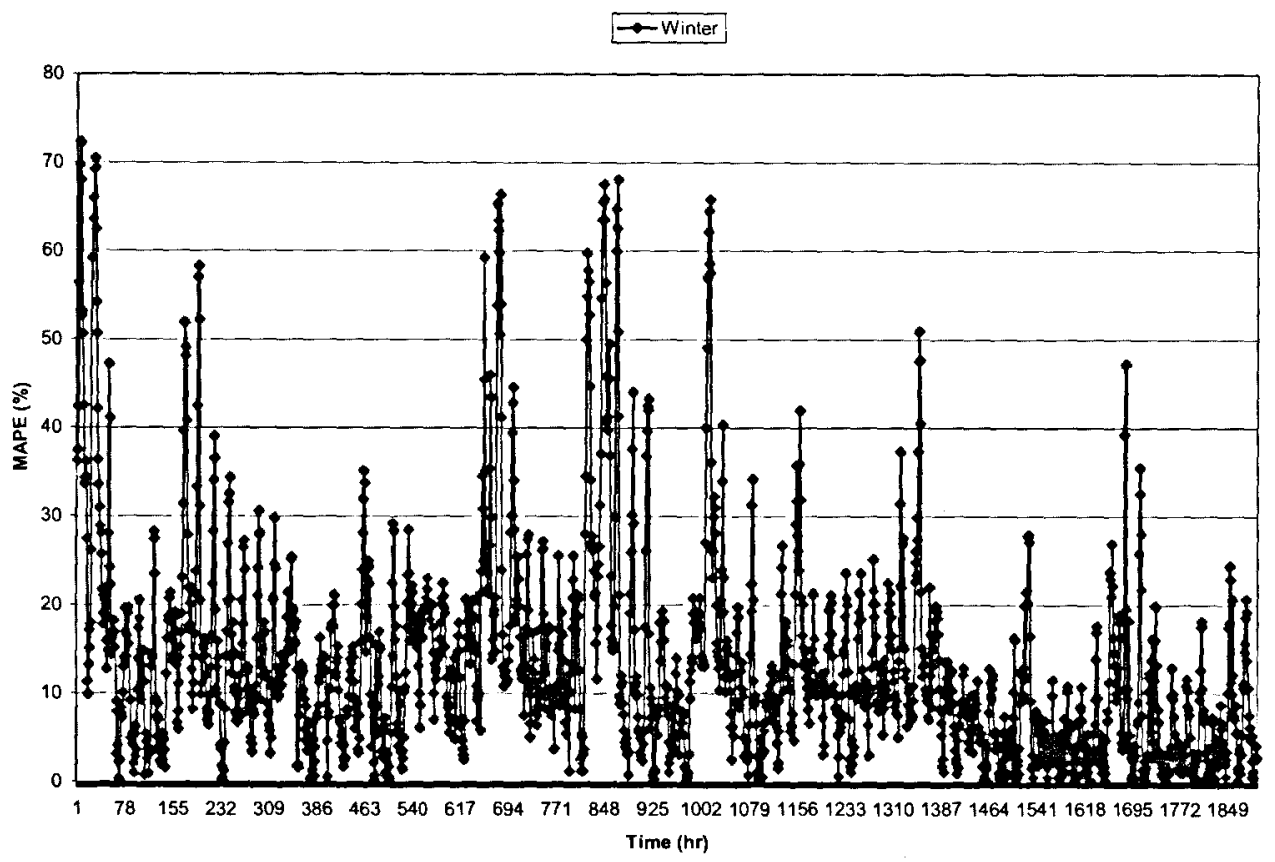

Figure C-25: MAPE profile for winter \% coal test case

Figure C-26 shows the MAPE profile for the spring of 2006. The MAPE was the highest during April and early May.

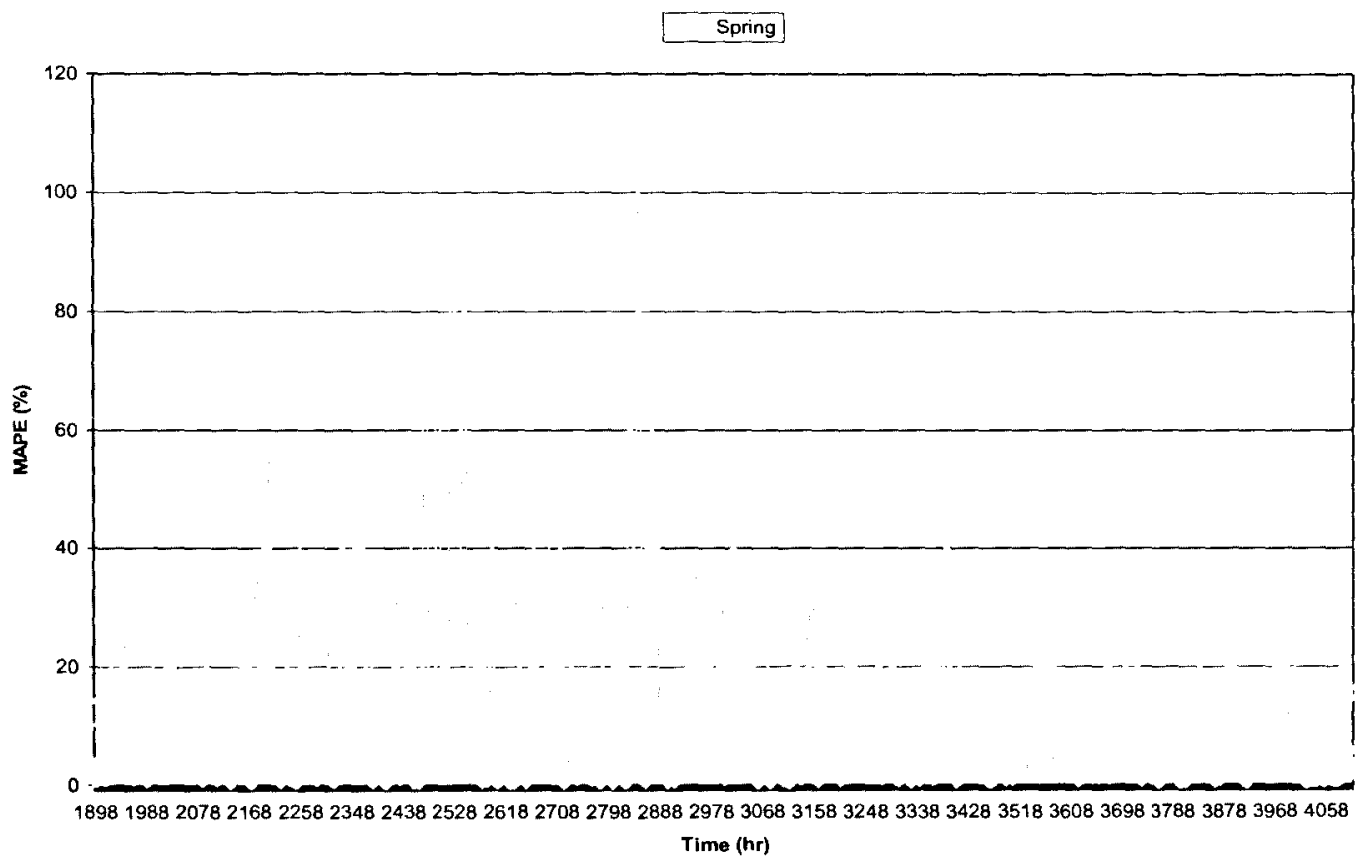

Figure C-26: MAPE profile for spring \% coal test case 
Figure C-27 shows the MAPE profile for the summer of 2006. The MAPE was highest in August.

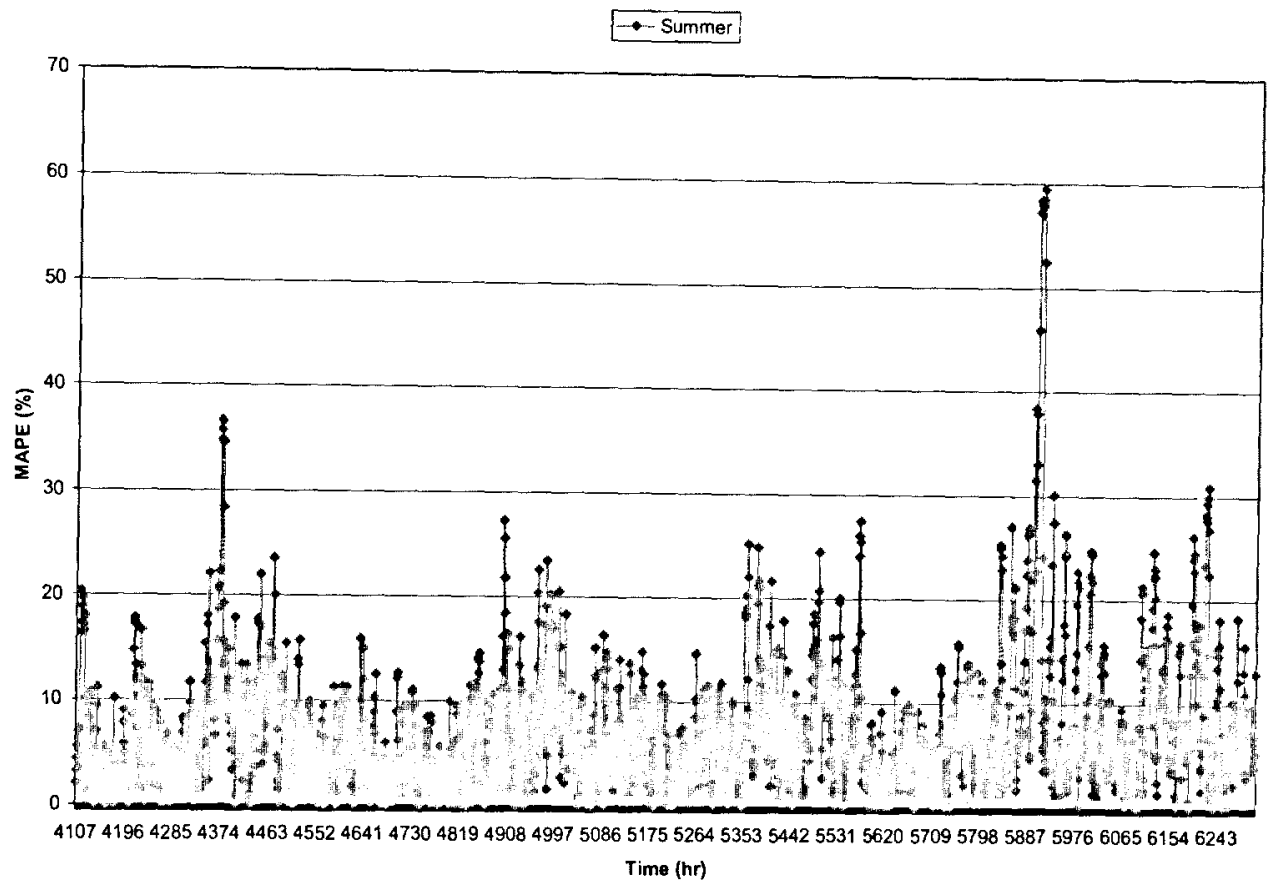

Figure C-27: MAPE profile for summer \% coal test case

Figure C-28 shows the MAPE profile for the fall of 2006. The MAPE was the highest during December and October.

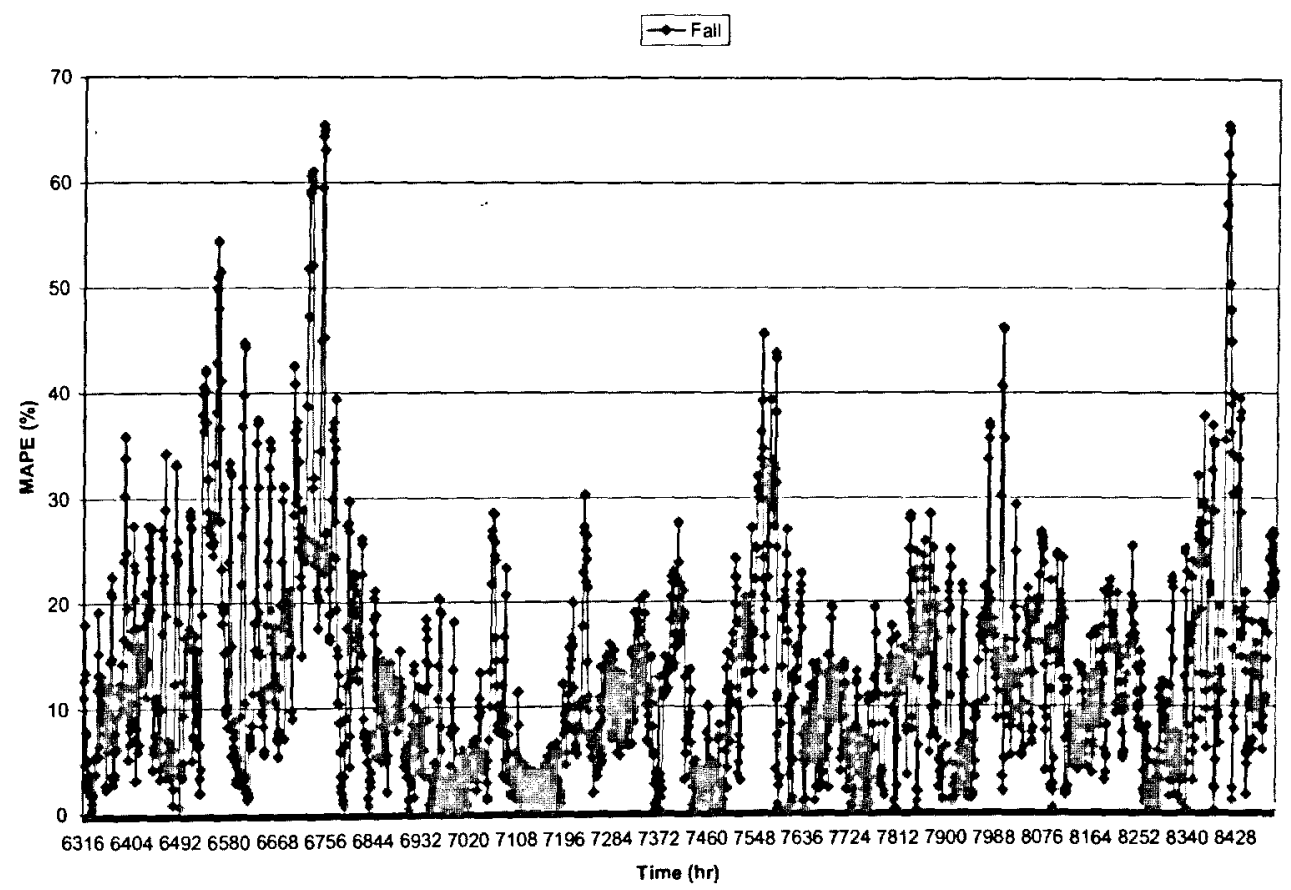

Figure C-28: MAPE profile for fall \% coal test case 


\section{C.5 Percentage Mix from Other Network}

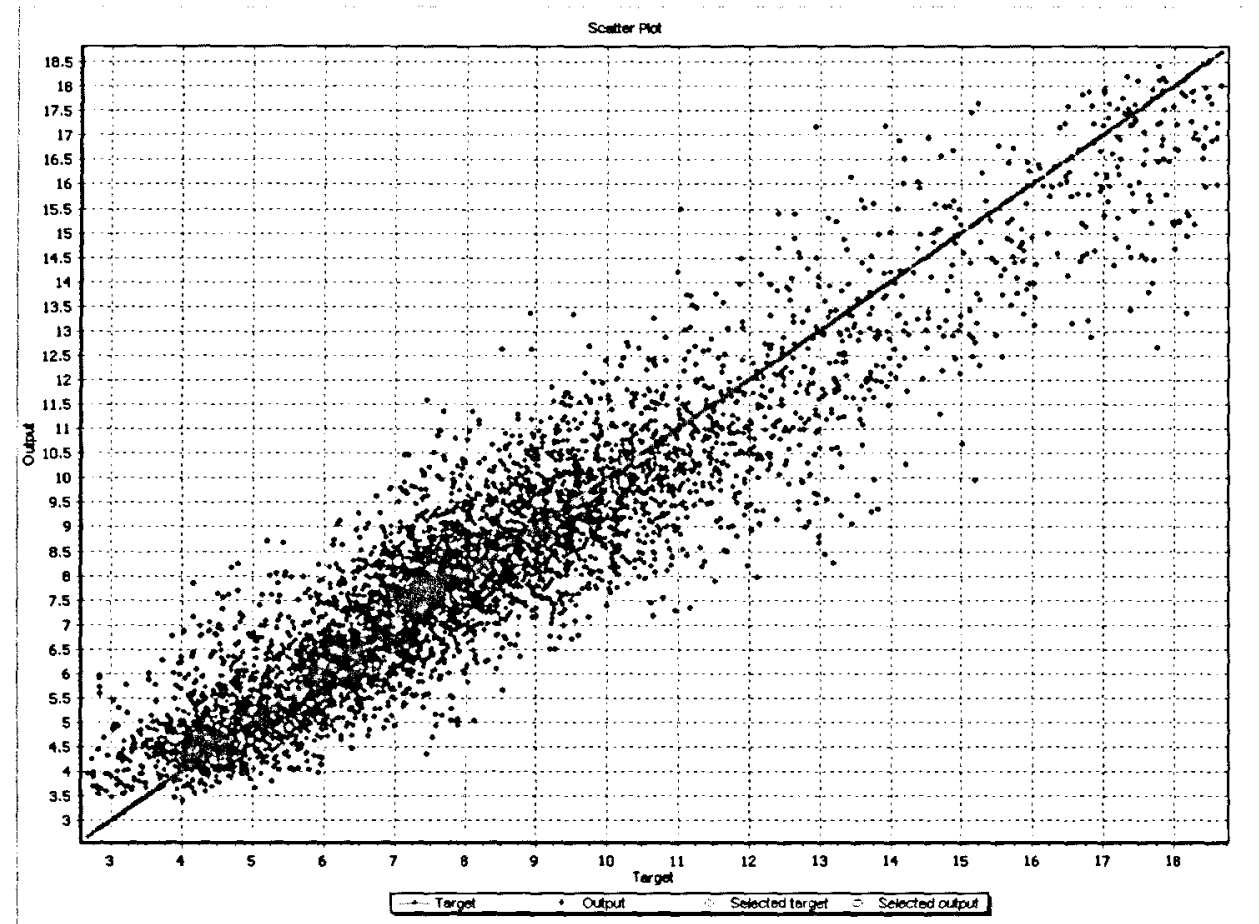

Figure C-29: Scatter plot comparing actual vs. predicted values for the training of the \% other NN

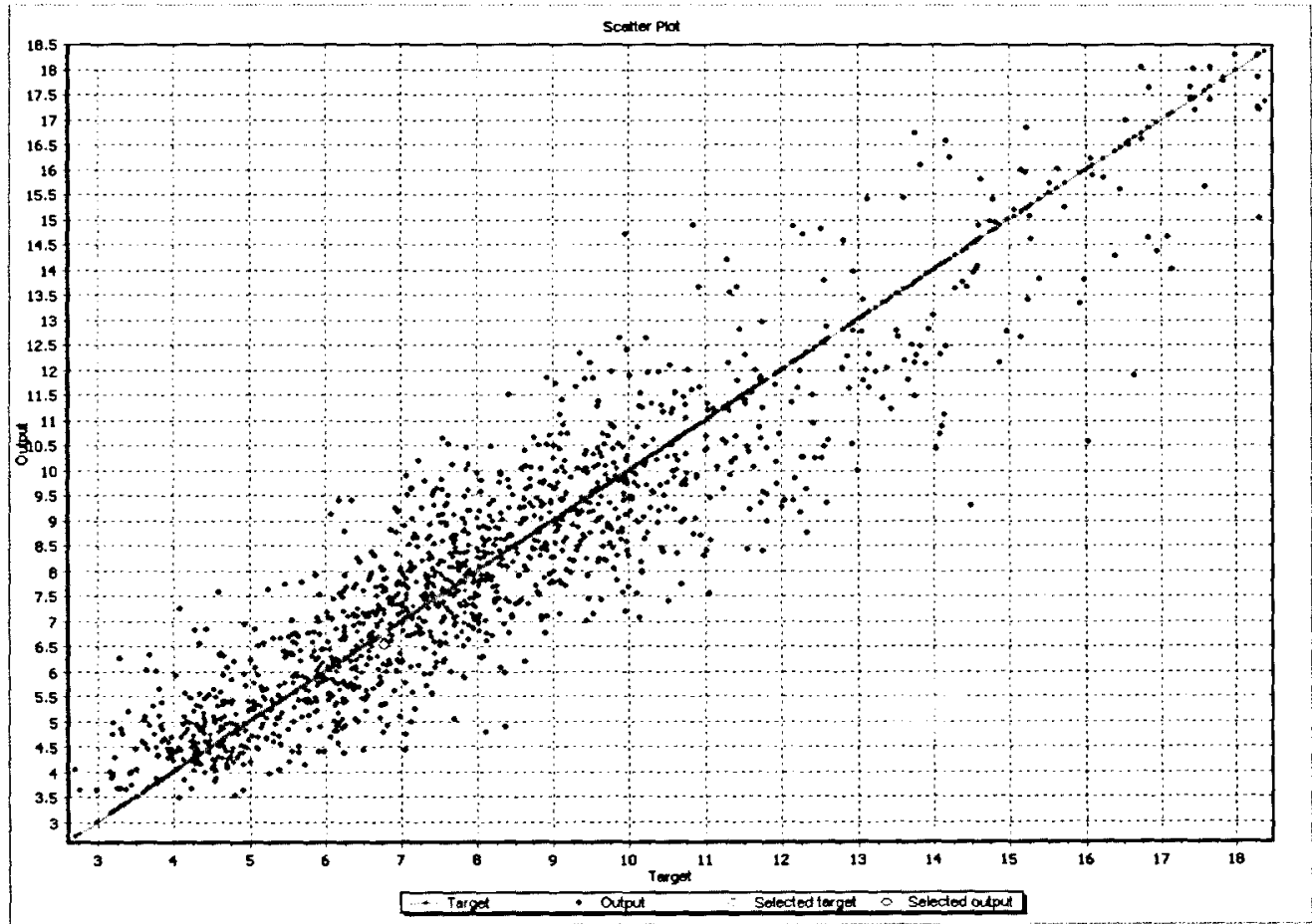

Figure C-30: Scatter plot comparing actual vs. predicted values for the validation of the \% other NN 


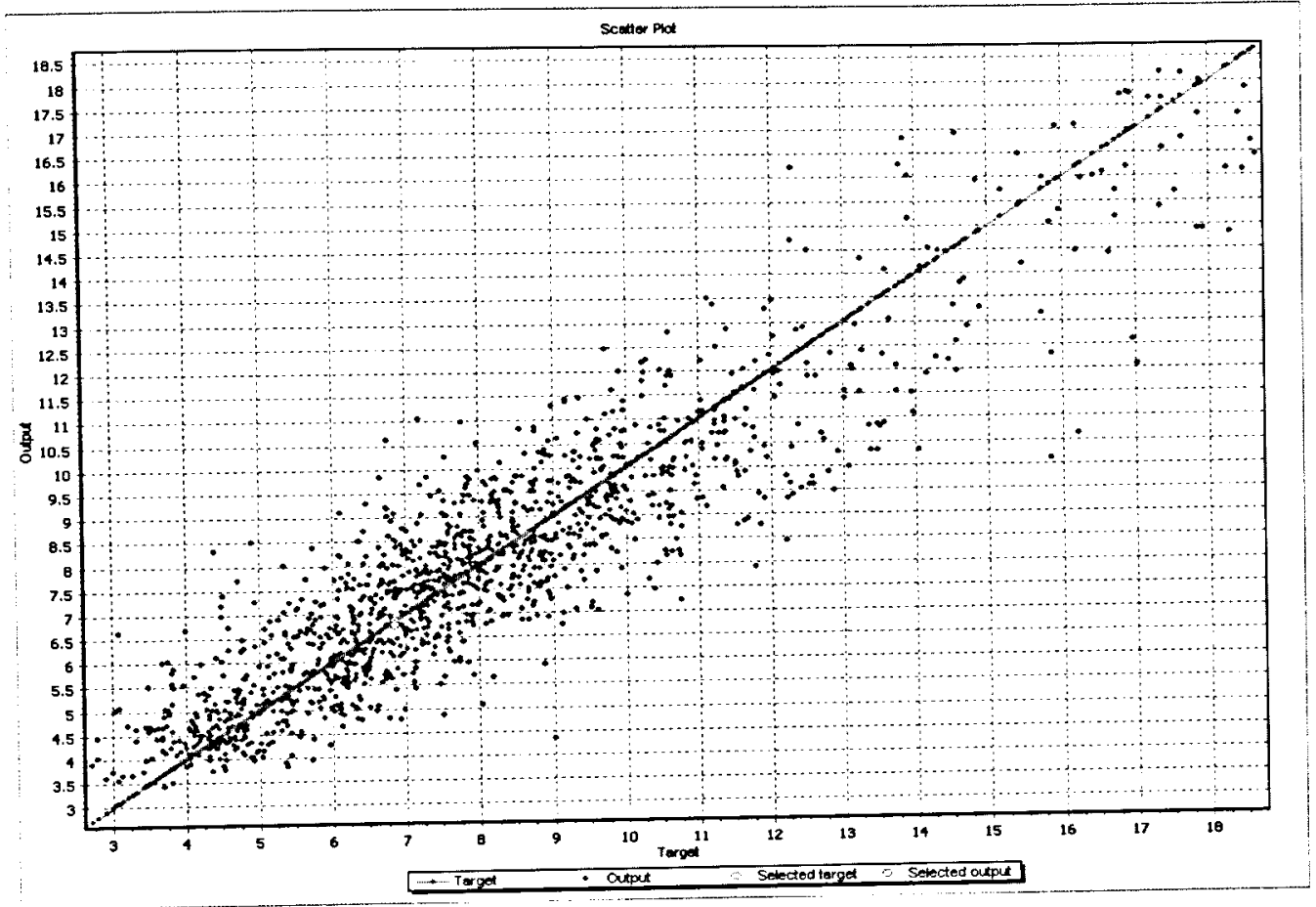

Figure C-31: Scatter plot comparing actual vs. predicted values for the testing of the \% other NN

\section{Test Case Result}

Figure C-32 shows the MAPE profile for the winter of 2006. The MAPE fluctuated throughout the entire season with its highest value in early February.

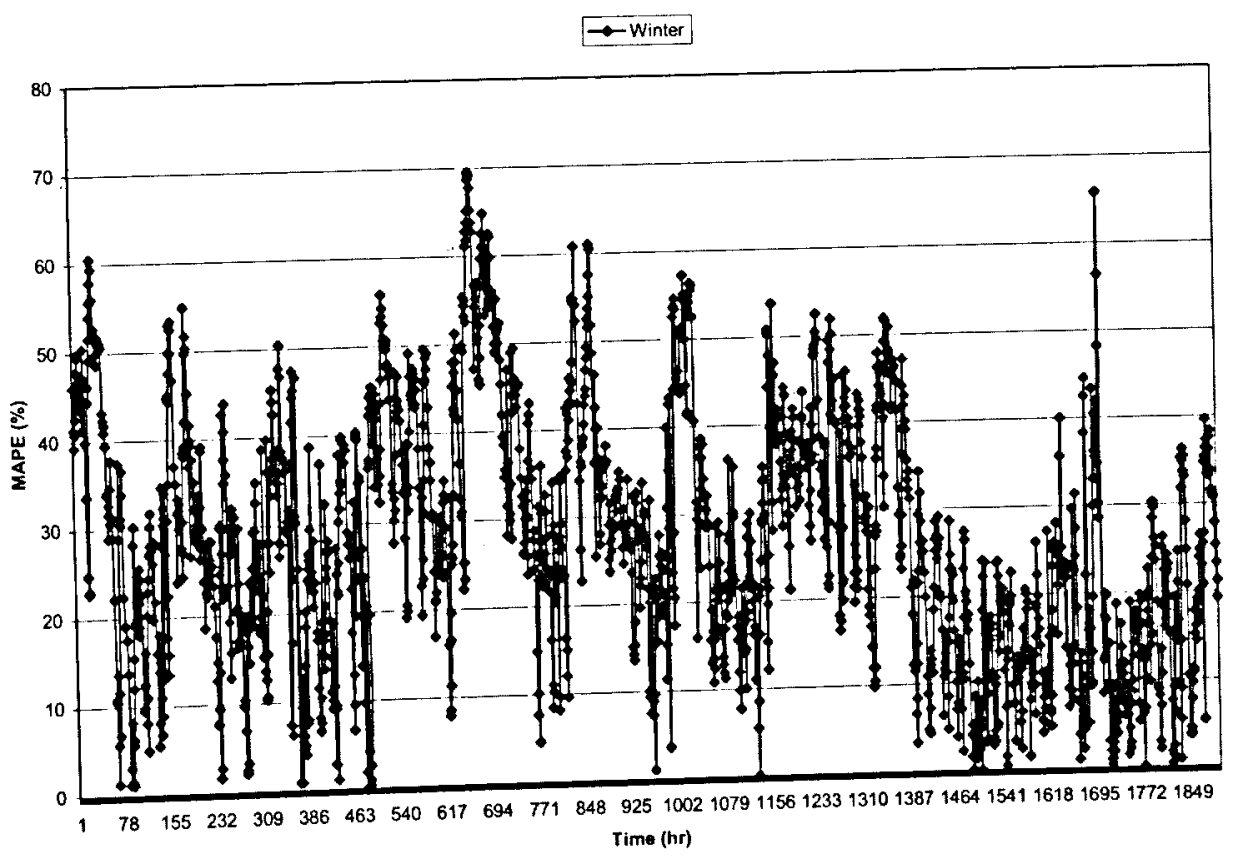

Figure C-32: MAPE profile for winter \% other test case 
Figure C-33 shows the MAPE profile for the spring of 2006. The MAPE was the highest during late May and early June.

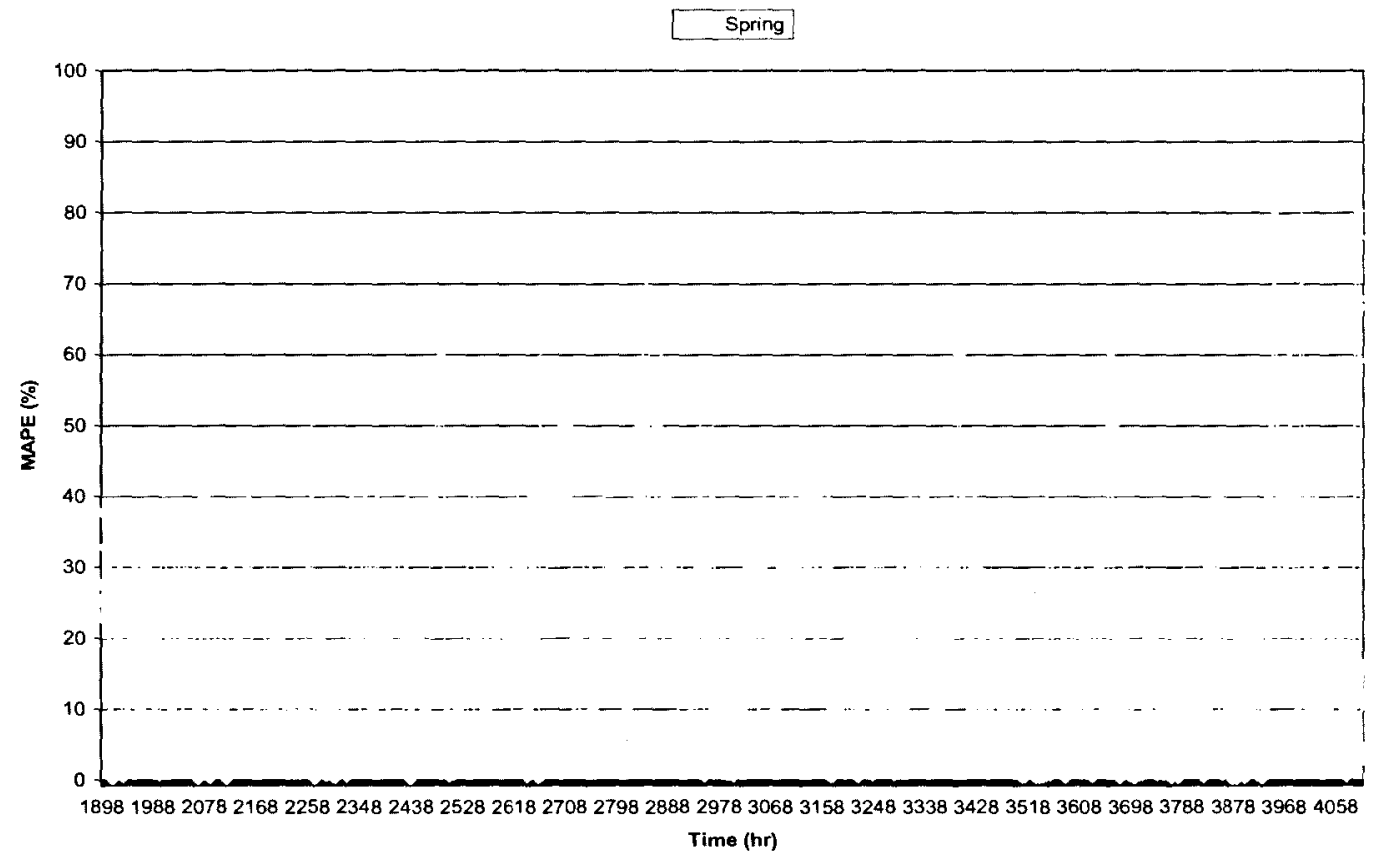

Figure C-33: MAPE profile for spring \% other test case

Figure C-34 shows the MAPE profile for the summer of 2006. The MAPE was highest in late September.

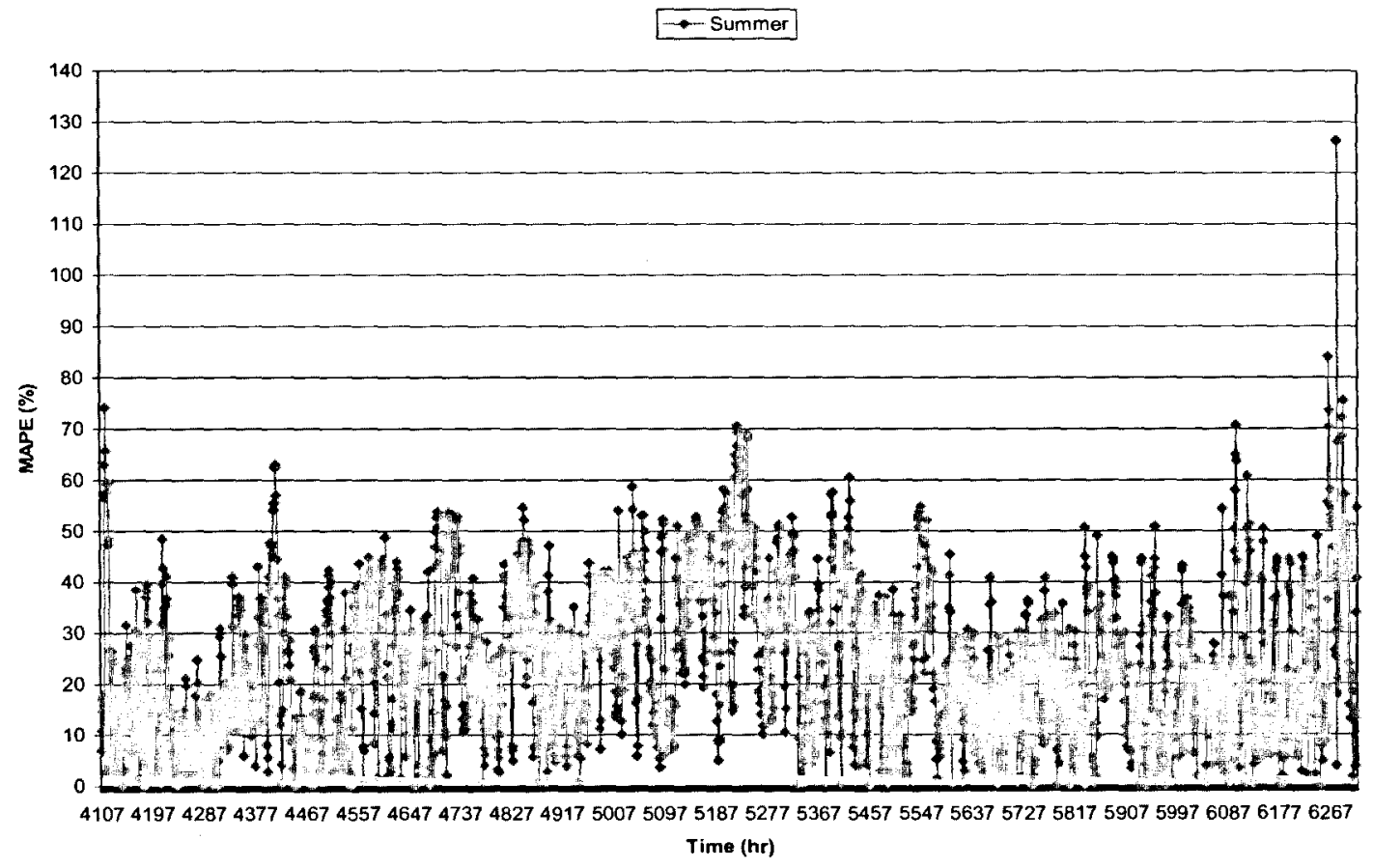

Figure C-34: MAPE profile for summer $\%$ other test case 
Figure C-35 shows the MAPE profile for the fall of 2006. The MAPE was the highest in November.

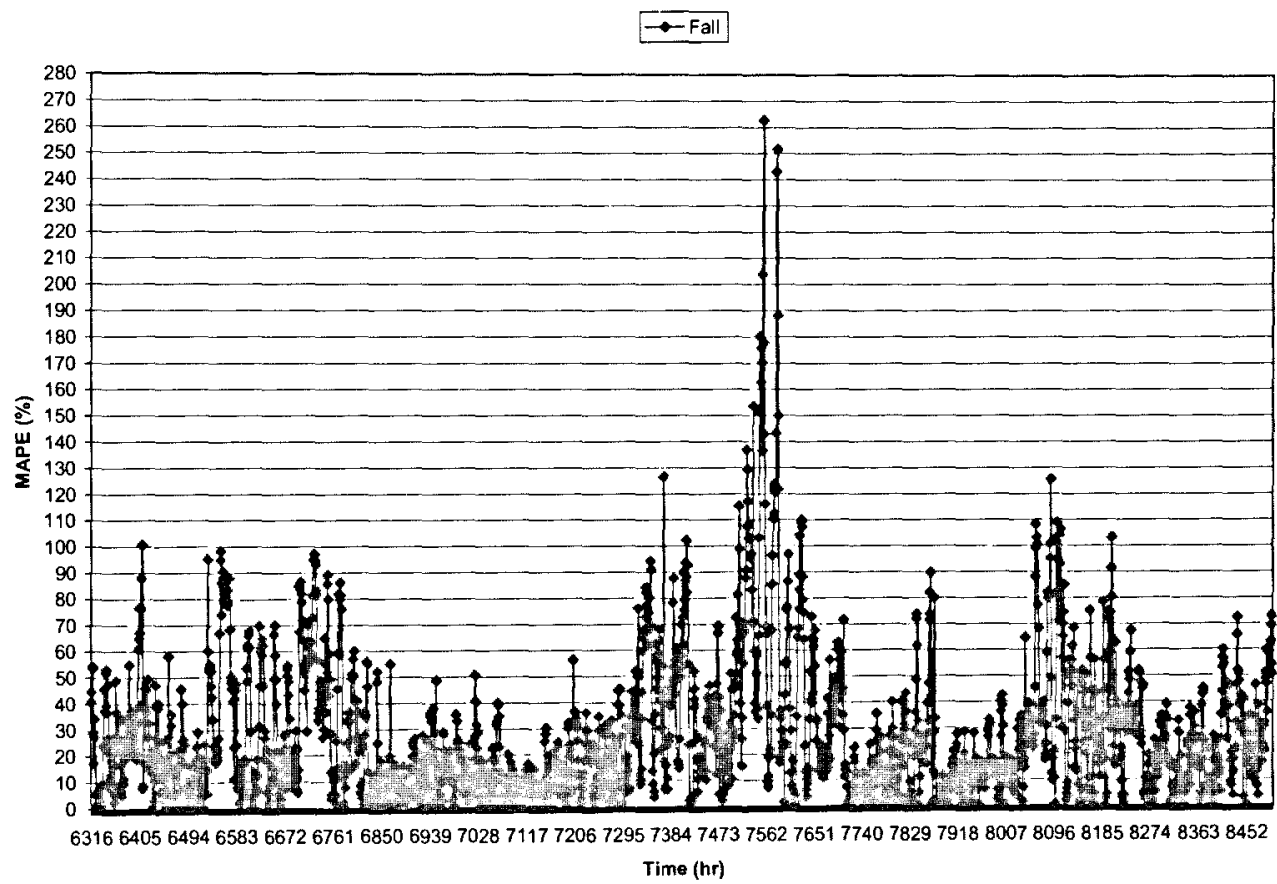

Figure C-35: MAPE profile for fall \% other test case

\section{C.6 Emission Factor NN Methodology 1}

Figure C-36 shows the MAPE profile for the predicted $\mathrm{NGHGIF}_{\mathrm{A}}$ during the winter of 2005. The MAPE was constant throughout the entire season with its highest value in early January due to unexpected fluctuations in the grid 


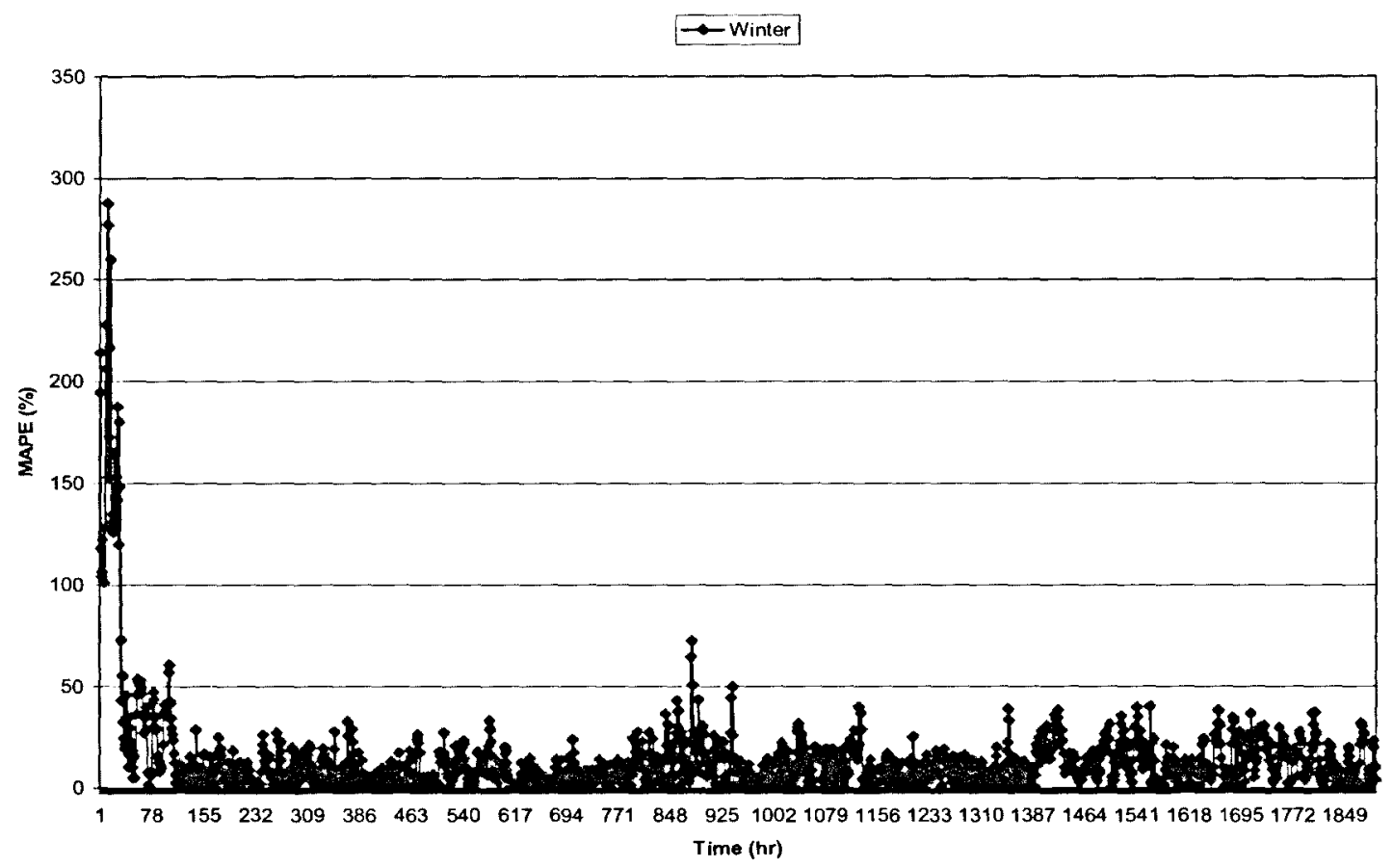

Figure C-36: MAPE profile for $\mathrm{NGHGIF}_{\mathrm{A}}$ - winter test case

Figure C-37 shows the MAPE profile for the predicted NGHGIF $_{A}$ during the spring of 2005. The MAPE was not as low throughout the entire season with its highest value in April and late May. The peak MAPE values are due to grid fluctuations in Ontario.

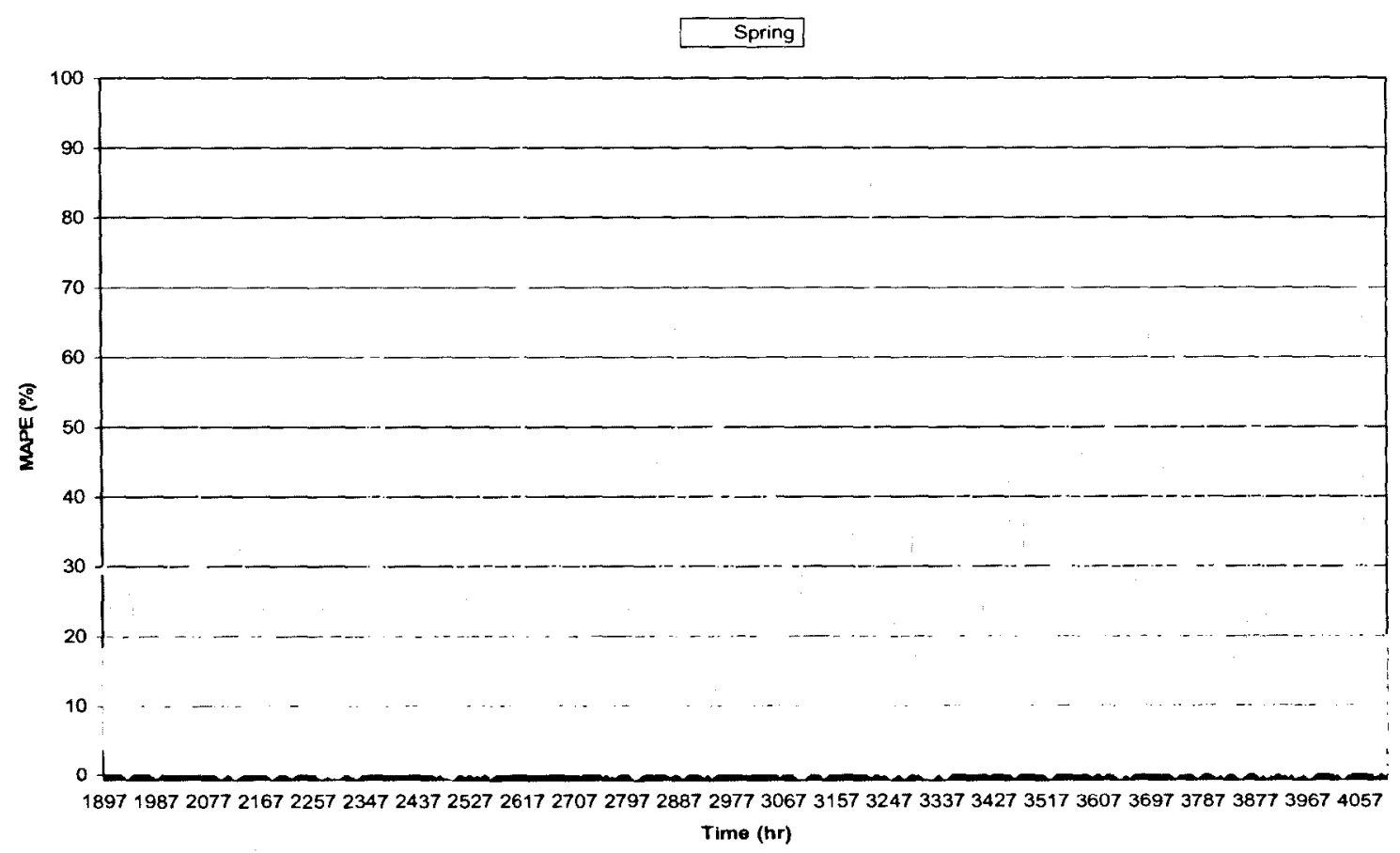

Figure C-37: MAPE profile for NGHGIF $_{A}$ - spring test case 
Figure C-38 shows the MAPE profile for the predicted $\mathrm{NGHGIF}_{\mathrm{A}}$ during the summer of 2005. The MAPE fluctuated throughout the entire season with its highest value in July.

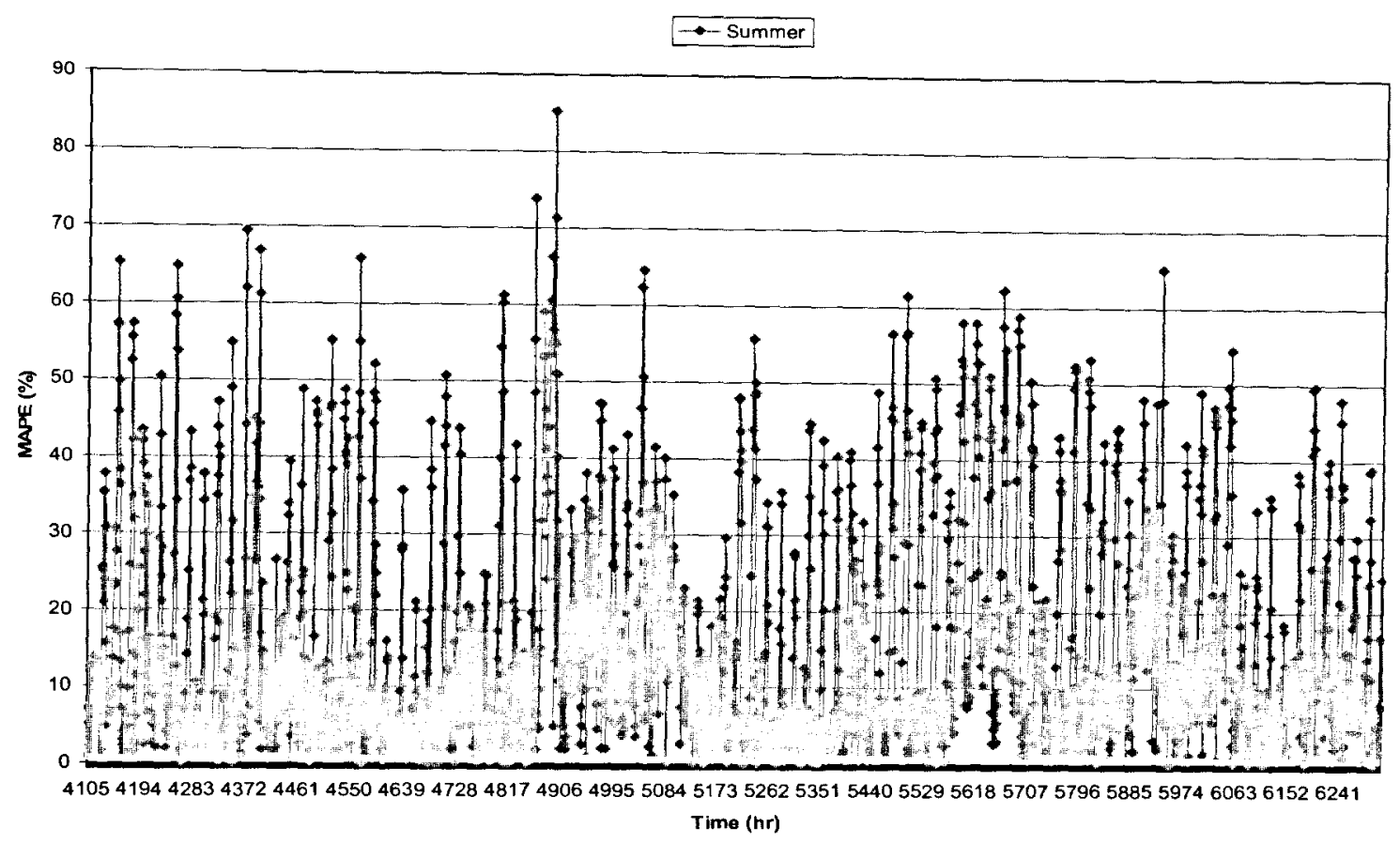

Figure C-38: MAPE profile for NGHGIF $_{A}$ - summer test case

Figure C-39 shows the MAPE profile for the predicted NGHGIF $\mathrm{N}_{\mathrm{A}}$ during the fall of 2005. The MAPE was constant throughout the entire season with its highest value in October.

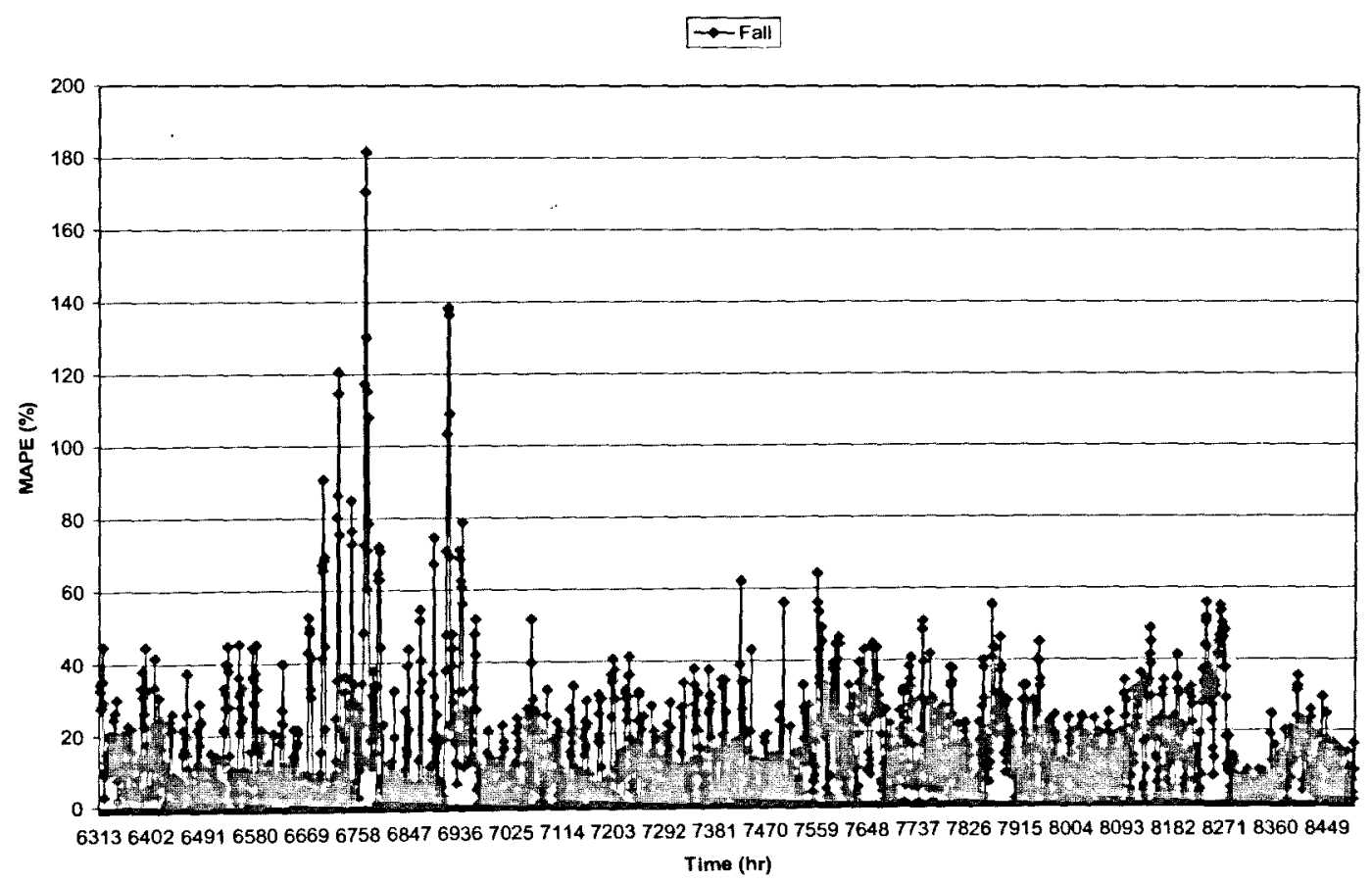

Figure C-39: MAPE profile for NGIIGIF $_{A}$ - fall test case 


\section{C.7 Emission Factor NN Methodology 2}

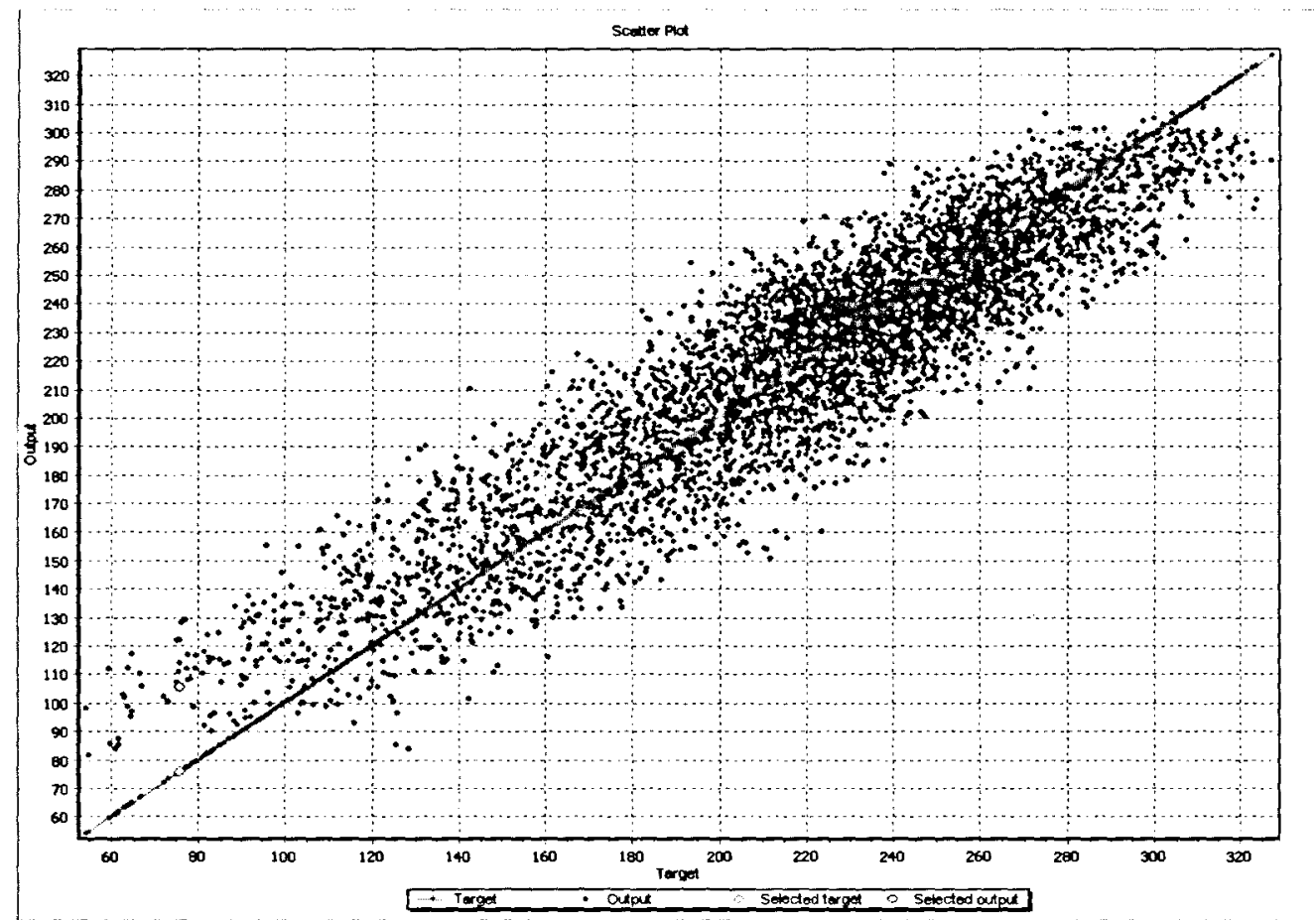

Figure C-40: Scatter plot comparing actual vs. predicted values for the training of the EF NN

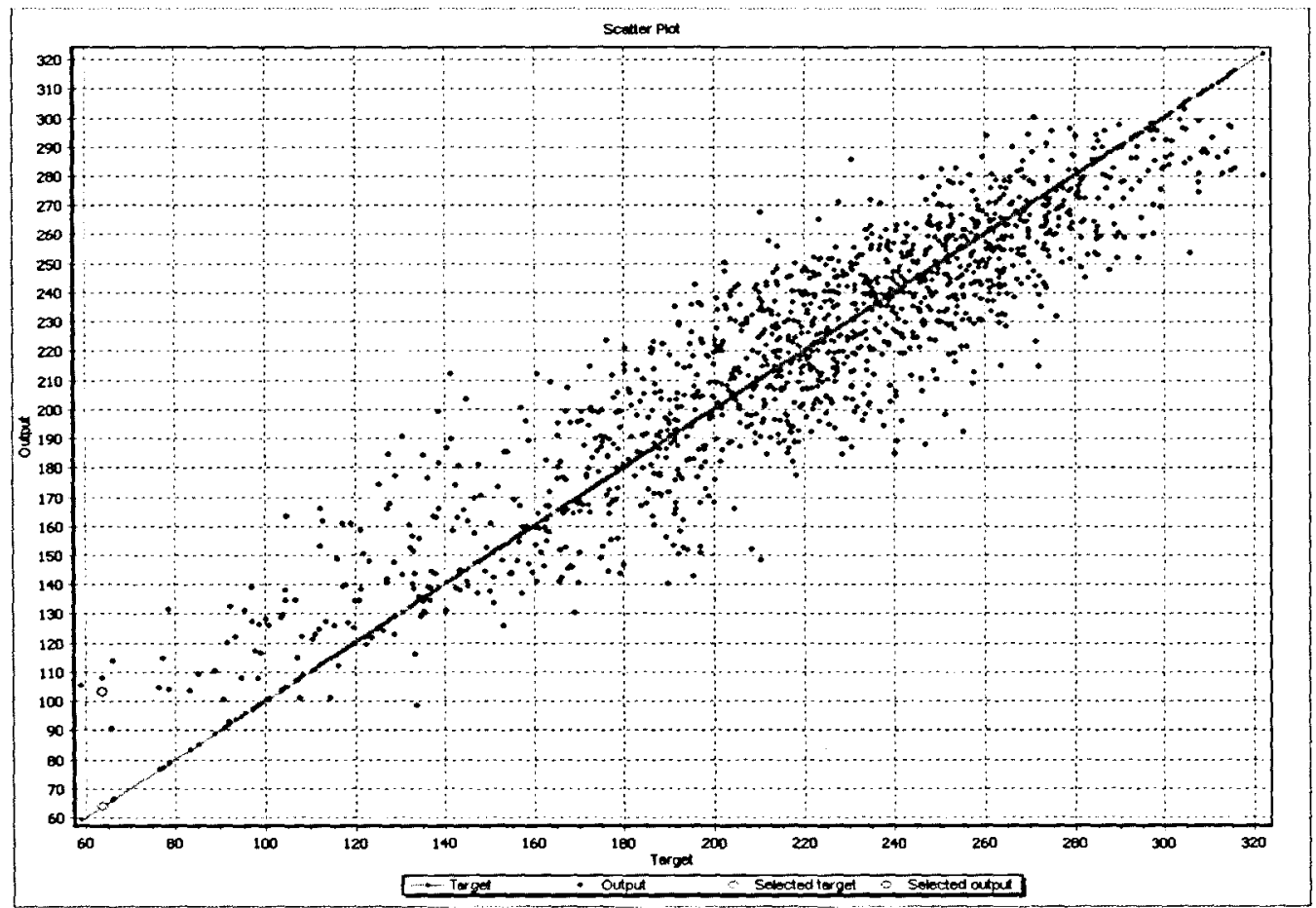

Figure C-41: Scatter plot comparing actual vs. predicted values for the validation of the EF NN 


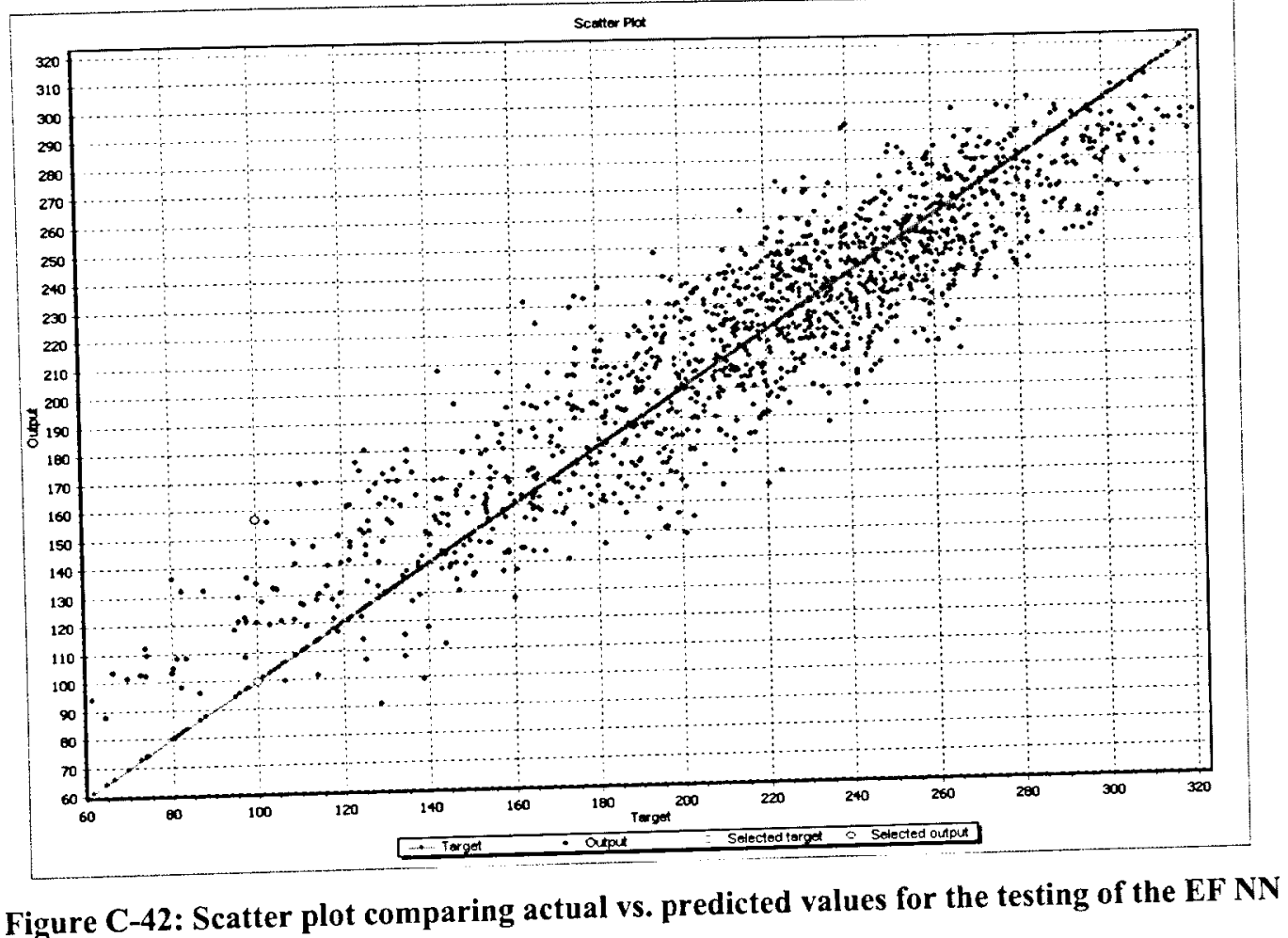

Figure C-42: Scatter plot comparing actual vs. predicted values for the testing of the EF NN

209 